TE WHARE WĀNANGA O TE ŪPOKO O TE IKA A MĀUI

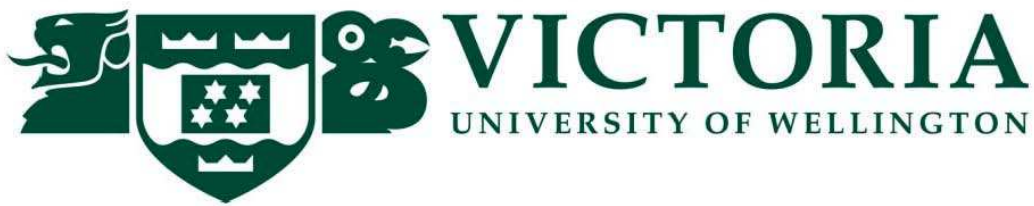

\title{
A MULTI-METHOD STUDY OF THE IS IMPACT OF SAP IN A LARGE ORGANIZATION
}

MCom Thesis Requirements

Information Systems

Submitted by Azim Ali (VUW)

Supervised by Dr Mary Tate (VUW)

School of Information Management

Victoria Business School

Victoria University of Wellington

November 2012/2013 


\section{O N T E N T S}

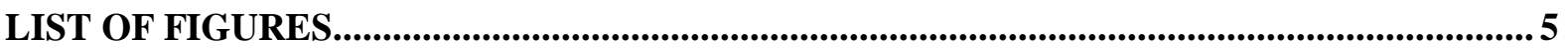

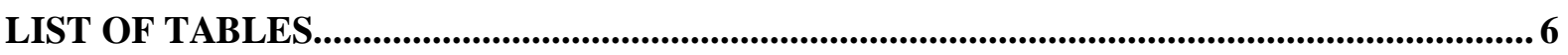

LIST OF ABBREVIATIONS.............................................................................................................. 6

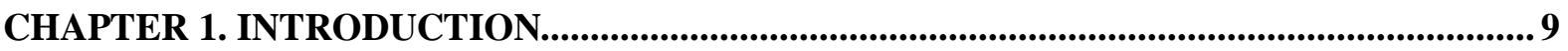

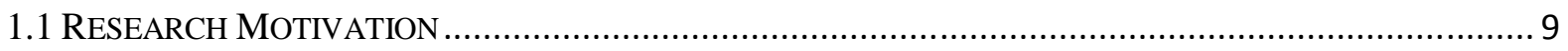

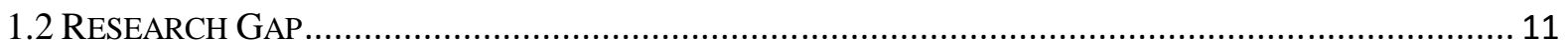

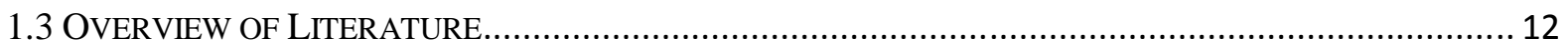

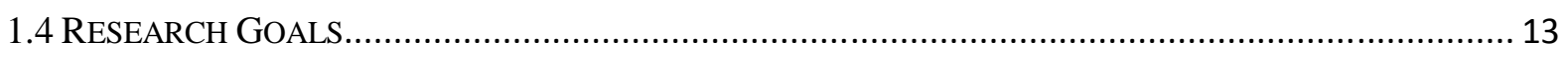

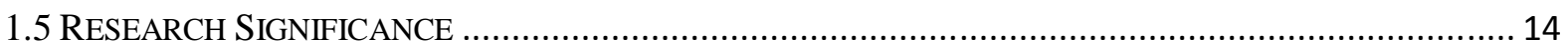

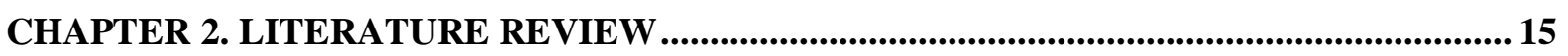

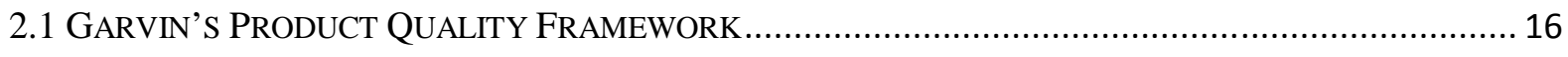

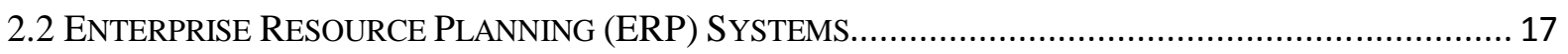

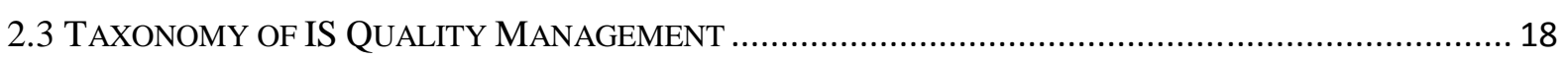

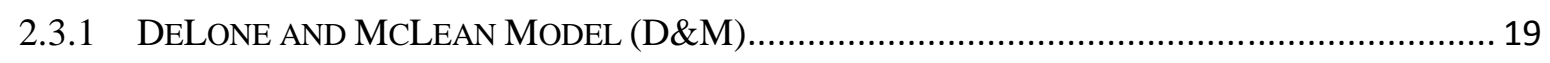

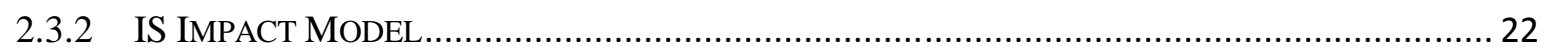

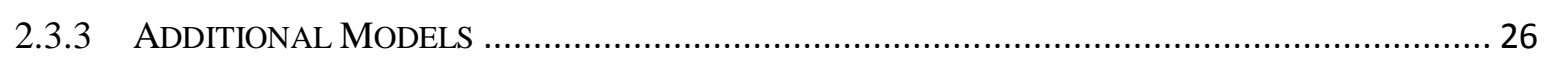

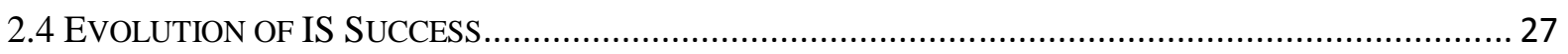

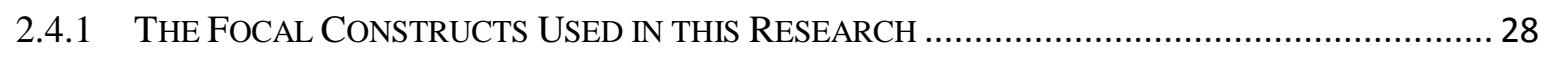

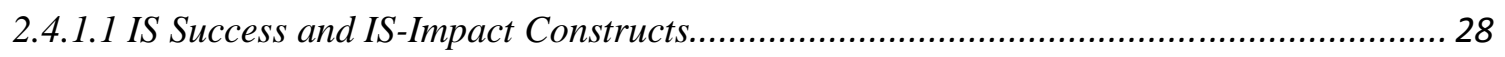

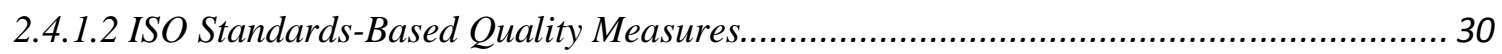

2.4.2 INTEGRATION OF QUALITY PERSPECTIVES AND IS SUCCESS, QUALITY AND IMPACT

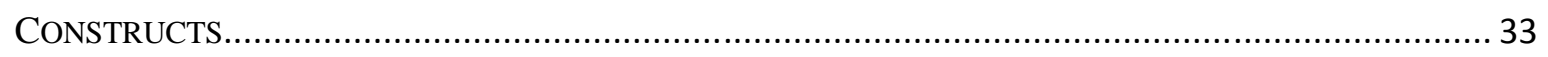

2.5 INTEGRATED FRAMEWORK FOR COMPARISON OF QUALITY AND IMPACT MEASURES................... 36

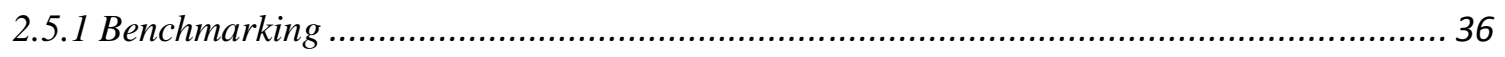

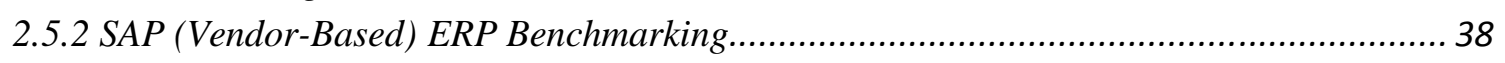

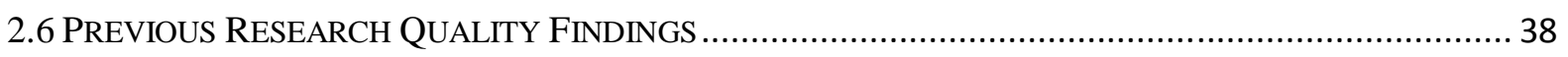

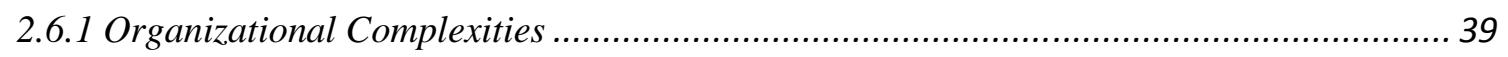

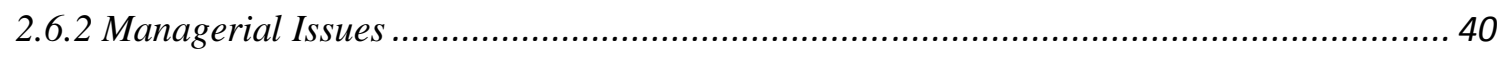

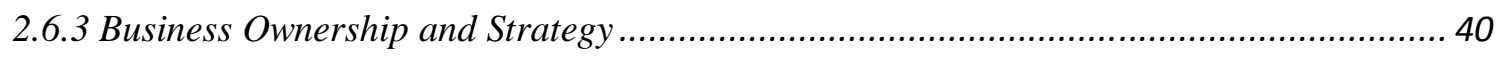

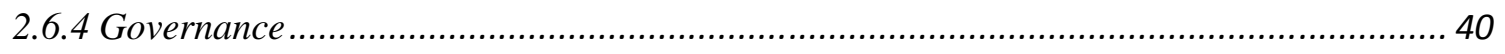

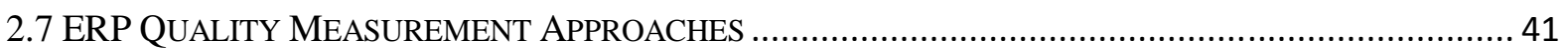

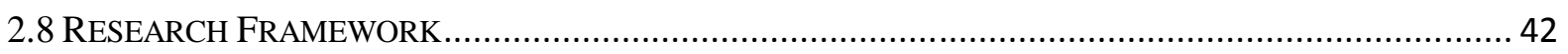

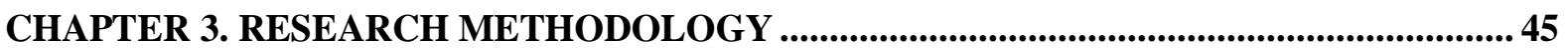

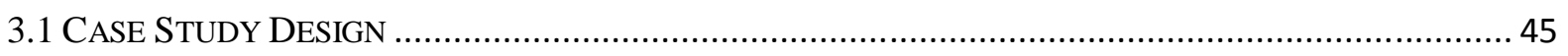

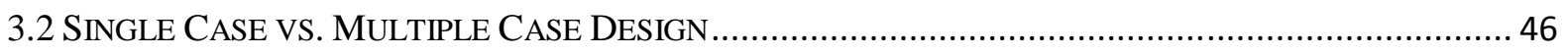

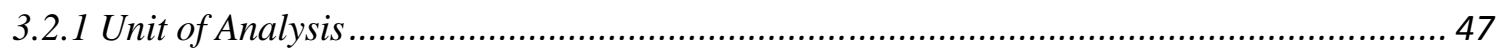

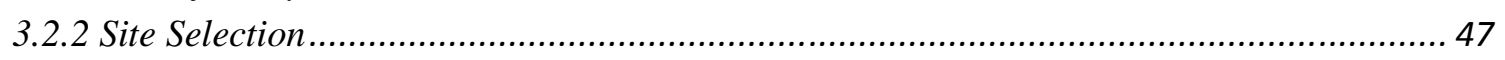

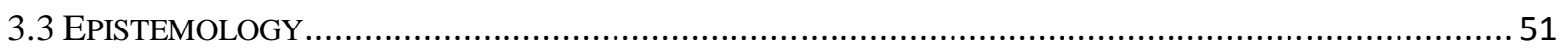

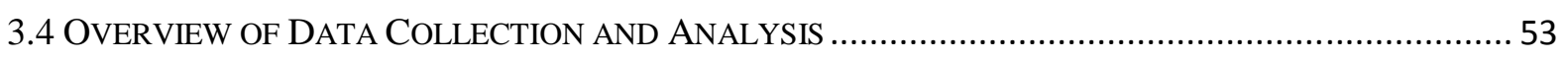

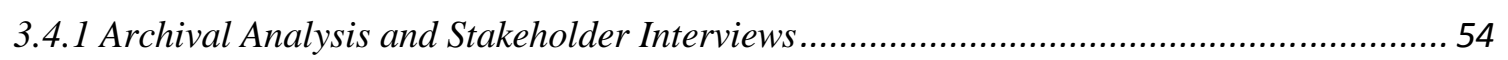

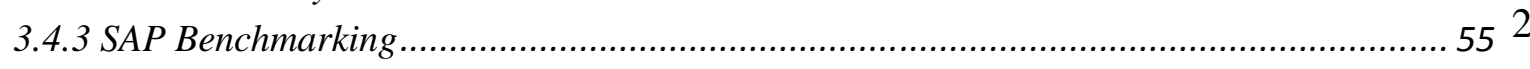




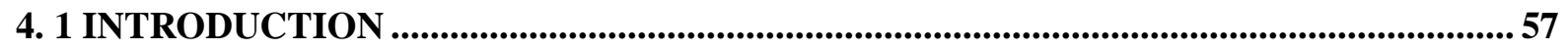

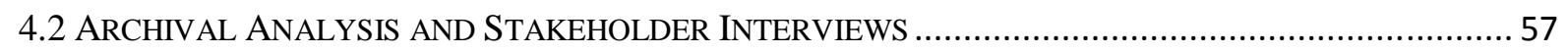

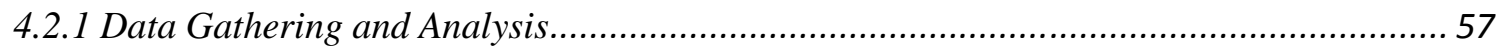

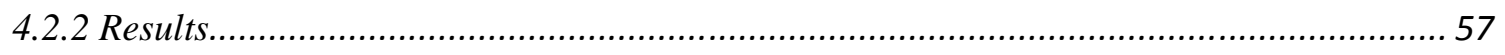

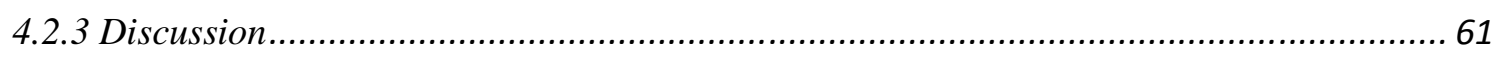

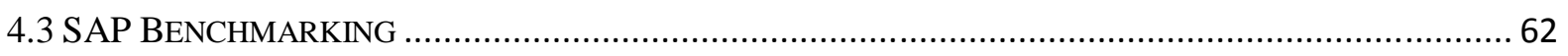

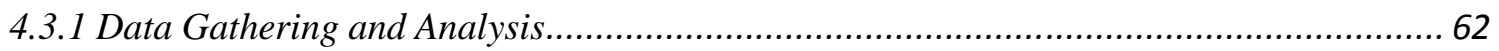

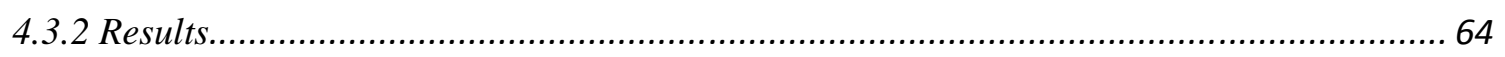

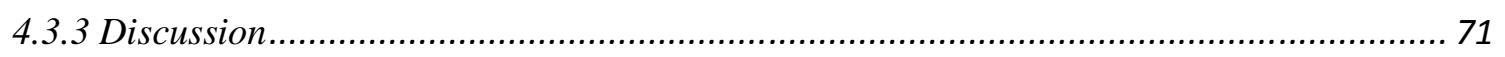

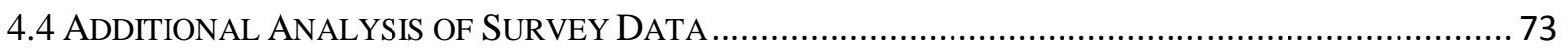

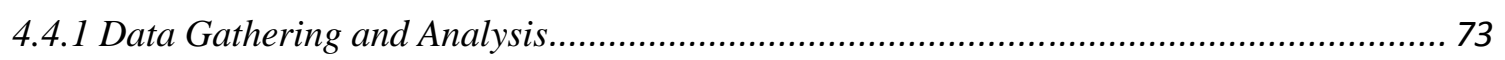

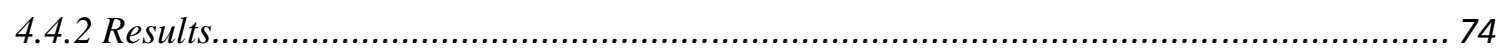

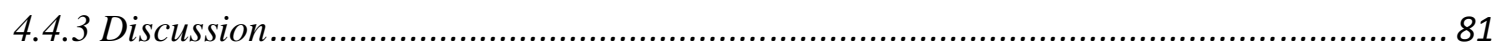

4.5 CARD SORTING TO ESTABLISH EQUIVALENCE BETWEEN MEASURES …........................................ 82

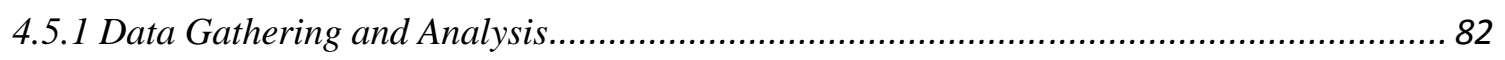

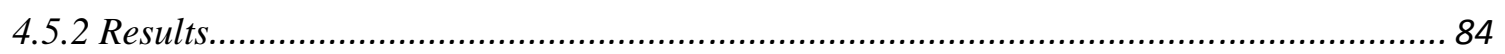

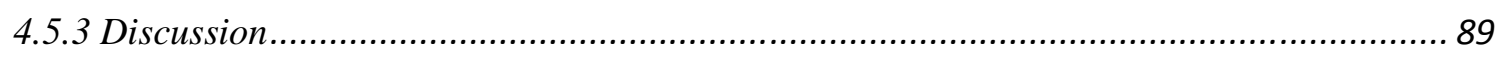

4.5 ACTUAL OUTCOMES VERSUS PERCEIVED OUTCOMES ......................................................... 92

4.6 SAP BENCHMARKING (2012) AND HACKETT BENCHMARKING (2009) ...................................... 95

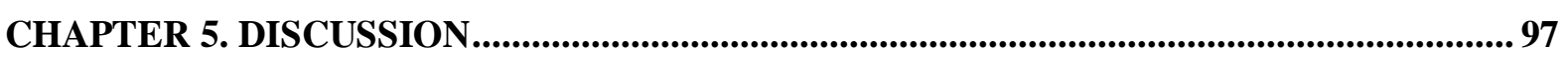

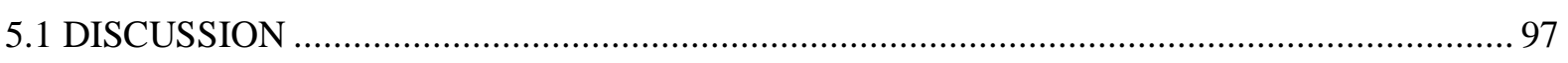

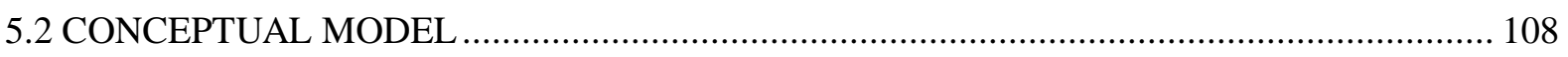

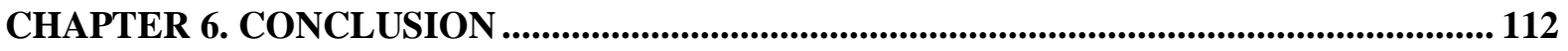

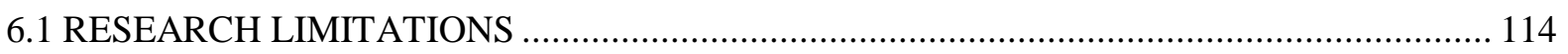

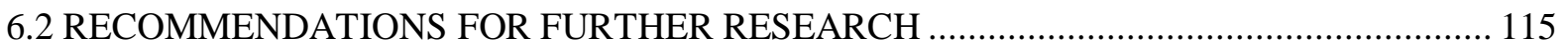

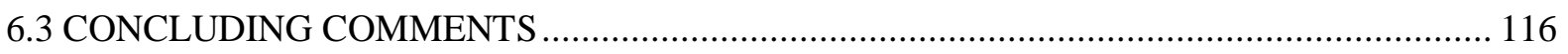

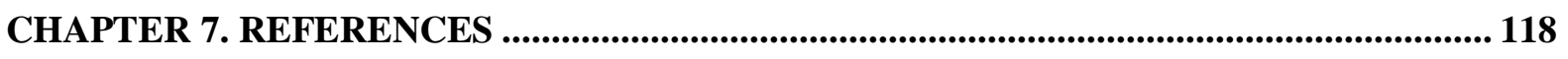

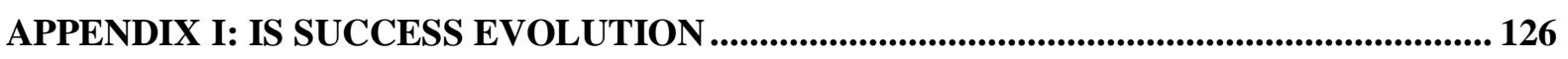

APPENDIX II: IS-IMPACT CHARACTERISTICS ................................................................... 127

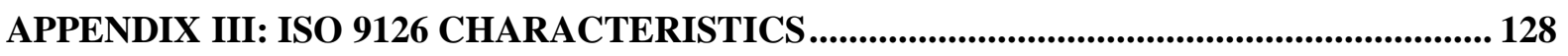

APPENDIX IV: IS-IMPACT \& ISO 9126 SURVEY .................................................................. 129

APPENDIX V: SAP BENCHMARKING TEMPLATE, BEST RUN \& TCO ........................... 135

APPENDIX VI: CARD SORTING ................................................................................................. 153

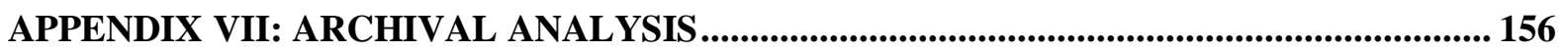

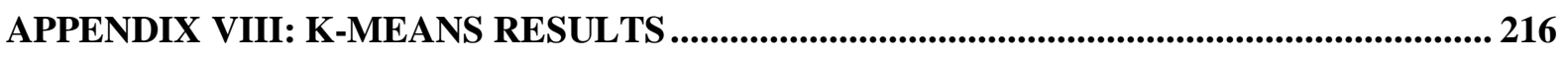

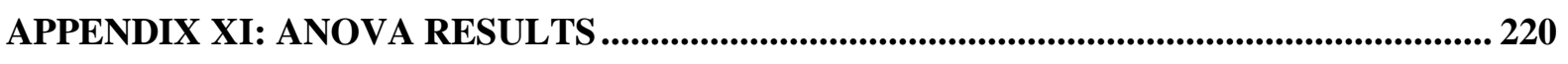

APPENDIX X: CARD SORTING RESULTS........................................................................... 223 
APPENDIX XI: HEC FORM . 226

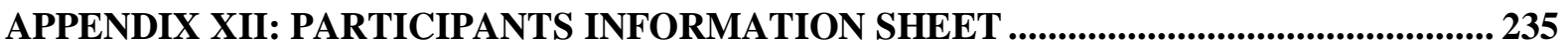

APPENDIX XII: SAP BENCHMARKING RESULTS ........................................................ 239 


\section{LIST OF FIGURES}

Figure 1: Five Approaches to Defining Quality (Garvin, 1984) ...................................... 16

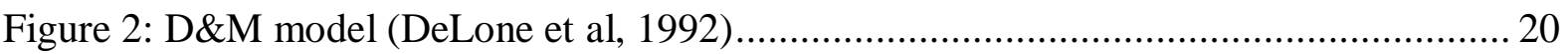

Figure 3: Revised D\&M model (DeLone et al, 2003) ....................................................... 21

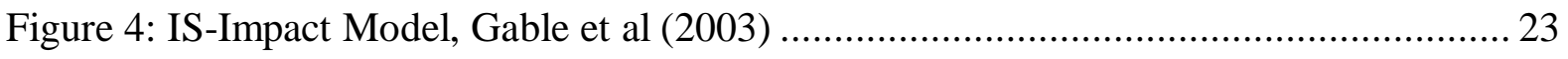

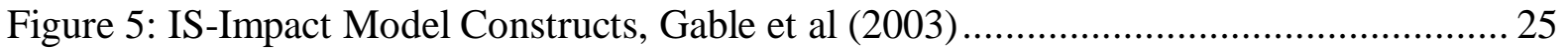

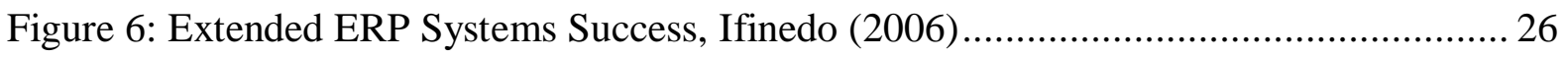

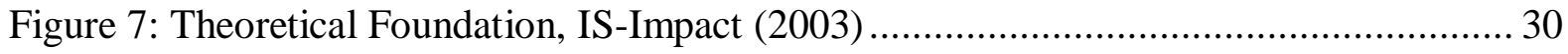

Figure 8: Approach to Software Quality, Padayachee et al (2010) ...................................... 31

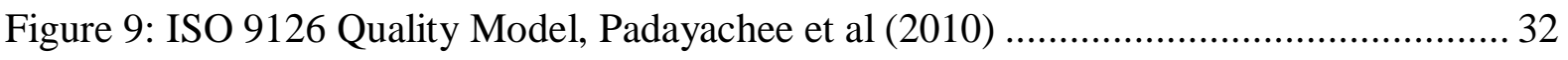

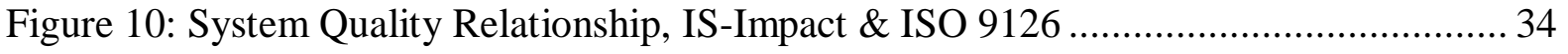

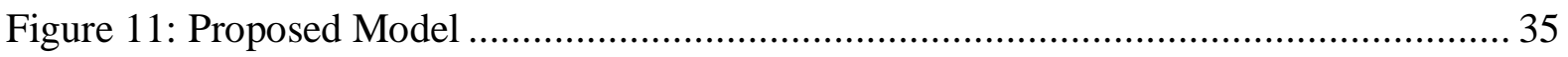

Figure 12: Model of Measures for IS-Impact Constructs System Quality and Organizational

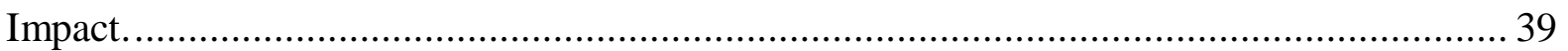

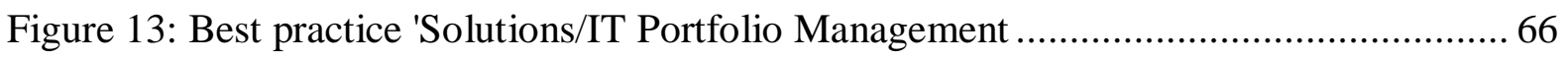

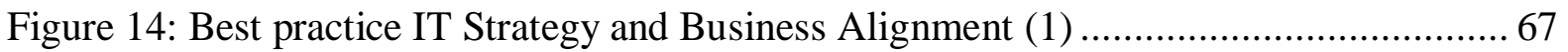

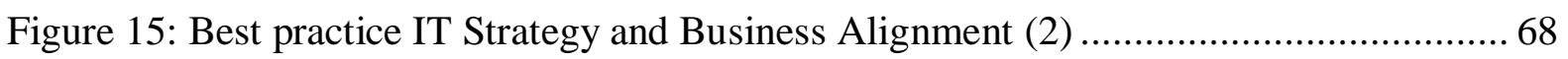

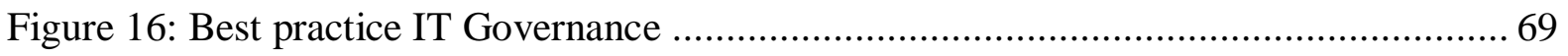

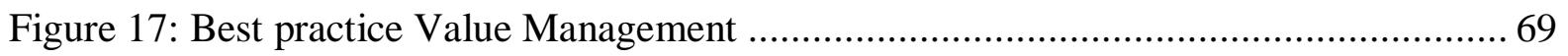

Figure 18: Best Practice Business Continuity and TCO .................................................. 70

Figure 19: Best Practice Business Process Improvement ................................................. 71

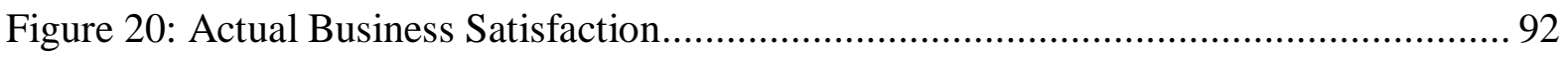

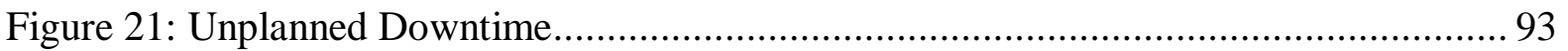

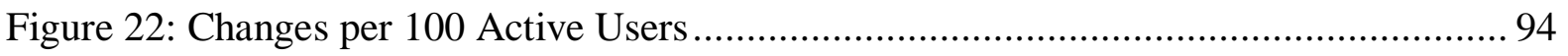

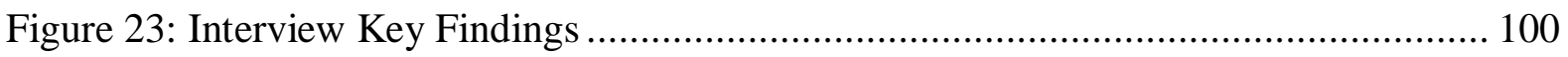

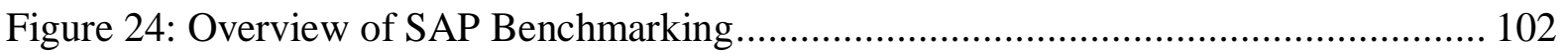

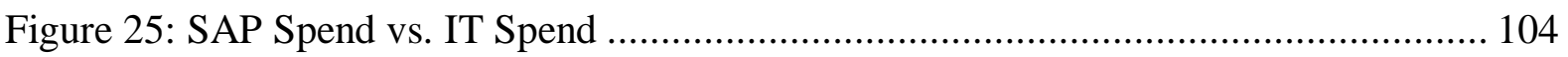

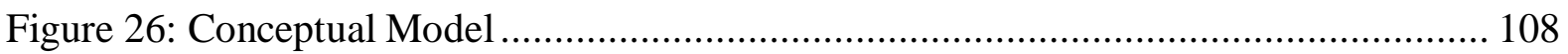




\section{LIST OF TABLES}

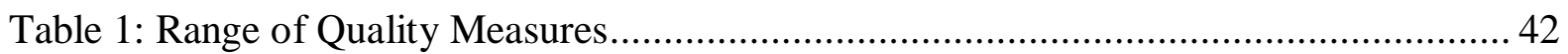

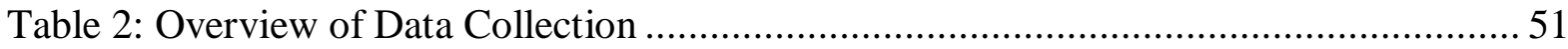

Table 3: SAP Platform Technical Procedures ......................................................................... 58

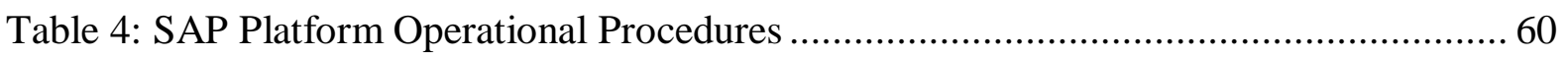

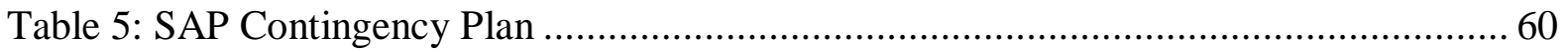

Table 6: Overview of Stakeholder Interviews and Archival Analysis................................. 61

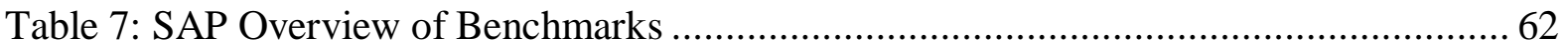

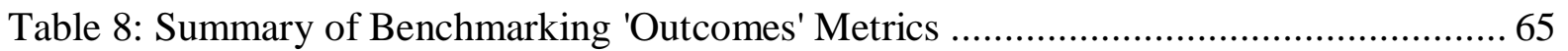

Table 9: Summary of Benchmarking Processes and Outcomes .......................................... 72

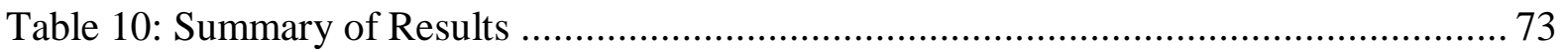

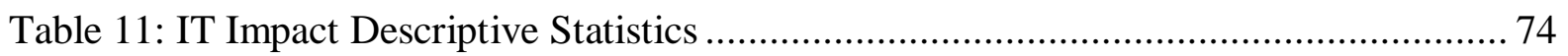

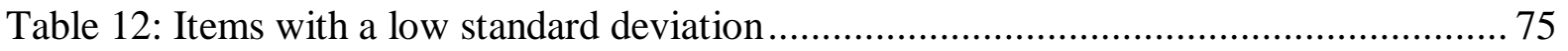

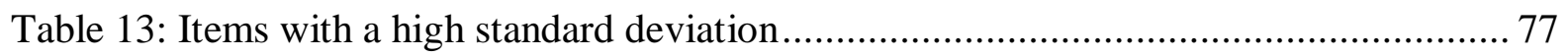

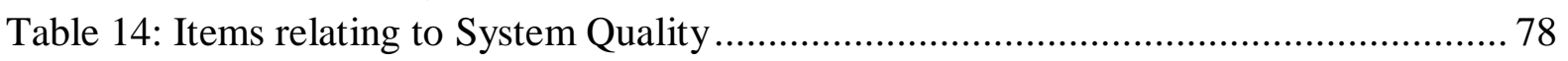

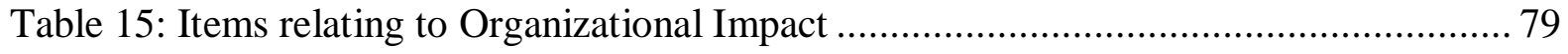

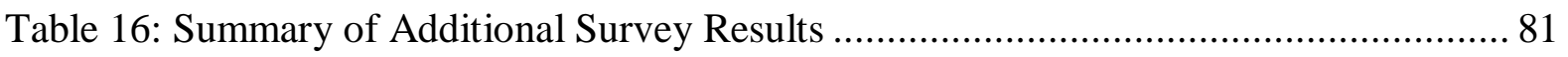

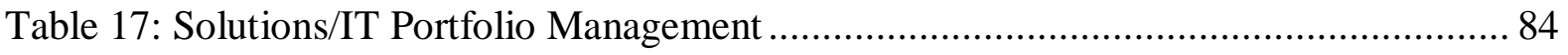

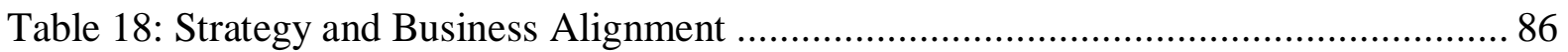

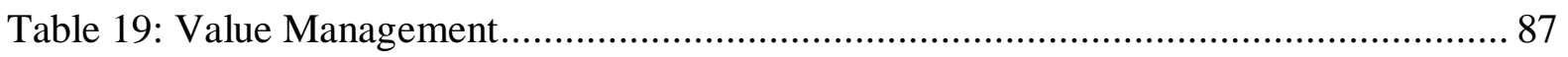

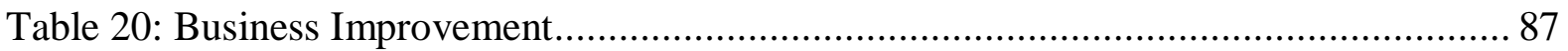

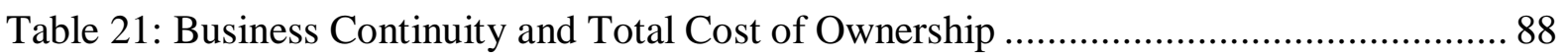

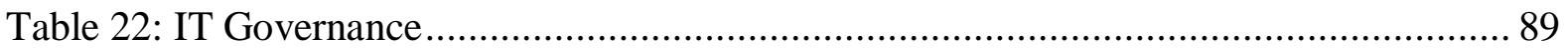

Table 23: Hackett Group Benchmarking Results (2009)............................................... 95

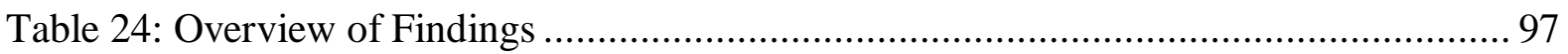

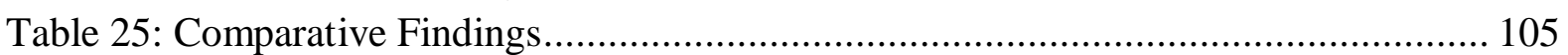

\section{LIST OF ABBREVIATIONS}

\begin{tabular}{|c|c|}
\hline SAP & $\begin{array}{l}\text { SAP is defined as Systems, Applications and Products in Data Processing. SAP is an integrated } \\
\text { enterprise resource planning application, a system that provides users with a soft real-time } \\
\text { business application that could be used with multiple currencies and languages. }\end{array}$ \\
\hline ISO 9126 & $\begin{array}{l}\text { ISO/IEC } 9126 \text { is an international standard for the evaluation of software quality. ISO/IEC } 9126 \\
\text { was issued in 1991; a revision was issued in } 2001 \text { in four parts (ISO/IEC 9126-1 to 9126-4). } \\
\text { The evaluation was replaced in } 2010 \text { by ISO/IEC 25010:2011 }\end{array}$ \\
\hline ERP & $\begin{array}{l}\text { An Enterprise Resource Planning system is a business management software. The suite is an } \\
\text { integration of applications, where organizations can use to store and manage data from every } \\
\text { stage of business such as HR, Payroll, Finance, Manufacturing or Plant Maintenance. }\end{array}$ \\
\hline IS & An abbreviation for Information Systems \\
\hline D\&M & Delone and McLean model of IS Success (1992 \& 2003). \\
\hline
\end{tabular}




\section{ACKNOWLEDGEMENTS}

I would like to acknowledge those who have supported me during the construction of this dissertation. Without their support this would have not been completed. I would like to firstly acknowledge my supervisor Dr Mary Tate was has been an exceptional mentor and always believed in my ability to perform at a high level and has been inspiring throughout this entire process. Secondly I would like to thank my parents and brother for their continued support, without them this would have been impossible. I would also like to thank Sara who has always supported me and provided the ongoing motivation needed. Lastly, I would like to thank all my friends who have kept in contact regardless of the fact that time was limited! 


\section{A B S T R A C T}

The latest Gartner report states that in 2012, the figure for global Information Technology (IT) spending amounted to US \$3.6 trillion and a predicted \$3.8 trillion in 2013. Achieving an effective measure of IS success and impact of information systems has been a goal for information systems researchers for decades.

Numerous methods exist for measuring the quality, value and impact of information systems in organizations, including benchmarking, ISO standards, and user surveys. However, typically, often due to restricted access to data, researchers only use one type of measure.

This study uses a single-organization case study investigating measures of the quality, value and impact of the SAP system in the largest telecommunications organization in New Zealand, using and comparing a range of methods and perspectives. The researcher also evaluates the best possible measures for organizations to adopt by comparing multiple methods.

KEYWORDS: ERP Success, Metrics, IS Success, System Quality, Organization Impact, SAP, Information Systems, Garvin, IS-Impact, ISO 9126, Benchmarking 


\section{Chapter 1. INTRODUCTION}

\subsection{Research Motivation}

Gartner has reported that worldwide spending on Enterprise Application software will total $\$ 120.4$ billion in 2012, a 4.5 per cent increase from 2011 spending of $\$ 115.2$ billion (Gartner, 2012). Measuring Information Systems' (IS) success has been researched for over four decades and has plagued researchers with trying to determine a silver bullet for IS success. An information system is no longer thought of as 'just' a computer system that processes information; it is much more than that. In a rapidly changing environment, many organizations frequently change their IT strategies to align with their contemporary business model (Hong, 2002; Chang, 2000).

IT investment is expensive and organizations need to implement resources that result in some form of tangible value (Zhang et al, 2002). The latest Gartner report states that in 2012, the figure for global IT spending amounted to \$3.6 trillion US, and predicted \$3.8 trillion in 2012 (Gartner 2010). With a growing amount of investment in information systems, organizations look to become more effective and efficient, with the overall goal of increasing profit and productivity (Rao, 2005). "Yet, it is often claimed that the actual benefits of IT are disappointing at best and that IT spending has failed to yield significant productivity gains, leading to the productivity paradox" (Pinsonneault, 1998, p. 297). Chan states productivity is the fundamental economic measure of a technology's contribution (Chan, 2000). Farbey et al (1999) implied that statistics used previously might have been of variable quality, leading to confusion, while poor evaluation practices have led to incorrect selection and management of projects, resulting in unsatisfactory returns. Other academics have suggested that information systems success variables tested are inconsistently defined or measured (Heo, 2001).

However, determining whether an information system is successful or not, relies heavily on the metrics and methods used. Investment in Enterprise Resource Systems (ERP), totaled $\$ 24.9$ billion in 2012, making it the largest information system within the IT market (Gartner, 2012). ERP is a set of configurable information system packages that integrate information and information-based processes within and across functional areas in an organization (Ifinedo, 2006). It can be difficult to evaluate an ERP due to the range of modules available e.g. human resources, financials, facility management, sales and distribution and 
manufacturing (Rabaai, 2009).

This leads to the overarching issue of the quality and efficacy of measures used in IS research, which is still regarded as one of the most critical scientific issues (Straub et al, 2004). Kronbichler (2010) suggests that what you measure is what you get. So organizations need to ensure that every measure of performance is pertinent to the achievement of a goal or value of your organization (Meliville et al, 2004). Otherwise you run the risk of misdirecting your organization.

It is ineffective to measure a large information system if the metrics and tools used are not continually validated to align with the contemporary business and IT environment, but also changing business requirements relating to IT infrastructure. This issue of the quality and appropriateness of measures of IS success, impact and quality provides the motivation for this study.

Many research academics have tried to explain the complex dependent variable, IS success (Ifinedo, 2006; DeLone and McLean, 1992). Information Systems investment is often attentively evaluated post implementation. The use of measures and reviews are under great scrutiny as there is a lack of credibility with the processes often adopted (Gable et al, 2008). It has also been suggested that many measures originating from IS research are overly generalized and fail to provide actionable insight for practitioners (Benbasat and Barki, 2007).

Organizations still place importance on financial measures, such as return on investment or total cost of ownership; however this is not enough as a measuring tool for large organizations (Petter, 2007). Organizations have moved towards measures such as balanced scorecards or benchmarking to better understand the intangible and tangible benefits of their information systems (Seddon, 2002; Markus, 2003), but also to better understand how their organization is comparative in the industry to keep aligned with competitors. Research academics also have created various models of information systems success, (for example, DeLone \& McLean, 1992; Ballentine et al, 1996; Gable et al, 2008; Ifinedo, 2006). ,

The widely cited DeLone and McLean (D\&M) model of IS Success (1992) has provided the foundation for other researchers, as the IS Success model serves as a basis for measuring arguably the most important dependent variable within the IS discipline, that is IS Success 
(Petter, 2007). Various academics have refined and extended the IS Success Model since its inception in 1992 (Seddon, 2002; Ballentine, 1996; Gable, 2003). Typically, measurements used to measure IS success do not include multiple models or multiple methods. Thus, this research takes is innovative in measuring the IS success of an ERP application through the use of alternative methods. The researcher also examines how multiple measures compare with one another. This will essentially lead to a richer and more nuanced understanding of measuring the success of an ERP system within a corporate organization.

\subsection{Research Gap}

The most prominent reason for organizations to implement ERP systems is to standardize their IT infrastructure but more importantly integrate the multiple functions of their organization with the overall goal of having a simplified technology stack to reduce operating expenditure (Shang \& Seddon, 2002). Many implementations that take place can amount to $\$ 100$ million and a total cost of ownership of \$200 million (Shang \& Seddon, 2002), so it is imperative for organizations to measure the success of their technological investment after implementation on a consistent basis and more importantly to have faith in the measurement tools used. .

In this study, the researcher had privileged access to organizational data. This provided a rich opportunity to further explore and compare quality measures relating to ERP success, and the differences between the methods; and the insights that can be obtained from different methods used to measure success. , It was therefore logical for this research to adopt a muiltimethod approach. To compare and contrast different measurement approaches the researcher framed the research using Garvin's (1984) five approaches to defining quality. These are: (1) the transcendent approach (largely based on moral philosophy) (2) the productbased approach (from economics); (3) the user-based approach (from economics, marketing, and operations management); and (4) the process or manufacturing-based approach and (5) value based approaches (from operations management).

In particular, the researcher compares multiple quality measures of the same focal system, adopting different quality perspectives. User-based surveys such as the results of results of the IS Impact and ISO 9126 model from a previous study (Ali \& Tate, 2012) are compared with a vendor-run benchmarking exercise. This is supplemented by archival analysis and 
interviews with key stakeholders.

\subsection{Overview of Literature}

Information systems "quality" on various dimensions is widely considered to be an important component of the success (Delone and McLean, 1992, 2003) and impact (Gable et al, 2008) of an information system. However, quality is a broad and nebulous concept. One of the most influential conceptualizations of quality in a business context has been Garvin's (1984) framework of quality, which has also been applied in an IS context (Sosua \& Voss, 2001; Myers et al, 1997; Ravichandran et al, 1999).

Garvin (1984) stated that product quality is becoming an important competitive issue. Several surveys in 1984 indicated dissatisfaction with the existing levels of quality and services of the products they buy. In a study of business units of major North American companies, managers ranked "producing to high quality standards" as their chief current concern. Nearly thirty years later, quality is still seen as an important facet for successful organizations (Gartner, 2013). Increased organizational dependence on information systems drives managerial attention towards improving information systems quality. Since Garvin's (1984) discussion of product quality, this issue of quality has remained important. A recent survey outlined that "Improve IT quality" is still one of the top concerns facing IT executives (Luftman \& Ben-Zvi, 2010). As IT quality is a multidimensional measure, it is important to understand what aspects of IT quality are critical to the organizations and for which the CIOs must devise sound and effective IT quality improvement strategies (Gorla et al, 2010). Garvin's conceptualization of quality also includes perspectives such as value, which can be applied to the quality of the IT portfolio at an organizational level. Overall, Garvin's quality framework provides a conceptual framework for integrating and comparing different approaches to measuring the quality, success and impact of an information system.

The literature review undertaken will look to outline the main theoretical understandings of quality based on Garvin's (1984) quality framework. The author identified five main approaches of defining quality arising from multiple disciplines (philosophy, economics, marketing and operations management. Several dimensions involve measurable product attributes. Others reflect individual preferences; some are objective while others reflect shifts in perceptual trends (Garvin, 1984). 
In the literature review, the researcher examines a range of perspectives that can be used for measuring IS success, and the researcher positions these approaches within Garvin's quality framework.

\subsection{Research Goals}

The complexity of measuring SAP success is apparent within IS literature (Gable et al, 2003; Ifinedo, 2006). The literature shows the dominance of subjective, perceptual measures; a lack of comparison between academically-orientated and practitioner-focused methods; and a lack of multi-method studies generally. This research aims to provide insights on how the different methods used to evaluate IS success compare with one another. The research is interested in further exploring and comparing quality measures relating to ERP success, and the differences between the methods; and the insights that can be obtained from different methods used to measure this success.

The most prominent reason for organizations implementing ERP systems is to standardize their IT infrastructure but more importantly integrate the multiple functions of their organization with the overall goal of having a simplified technology stack to reduce operating expenditure (Shang \& Seddon, 2002). Many implementations that take place can amount to $\$ 100$ million (Shang \& Seddon, 2002), so it is imperative for organizations to measure the success of their technological investment after implementation on a consistent basis and more importantly to have faith in the measurement tools used to measure the said success. However, ERP implementations also aim to provide better information for individuals to complete tasks. Research has been conducted on the goals of ERP increasing individual productivity.

Hitt et al (2002) indicates that ERP adopters are consistently higher in performance across a wide variety of measures than non-adopters. Suggesting that most of the gains occur during the (relatively long) implementation period, although there is some evidence of a reduction in business performance and productivity shortly after the implementation is complete.

In order to provide a framework in which the research can compare different quality evaluations, the research adopts Garvin's (1984) five approaches to defining quality. These are: (1) the transcendent approach of philosophy; (2) the product-based approach of 
economics; (3) the user-based approach of economics, marketing, and operations management; and (4) the manufacturing-based and (5) value based approaches of operations management.

In particular, the research compares and contrasts a range of measures from different perspectives. This includes the results of an IS Impact survey from a previous study (Ali \& Tate, 2012), as an example of a measure that originated within the academic research community. This will be compared with popular methods used by practitioners such as benchmarking and ISO standards management. The research also uses archival analysis, focus groups and interview data to gain additional perspectives on the success of the ERP implementation in our case organization.

The proposed research wants to identify what methods can be used to evaluate the success of an ERP system post implementation? What insights can be obtained from these measures? How do these measures compare with one another? Is there any convergence between the findings of different quality measurement approaches? Thus this project conducts the following sub research questions:

- Are quality measures based on the various perspectives of quality (Garvin, 1984) consistent and commensurate? How do the different approaches to quality measure complement each other? Are they consistent? What insights triangulating different quality measures can derive?

\subsection{Research Significance}

Developing valid measures is one of the major challenges we face as scholars, and arguably one of the major advantages offered by 'scientific research' over the insights of reflective practitioners informed by experience. Nevertheless, different operationalisations of 'the same' construct abound, running the risk of meaning variance in the construct, where researchers "may utter the same words, but the words have different meanings, so any logical comparison of their utterances is precluded" (Curd et al. 1998, p 222).

Measuring the success of SAP as an ERP, more generally as an information system has evolved. Research academics have created various models, such as the prominent IS success models (DeLone \& McLean, 1992; Ballentine et al, 1996; Gable et al, 2003; Ifinedo, 2006) which have been applied in an ERP context. However, it is difficult to capture a range of 
perspectives in a single measure, and conversely, it can be hard to meaningfully compare different measures. This is one of the first studies to use a multi-method to compare and triangulate a range of quality perspectives on the same information system, within the academic and practitioner industry.

\section{Chapter 2. LITERATURE REVIEW}

The research first introduces Garvin's 'Quality' framework, which will be used to frame the dissertation. The literature review will take a top-down approach to assess IS literature on I/S success, and transition into ERP systems as an IS system with concentration on SAP which will be used in a case study for this dissertation. The introduction of the evolution of IS success to date will provide clarity on the background in this area and show how it has progressed overtime. In order to gain a comprehensive coverage of research literature, Proquest and ACM databases were used for appreciable publications. The search terms used were; 'success', 'measure' in combination with 'information systems', 'quality' and 'ERP'.

The research then provides a brief overview of the characteristics of ERP systems, as an ERP system is the focus of the study. Next the research provides a brief history of the academic literature on IS quality measurement, and introduce the leading models that are used in this research. By way of contrast to this academic stream of measurement, also examined are other approaches to quality measurement and management have arisen from academic and practitioner quality management communities, in particular, the ISO 9126 model of system quality was developed by the international ISO standards organization. At this point the research introduces and integrates the focal constructs for the study and their relationship to Garvin's quality framework.

Following this, the research reviews relevant literature on benchmarking and more specifically SAP Benchmarking. Benchmarking data is used to triangulate data from the IS Impact model and ISO 9126 models, and other sources of information gathered for this study. Finally, the research present an integrated framework organizing and comparing the empirical evidence gathered using multiple methods. 


\subsection{Garvin's Product Quality Framework}

The literature review undertaken will look to outline the main theoretical understanding of Garvin's (1984) quality framework. The author identified five main approaches of defining quality arising from multiple disciplines (philosophy, economics, marketing and operations management (Figure 1). Several dimensions involve measurable product attributes. Others reflect individual preferences; some are objective, while others shift with trends. This framework was used to addresses the empirical relationships between quality and other important variables (Garvin, 1984).

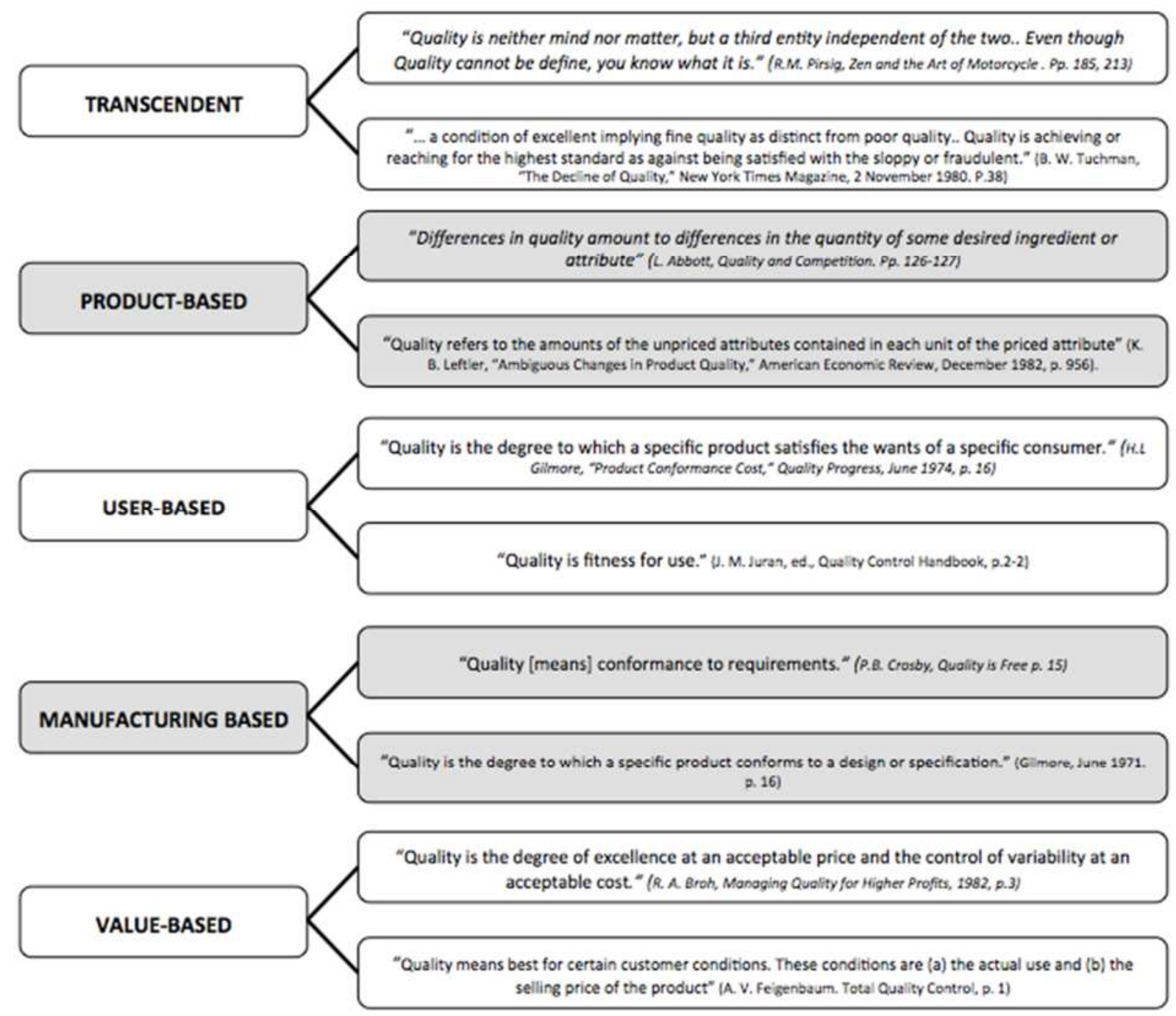

Figure 1: Five Approaches to Defining Quality (Garvin, 1984)

- The Product-Based approach focuses on performance, features and durability.

- The User-Based approach focuses on aesthetics and perceived quality.

- The Manufacturing-Based approach focuses on conformance and reliability. 
- The Value-Based

- $\quad$ The Transcendent-Based

There are many different approaches to conceptualising and measuring quality. One of the most influential was that proposed by Garvin (1984), who proposes five major approaches for defining product quality. Of these major approaches outlined the following, "user-based", "process based" and "value-based" are of most interest to this study.

The user-based approach defines quality in terms of the subjective perceptions of individual users. The difficulty of this approach is that each individual may value particular quality characteristics differently. This approach relies on the ability to obtain and aggregate a wide spectrum of individual preferences into a meaningful overall definition of quality at a market level. This makes survey-style research particularly useful for this approach. The manufacturing process approach can be summarized as "conformance to specifications". This is a "supply-side" definition that does not concern itself with defining what desirable quality features are, but with ensuring that, once defined, the products or services that are produced reliably demonstrate those characteristics.

A quality product is one that meets the specifications, and deviation from specifications implies a reduction in quality. Most software engineering methodologies are based on this approach, and on analogies between the software development process and the manufacturing process. The value-based approach defines quality in terms of costs and prices. A quality product is one that "provides performance at an acceptable price, or conformance at an acceptable cost" (Garvin, 1984).

\subsection{Enterprise Resource Planning (ERP) Systems}

Enterprise Resource Planning (ERP) systems can be defined as 'a software system that integrates key business and management processes within and beyond a firm's boundary' (Hitt et al, 2002). Two of the most dominant vendors for these ERP systems are SAP, which produces the SAP R/3 and its latest ECC6 package and Oracle. Models developed for measuring IS success in a traditional IS context are not necessarily suitable for measuring ERP success (Gable et al, 2003). Various models do not take into account the complexity of ERP systems, largely due to the nature of the system. 
ERP systems are comprehensive packages designed to support a wide range of business functions, to provide a holistic view of the firm from single information technology architecture (Wang \& Chen, 2005; Hitt et al 2002). An ERP system includes various functional components in order to automate operations from supply chain management, manufacturing, sales support, customer relationship management, financial and cost accounting, human resources, scheduling and production and payroll (Hitt et al, 2002). The integration of various components makes measuring the success after implementation more complicated than traditional packages, and organizations are lacking the appropriate success metrics in order gain valuable insights into success (Gable et al, 2003; Ifinedo, 2006). A large amount of IS literature within the domain concentrates efforts on the implementation and adoption of ERP systems (Ifinedo, 2006). There is little literature on the actual success of ERP systems in the adopting firms, these include Gable et al (2003) IS Impact Model, Ifinedo (2006) ERP Systems Success framework and Markus and Tanis (2003) Enterprise System Experience Cycle.

Ifinedo (2006) defines ERP success as "the utilisation of such systems to enhance organizational efficiency and effectiveness" (Ifinedo, 2006). It is vital for organizations that have adopted ERP systems to have appropriate measures in place in order to effectively become efficient and increase productivity and utilise ERP systems to its potential.

\subsection{Taxonomy of IS Quality Management}

Information Systems success has been researched for over five decades, the topic is not a new phenomenon (Benbasat \& Goldstein, 1987). Measuring the value of IT investments is reportedly a top five concern for IT executives internationally (Luftman and Ben-Zve, 2010). As noted by DeLone and McLean (1992) there are as many measures as there are studies when searching IS success measures (DeLone \& McLean, 1992). Organizations are continually assessing the benefits that IT provides (DeLone \& McLean, 1992; Seddon, Graeser, \& Willcocks, 2002; Chan, 2000; Daneva, 2001).

The origins of many IS success measures are based on the work of Shannon and Weaver (1949) on information. Three levels of measures were proposed. These levels included the technical level, semantic level and effectiveness level. Shannon and Weaver (1949) defined these levels as follows; the technical level is the accuracy and efficiency of the system which 
creates information, the semantic level is the successful output of information; that is the output generated conveys what it intended to generate and lastly the effectiveness level is the end effect for the receiver (DeLone and McLean, 1992).

Mason developed this further by modifying the effectiveness level as 'influence', which defined the influence level of information to be a "hierarchy of events which take place at the receiving end of an information system which may be used to identify the various approaches that might be used to measure output at the influence level" (DeLone and McLean, 1992). In our literature review, the research traces the evolution of the original Shannon and Weaver framework through leading models such as the Delone and McLean IS Success model (1992, 2003) and the Gable et al, (2008) IS-Success model. The DeLone and McLean model is still the most widely cited study of IS success in literature according to Google scholar (nearly 6,000 citations).

\subsubsection{DeLone and McLean Model (D\&M)}

DeLone and McLean constructed six independent dimensions or constructs of IS success from a diverse range of academic literature they reviewed during the period $1981-1987$, and created a model of IS success based on this review (DeLone and McLean, 1992; Petter et al, 2007). This comprehensive review of different IS success measures provided two important contributions to our understanding of IS Success. It provides a structure for classifying the mass of IS success measures that have been used in literature; secondly it developed a model of temporal and causal interdependencies between these constructs (DeLone and McLean, 1992; Seddon, 1998; Petter et al, 2007). 


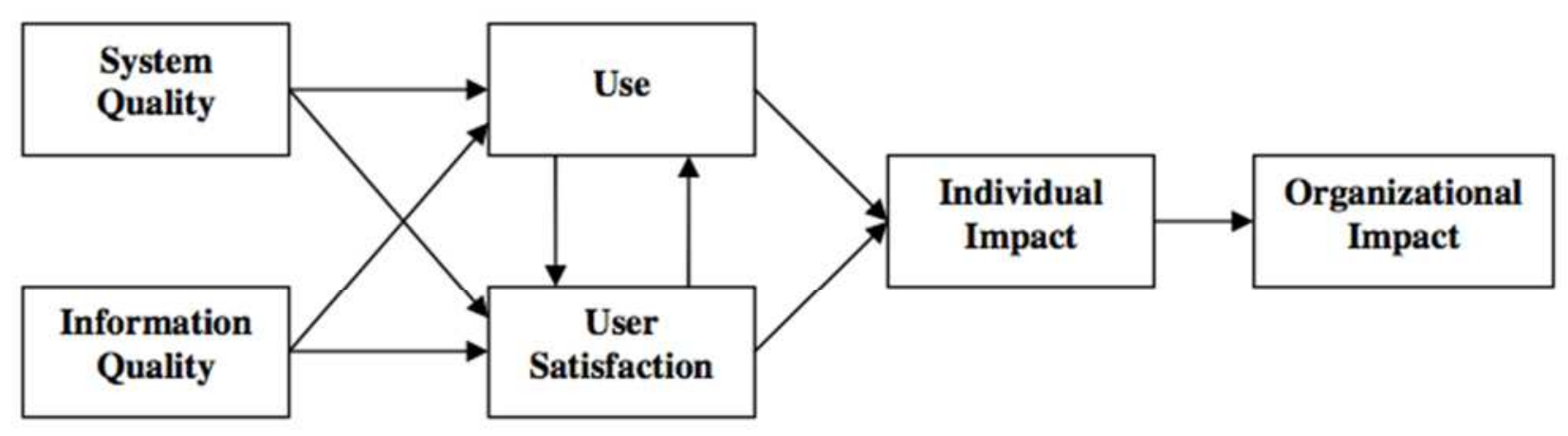

Figure 2: D\&M model (DeLone et al, 1992)

The DeLone and McLean model consists of six constructs that are system quality, information quality, user satisfaction, use, individual impact and organizational impact as represented in Figure 2.

It is important to clarify that the dimensions represented above are not independent success measures, but rather are interdependent (Petter et al, 2007; DeLone and McLean, 1992). The model suggests that system quality and information quality affect both system use and user satisfaction, independently or collectively. Increased system use suggests that it affects the degree of user satisfaction, negatively or positively; the degree of user satisfaction also affects system use. System use and user satisfaction are direct precursors of individual impact. Lastly individual impact will influence organizational impact (DeLone and McLean, 1992; Rabaai, 2009; Livari, 2002). System quality is seen to be a preferred characteristic of the information itself whereas information quality is seen to be a preferred characteristic of the information product (Livari, 2002).

The above measures of IS involves one hundred and twelve measurement items spread over the six dimensions, outlining that the measurement items selected are dependent on the organizational setting and requires the researcher to select the most appropriate measures (DeLone and McLean, 1992), the large selection of measures has been a concern for various researchers (Seddon, 1997; Rabaai, 2009; DeLone and McLean, 2003; Ballentine et al, 1996). DeLone and McLean (2003) suggest an attempt should be made to reduce the number of different measures significantly in order for research results to be compared and findings to be validated (DeLone and McLean, 2003). 
Although the D\&M model provided development for IS success measures and models, many researchers criticised the model (Seddon, 1997; Livari, 2005; Elisa, 2009; Ballantine et al, 1996; Gable et al, 2008, DeLone and McLean, 2003; Kronbichler et al, 2010; Rabaai, 2009). Seddon (1997) provided limitations of the model in extensive detail; the author believes the model exhibits 'muddled thinking', the model claimed to be ambiguous and the dimension USE had potentially three different meanings (Seddon, 1997; Livari, 2005). Newman and Robey (1996) tried to explain the relationships between dimensions, confirming the arrows in variance and process model diagrams represent different outcomes and meanings (Seddon, 1997).

However, with the D\&M model the measures used for organizational impacts are primarily focused on financial measures and thus does not include other possible measures for potential organizational impacts (Ballantine et al. 1996). As with any financial measure, it is important to determine the economical value of an IS system, however with the contemporary environment of IS, intangible benefits are unable to be determined through such financial measures as an organization can be successful in alternative ways. Other notable limitations with the model outlined was the insufficient explanation of its underlying theory; user involvement is a critical component that should be included, concerns with causal or process nature of the model (Gable et al, 2008; Ballantine et al, 1996).

Eleven years later DeLone and McLean provided a revised framework as displayed in figure 3:

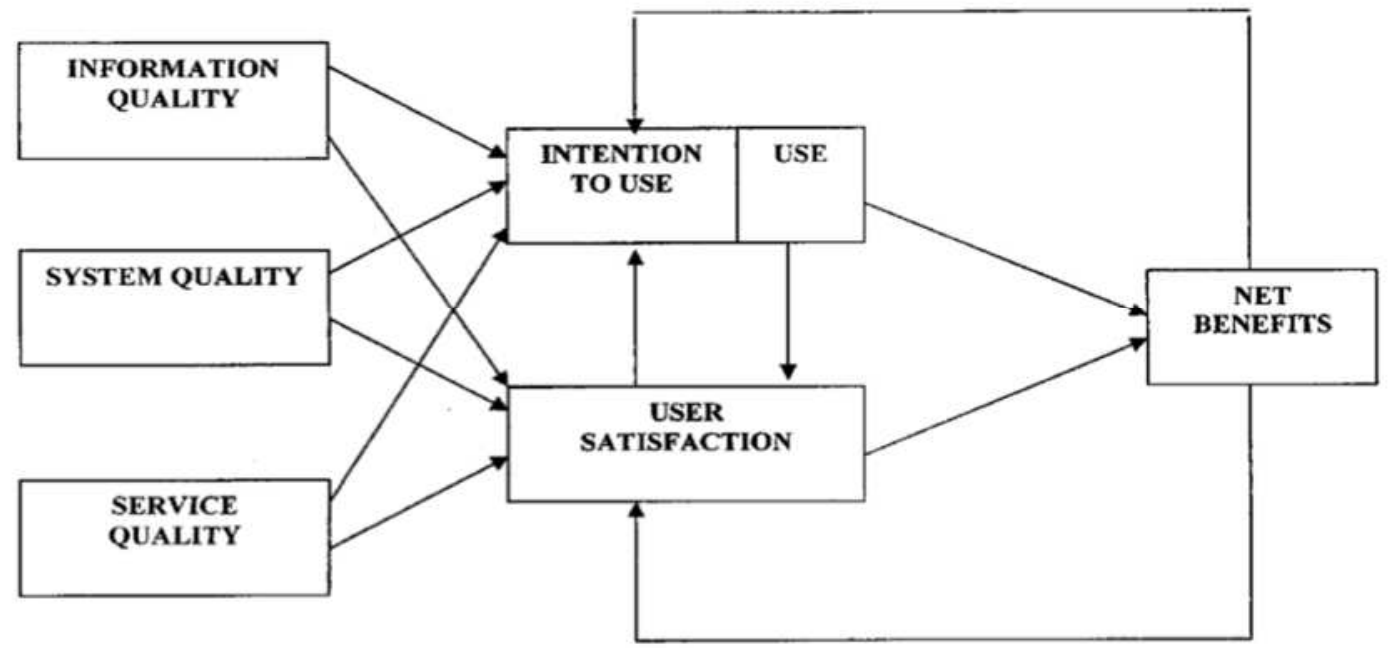

Figure 3: Revised D\&M model (DeLone et al, 2003) 
The revised model demonstrates further development and validation, acknowledging the various IS researchers' recommendations (Ballentine et al, 1996; Seddon, 1997). The modified model extracts the various literature on IS success since its inception in 1992. The new model proposes various changes: (1) 'Service Quality' was added; (2) 'Use' was replaced by 'Intention to use'; (3) 'Individual Impact' and 'Organizational Impact' were replaced with 'Net Benefits'; (4) A feedback loop was added, which reflects the continuation or discontinuation of use and user satisfaction of an information system, as influenced by the net benefits and (5) Explanation between the dimensions with the represented arrows were provided to make the process more simple (DeLone and McLean, 2003).

The use of the D\&M model is dependent on the context of the organization; it has been used in various contexts such as E-Commerce (DeLone and McLean, 2003). Based on the organizational setting the measures will vary respectively for each success dimension. The diverse context of IS organizations can range from supply chain management through to enterprise resource planning systems, allowing for different IS systems in terms of characteristics to use the D\&M model, but requires different and appropriate measures to be used within the model.

\subsubsection{IS Impact Model}

From the review of IS literature, the latest IS success model identified is the IS-Impact model which has been introduced by Gable et al (2003). The authors have created a multidimensional instrument for IS success but more importantly ERP success, through a comprehensive literature review and an exploratory survey.

An exploratory survey was conducted to empirically test the model using survey data from 456 respondents of which 27 were from government agencies that had implemented SAP R/3, a form of ERP. Once the first survey was completed, a second confirmatory survey demonstrated the discriminate validity of four constructs and the dependent variable IS success (Gable et al, 2008; Rabaai, 2009). The purpose of the two surveys was simply to first identify success measures and secondly to determine the purpose of the success measures. Several amendments have been made from the D\&M model to represent an appropriate fit for ERP systems success, but was fuelled by the lack of reliable standardised and empirically validated models for IS success. The IS Impact model is also the most comprehensive and validated measure model for IS success (Elias, 2009). The IS Impact model has been defined 
to be the most comprehensive measurement tool for IS success, as the model measures four key success dimensions and involves at least four items for each construct, providing strong construct validity, capturing the multinational and complex nature of ERP success (Petter et al, 2007).

Gable et al (2008) defined the IS Impact Model as "a measure at a point in time, of the stream of net benefits from the IS, to date and anticipated, as perceived by all key-user groups" (Gable et al, 2008; Rabaai, 2009).

Researchers continue to strive to provide a comprehensive IS success model or validate already existing IS success models; the IS-Impact model removes various concerns with the prominent D\&M Model. It is also differentiates itself by; (1) depicting a measurement model and does not purport a causal/process model of success, (2) it omits the construct use, (3) rather than a construct of success, satisfaction is reflected as an overall measure of success, (4) new measures were added to reflect the contemporary IS context and organizational characteristics and (5) it includes additional measures to examine a more holistic organizational impacts construct (Gable et al, 2008).

Figure 4 depicts the IS Impact Measurement Model.

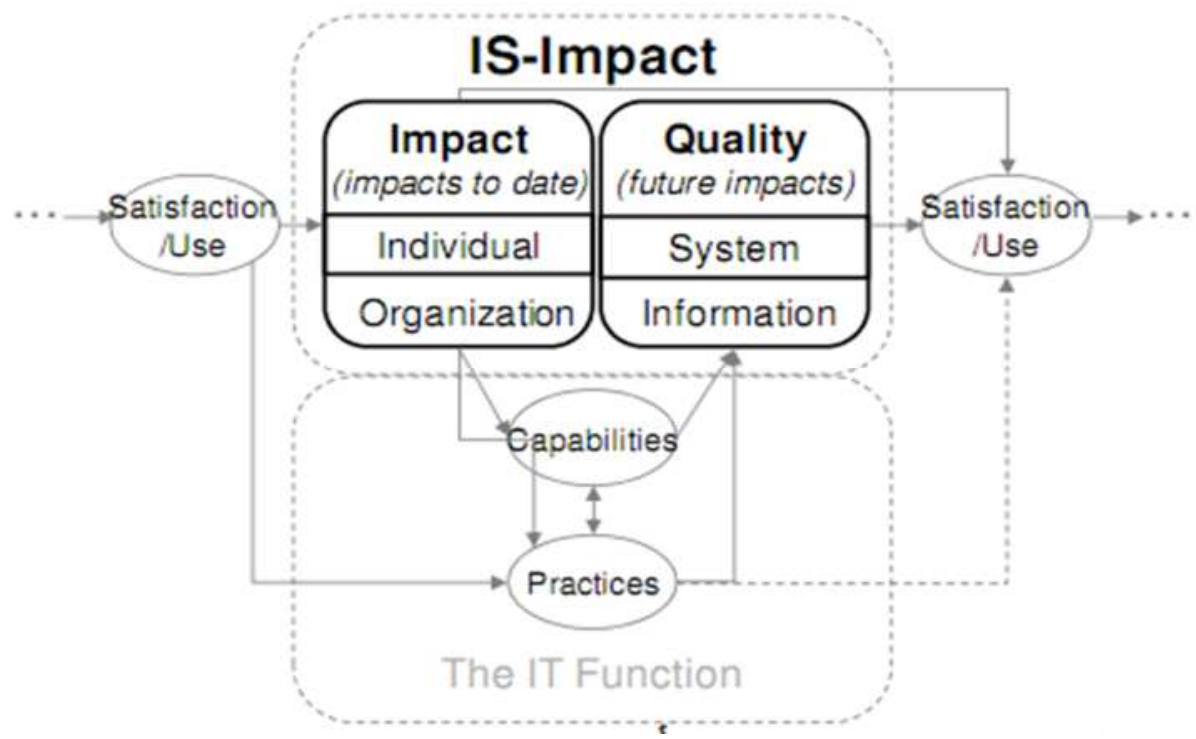

Figure 4: IS-Impact Model, Gable et al (2003)

The redundancy of a causal process model of success was made with the IS Impact model that was evident in the D\&M model. Many researchers have thoroughly tested the causal relationships between the six constructs of the D\&M model, outlining mixed conclusions 
(Ballentine, 1996; Seddon, 1997). The issue with the validity of the relationships has been a result of a poor explanation for causality and lack of theoretical grounding (Gable et al, 2008; Ballentine, 1996; Seddon, 1997).

The elimination of the constructs 'Use' and 'User Satisfaction' was conducted through statistical analysis, along with this, 'Use' can only be a measure of success where IS use is not mandatory (Ifinedo, 2009). The model represents the four distinct and independent dimensions which are, 'System Quality (SQ)', 'Information Quality (IQ)', 'Individual Impact (II) and 'Organizational Impact (OI)'. Gable et al (2008) stated 'the 'impact' half measuring net benefits to date, while the 'quality' half, form our best proxy measure of probable future impacts, with 'impacts' being the common denominator (Gable et al., 2008).

DeLone and McLean (1992) used satisfaction as a mediator between Quality and Impact, thus Gable et al (2008) excluded this based on factor analysis of the survey. Through various findings, the construct can be concluded to be an immediate consequence of IS Impact as acknowledge by literature (Gable et al, 2008).

Contemporary information systems require contemporary measures when evaluating IS success. With the rapidly evolving environment of IS, researchers must acknowledge the need to continue to provide rationale for the choice of success constructs and measures selected and employed. It was this reasoning that motivated Gable et al (2008) to develop a comprehensive measurement model and instrument for a particular context. Taking a more holistic view of IS success in a contemporary environment, existing and new measures were used in order to better represent features that are more understandable.

Each dimension involves thirty seven measures that are depicted in Figure 5. It is important to note that the most important constructs of interest for this research are 'Systems Quality' and 'Organizational Impact'. 


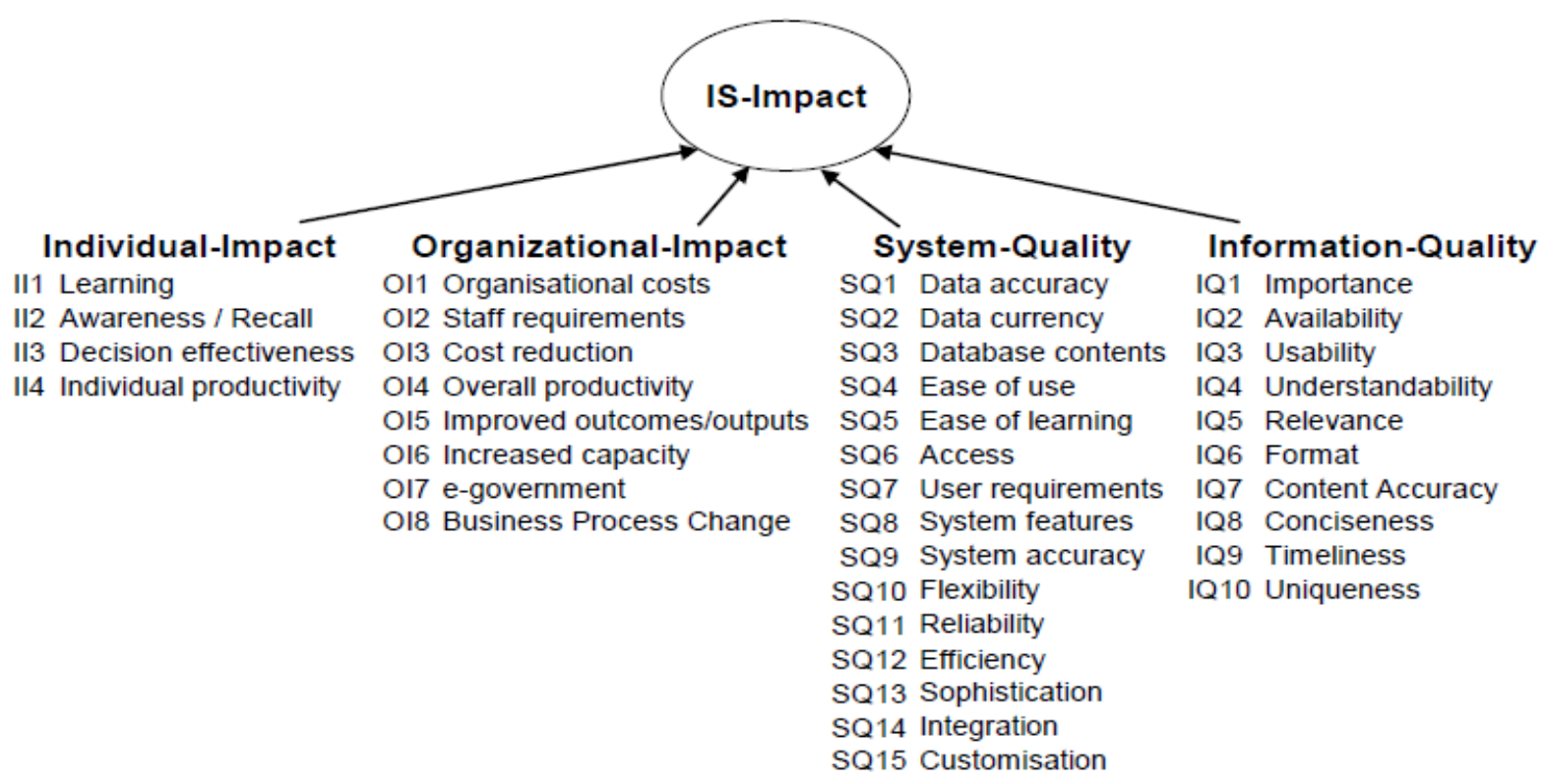

Figure 5: IS-Impact Model Constructs, Gable et al (2003)

The IS-Impact model will be the theoretical foundation for this research; it delivers a model that is robust, generalizable and also simple. Overlapping measures identified in the D\&M model were comprehensively evaluated and removed to provide a more rigorous and relevant IS success model. The model and measurement approach employs perceptual measures and offers an instrument that is relevant to all key stakeholder groups, providing a comparison between users perceptions of IS success. Unlike the DeLone and McLean IS Success Model, the IS Impact model has a specific approach to measure ERP systems success (Petter, 2008; Gable et al, 2003; Ifinedo, 2006). System quality and organizational impact survey items can be found in appendix ii.

The IS Impact model is rigorous and relevant to research and practice as outlined, the model can be used to: (1) Evaluate the quality of contemporary IS using an easy to understand perceptual survey instrument; (2) Assess the level of IS Impact from multiple stakeholder perspectives; (3) Measure IS Impact using tangible as well as less tangible indicators; (4) Identify and understand trends in system performance over time; (5) Establish an IS Impact benchmark for comparison across other demographic groupings; (6) Further justify the IS subsequent to implementation; and lastly (7) Focus scare resources and attention on those aspects of the IS and the organization most in need (Gable et al, 2008). 


\subsubsection{Additional Models}

The research identified an extension of the IS-Impact model in an ERP context by Ifinedo (2006). Derived from the IS-Impact model, the ERP Systems Success Framework extended the dimensions of IS success proposed by Gable et al (2003). Through statistical analysis, the goal was to determine the prioritisation and evaluation of measures relating to success of ERP systems. A lack of literature on post adoption ERP systems success was the motivation to create the six-dimension model 'Extended ERP Systems Success Measurement Model' as indicated in Figure 6 (Ifinedo, 2006; Kronbichler, 2010).

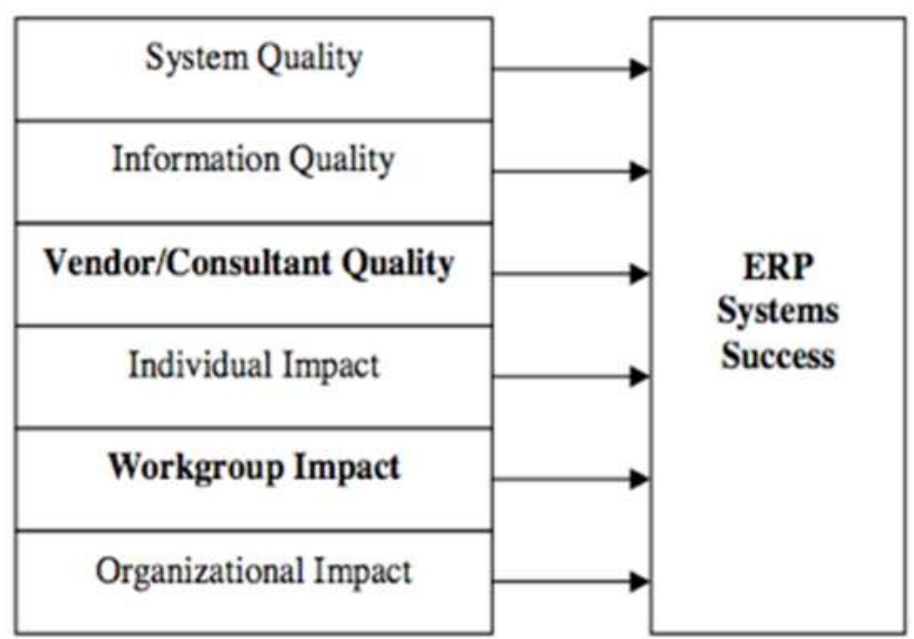

Figure 6: Extended ERP Systems Success, Ifinedo (2006)

The extension to this model incorporated two further constructs to IS success, literature on ERP success has advised that the IS-Impact model may be limited because two important constructs have not been considered (Kronbichler, 2010).

Vendor/Consultant Quality was added as a result of empirical evidence suggesting that organizations tend to associate the role and quality of the providers of their software with its overall success of the organization (Ifinedo, 2006; Markus \& Tanis, 2000). The addition of the construct Workgroup Impact reveals that sub-units and / or functional departments of an organization, thus workgroups contribute to the success of IS. However, these two additional constructs will not be covered within this study.

Through validation, findings suggested that 'System Quality' and 'Organizational Impact' were the two most important dimensions for ERP systems success (Ifinedo, 2006). The Ifinedo (2006) model replicates a similar area of application as the IS Impact model but the 
framework provided allows to collect more comprehensive data influencing the ERP systems success (Kronbichler, 2010). Findings further implied that large organizations adopt top of the line systems and smaller enterprises adopt mid-market products.

Further validation is required for the Ifinedo model; it was conducted through an exploratory study with a small sample of 62 individuals and comprised of various organizations using diverse ERP software, including the most dominant in the market SAP and Oracle. However, the context of our study, and the organizational data that the researcher had access to did not include measures of vendor quality or workgroup impact. Therefore the researcher was not able to use this model to extend the comparative study. Other methods which were considered but not implemented included the balanced scorecard measurement model (Kaplan et al, 1992). However, due to the nature of IS and focal constructs, this approach was not considered.

\subsection{Evolution of IS Success}

The above section summarised models which have been the focal point in IS success literature, with the most prominent being the DeLone and McLean (1992) model providing the foundation for researchers and practice, the research has outlined the models via visual timeline in appendix $i$. However due to the contemporary nature of information systems, the IS-Impact model is the most relevant IS success measurement model to date (Petter et al, 2007; Ifinedo, 2006; Kronbichler, 2010). In the case of this research the IS-Impact model is the most appropriate model that the research is more interested in measuring the success of ERP systems, but more importantly the two dimensions Systems Quality and Organizational Impact.

The above section provided the historical evolution of IS success models since Shannon and Weaver (1949), who defined IS success based on three levels; the technical level, the semantic level and the effectiveness level. It has evolved dramatically and since then various constructs have been validated to measure the success of IS systems, such as system quality, organizational impact and user satisfaction displaying the severity of the contemporary IS environment.

Petter et al (2007) has encouraged further research to be continued based on the IS-Impact model of IS success (Petter, 2007). There is vast literature on IS success at both individual 
and organization levels, with empirical studies demonstrating minimal improvement over the past two decades.

Empirical evidence suggests that valid and reliable measures have yet to be developed and consistently applied for system quality (Petter et al, 2007). Rigorous success measurements are required, although the development of models such as the D\&M model and IS-Impact have been vast in literature, it is important to validate each construct in greater detail (Petter et al, 2007; Gable et al 2003; Ifinedo, 2006, Seddon et al, 2002). Thus, this study embarked to further improve system quality and organizational impact constructs.

\subsubsection{The Focal Constructs Used in this Research}

In this section the research introduce the specific constructs that were used in the surveybased measures that were conducted in the case organization. As discussed, the research was constrained in our study by the availability of data, so the research has opted to introduce in detail the constructs that was used, rather than examine alternative measures for which no data is available.

\subsubsection{IS Success and IS-Impact Constructs}

Tested and proven measures of IS Success must have adequate and acceptable qualities. Gable et al (2008) stated a low number of researchers explain the rationale for their choice of success constructs and measures employed. The below outlines a brief description of the items that have been incorporated in the D\&M model but also provided the fundamental grounding for the IS-Impact model (Petter et al, 2007; DeLone and McLean, 1992; Gable et al, 2003).

- System Use - This construct examines the actual use of an information system, the manner in which stakeholders utilise the capabilities of an information system, e.g. frequency of use, appropriateness of use, nature of use, extent of use, amount of use, and purpose of use

- User Satisfaction - This construct is determining the successful interaction between the information system and user e.g. enjoyment, software satisfaction, decision making satisfaction, satisfaction with specifics and information satisfaction. 
- Net Benefits - Examines whether an information system is providing benefits to stakeholders and society e.g. improved decision making, improved productivity, increased sales, cost reductions, improved profits, market efficiency, consumer welfare, creation of jobs and economic development.

- System Quality - The anticipated characteristics of an information system are whether or not there are 'bugs' in the system i.e. usability, system flexibility, system reliability, and ease of learning, as well as system features of intuitiveness, sophistication, flexibility and response times.

- Information Quality - The anticipated characteristics of the system outputs e.g. importance, relevance, understandability, accuracy, conciseness, completeness, currency, timeliness, sufficiency and usability.

- Service Quality - The quality of the support that system users receive from the IS department and IT support personnel, e.g. responsiveness, accuracy, reliability, technical competence and empathy of the personnel staff. SERVQUAL adapted from the field of marketing is a popular instrument for measuring IS service quality.

These above measures have been tested and validated for IS success (Rabaai, 2009; Gable et al, 2008; DeLone and McLean, 2003; Ifinedo, 2006; Seddon, 1997).

The above metrics measuring IS success in a traditional IS context are not necessarily suitable for measuring ERP success (Gable et al, 2003). Various models do not take into account the complexity of ERP systems, largely due to the nature of the system. As mentioned previously the below metrics outlined by Gable et al (2008) were to specifically measure the success of ERP systems, the IS-Impact characteristics can be seen via appendix ii. The model comprises (figure 7) of the four constructs with system quality and information quality derived from the D\&M model, the two constructs that differ from the DM model are:

- Individual Impact - Examines the result of IS on the individuals capabilities and effectiveness e.g. productivity, effectiveness, learning, awareness

- Organizational Impact - Examines the impact of IS at the organizational level; e.g. organizational costs, staff requirements, cost reduction, improved outcomes/output and improved processes. 


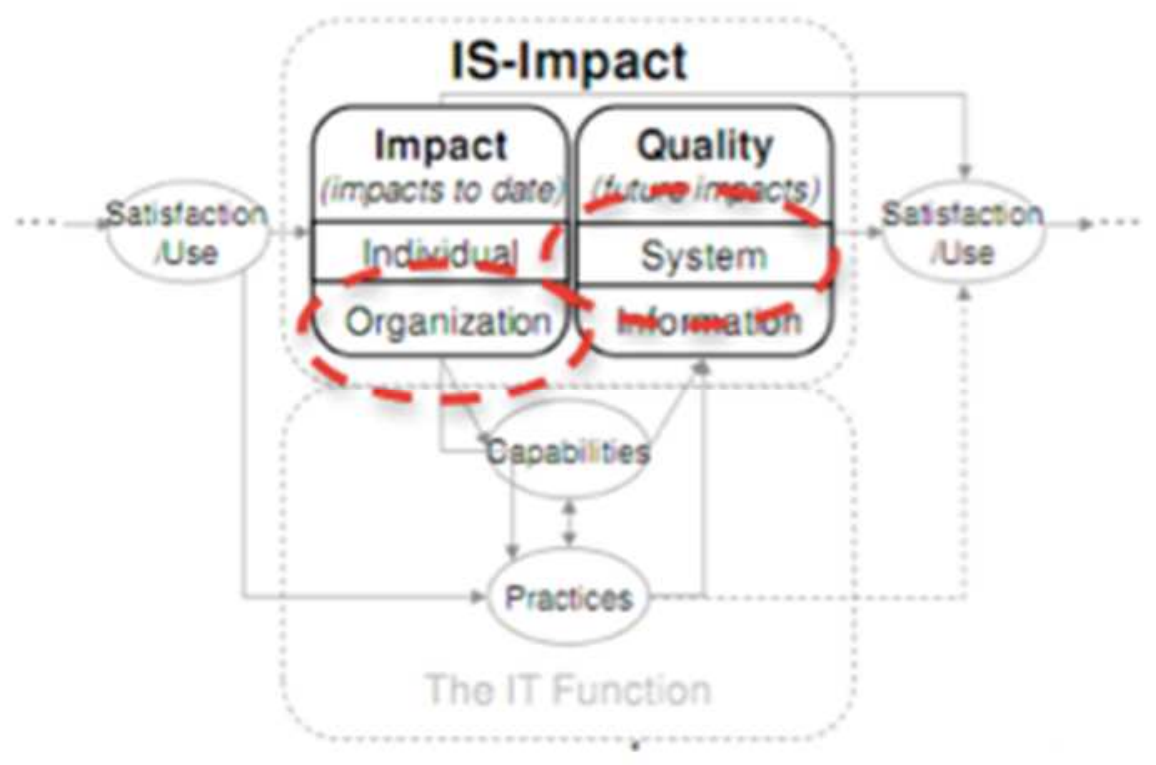

Figure 7: Theoretical Foundation, IS-Impact (2003)

\subsubsection{ISO Standards-Based Quality Measures}

The ISO 9126 standard focuses on system quality. System quality represents the quality of the information systems and it is a measure of the extent to which the system is technically sound. Seddon (1997) notes "system quality is concerned with whether there are bugs in the system, the consistency of user interface, ease of use, quality of documentation, and sometimes quality and maintainability of program code" (Seddon 1997). Indicators were further developed from the D\&M model by Gable et al (2008) using fifteen attributes such as accuracy, ease of use, ease of learning, system features, flexibility, reliability, efficiency, sophistication, integration and customisation.

System quality can be defined into two separate categories, one from the designers' perspective (external) and from the end users perspective (internal). Padayachee et al (2010) provides an approach to software quality which can reflect the view that should be essential to determine system quality for IS success as displayed in figure 8 . 


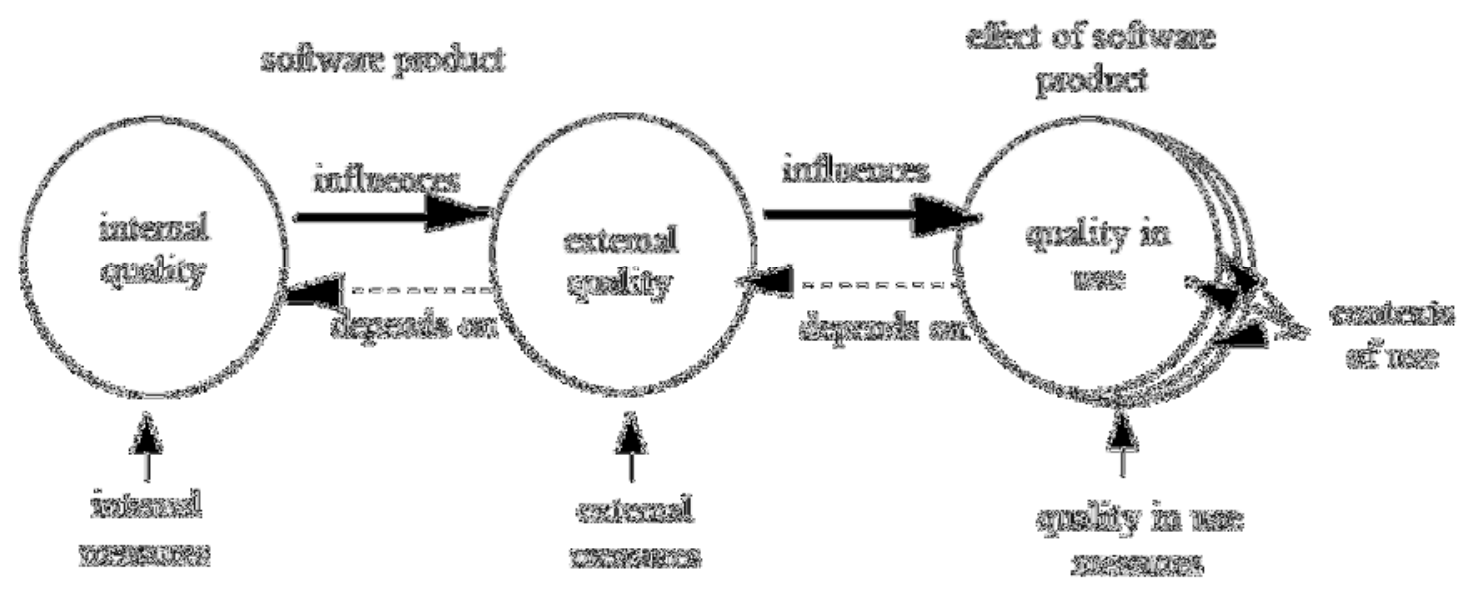

Figure 8: Approach to Software Quality, Padayachee et al (2010)

Quality itself is conceptual while measurement is operational. System quality can be measured internally (user) or externally (vendor). For example, reliability can be measured externally by observing the number of failures in a given period of execution time during a trial of the system and internally by inspecting the perceptions of those users experience issues (Padayachee et al, 2010). The reasoning acknowledges that internal quality and external affect the end result of system quality. It is important to balance the two views in order to comprehensively evaluate quality.

Gorla et al (2010) separated system quality into two perspectives 'system flexibility' and 'system sophistication' with system flexibility reflecting that the system is designed with useful/required features and the system designer can perform modifications with ease. System sophistication involves a user-friendly system, ease of use and has great response turnaround time (Gorla et al, 2010). Indicators from the ISO 9126 model can be used to facilitate indicators for system quality to measure ERP system success, incorporating both the views of external vendor and user system quality attributes, but also to compare between the IS Impact model measurements. The ISO 9126 model is depicted in figure 9. The quality characteristics are defined below:

- Functionality - set of attributes that bear on the existence of a set of functions and their specified properties. The functions are those that satisfy stated or implied needs.

- Reliability - set of attributes that bear on the capability of the system to maintain its level of performance under stated conditions for a stated period of time. 
- Usability - set of attributes that bear on the effort needed for use, and on the individual assessment of such use, by a stated or implied set of users.

- Efficiency - set of attributes that bear on the relationship between the level of performance of the system and the amount of resources used, under stated conditions.

- Maintainability - set of attributes that bear on the effort needed to make specified modifications.

- Portability - set of attributes that bear on the ability of the system to be transferred from one environment to another.

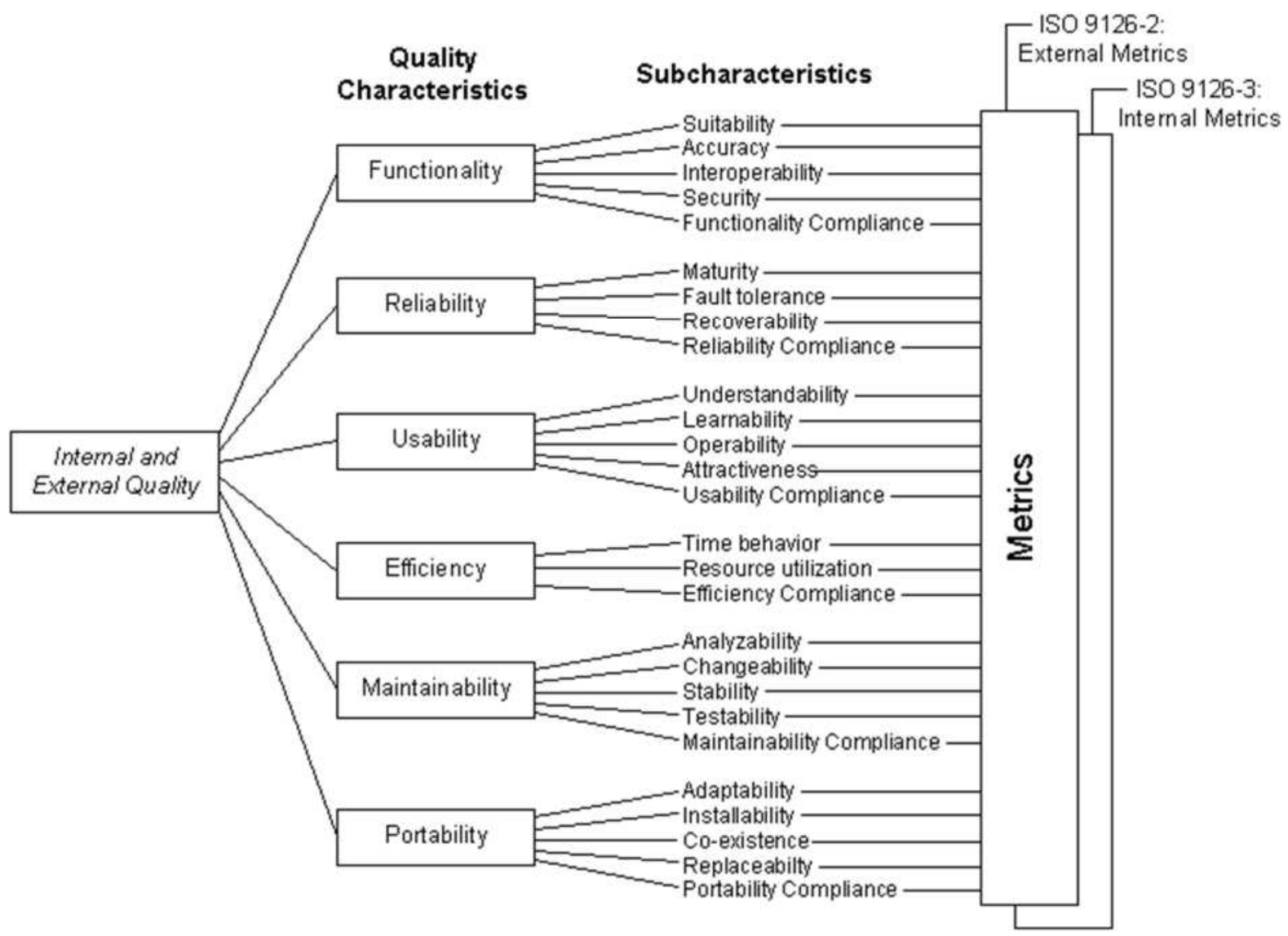

Figure 9: ISO 9126 Quality Model, Padayachee et al (2010)

Empirical evidence suggests that organizations tend to associate the role and quality of the providers of their software with its overall success of the organization (Markus and Tanis, 2000). This is the reasoning why the ISO 9126 quality model is incorporated as it takes into consideration those views from an external source; further explanation of characteristics is displayed in appendix iii.

The research can identify various quality characteristics which relate directly to those included in the IS Impact model. Originally the ISO 9126 quality model has been used for 
software quality; the indicators used can be reflected into an ERP system. The model can be used to represent the external view that is the designer's perspective.

There is a clear relationship, which provides researchers and practices a quality framework to consider, as it involves internal and external quality characteristics. The standard refines the features into several subcategories; the arrows indicate how the characteristics are decomposed into sub characteristics, the model is hierarchical, each sub characteristic is related to only one characteristic (Kitchenham and Pfleeger, 1996). The most relevant for system quality characteristics are all defined; these characteristics can be measured by further.

ISO quality measures are often operationalized differently in each organization that uses those (Padayachee et al, 2010). However, they have also been used as the basis for survey items (Ali et al, 2012; Chua et al, 2004; Behkamal et al, 2009; Zeiss et al, 2007).

\subsubsection{Integration of Quality Perspectives and IS Success, Quality and Impact Constructs}

Quality is perceived differently in various disciplines such as economics, philosophy or marketing, quality is a complex and multifaceted concept (Kitchenham and Pfleeger, 1996). There are various views on quality itself; Kitchenham and Pfleeger (1996) following Garvin (1984) group these into five different views as outlined below:

- Transcendental - views quality that is recognised but not defined

- User - views quality as fitness for purpose

- Manufacturing - views quality as conformance to specifications

- Product - views quality as tied to inherent characteristics of the product

- Value-Based - views quality as dependent on the amount a customer is willing to pay

The ISO 9126 standard can be characterised as a "product-based" view - it essentially assumes that systems that possess qualities of functionality, reliability and so on, are of good quality. The IS-Impact model, which is survey-based, is a "user-based" view of some of the same characteristics of a system. The research shows how these two perspectives both focus on system quality in figure 10 . 


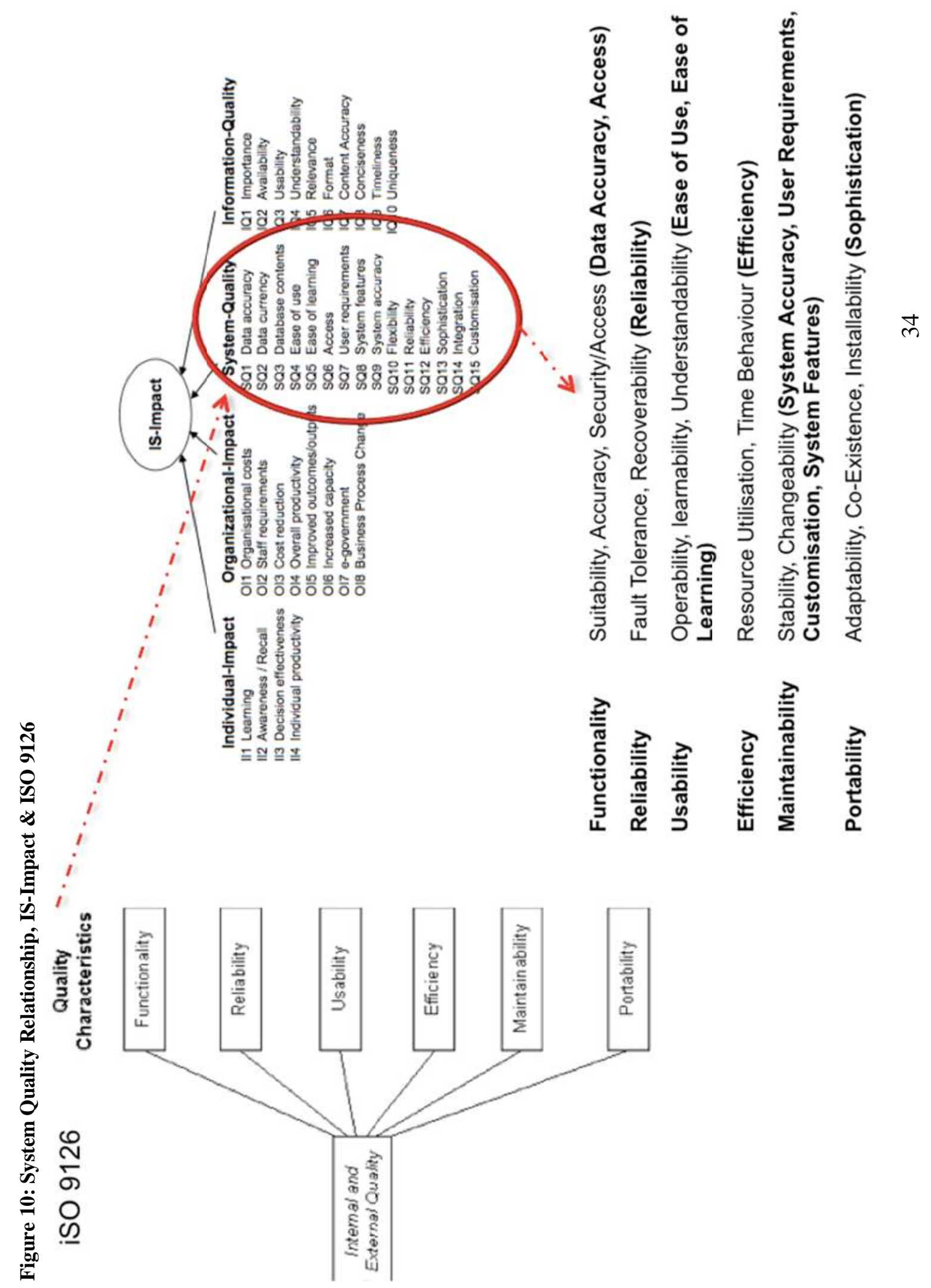


This provides an opportunity to compare the two measures. The overall value to the organization ("value-based" measures) can be captured using various financial measures such as total cost of ownership. Once again, in the IS-Impact model, user perceptions are used as a proxy for other types of measure. Organizational impact has been validated by an eight-item scale instrument by Gable et al (2008) for the measurement of ERP success that includes cost reduction, productivity improvements, increased capacity and business process improvement. This construct represents [user perceptions of] the firm level benefits received by an organization as a result of IS. Organizational impact of IT is realised through business performance that evolves into business value (Hitt and Brynjolfsson, 1996; Hong, 2002).

Indicators derived from the IS Impact model are organizational costs, staff requirements, costs reduction, overall productivity, improved outcomes/outputs, increased capacity, e-government and business process change (Gable et al, 2008). These indicators are supported in literature but also equally important for practice, with various senior executives advising the use of both subjective and objective measures are necessary as no one single measure is appropriate to determine the organizational impact of IT (Tallon et al, 2000). Profitability measurements are the preferred when determining organizational impact/benefits, In order to determine organizational benefits senior executives or managers are the most appropriate as the objective data is derived from annual reports or more informative means (Petter et al, 2007).

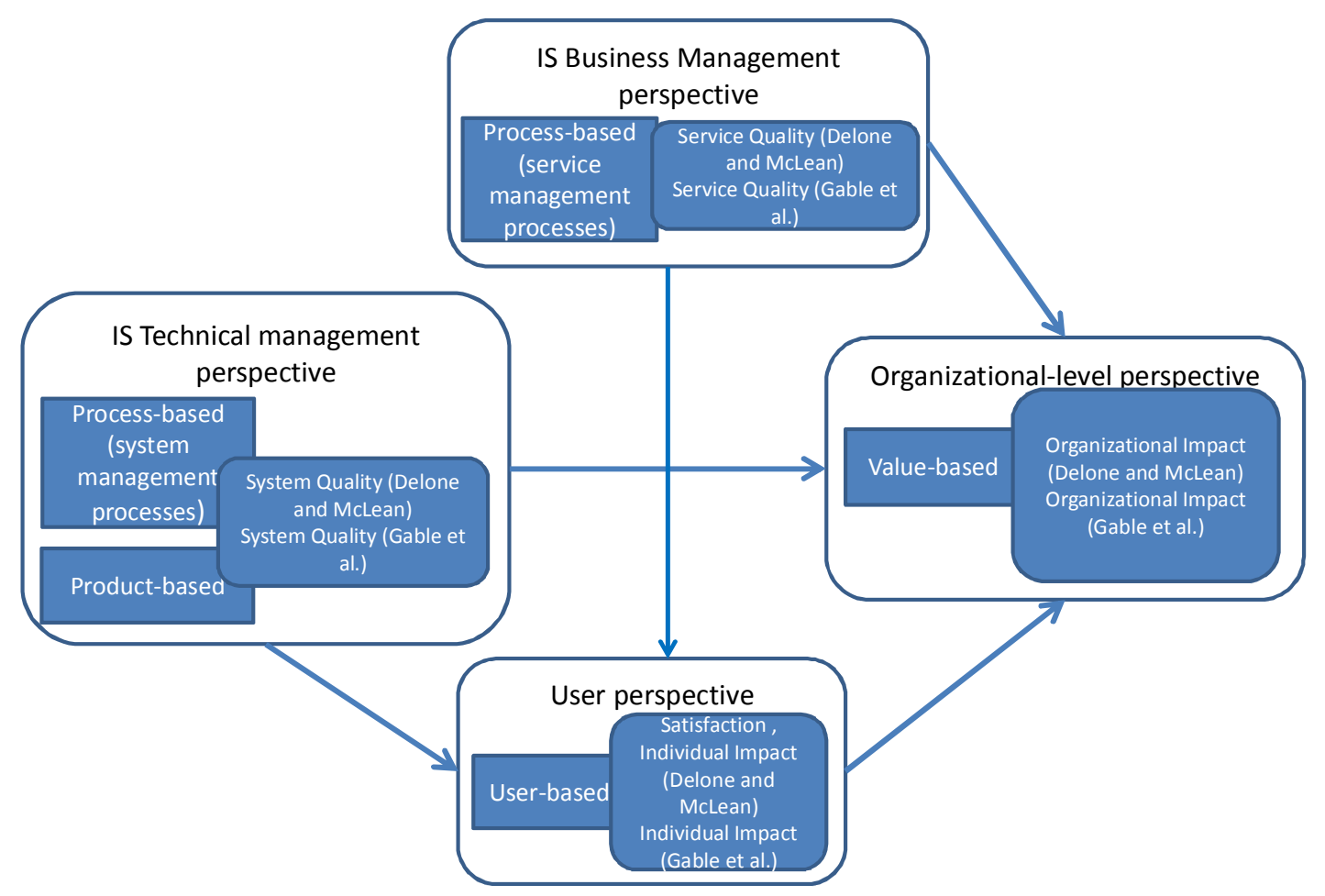

Figure 11: Proposed Model 
Figure 11 outlines the proposed model, which incorporates process-based, product-based, userbased and also value-based. These multiple perspectives takes into consideration the IS technical perspective which is associated with the system quality of the IS. Secondly, it takes into account the user perspective, which looks at the individual impact and satisfaction towards the IS. Following this, the IS business management perspective measures the service quality of the IS. Lastly, the organization level perspective takes into consideration the value, which is the organizational impact of the IS.

The most influential constructs are the IS business management and Organizational level perspective. These constructs take into consideration the stakeholders view. As Frisk (2008) indicates, the economic evaluation methods are not sufficient since they do not consider the stakeholders or the context of the IT system.

\subsection{Integrated Framework for Comparison of Quality and Impact Measures}

This section will outline the integrated framework used for the comparison of IS quality and impact measures used for this research.

\subsubsection{Benchmarking}

Benchmarking can be defined as "a systematic search for business excellence through continuous improvement, both from a strategic and an operation perspective" (Holm \& Mattsson, 2008). One fundamental approach taken with benchmarking is to place the benchmark's focus on key processes (Holm \& Mattsson, 2008; Dattakumar \& Jagadeesh, 2003). Through comparing key processes against a reference benchmark, this allows organizations to discover key differences and performance gaps that may exist. Many organizations conduct benchmarking for differing needs, such as financial cycle close reduction, productivity improvements, procurement cost reduction, order management improvements, on time delivery improvements, personnel reductions, IT cost reductions, cash management improvements, inventory reductions, maintenance reduction, logistics reduction or revenue/profit increase (Hawking \& Stein, 2004). Historically organizations initiate in benchmarking programs to reduce costs in specific areas of the organization, to better understand their market position. Benchmarking can also determine how customer needs are evolving, encouraging innovation or even developing new strategic roadmaps. Before any organization conducts such a project, the 
organization must initially understand why it requires conducting benchmarking; this will decide what the dimension will be for analysis; whether the analysis be internal or external benchmarking (Holm \& Mattsson, 2008).

Holm \& Mattsson (2008) outline key requirements for when organizations consider the use of benchmarking. When deciding what to benchmark, the strategic importance of the investigated area has to be measured, but also expected improvements in that area for overall business performance, thus the organization must have an idea of the key organization bottlenecks it faces. When the subject area has been selected, key processes have to be identified. In order to identify key processes, the organization has to agree on critical success factors in order to gain competitive advantage. The authors suggest three fundamental steps organizations must during a benchmarking project:

1. Study planning and targeting phase (Defining expected goals, processes and practices)

2. Data collection and analysis phase (Evaluation and assessment of internal processes and differences with best practice)

3. Definition of study goals (New objectives and actions are recognised and actions are carried out and results are examined)

The most common data collection is generally obtained through interviews and questionnaires (Holm \& Mattsson, 2008). After the internal analysis has been conducted, data is collected about the reference benchmark, with the most imperative factor being the data consistency. The next step is to resolve performance gaps between the compared processes. Generally, an index is used to evaluate the gap. Improvements are then made by closing these gaps and identifying differences in business processes to discover discrepancies in performance. Throughout the benchmarking process, it is vital to ensure executive stakeholder engagement in order to gain support throughout the implementation phase.

The benchmarking project should be considered among most organizations to ensure consistency in processes but also ensure bottlenecks are subdued with a logical and sound strategic roadmap, developed through benchmarking processes against other organizations in similar industries. Cox and Thompson (1998) indicate that the benchmarking concept is understood to be an act of 
imitating or copying. The reality is it proves to be a concept that helps organization in innovation rather than imitations and allow decision makers to make quality improvement.

As previously indicated, benchmarking is recognised as an essential tool for continuous improvement of quality (Dattakumar \& Jagadeesh, 2003). Dattakumar and Jagadeesh (2003) conducted a comprehensive review of literature on benchmarking. The authors' attempt and approach looked to assist researchers; academics and practitioners take a more vital look at the growth, development and applicability of this technique.

\subsubsection{SAP (Vendor-Based) ERP Benchmarking}

SAP customers conventionally invest a large part of their IT budget to SAP-related activities. Throughout the use of SAP within organizations, many projects and organizational time is consumed, thus it is imperative for SAP to be proactive to ensure customers are realising the benefits derived from the market leading ERP system (Gartner, 2010). SAP allows customers to understand benefit realisation through their SAP Value Management services. Historically, vendors such as SAP have assisted organizations in developing business cases to validate why their software should be purchased. However, these efforts have traditionally been only short term with minimal effort spent on the long term value for the customer. It has been indicated that only $37 \%$ of large organizations ever go back and measure the value of their ERP system (Gartner, 2010).

SAP over the last several years has made major investments in preparing processes and services to assist organizations who use their software to develop rigorous business cases, understanding of the process changes required to generate value and the measurements to ensure that it is achieved. This is reflected in tools and services SAP provides surrounding methodologies for value management and implementation, with the overarching goal that their customers realise substantial benefits from the use of their application (Gartner, 2010; SAP, 2013).

\subsection{Previous Research Quality Findings}

This study represents the continuation of a previous study in the same organization (Ali \& Tate, 2012). In this section, the research briefly summarises key findings from the previous study which are included in the comparative analysis; the findings were the catalyst to further pursue 
and investigate quality and IS success. The conceptual model in figure 12 (Ali \& Tate, 2012) was an outcome of the previous study.

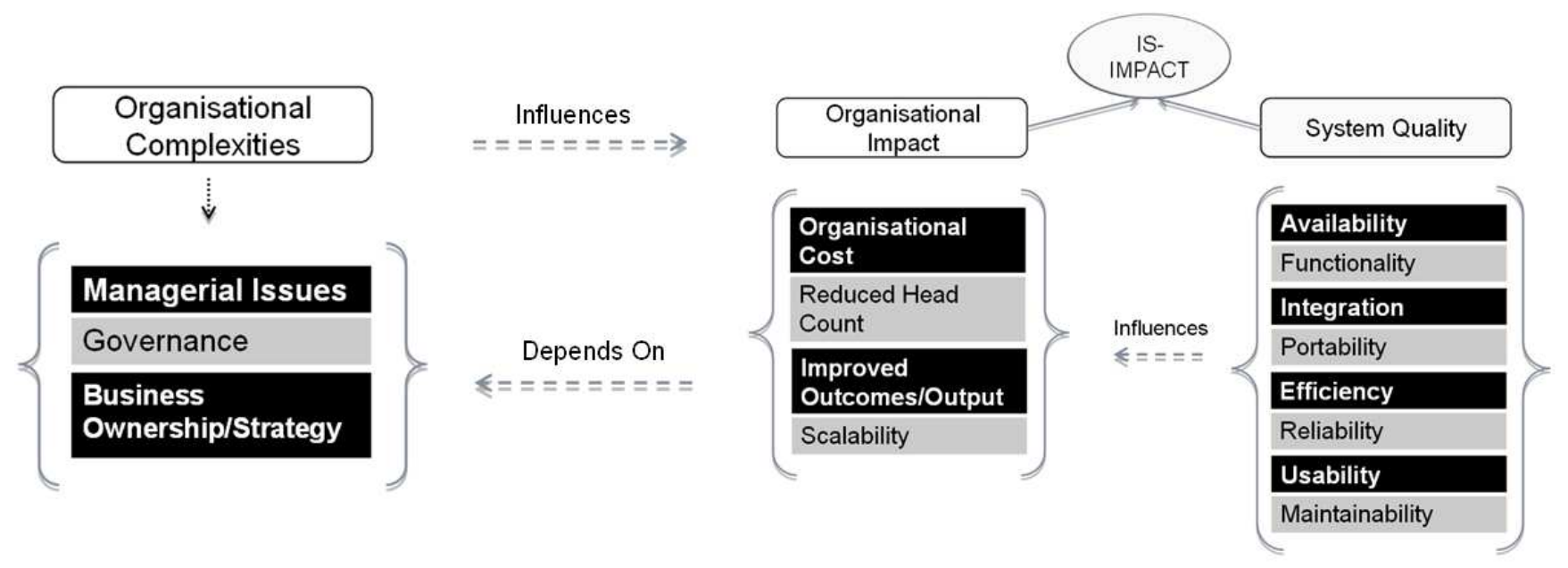

Figure 12: Model of Measures for IS-Impact Constructs System Quality and Organizational Impact.

\subsubsection{Organizational Complexities}

In our previous study, the researcher introduced the construct 'Organizational Complexities' which looks at the managerial issues, governance and business ownership/strategy around SAP within an organization. Through our analysis it is recommended that in order to measure the system quality and organizational impact of SAP, the organization must first resolve any managerial issues that occur, resolved governance issues by implementing relevant frameworks surrounding the communication and lastly the business ownership/strategy that requires accountability and direction. As depicted in the model the organizational complexities have a direct impact on the two underlying constructs and vice versa.

The research also posited that system quality has a direct influence on the organizational impact. The reasoning for this can be seen with the efficiency of the system quality, which will have a direct impact on the organizational cost and resources. Also the level of integration of SAP has had an impact on the organization. The Business Support Manager confirmed how SAP has delivered successful outcomes to the organization. "It has enabled us to run our entire business on one platform and with standardized systems and processes and for example we can run one payroll for the company, one AP for the company." Integration played an important role in improved output and outcomes by standardising the entire business and ensuring a more centralised approach within the organization. The above organizational complexities were found 
to be fundamental for an organization preparing to measure the success of an information system.

\subsubsection{Managerial Issues}

Markus and Tanis (2007) define managerial issues to where enterprise systems raise interesting challenges which consists of IT project management, IT project sponsorship and user involvement IS business relationships, vendor management, and IT management and lastly IS personal management.

In our previous study, participants expressed their frustrations around their involvement with the process surrounding SAP. Even though the HR module is a critical module within SAP, the Human Resources group feel discouraged by their limited engagement in the way SAP should be developed within the organization. Our study found limited engagement between the different business units with the key stakeholders of SAP, and also a lack of strategy with regard to the utilisation of SAP.

There also appeared to be a low level of management of the application portfolio, SAP footprint, and integration between applications. An example of this was the Human Resources business unit who implemented a third party application to support employee performance, despite this being a function that was available through SAP HCM module. In some cases the SAP modules were not perceived as being "best of breed" or meeting requirements, so third party products were purchased that then needed to be integrated with SAP.

\subsubsection{Business Ownership and Strategy}

Business Ownership and Strategy was identified as an issue in our previous study. The majority of participants were unable to determine who the key owner of SAP was within the case organization. The group that had been responsible for SAP strategy had been restructured and broken up, and ownership was unclear

\subsubsection{Governance}

Information Systems governance practices involve efforts by an organizations leadership to influence IS related decisions through decision rights and the structure of decision processes. IT governance is defined as "specifying the framework for decision rights and accountabilities to encourage desirable behaviour in the use of IT" (Sia et al, 2010). IT governance is an important 
area as it influences the benefits received from IT investments. Sia (2010) suggests that organizations that have redesigned business processes and well-defined governance mechanisms in place experience up to forty per cent greater return than organizations that have not.

Our previous study outlined various governance issues relating to SAP. Issues in IT governance, which were raised, included the effectiveness of the IT steering committees and IT-related communication policies. As many organizations do not understand the nature of effective steering committees and the IT governance communication policies. IT steering committees serve to direct, coordinate and provide oversight regarding specific IT-related activity domains. Communications policies look to see if communication is consistent from the top level of executive's right to the bottom level (Huang, Zmud \& Price, 2010). The General Manager noted there was an IS steering committee in place, but it appeared this had only been created specifically for an upgrade project rather than all other projects commencing within the organization surrounding SAP. The communication policies appeared to be fragmented in the organization.

\subsection{ERP Quality Measurement Approaches}

ERP systems are complex and many of the benefits have an intangible nature (Holm \& Mattsson, 2008). The complexity, costs, tangible benefits, organizational, technological and behavioural impact on ERP's requires a holistic approach when evaluating ERP's. It has been suggested that:

1. Evaluation requires an assessment of costs and benefits during the entire ERP system lifecycle (Holm \& Mattsson, 2008). However, financial measures are necessary but are by themselves not adequate to evaluate the broad success of ERP systems. The reasoning for this is that costs and benefits are not easy to determine because of their intangible nature. If certain elements are recognised, it is still a problematic task to measure the entirety of an ERP (Holm \& Mattsson, 2008). Even if they are recognized, it is still a problematic task to measure them, there is a scare level of how to measure and evaluate cost and benefits in operation, maintenance and evolution of the ERP-system.

2. ERP user satisfaction and partners or customers satisfaction are important metrics. Perceived customer satisfaction and benefits from better decision making is problematic but significant 
to calculate. The complexity of measuring SAP success has seen numerous perceptual measures exist such as surveys that ask IS professionals, users or managers about their beliefs or perceptions with regard to various aspects of IS (Gable et al, 2003; Ifinedo, 2006). However, these are typically subjective and difficult to translate into actionable advice for IS stakeholders.

3. Organizational KPI's are metrics used to measure an essential task, operation or process. Selecting and defining KPI's is not simple but it is important that the KPI's lead to improved performance not just locally but in an enterprise perspective (Holm \& Mattson, 2008). However, this still doesn't measure the whole spectrum of important facets of quality and quality of an ERP system.

The main focus of this study is to obtain and compare measures used within a case organization to understand and provide clarity around approaches for measuring the success and organizational impact of SAP.

\subsection{Research Framework}

The research also used qualitative analysis to discover managers' perceptions of the organizational impact of SAP. SAP's benchmarking process concentrates primarily on a "process" view, and evaluates the organizations processes with regard to governance, system management and so on. It also includes a number of summative measures of organizational impact, such as TCO and "cost per seat" (the average cost of the SAP system per user).

In combination, the range of measures used in our case organization covers a wide range of perspectives, as summarized in table 1:

Table 1: Range of Quality Measures

\begin{tabular}{|l|l|l|}
\hline Quality & $\begin{array}{l}\text { Primary } \\
\text { Perspective }\end{array}$ & $\begin{array}{l}\text { Comments } \\
\text { Evidence }\end{array}$ \\
\hline Transcendent & Not used & $\sim$ \\
\hline
\end{tabular}




\begin{tabular}{|c|c|c|}
\hline User-based & $\begin{array}{l}\text { IS-Impact } \\
\text { ISO } 9126\end{array}$ & $\begin{array}{l}\text { Data for both of these perspectives was gathered } \\
\text { using a user-survey, so these should be considered as } \\
\text { adopting a user-based approach. However, users } \\
\text { were asked about their perceptions of other quality } \\
\text { perspectives e.g. organizational value (in some of } \\
\text { the organizational impact questions) and system and } \\
\text { software "product" characteristics (in some of the } \\
\text { system quality questions) }\end{array}$ \\
\hline $\begin{array}{l}\text { Manufacturing } \\
\text { (Process) }\end{array}$ & $\begin{array}{l}\text { SAP } \\
\text { Benchmarking } \\
\text { Interviews }\end{array}$ & $\begin{array}{l}\text { Expert informants, interviews, documents and } \\
\text { archival analysis were used to gather information } \\
\text { about quality management processes. } \\
\text { Management processes are a major focus of the SAP } \\
\text { bench-marking method. }\end{array}$ \\
\hline Product & ISO 9126 & $\begin{array}{l}\text { The ISO standards aim at identifying quality features } \\
\text { and characteristics that can be engineered into IT } \\
\text { systems. The development of the ISO } 9126 \text { standard } \\
\text { is essentially a "product" based approach, although } \\
\text { we operationalized these dimensions into a survey } \\
\text { and used user perceptions to gather evidence on } \\
\text { these dimensions. }\end{array}$ \\
\hline Value & $\begin{array}{l}\text { SAP Bench- } \\
\text { marking. } \\
\text { Summative } \\
\text { Questions in } \\
\text { IS-Impact }\end{array}$ & $\begin{array}{l}\text { Both the SAP benchmarking approach and the IS- } \\
\text { Impact survey include summative questions about } \\
\text { overall value to the organization. }\end{array}$ \\
\hline
\end{tabular}

As demonstrated in Table 1, the IS technical view is primarily built via the IS technical management perspective. This incorporates the Process-based and Product-based measures which includes the IS-Impact Survey and ISO 9126 Survey.

The IS Business Management perspective is Process-based, where the archival analysis, interviews and benchmarking is used to determine a ‘business process, best run' view of SAP. The User perspective is user-based, which incorporates the ISO 9126 and IS-Impact measures. 
Lastly, the Organizational-Level perspective is value based, which includes the Archival analysis, interviews, benchmarking and IS-Impact survey. 


\section{Chapter 3. RESEARCH METHODOLOGY}

In this section the research design and methodology approach are described for this study to outline and also justify why selection was appropriate for this research. A single case study approach was used. Since the researcher had privileged access to the case organization, multiple sources of evidence, using multiple methods, were used to gather data. The case study design, the case organization, and the methods used to collect data are discussed in this section.

\subsection{Case Study Design}

Case study research has been defined as 'a phenomenon in its natural setting, employing multiple methods of data collection to gather information from one or few entities (people, groups or organizations) and the boundaries of the phenomenon are not clearly evident at the outset of the research and no experimental control or manipulation is used' (Benbasat et al, 1987). It is important to note that case study research does not advise the use of a certain type of evidence; qualitative or quantitative evidence, or both can be used to carry out case study research.

Case studies explore and understand the investigated subject, research questions which focus on 'what' can be justified by either an exploratory case study or survey (Yin, 1994; Strauss \& Corbin, 1998). The case study research will allow the problem in a natural setting to be investigated and provide diverse insights. Benbasat et al (1987) provides eleven key characteristics of case studies; this is provided below:

Key Characteristics of Case Studies (Benbasat et al, 1987)

1. Phenomenon is examined in a natural setting.

2. Data are collected by multiple means.

3. One or few entities (person, group, or organization) are examined.

4. The complexity of the unit is studied intensively.

5. Case studies are more suitable for the exploration, classification and hypothesis development stages of the knowledge building process; the investigator should have a receptive attitude towards exploration. 
6. No experimental controls or manipulation are involved.

7. The investigator may specify the set of independent and dependent variables in advance.

8. The results derived depend heavily on the integrative powers of the investigator.

9. Changes in site selection and data collection methods could take place as the investigator develops new hypotheses.

10. Case research is useful in the study of "why" and "how" questions because these deal with operational links to be traced over time rather than with frequency or incidence.

11. The focus is on contemporary events

The rationale for adopting a case study strategy for this research stems from the phenomenon of interest that is SAP success in an organization from multiple perspectives. This is a single, but complex phenomenon, in a single organization, that needs to be studied in its organizational context the research is looking to further understand the complex issue of measuring the quality of SAP and also SAP's impact on organizational value, the case study is suitable for this exploration. As Yin (1994) states the research questions that focus on 'what' can be justified by either an exploratory case study or survey. As the research is looking into 'what' metrics can be used to measure SAP, the research also provides our second research question 'what' is SAP's contribution to organizational impact. No experimental control or manipulation is required of subjects. The integrative contribution of the researcher is critical to this study. A major contribution of the study is to compare and contrast various measurement methods, and to derive theoretical insights as to the appropriateness and salience of various measures for different management purposes.

With these above conditions and outlined characteristics by Benbasat et al (1987) the research can be confident that a case study is the most suitable strategy of inquiry to select. Following these characteristics, Benbasat et al (1987) specifies guidelines to offer practical aid to researchers for understanding and implementing case research. The next sections determine the unit of analysis, single or multiple case designs and site selection

\subsection{Single Case vs. Multiple Case Design}

Single case studies are appropriate if it is a revelatory case; it represents a critical issue or is an extreme or unique case (Benbasat et al, 1987). While the case organization may not be 
necessarily unique, our privileged access to measurement data is unusual, and offers the opportunity for richer insights than can be obtained from individual cross-sectional studies.

\subsubsection{Unit of Analysis}

The unit of analysis in a study is the units of observation; these are examined in order to create summary descriptions of all such units and to explain differences between them (Babbie, 1997). The determining factor to selecting the unit of analysis is based closely on the research questions that are pursued but also what generalizations are predicted at the end of this project (Benbasat et al, 1987).

Based on the above the unit of analysis for this research is at the organizational ERP implementation level, with the purpose of gaining insights into the experience of the business owners of SAP; but also all related stakeholders. The research also includes users and superusers of SAP to gain a wider perspective of viewpoints, super users are considered to have more fundamental configuration knowledge of SAP rather than just end users of the application which includes data entry. The individuals will be accessed through the same organization where SAP is used. However, it is important to note why a wide range of stakeholders is considered, since SAP is a large enterprise resource planning system, it is important to gain insights from people at various levels on the organization as users holding various roles, and various business units may deploy different measures due to the different modules and functionality adopted.

The unit of analysis for our quantitative approach will include only users who have access to the backend of SAP. Every employee within an organization can be classified as a user of SAP through the interaction of the portal. However, as the researcher wants to increase the validity of the results, only users who have access to the back end of SAP will be suitable to complete the survey designed. A number of users will be generated through SAP security access, which will be provided by the SAP Business Support manager, it is important to note that these backend users also had access to the portal.

\subsubsection{Site Selection}

As Benbasat et al (1987) suggests the factors that dictate a single case design also determines the site selection. As the research is interested in a specific technology, it is important to consider the nature of the topic and align this with the characteristics of the organization. With this consideration, it is vital to determine the preferable characteristics before deciding which 
organization to pursue. Since SAP is one of the largest enterprise resource systems and the most predominant information system worldwide, a large organization required as SAP tailors largely to large organizations. The researcher also wanted an organization with a large SAP "footprint" (a wide range of modules implemented) and a mature implementation, as it sometimes takes time for the benefits of ERP implementation to be realised (Markus \& Tanis, 2007). The researcher also needed an organization where there was good access to stakeholders at various levels and the ability to collect data using multiple methods.

\subsubsection{Case Organization: Telecom New Zealand Limited}

Telecom was formed in 1987 from a division of the New Zealand Post Office, becoming privatized in 1990. Telecom is the $39^{\text {th }}$ largest telecommunications company in the OECD with just under 10,000 employees. Telecom provides various services within Australasia, this includes providing fixed line telephones services, Internet service provider, mobile network, a major ICT provider to various New Zealand organizations and also a network infrastructure provider through its Chorus division (Telecom, 2011).

Telecom successfully installed SAP on the 17/04/1996 with around six hundred trained users following the two-year project called PROFILE. The project redesigned a broad range of business processes in finance, logistics and project management. Since 1996 Telecom has implemented the following SAP modules (Project System, Controlling, Assets Management, General Ledger, Accounts Payable, Accounts Receivable, Human Resources, Payroll, Materials Management, Warehouse Management, Business Intelligence and Sales \& Distribution) with currently over 5,000 using SAP either through its basic form of the portal through to the backend of SAP (Telecom, 2011).

SAP replaced twenty-two existing financial systems, including most of the District Accounting System (DAS), the Capital Budgeting System (CBS), and Job Costing. Telecom selected SAP, as it was the only product on the market that meets the requirements for a complete integrated system.

Over the 2012/2013 financial year, the organization faced strong competition within the telecommunication industry from competitors (2 Degrees, Vodafone, Telstra), as such forced the organization to reengineer their strategy (Telecom, 2013). While IT is seen as one of the most influential drivers for organizations (Gartner, 2012), the organization began to reduce headcount, Telecom would shed between 930 and 1230 full-time jobs by the end of June 2013, taking its 
workforce from 7530 "full-time equivalents" at the start of the year down to between 6300 and 6600 (Telecom, 2013). This outlines that in competitive industries, IT is seen to not be a more influential facet to reduce operating expenditure. This trend has continued since the 1980's.

The downsizing strategy is where organizations reduce headcount in order to become more competitive. This method allows organizations to cut operating costs quickly in order to meet the demands of global marketplaces (Mishra and Mishra, 2012). Even firms such as IBM have had to abandon their famous "no-layoff" policies due to increased competition (Mishra and Mishra, 2012). While this method will reduce costs in the short team, Mishra (2012) stated "Research indicates that only one-fourth of firms that downsized have enjoyed improvement in productivity, cash flow, or shareholder return on investment. This is because organizations have focused too much on eliminating unnecessary jobs and out placing people and limited attention on cutting or out placing unnecessary work".

Participants in various phases of the study were drawn from a range of roles and levels of seniority within the organization.

1. In the previous quantitative study, (Ali \& Tate, 2012) a survey was sent out to Telecom's active users. The research defined users as those who have a daily interaction with SAP. It is important to note that all employees within the case organization have some form of interaction with SAP; however the research is interested in those users who are more technically involved. After deliberation with the SAP Business Support manager, the researcher derived a list of 400 users. The survey was sent to all these users.

2. Nine semi-structured interviews were conducted in the previous study (Ali \& Tate, 2012), and the same informants provided input for the benchmarking. The interviews on average lasted forty minutes, participants not only provided insights into the semistructured script but also provided additional insights. The researcher also used the snowball effect to locate further appropriate participants within the organization.

The participants who were interviewed are listed below, it is important to add that all participants had more than ten years' experience using SAP, either through a technical aspect or process.

\section{General Manager - Technology and Shared Services}

2. SAP Business Support Manager

3. Purchasing Manager - Logistics Module 
4. Head of Group HR - HCM Module

5. SAP Domain Manger

6. Head of Finance - FICO Module

7. SAP Capability Manager

8. SAP Billing Manager-Logistics Module

9. Group Finance Controller - Finance/FICO Module

Once the research had been completed, a SAP Benchmarking programme was conducted to determine how Telecom compared to other organizations. . The benchmarking data was collected by the researcher, based on publicly available information such as the annual report, and the key informants who contributed to the previous interviews.

A focus group which included 12 SAP Functional consultants from Telecom was conducted to establish the relationship between the constructs in the IS Impact and ISO quality metrics model and the SAP benchmarking process.

The researcher coordinated the card sorting activity, which consisted gathering a group of ten SAP expert practitioners from the SAP support team. The organization recommended the activity to be conducted by participants who have a vast knowledge of SAP, with the general years of experience of the team exceeding ten years. The participants are listed below:

1. SAP Functional Consultant - Finance $x 2$

2. SAP Functional Consultant - HR $x 2$

3. SAP Functional Consultant - Payroll

4. SAP Functional Consultant - Logistics

5. SAP Functional Consultant - SRM

6. SAP Functional Consultant - Developer/ABAP

7. SAP Functional Consultant - Security

8. SAP Functional Consultant - Basis

9. SAP Functional Consultant - Basis

10. SAP Application Support Manager

In addition other sources of data was derived from the organization such as field notes, news articles and performance reports, concluding multiple forms of empirical data were gathered in this study. This allowed us to better understand the case organization but also improved the 
validity and reliability with the use of additional data. Table 2 provides an overview of the data collected via the multiple methods and which sources of data were used for each method. The nine executives were used for the survey, benchmarking and interviews. Ten SAP specialists were used for the survey and card sorting. 140 end users participated in the survey. The SAP project documents were used for the archival analysis.

Table 2: Overview of Data Collection

\begin{tabular}{|l|c|c|l|l|}
\hline & Survey & Benchmarking & $\begin{array}{l}\text { Interviews and } \\
\text { Archival } \\
\text { Analysis }\end{array}$ & $\begin{array}{l}\text { Card Sorting } \\
\text { (to establish } \\
\text { equivalence } \\
\text { between } \\
\text { measures) }\end{array}$ \\
\hline $\begin{array}{l}\text { Nine } \\
\text { Executives }\end{array}$ & $\mathrm{X}$ & $\mathrm{X}$ & $\mathrm{X}$ & \\
\hline $\begin{array}{l}\text { Ten SAP } \\
\text { Specialists }\end{array}$ & $\mathrm{X}$ & & & $\mathrm{X}$ \\
\hline $\begin{array}{l}\text { Regular users } \\
\text { if SAP (140 } \\
\text { respondents) }\end{array}$ & $\mathrm{X}$ & & & \\
\hline $\begin{array}{l}\text { SAP Project } \\
\text { Documents }\end{array}$ & & & & \\
\hline
\end{tabular}

\subsection{Epistemology}

The philosophical perspective for this research uses a mixture of post-positivist and interpretivist world-views. Myers (2006) describes there are three frequently used underlying philosophical perspectives for qualitative and quantitative research. These are briefly described below:

1. Positivist Research: Positivist research assumes to build knowledge of a reality that exists beyond the human mind. The human experience of the world reflects an objective and the reality that exists provides the foundation of human knowledge (Weber, 2004).

2. Interpretive Research: Interpretive research assumes that access to reality is only through social constructions i.e. language, consciousness and shared meanings. This philosophical 
assumption attempts to understand phenomena through the meanings that individuals assign to them and interpretive methods of IS aim to produce an understanding of the context of the IS and process where the IS influences and is influenced by the context (Myers, 2007; Weber, 2004).

3. Critical Research: Critical research believes that social reality is historically constituted, which is produced and reproduced by individuals. With a focus on the oppositions, conflicts and contradictions in modern society, it assists to eliminate the causes of alienation and domination.

Interpretivism is defined by that knowledge lies deep within people and that the known and the knower are both interdependent. The only way to gain access to the knowledge is by human intervention (Chua, 1986).

This philosophical assumption attempts to understand phenomena through the meanings that individuals assign to them and interpretive methods of IS aim to produce an understanding of the context of the IS and process where the IS influences and is influenced by the context (Myers, 2006). While positivists undertake research to test theory in order to increase the predictive understanding of the phenomena, Orlikowski and Baroudi (1991) state IS research is classified as interpretive when social process is not captured in hypothetical deductions, co variances, and degrees of freedom. Rather understanding social process involves getting inside the world of those generating it.

This study aims at gathering knowledge about SAP measurement metrics and practices from core stakeholders, users and super users but also the business owners. The objective is to find out what things are or what they have been, in the qualitative research tradition. This is ideal for this research because it attempts to capture the world as it is through human intervention.

However although the research is interested in the constructions of the participants in context, the research also used gathered data using established survey instruments, and engaged in benchmarking. Both of these methods imply post-positivist assumptions of an objective reality that can be measured, compared and contrasted between organizations. Positivists believe the underlying assumption is that the research subject has inherent qualities that exist independently of the research. To some extent, the use of multiple paradigms, in particular, the ability to compare and contrast situated, interpretivist perspectives, and 'objective' metrics are a major aim of this study. 


\subsection{Overview of Data Collection and Analysis}

This section provides an overview of the data collection and analysis. For clarity, the detailed research approach used for collecting and analysing each separate source of evidence is presented in the relevant chapter.

A multi-method and multi-paradigm approach was taken with this research. Falconer et al, (1999) outlines that researchers that combine qualitative and quantitative methods within positivist research is a valid approach to research design. Subsequently, the research has taken the methodological triangulation approach which refers to the combination of two or more research strategies in the study of the same empirical unit (Falconer et al, 1999).

\section{Qualitative Validity}

There are various academics (Golafshani, 2003; Punch, 2005; Creswell, 2003) who advise issues with testing the external validity of qualitative research that does not use formalized sampling methods, but also the reliability of the data can not be judged if there is no mechanism for estimating the true score. Thus, it was logical to adopt Guba and Lincoln's (1989) four criteria for determining the soundness of qualitative research; these four proposed criteria are credibility, transferability, dependability and confirmability. These criteria for testing validity and reliability are described below:

Credibility: This involves establishing that the qualitative results are credible and believable from the perspective of participant of the research being conducted. As these are based on individual perspectives, the researcher must ensure the phenomenon being investigated is legitimate from the perspective of the participant.

Transferability: Transferability refers to the degree to which the results received through qualitative research can be generalized and transferred to other settings or contexts. The research can ensure this by describing the research context and assumptions thoroughly. This will allow other research to apply the results and transfer it to a different context.

Dependability: Requires the researchers to account for the contemporary and changing context within the research occurs, the researcher is required to describe the changes that occur within the setting and how these changes in the setting affected the outcome of the research approach. Confirmability: Confirmability is the degree to which the results could be confirmed or substantiated by others, following procedures such as checking and rechecking the data. 


\section{Quantitative Validity}

There are several types of validity when using quantitative methods. Firstly, internal validity is concerned with the degree of certainty that observed effects in an experiment are actually the result of the experimental treatment or cause, rather than intervening, extraneous or confounding variables. Internal validity is improved by increasing the control of these variables (Trochim, 2006). External validity is concerned with the degree to which research findings can be applied to the real world, beyond the controlled setting of the research. The issue of generalisability attempts to increase internal validity are likely to reduce external validity as the study is conducted in a manner that is increasingly unlike the real world (Trochim, 2006).

\subsubsection{Archival Analysis and Stakeholder Interviews}

Nine individuals from the above organization were invited to participate in this study. Firstly the General Manager of technology services was contacted via email with a description of the research objectives and requirements, this was received and the researcher was provided with potential candidates to approach who were considered to be the key stakeholders of SAP within the organization, these individuals ranged from general managers, business support managers, head of various departs, end users and super users of SAP who were located across various divisions of Telecom i.e. Telecom New Zealand, Wholesale, Technology Shared Services and Gen-i. The interviews were transcribed and analysed using content analysis. The majority of these findings were reported in the previous study (Ali \& Tate, 2012), and are summarised in the literature review.

In addition, SAP system management documents were obtained and analysed using qualitative content analysis techniques. The purpose of this analysis was to identify the types of measurement metrics and practices the organization was engaged in and classify them based on insights from the literature review.

\subsubsection{Additional Analysis of Survey Data}

In a previous study, a survey was conducted to capture the perceptions of SAP users in the organization (Ali and Tate, 2012). In this study, the results of this work are compared with other sources of evidence (see appendix iv for IS-Impact and ISO 9126 survey). The researcher carried out further exploratory analysis on the previously collected survey data. In particular, the 
researcher was interested in establishing whether there were any specific quality or value management concerns that could be identified from the survey data. The researcher examined the descriptive statistics to determine if there were any areas where there seemed to be a diversity of opinions within the organization (as evidenced by high standard deviations), and the researcher also investigated the overall means for the various items to determine whether there were any patterns in the characteristics of the system that were considered to be of greater or lesser quality. Following this, the research conducted ANNOVA analyses and K-means cluster analysis using demographic questions, to help further explain the results.

\subsubsection{SAP Benchmarking}

Benchmarking with other comparable organizations is a service provided by SAP as a vendor to their client organizations. The aim of the benchmarking process is to assist participating organizations to improve "value management" of their project and application portfolio. SAP promotes their benchmarking service as follows:

"Research shows that $98 \%$ of companies can extract more value from their implementation projects. Join the $2 \%$ that execute their projects on time, on budget, and on-value - with value management services from SAP. These services can help you identify the right projects, measure and optimize progress during implementation, maximize ROI, and more” (SAP, 2013). As you focus on technology innovations to help navigate an increasingly complex business environment, stay focused on delivering value and business outcomes aligned with your organization's strategy. That's the lesson SAP has learned as we've worked with thousands of companies to ensure that projects are delivered on time, on budget - and on-value. We've learned that successful companies see significantly better performance when they keep their eye on achieving the expected value from project definition to delivery. Successful companies apply the value management discipline consistently across the project portfolio through the value management life cycle"While this is partly "marketing-speak" from SAP, the research team were interested in exploring the vendor-led approach as a complement to metrics originating on the academic community.

The bench-marking approach is largely "process" based, and investigates the SAP quality and value management processes carried out by the organization. It also includes some summative measures. Bench-marking data was collected using the vendor's methodology, and based on 
publically available organizational information and interviews with the managers responsible for the various processes that were included in the bench-marking study. The SAP benchmarking template for both the best run and total cost of ownership can be found in appendix $v$.

\subsubsection{Card Sorting to Establish Equivalence between Measures}

One of the major challenges of this study was to establish the degree to which the various measurement approaches included in the study were commensurate. A card-sorting exercise was conducted to establish the perceived relationship between the management processes included in the benchmarking exercise, and the measures included in the user survey. See appendix vi. 


\section{Chapter 4. FINDINGS}

\section{1 Introduction}

In this section the research outlines the research findings found through the various data sources used within this dissertation. As outlined earlier, for clarity, the detailed data gathering and analysis process for each source of evidence is reported, followed by the results. The research findings will be outlined based on Garvin (1985) quality framework. Firstly, the research will report on the process-based (Manufacturing) findings. This will outline the results relating to the card sorting data which was collected between the SAP benchmarking best practices and the IS Impact, organizational impact and system quality constructs. Following this, the user-based quality that will look at descriptive statistics, k-means cluster analysis and ANOVA analysis. Lastly, the results of comparing perceptions of practices and perceptions of outcomes will be outlined. This will be looking at results relating to data collected from the multiple methods.

The IS Impact versus ISO9126 results will be firstly presented. Following this, the SAP benchmarking versus IS Impact data is compared. Following this, process/best practice versus actual outcomes will be examined. Next the actual outcome versus the perceived outcomes is outlined. Lastly, approaches to management of the IS function versus the outlined is detailed.

\subsection{Archival Analysis and Stakeholder Interviews}

\subsubsection{Data Gathering and Analysis}

The research discussed in the literature review our previous findings; that clear business ownership, an agreed strategy, and appropriate governance processes were identified as issues for the organization (Ali and Tate, 2012).

A further source of evidence collected during the interview process was an archival analysis of SAP system management documentation. This was provided after the researcher asked for additional information about the current state of the system processes, system quality, and organizational impact of SAP.

\subsubsection{Results}

The researcher was not able to identify any processes or documents specifically relating to value management of the overall application portfolio, the management of the total cost of ownership, 57 
or any strategy documents. The documents provided to the researchers had a strong focus on the management of individual projects. These projects were generally major or minor system upgrades.

A key system management document was the product application reference manual (PARM). The process-orientated document covered the functionality of the SAP system within the Telecom environment. It also covered supporting details for the SAP application, technical and operational teams. A summary of the contents of the PARM is included below.

The document provides an overview of SAP (see appendix vii) and its current business purpose, overview of the SLA requirements for the application, including application portfolio, application tier, SDG cover and software asset information. Following this, it describes the SAP technical components, including hardware and software specifications. Identifying systems that SAP interfaces with and impacts of failure/recovery measures and also provides information on integration into the processes and procedures applicable to the case organization, including data retention, scheduling and operation activities.

The document has an extremely technical, operational focus, aimed at maintaining the technical "system quality" and minimising downtime. Specific system procedures are enumerated and defined, and either a contact person or group within the organization, or a document explaining the process, is listed. These technical procedures are listed below in table 3 .

Table 3: SAP Platform Technical Procedures

\begin{tabular}{|l|l|l|}
\hline \multicolumn{1}{|c|}{ Procedure } & \multicolumn{1}{|c|}{ Description } & \multicolumn{1}{c|}{ Contact or Document } \\
\hline \hline Backups & $\begin{array}{l}\text { File system and database } \\
\text { backups. }\end{array}$ & $\begin{array}{l}\text { Refer to Chapter 6 - Data Management } \\
\text { or contact Enterprise Storage BUR. }\end{array}$ \\
\hline File Transfers & $\begin{array}{l}\text { System interfacing - file } \\
\text { transfer }\end{array}$ & Contact the application support team \\
\hline Archiving & \multicolumn{2}{|c|}{$\begin{array}{l}\text { Refer to Chapter 2 - Databases or contact } \\
\text { the Database Administration team }\end{array}$} \\
\hline IPL/Reboots & Restart system from boot & $\begin{array}{l}\text { Contact ITO Unix Engineering or } \\
\text { Workplace Services }\end{array}$ \\
\hline
\end{tabular}




\begin{tabular}{|c|c|c|}
\hline $\begin{array}{l}\text { Platform Power } \\
\text { Up/Down }\end{array}$ & $\begin{array}{l}\text { Planned outage power } \\
\text { downs/ups }\end{array}$ & $\begin{array}{l}\text { Refer to the associated Change Request } \\
\text { or contact ITO Unix Engineering or } \\
\text { Workplace Services }\end{array}$ \\
\hline $\begin{array}{l}\text { Application } \\
\text { Shutdown and } \\
\text { Restart }\end{array}$ & $\begin{array}{l}\text { Controlled shutdown and } \\
\text { restart }\end{array}$ & $\begin{array}{l}\text { Refer to the associated Change Request } \\
\text { or contact the application support team }\end{array}$ \\
\hline $\begin{array}{l}\text { Application } \\
\text { Recovery and Restart }\end{array}$ & $\begin{array}{l}\text { Recovery after an } \\
\text { unplanned downtime }\end{array}$ & Contact the application support team \\
\hline Application Installs & $\begin{array}{l}\text { Install of new/revised } \\
\text { versions of application } \\
\text { software }\end{array}$ & $\begin{array}{l}\text { Refer to the associated Change Request } \\
\text { or contact ITO Unix Engineering or } \\
\text { Workplace Services }\end{array}$ \\
\hline $\begin{array}{l}\text { Operating System } \\
\text { Installs }\end{array}$ & $\begin{array}{l}\text { Install of new/revised } \\
\text { version of operating system } \\
\text { software }\end{array}$ & $\begin{array}{l}\text { Refer to the associated Change Request } \\
\text { or contact ITO Unix Engineering or } \\
\text { Workplace Services }\end{array}$ \\
\hline Disk Management & $\begin{array}{l}\text { Disk space monitoring and } \\
\text { maintenance }\end{array}$ & $\begin{array}{l}\text { Contact the ITO Unix Engineering or } \\
\text { Workplace Services }\end{array}$ \\
\hline $\begin{array}{l}\text { Dynamic Monitoring } \\
\text { and Alerting }\end{array}$ & $\begin{array}{l}\text { System Dynamically } \\
\text { signals a predefined alert }\end{array}$ & $\begin{array}{l}\text { Contact ITO Unix Engineering, } \\
\text { Workplace Services or the Database } \\
\text { Administration team }\end{array}$ \\
\hline $\begin{array}{l}\text { Security - User Id's } \\
\text { and Passwords }\end{array}$ & $\begin{array}{l}\text { Maintenance of non- } \\
\text { application users on the } \\
\text { system }\end{array}$ & $\begin{array}{l}\text { Contact ITO Unix Engineering or } \\
\text { Workplace Services }\end{array}$ \\
\hline $\begin{array}{l}\text { Performance } \\
\text { Monitoring and } \\
\text { Reporting }\end{array}$ & $\begin{array}{l}\text { System monitoring against } \\
\text { pre-defined levels (daily } \\
\text { reporting) }\end{array}$ & $\begin{array}{l}\text { Contact Peter Poortman or refer to the } \\
\text { EDS BAU Process Document (40985) }\end{array}$ \\
\hline $\begin{array}{l}\text { Comms } \\
\text { administration and } \\
\text { monitoring }\end{array}$ & $\begin{array}{l}\text { Management of user access } \\
\text { network }\end{array}$ & $\begin{array}{l}\text { Refer to Telecom Network Security } \\
\text { Operations (NSO) }\end{array}$ \\
\hline
\end{tabular}

The same themes are continued in the clear codification of operational management procedures for the platform, which are also focussed primarily at a technical system management level. Table 4 outlines the operational procedures for the case organization for the SAP application support. While "consultancy" is included, this does not appear to have a strategic or business focus. 
Table 4: SAP Platform Operational Procedures

\begin{tabular}{|c|c|c|}
\hline Procedure & Description & Contact or Document \\
\hline $\begin{array}{l}\text { Operational } \\
\text { Support }\end{array}$ & $\begin{array}{l}\text { - Investigating and answering customer queries } \\
\text { - Monthly faults analysis and review } \\
\text { - Regular progress reporting of all changes i.e. } \\
\text { faults, proposals, etc } \\
\text { - Interaction with operations teams i.e. Unix, } \\
\text { DBA, Data Centre, etc } \\
\text { - Proactive monitoring and impact assessments } \\
\text { for changes to upstream/downstream systems }\end{array}$ & Workpacket \# WP804 \\
\hline $\begin{array}{l}\text { Corrective } \\
\text { Maintenance }\end{array}$ & $\begin{array}{l}\text { Pre-approved and Subject to Budget faults } \\
\text { management. Investigate and correct defects that } \\
\text { have resulted from errors in the system's } \\
\text { development or operation }\end{array}$ & $\begin{array}{l}\text { Workpacket \# WP804 } \\
\text { and DW Incident } \\
\text { Management Process }\end{array}$ \\
\hline $\begin{array}{l}\text { Perfective and } \\
\text { Adaptive } \\
\text { Maintenance }\end{array}$ & $\begin{array}{l}\text { System improvement proposals and support to } \\
\text { Operations due to operating system upgrades. }\end{array}$ & Workpacket WP804 \\
\hline $\begin{array}{l}\text { Supplier } \\
\text { Management }\end{array}$ & License purchasing and management etc & Workpacket \# WP804 \\
\hline $\begin{array}{l}\text { Release } \\
\text { Management }\end{array}$ & $\begin{array}{l}\text { - Management and planning of all software } \\
\text { changes into releases as a result of system } \\
\text { faults or enhancements (work requests) } \\
\text { - Change Control Management. }\end{array}$ & $\begin{array}{l}\text { Workpacket \# WP804 } \\
\text { and DW Change } \\
\text { Management Process }\end{array}$ \\
\hline $\begin{array}{l}\text { Project } \\
\text { Management }\end{array}$ & $\begin{array}{l}\text { Management of all software changes (activities } \\
\text { relating to maintenance and support undertaken } \\
\text { within the Work Packet). }\end{array}$ & Workpacket \# WP804 \\
\hline Documentation & $\begin{array}{l}\text { - Maintain high level system requirements } \\
\text { documentation } \\
\text { - } \quad \text { Maintain coding standards and user guides. }\end{array}$ & Workpacket \# WP804 \\
\hline Consultancy & $\begin{array}{l}\text { Client meetings to answer queries with regards to } \\
\text { system performance to identify potential areas for } \\
\text { improvement and advise possible developments }\end{array}$ & Workpacket \# WP804 \\
\hline
\end{tabular}

The researchers also identified a contingency plan if SAP were to become inactive within the production environment (table 5). Once again, this concentrates on "recoverability" (a dimension of system reliability):

Table 5: SAP Contingency Plan 
- Possible failure points

- Recovery priorities

- Initiating contingency

- SAP support team responsibilities

- Disaster recovery
Network failure on a database machine.

The priority for recovery of the application is production boxes first boxes first, then development, then pre-production / staging. Once the SAP application is available, all activities are available.

As previously mentioned, failover is an automated process for both HA cluster and other machines. Notification that a failure has occurred should be in accordance with standard escalation processes.

Ensuring that the failover completes and that SAP is running on two machines instead of three machines Failing back to normal operation following resolution of the fault.

There is no Disaster recovery Plan in place for SAP. Telecom Finance Information Systems have accepted this risk.

\subsubsection{Discussion}

In our view, these documents were aimed at a "process-based" approach to quality management (i.e. they documented organizational processes or procedures), and were entirely focussed on the management of factors that would be included within the "system quality" construct in the ISO 9126 model, or the IS-Impact model. While is difficult to establish direct equivalence for every procedure listed with a dimension of IS-Impact or ISO 9126, the researcher can see that some of the procedures are clearly aimed at dimensions included in these models. For example, backups, restarts and reboots relate to recoverability (a dimension of reliability on the ISO 9126 model) and disk management and performance monitoring relate to stability, which is a dimension of maintainability in the ISO 9126 model.

The technical "system quality" focus of the documents identified in the archival analysis, and the general lack of any more strategic documents associated with business alignment, value management, total cost of ownership, or management of the application portfolio, provided further evidence supporting the findings of the key informants in the benchmarking: these business-oriented areas were not a major focus for the organization, this is summarised in table 6.

Table 6: Overview of Stakeholder Interviews and Archival Analysis

\begin{tabular}{|l|l|l|l|l|}
\hline $\begin{array}{l}\text { Source of } \\
\text { evidence }\end{array}$ & $\begin{array}{l}\text { Quality } \\
\text { management } \\
\text { perspective(s) }\end{array}$ & $\begin{array}{l}\text { Quality } \\
\text { "type" }\end{array}$ & $\begin{array}{l}\text { Intended } \\
\text { outcome }\end{array}$ & Comments \\
\hline Interviews & Various & $\begin{array}{l}\text { "User- } \\
\text { based" and }\end{array}$ & $\begin{array}{l}\text { Organizational } \\
\text { impact }\end{array}$ & $\begin{array}{l}\text { Identified weaknesses in } \\
\text { business ownership, }\end{array}$ \\
\hline
\end{tabular}




\begin{tabular}{|l|l|l|l|l|}
\hline & & interpretive & & strategy and governance \\
\hline $\begin{array}{l}\text { Archival } \\
\text { analysis of } \\
\text { SAP } \\
\text { management } \\
\text { documents }\end{array}$ & $\begin{array}{l}\text { Technical } \\
\text { system } \\
\text { management }\end{array}$ & $\begin{array}{l}\text { Process- } \\
\text { based }\end{array}$ & System quality & $\begin{array}{l}\text { Extensive and well } \\
\text { documented processes for } \\
\text { managing system quality } \\
\text { were identified in the } \\
\text { archival analysis. We were } \\
\text { unable to identify any } \\
\text { processes for managing } \\
\text { organizational value and } \\
\text { impact. }\end{array}$ \\
\hline
\end{tabular}

\subsection{SAP Benchmarking}

\subsubsection{Data Gathering and Analysis}

The quantitative SAP benchmarking data was collected via a survey provided by SAP New Zealand. The case organization wanted to conduct a benchmarking programme that was part of the discovery phase of the SAP value management life cycle. While SAP offer a large range of benchmarks as presented in table 7, the organization saw purpose in conducting the total cost of ownership and best run benchmarks which are part of the strategic IT segments highlighted below.

Table 7: SAP Overview of Benchmarks

\begin{tabular}{|c|c|c|}
\hline Financial Excellence & Responsive Supply Networks & Strategic IT \\
\hline Finance & Supply Chain Planning & Business Intelligence \\
\hline $\begin{array}{c}\text { Financial Performance and Risk } \\
\text { Management }\end{array}$ & Warehouse Management & Enterprise Information Management \\
\hline Public Finance & Transportation Management & Enterprise Mobility \\
\hline Finance Shared Services & Retail - Integrated Demand and Replenishment \\
& $\begin{array}{c}\text { Planning } \\
\text { Access Control }\end{array}$ & Trofessional Business Networks Cost of Ownership \\
\hline Process Control & Oil \& Gas - Primary Distribution & Business Intelligence in Fashion Industry \\
\hline & Supply Chain Planning in Fashion Industry & Enablement \\
\hline Best People and Talent & Demand Signal Management & Value Management \\
\hline & & Enterprise Architecture \\
\hline Human Capital Management & High Performing Assets & Information Governance \\
\hline Talent Management & Enterprise Asset Management & \\
\hline & & \\
\hline
\end{tabular}




\begin{tabular}{|c|c|c|}
\hline & Environment, Health, and Safety Compliance & Enterprise Mobility Business Impact \\
\hline \multirow[t]{2}{*}{ Operational Excellence } & $\begin{array}{c}\text { Utilities - Optimized Asset Operations and } \\
\text { Maintenance }\end{array}$ & \\
\hline & $\begin{array}{c}\text { SAP Capital Project and Portfolio Management } \\
\text { Survey }\end{array}$ & \\
\hline Manufacturing & Environmental Sustainability Survey & \\
\hline \multicolumn{2}{|l|}{ Procurement/ Sourcing } & \\
\hline Procurement in Fashion Industry & Product and Service Leadership & \\
\hline \multicolumn{2}{|l|}{ Manufacturing in Fashion Industry } & \\
\hline Lean Enterprise & Product Lifecycle Management & \\
\hline Hospital Operations & After Sales Service & \\
\hline \multirow[t]{2}{*}{$\begin{array}{l}\text { Real Estate Mgmt. - Lease and } \\
\text { Maintenance Processes }\end{array}$} & & \\
\hline & End to End Processes & \\
\hline \multicolumn{2}{|l|}{ Superior Customer Value } & \\
\hline & Order To Cash & \\
\hline Sales Effectiveness & Enterprise Health Check - Manufacturing & \\
\hline Customer Contact Center & Enterprise Health Check - Public Sector & \\
\hline Trade Promotion Management & Enterprise Health Check - Services & \\
\hline Customer Service \& Support & Retail Merchandising & \\
\hline Accountable Care Organizations & Private Equity Operational Assessment & \\
\hline \multirow[t]{4}{*}{ Customer Centricity in Banking (Retail) } & Order To Cash in Fashion Industry & \\
\hline & Cash-To-Cash & \\
\hline & Innovation Index & \\
\hline & Commodity management & \\
\hline
\end{tabular}

The rationale for the case organization selecting these two benchmarks were based on the ability to realign their IT functions with changing business needs, but also try to add a strategic dimension to day-to-day operations. As an organization grows in size and complexity, the IT function faces the pitfalls of being caught up in a transactional focus, with increased pressure to respond quickly and efficiently to business challenges (SAP, 2013).

In order to complete the total cost of ownership benchmark the survey required financial information from the case organization both current and historical, the Group Financial 
Controller collaborated with the researcher to produce this information, using the annual report, and other internal financial information and organizational knowledge.

To complete the "Best Run IT" benchmarking survey, the SAP application support manager assisted with gathering appropriate data relating to the operational metrics. In order to complete the Likert scale questions relating to process orientated metrics, the SAP application support manager gathered ten individuals to gain a holistic view of best practices.

To have consistency with results a proportion of participants that had partaken in the qualitative semi structured interviews in the last study conducted by Ali \& Tate (2012). The participants included the Group Financial Controller, SAP Application Support Manager, Manager of Component Design and Build, Head of Component Design and Build, GM of Technology Shared Services, Chief Information Officer, SAP Solution Architect, Head of HR (one of the core SAP modules), GM of Finance (the other core SAP module) and the SAP Domain Manager. Once the surveys were completed they were then returned back SAP New Zealand, where the data was then processed via the SAP value management centre, then results made available via PDF and also an online copy via https://valuemanagement.sap.com with a unique ID provided by SAP New Zealand.

\subsubsection{Results}

The benchmarking exercise yielded a consensus of expert informants within the organization about the overall company score, and the importance to the company, of a range of SAP management processes, including IT portfolio management, IT strategy and business alignment, IT governance, and IT value management. The following charts report the results from the case organization, and the position of the organization when benchmarked against comparable organizations by SAP.

In addition, a the benchmarking exercise provided a number of "objective" measures that were gathered by the researcher using key informants and internal documents, such as the number of interfaces, the number of full-time equivalent SAP support staff, and so on. These were triangulated with the management processes. As might be expected, processes on which the organization scored poorly also yielded below average outcomes on a range of objective measures. The benchmarking exercise also included some summative measures, including some 
"value-based" measures. The summaries of the benchmarking outcome metrics are listed below in table 8.

The charts show: 1) the overall company score on each metric on a scale of 1-6, calculated as an average of the scores of the participating expert respondents (yellow line); 2) the average importance to the company of each metric on a scale of 1-6, calculated as an average of the scores of the participating expert respondents (red line); the average score for the companies included in the benchmarking calculation (dark blue bar); and the average score for the top 25\% of companies included in the benchmarking calculation (pale blue bar).

The results of the process benchmarking are compared, where relevant, with a range of organizational outcomes that result from these processes, for example, the number of application interfaces, the number of SAP modules that have been customized, and so on.

Table 8: Summary of Benchmarking 'Outcomes' Metrics

\begin{tabular}{|c|c|c|c|}
\hline Metric & $\begin{array}{l}\text { Company } \\
\text { Value }\end{array}$ & $\begin{array}{l}\text { Average } \\
\text { Peer Group } \\
\text { Value }\end{array}$ & $\begin{array}{l}\text { Average Value of Top } 25 \% \\
\text { of Companies Included in } \\
\text { the Benchmarking }\end{array}$ \\
\hline IT Spend as \% of Revenue & 4.9 & 1.1 & 0.5 \\
\hline $\begin{array}{l}\text { Number of IT Projects per } \\
\text { Million IT Spend }\end{array}$ & 2.0 & 3.3 & 6.2 \\
\hline $\begin{array}{l}\% \text { of IT Projects Generating } \\
\text { Positive ROI }\end{array}$ & 50.0 & 68.0 & 100.0 \\
\hline $\begin{array}{l}\text { Total Number of Master } \\
\text { Data Files }\end{array}$ & 51.0 & 10.4 & 4.0 \\
\hline $\begin{array}{l}\text { IT - \% of Unplanned } \\
\text { Downtime }\end{array}$ & 4.0 & 0.6 & 0.1 \\
\hline $\begin{array}{l}\text { IT Operational Cost per } \\
\text { Licensed User }\end{array}$ & 15694 & 15217 & 6165.8 \\
\hline $\begin{array}{l}\text { IT Operational Cost per } \\
\text { Active User }\end{array}$ & 18896.3 & 18036.5 & 3771.0 \\
\hline $\begin{array}{l}\text { Applications per billion in } \\
\text { revenue }\end{array}$ & 97.6 & 18.1 & 4.6 \\
\hline \multirow[t]{2}{*}{$\begin{array}{l}\text { SAP Spend as a \% of IT } \\
\text { Spend }\end{array}$} & 1.9 & 32.4 & 51.8 \\
\hline & 2000 & 521 & 847 \\
\hline
\end{tabular}




\begin{tabular}{|l|c|c|c|}
\hline $\begin{array}{l}\text { Active users per production } \\
\text { instance }\end{array}$ & 250 & 18.7 & 3.8 \\
\hline $\begin{array}{l}\text { Total interfaces per } \\
\text { production instance }\end{array}$ & 30 & 28.1 & 6.0 \\
\hline Number of critical interfaces & 12.2 & 8.7 & 0.0 \\
\hline Actual planned downtime & & & \\
\hline
\end{tabular}

The results of the process/best practice items are compared with the objective benchmarking data that results in the actual outcomes. The best practice items that are compared to actual items are; solutions/IT portfolio management; strategy and business alignment; value management; business improvement; business continuity and TCO and lastly, IT governance.

Figure 13: Best practice 'Solutions/IT Portfolio Management

\section{Best Practice Listing}

\begin{tabular}{cl}
\hline 1 & The company has a consolidated single solution/ platform landscape \\
\hline 2 & $\begin{array}{l}\text { The company has a strategy in place for a single solution/ platform } \\
\text { landscape consolidation }\end{array}$ \\
\hline 3 & $\begin{array}{l}\text { The company has a strategy and enforce the application of support or } \\
\text { enhancement packs from vendors }\end{array}$ \\
\hline 4 & $\begin{array}{l}\text { The company has and enforces a no-modification strategy for vendor } \\
\text { applications }\end{array}$ \\
\hline 5 & $\begin{array}{l}\text { The business units have incentives aligned with the adoption of } \\
\text { standard, common solutions }\end{array}$ \\
\hline 6 & $\begin{array}{l}\text { The company has a master data strategy to drive common definitions } \\
\text { and standards }\end{array}$ \\
\hline 7 & $\begin{array}{l}\text { The company always evaluates licensed vendor(s) or legacy IT solution } \\
\text { for meeting business requirements before looking at niche products }\end{array}$ \\
\hline 8 & $\begin{array}{l}\text { The company has a strategy to maximize the value of integration for the } \\
\text { vendor(s) or legacy IT solutions }\end{array}$ \\
\hline 9 & $\begin{array}{l}\text { The company evaluates vendor viability and business strategy as part of } \\
\text { the IT portfolio management }\end{array}$ \\
\hline
\end{tabular}

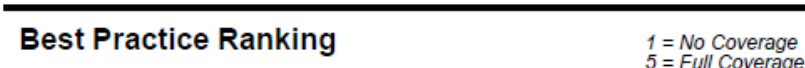

$1=$ No Coverage
$5=$ Full Coverage

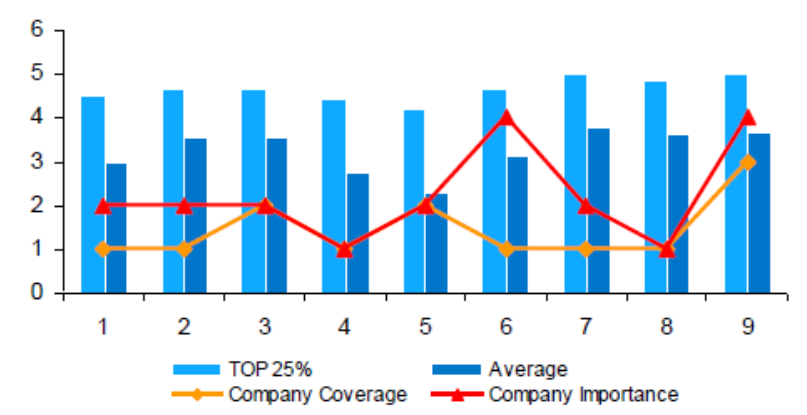

The best practice item, Solutions/IT Portfolio Management results are presented in figure 14 . Items one and two from the solution/IT portfolio management suggest the case organization had low coverage with consolidating IT landscape to a single solution with an overall company coverage of 1 , but also low company importance of 2 . This is translated with the actual outcomes, which indicates the organization had 2,500 applications within their IT portfolio. This is also validated with the total interfaces per production instance, with the case organization having 250 , with the industry average being 18.7 , but also the number of critical interfaces 
between SAP and the other applications reached 30, with the top 25 per cent run organizations outline to have 6 .

The organization has not enforced a well-executed strategy for no-modification, with both company coverage and importance ranking at 2 . The actual outcomes, which outlined custom SAP Y, or Z programs being around 2,000 validate this. The top 25 per cent organizations within the peer group have 832 custom programs.

Item 8 of the best practice item ranked company coverage and importance at 1 , which outlines the organizations, has a limited strategy in place to maximise the value of integration for the vendors or legacy IT solutions. This can also be validated by the actual outcomes which indicate that IT spend as a percentage of revenue is high, with the industry norm being 1.1 and top 25 per cent of peer organizations having a company value of 0.5 . The organization in this instance has a company value of 4.9 , which is below the industry norm by 3.8 .

Figure 14: Best practice IT Strategy and Business Alignment (1)

\section{Best Practice Listing}

\begin{aligned} & \hline 1 The company is using IT to enable strategic and competitive advantages \\ & \hline 2 $\begin{array}{l}\text { The company has established common, simple and streamlined IT and } \\ \text { business process standards across the organization }\end{array} \\ &$\hline 3 $\begin{array}{l}\text { The company has defined IT roles and responsibilities which are } \\ \text { consistently applied across the organization }\end{array} \\ &$\hline 4 $\begin{array}{l}\text { The company undergoes a formal budgeting and planning process to } \\ \text { approve initiatives and drive business value }\end{array} \\ &$\hline 5 $\begin{array}{l}\text { The company undergoes a formal annual portfolio rationalization } \\ \text { process to reduce operating expense }\end{array} \\ &$\hline\end{aligned}

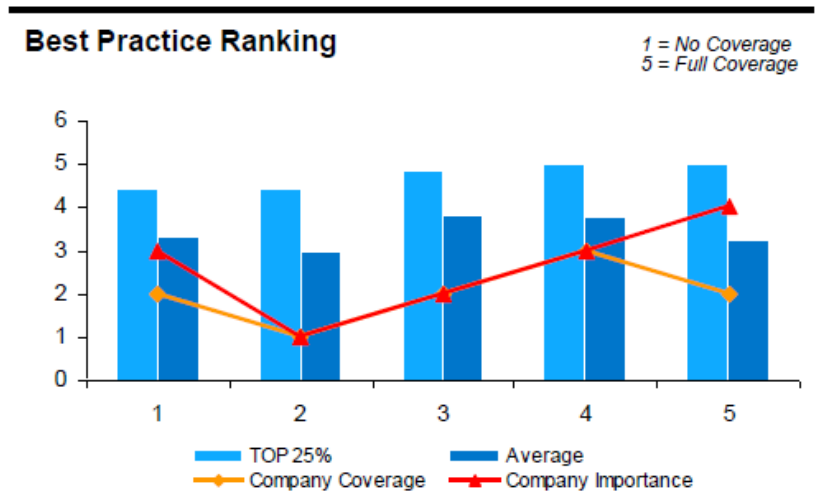

Best practice construct IT strategy and business alignment results are outlined in figures 13 and 14. Item two has a ranking of 1 for both company coverage and company importance. This outlines that the organization has not established common, simple and streamlined IT and business process standards across this organization. The actual outcomes to validate this would be the large volume of applications within the organizations IT portfolio as outlined in the previous section, but also the organization has no 'centres of excellence' implemented within the organization for its core SAP system. This best practice provided by SAP ensures organizations are using the best of breed processes across the organization. The high number of master data files, where the case organization had a company value of 51, explains this. The peer group average for this metric was 10.4 . 
Item three also had a low company coverage and company importance with a ranking of two. This outlines that the organization has a below average strategy for defining IT roles and responsibilities which are consistently applied across the organization. This is validated by the organizations high uptake of full time equivalents; with the SAP IT application support team having over 30 per cent more FTE's than the industry peer group average of 29 per cent.

Figure 15: Best practice IT Strategy and Business Alignment (2)
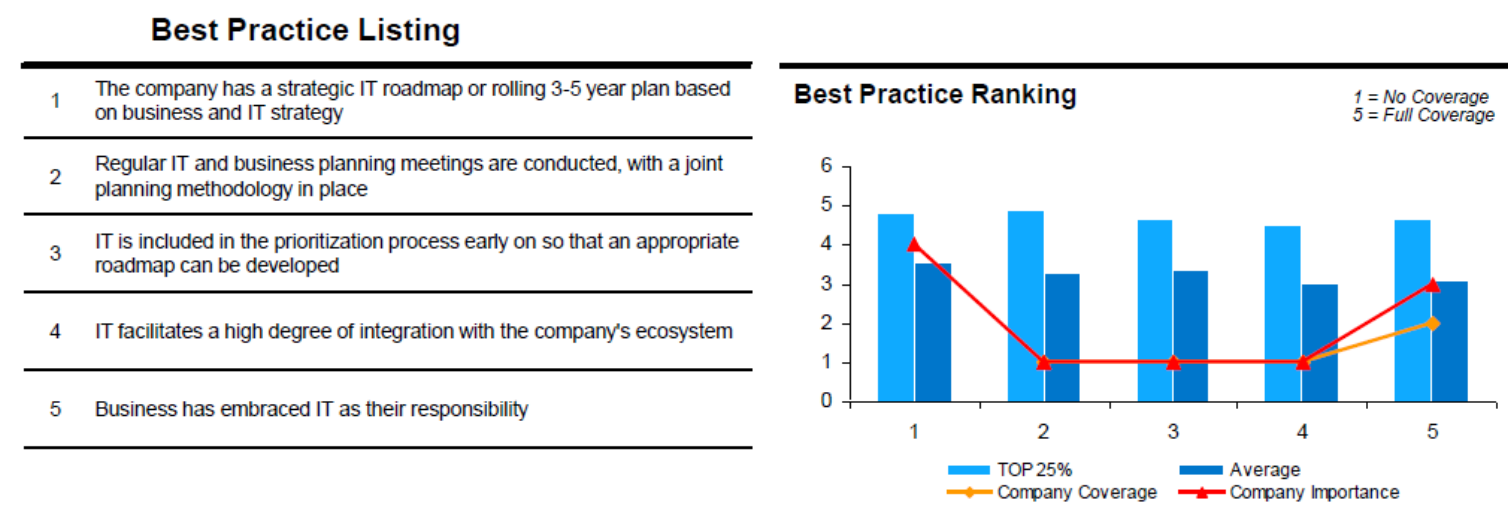

Following on, items two, three and four both had low rankings of company coverage and company importance, as indicated on figure 15 of the IT strategy and business alignment (2).

This indicates the case organization does not have regular IT and business planning meetings with a joint planning methodology in place, it also suggests the organization does not consider the need for IT to be included in the prioritization process early on during the strategic roadmap, but also the lack of integration of the organizations ecosystem. These best practice items can be well validated by actual outcomes. Firstly, the lack of comprehensive SAP IT strategy could be related to the percentage of IT projects generating positive return on investment. The company value indicated of the actual outcome of positive value is only 50 per cent. The average peer group average is 68 per cent, followed by the top 25 per cent of organizations having a 100 per cent return on investment. The number of IT projects per million IT spend could also account for this disconnect, which the organization positing 2.0, with the group average being 3.3 and the top 25 per cent being 6.2 .

The high number of applications per billion in revenue could also account for the lack of having a comprehensive IT strategy in place aligned to business initiatives and strategies. The company posted a high value of 97.6, with the average peer group having only 18.1 and the top 25 per cent of organizations having 4.6. 
Figure 16: Best practice IT Governance

\begin{tabular}{cl}
\multicolumn{1}{c}{ Best Practice Listing } \\
\hline 1 & $\begin{array}{l}\text { The company has a set of IT principles that help to make decisions on } \\
\text { IT architecture, infrastructure, business applications and prioritization. } \\
\text { For example, standardize technology and process wherever possible }\end{array}$ \\
\hline 2 & $\begin{array}{l}\text { The Company's IT performance management is linked with the business } \\
\text { outcomes }\end{array}$ \\
\hline 3 & $\begin{array}{l}\text { The Company's IT Architecture is an integral part of top management's } \\
\text { business planning }\end{array}$ \\
\hline 4 & $\begin{array}{l}\text { Company has a strategy to upgrade IT Infrastructure in an incremental } \\
\text { manner }\end{array}$ \\
\hline 5 & $\begin{array}{l}\text { The company has defined a set of policies (e.g. data standards like } \\
\text { UN/CEFACT CCTS) and choices (e.g. SSO must be used in web } \\
\text { interfaces) to ensure a consistent IT architecture }\end{array}$ \\
\hline 6 & $\begin{array}{l}\text { The company has adopted a risk-analysis template for making IT } \\
\text { investments }\end{array}$ \\
\hline 7 & $\begin{array}{l}\text { The company reconciles the IT investment portfolio against enterprise } \\
\text { wide strategic initiatives and individual business units }\end{array}$ \\
\hline
\end{tabular}

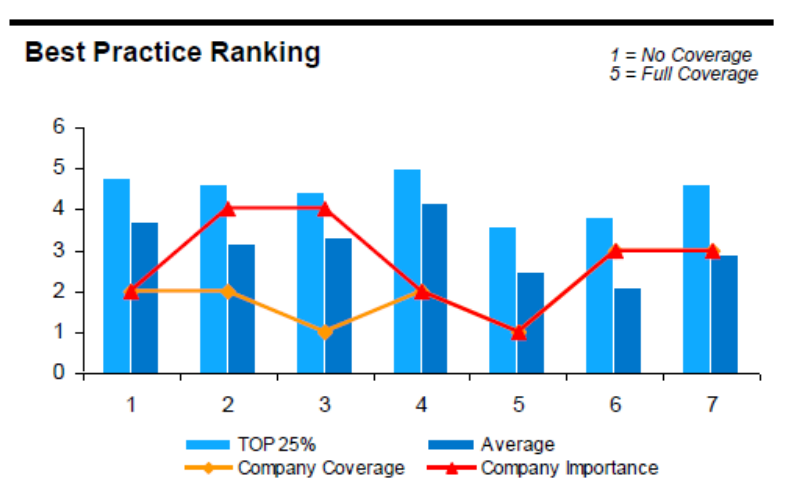

The best practice listing of IT Governance had three items below satisfactory rankings; with item one having company coverage of 2 and company importance of 2, as indicated in figure 16. Item's two and three had low company coverage rankings of 2 and 1, despite having a high company importance.

Item four also had a company coverage and importance of 2 . Item 5 had company coverage and importance ranking of 1 . This suggests the organization has a limited set of principles in place to assist with making decisions relating to IT architecture, infrastructure, business applications and prioritization. It also indicates the organization has minimal strategy in place to upgrade IT infrastructure in an incremental manner, but also a lack of defined policies relating to IT architecture and infrastructure. This can be validated by the actual outcomes of the organization not having SAP centres of excellence place, but also the lack of comprehensive strategic roadmap, which is exhibited by the loss on IT projects which only generated 50 per cent of revenue.

\section{Figure 17: Best practice Value Management}




\section{Best Practice Listing}

\begin{tabular}{cl}
\hline 1 & $\begin{array}{l}\text { Industry best practices supporting technology and process excellence } \\
\text { are available and reviewed during strategy reviews }\end{array}$ \\
\hline 2 & IT Plans are developed over a multi year horizon \\
\hline 3 & $\begin{array}{l}\text { Initiatives are prioritized based on a defined set of criteria, taking into } \\
\text { account business value, organizational readiness, potential risks and } \\
\text { technology impact }\end{array}$ \\
\hline 4 & Benchmarking is used to drive ongoing process improvement \\
\hline 5 & $\begin{array}{l}\text { Benchmarking includes comparisons with external peers as well as } \\
\text { internal benchmarking between divisions and/ or regions }\end{array}$ \\
\hline 6 & $\begin{array}{l}\text { A detailed quantitative business case and financial ROI analysis is } \\
\text { completed for all major implementations, outlining benefit areas, specific } \\
\text { sources of benefit for each area, and proposed operational impacts or } \\
\text { changes }\end{array}$ \\
\hline 7 & \begin{tabular}{l} 
Business cases follow a clear and consistent standard format \\
\hline 8
\end{tabular} \\
\hline $\begin{array}{l}\text { There is a clear and documented linkage between the organization's } \\
\text { strategic objectives and each business case objective }\end{array}$ \\
\hline
\end{tabular}
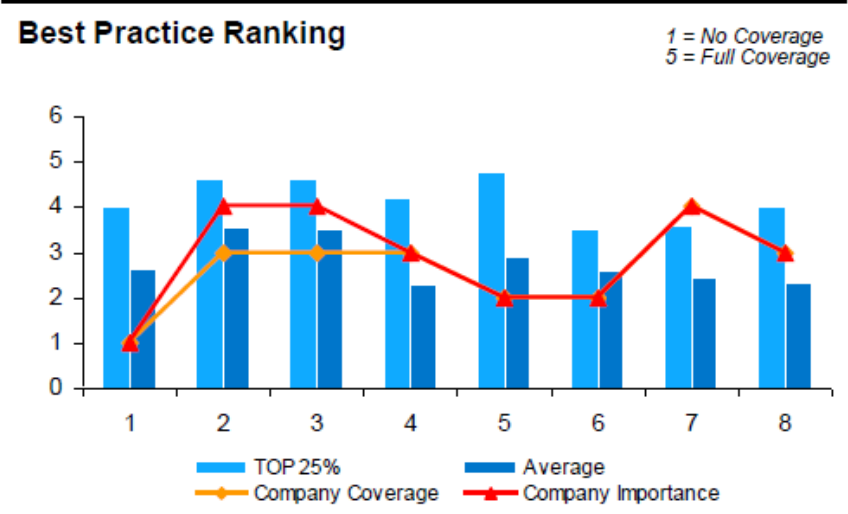

Figure 17 displays item one as having poor company coverage and company importance of one. This indicates that the organization does not have industry best practices supporting technology and process excellence available and are reviewed during strategy reviews. The actual outcomes validate one item of the value management best practice with the SAP support cost per active user being 939.7 , in comparison to the industry average of 4847.4 , indicating that SAP is heavily under resourced and thus unable to administer process excellence with minimal resources available to execute.

Figure 18: Best Practice Business Continuity and TCO

\section{Best Practice Listing}

\begin{tabular}{ll}
\hline 1 & $\begin{array}{l}\text { There is a defined process to conduct end-to-end root cause analysis } \\
\text { across the software components using the 'SAP Solution Manager } \\
\text { Diagnostics' functionality }\end{array}$ \\
2 & $\begin{array}{l}\text { Automated procedures for monitoring the infrastructure (including, } \\
\text { hardware, network, systems, operating system) are in place }\end{array}$ \\
\hline 3 & $\begin{array}{l}\text { Automated monitoring and error handling procedures for mission critical } \\
\text { business processes and interfaces are in place }\end{array}$ \\
4 & $\begin{array}{l}\text { There are defined procedures to ensure data integrity across SAP and } \\
\text { non-SAP components }\end{array}$ \\
5 & $\begin{array}{l}\text { A defined strategy exists to control database growth as well as an } \\
\text { archiving concept }\end{array}$ \\
\hline
\end{tabular}

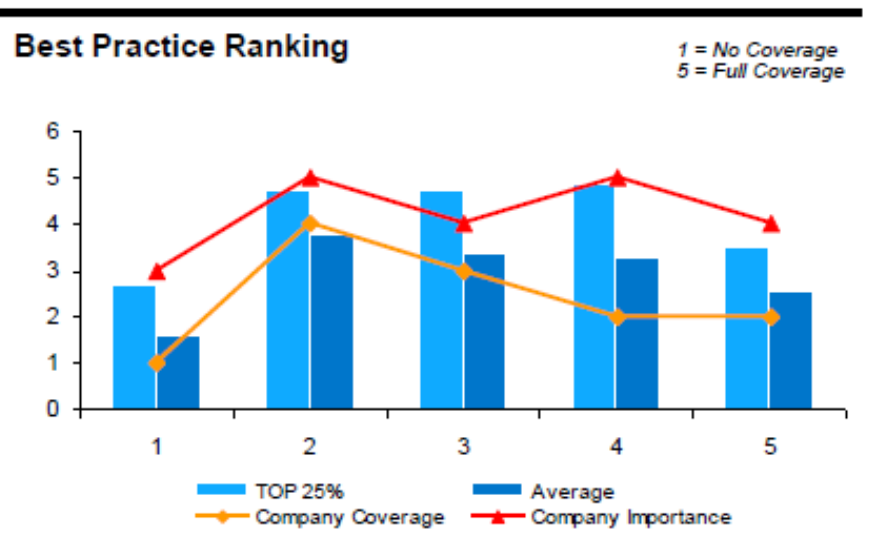

Figure 18 outlines the overall results of the best practice listing of business continuity and total cost of ownership. Item one had company coverage of 1 , and company importance of 
3. This suggests there is a lack of defined processes to conduct end-to-end root cause analysis across the software components using 'SAP Solution Manager Diagnostics' functionality. This could mean however that the organization does have a current process for end-to-end root cause analysis, but not through the SAP supplied functionality. Items 4 and 5 both had low company coverage of 2 however a high company importance of 5 and 4 had. This outlines there is a lack of defined procedures to ensure data integrity across SAP and non-SAP components, and also a lack of strategy around database growth.

Figure 19: Best Practice Business Process Improvement

\section{Best Practice Listing}

\begin{tabular}{|c|c|}
\hline 1 & $\begin{array}{l}\text { A standardized end-to-end test management process exists for both } \\
\text { new developments as well as for maintenance of the productive } \\
\text { solution, including the corresponding approval procedures }\end{array}$ \\
\hline 2 & $\begin{array}{l}\text { Business critical processes are technically analyzed end to end, } \\
\text { including interfaces, with focus on performance, technical correctness, } \\
\text { transactional correctness, and data consistency }\end{array}$ \\
\hline 3 & $\begin{array}{l}\text { Business key performance indicators are defined to measure the } \\
\text { success of the business process execution and to detect deviations of } \\
\text { the business process flow }\end{array}$ \\
\hline
\end{tabular}

Best Practice Ranking

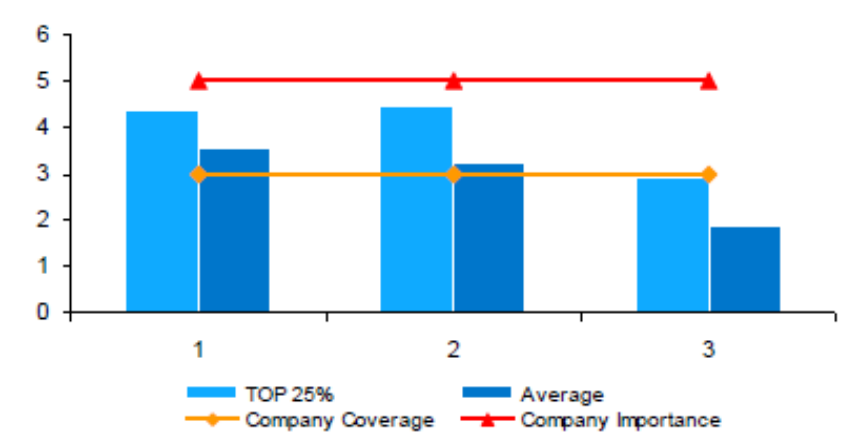

Business process improvement best practices listings all had an average rank of 3 with company importance of 5 which is outlined in figure 19. This indicates the organization has some coverage around test management processes, business critical processes and has key business performance indicators in place.

\subsubsection{Discussion}

The benchmarking exercise supported the previous evidence from the interviews; that there was relatively little attention paid to processes aimed at value management and organizational outcomes by comparison with the attention given to technical processes and system quality. Although there were some exceptions, the organization was ranking below average, and in many cases, in the bottom quartile compared to other organizations, for many of the processes benchmarked. For the majority of processes included in the benchmarking, the importance to the organization was rated more highly than the organization's current performance (Table 9). Unsurprisingly, the organization's relatively poor performance across the range of processes that were benchmarked was reflected in poor outcomes. 


\begin{tabular}{|c|c|c|}
\hline Processes & Outcome(s) & Comments \\
\hline $\begin{array}{l}\text { Solutions/IT Portfolio } \\
\text { Management } \\
\text { Company performance } \\
\text { generally lower than } \\
\text { importance to the } \\
\text { organization. }\end{array}$ & $\begin{array}{l}\text { Large number of total applications, high } \\
\text { number of total interfaces per production } \\
\text { instance, high number of critical } \\
\text { interfaces between SAP and the other } \\
\text { applications, large number of customer } \\
\text { programs, high IT spend per total revenue }\end{array}$ & $\begin{array}{l}\text { Unsurprisingly, lack of attention to } \\
\text { these processes, despite perceived } \\
\text { importance, led to below average } \\
\text { performance on the outcome } \\
\text { measures associated with these } \\
\text { processes }\end{array}$ \\
\hline $\begin{array}{l}\text { IT Strategy and Business } \\
\text { Alignment (1) }\end{array}$ & $\begin{array}{l}\text { Below average strategy for defining IT } \\
\text { roles and responsibilities which are } \\
\text { consistently applied across the } \\
\text { organization. Has not established } \\
\text { common, simple and streamlined IT and } \\
\text { business process standards across this } \\
\text { organization. High number of master data } \\
\text { files. }\end{array}$ & \\
\hline $\begin{array}{l}\text { IT Strategy and Business } \\
\text { Alignment (2) }\end{array}$ & $\begin{array}{l}\text { Does not have regular IT and business } \\
\text { planning meetings with a joint planning } \\
\text { methodology in place. Does not consider } \\
\text { the need for IT to be included in the } \\
\text { prioritization process early on during the } \\
\text { strategic roadmap. High number of } \\
\text { applications per billion in revenue }\end{array}$ & \\
\hline IT Governance & $\begin{array}{l}\text { Limited set of principles in place to assist } \\
\text { with making decisions relating to IT } \\
\text { architecture, infrastructure, business } \\
\text { applications and prioritization. Minimal } \\
\text { strategy in place to upgrade IT } \\
\text { infrastructure. Lack of defined policies } \\
\text { relating to IT architecture and } \\
\text { infrastructure }\end{array}$ & $\begin{array}{l}\text { Despite having a high company } \\
\text { importance across all measures, the } \\
\text { company coverage was lacking } \\
\text { which again is no surprise given } \\
\text { the lack of IT strategy and business } \\
\text { alignment }\end{array}$ \\
\hline Value Management & $\begin{array}{l}\text { Does not have industry best practices } \\
\text { supporting technology and process } \\
\text { excellence available and are reviewed } \\
\text { during strategy reviews. SAP is heavily } \\
\text { under resourced and thus unable to } \\
\text { administer process excellence with } \\
\text { minimal resources available to execute. }\end{array}$ & \\
\hline $\begin{array}{l}\text { Business Continuity and } \\
\text { TCO }\end{array}$ & $\begin{array}{l}\text { Lack of defined processes to conduct end- } \\
\text { to-end root cause analysis. Lack of } \\
\text { defined procedures to ensure data } \\
\text { integrity across SAP and non-SAP } \\
\text { components, and also a lack of strategy } \\
\text { around database growth. }\end{array}$ & $\begin{array}{l}\text { The defined processes were not } \\
\text { available when it came to root } \\
\text { cause analysis. But should expect } \\
\text { the organization to use the best-run } \\
\text { services available by SAP, such as } \\
\text { the root cause analysis } \\
\text { functionality. }\end{array}$ \\
\hline $\begin{array}{l}\text { Business Process } \\
\text { Improvement }\end{array}$ & $\begin{array}{l}\text { Some coverage around test management } \\
\text { processes, business critical processes and } \\
\text { has key business performance indicators }\end{array}$ & $\begin{array}{l}\text { Lack of processes is derived from } \\
\text { the lack of governance surrounding } \\
\text { SAP. }\end{array}$ \\
\hline
\end{tabular}


The researcher has included SAP benchmarking broadly in the category of "process based" metrics, as the benchmarking process focuses mainly on the way the SAP application is run and managed within the organization. The data collected for benchmarking purposes however does include some summative "value-based" metrics. These are summarised below in table 10.

Table 10: Summary of Results

\begin{tabular}{|l|l|l|l|}
\hline $\begin{array}{l}\text { Source of } \\
\text { evidence }\end{array}$ & Quality management perspective(s) & $\begin{array}{l}\text { Quality } \\
\text { “type" }\end{array}$ & Intended outcome \\
\hline $\begin{array}{l}\text { SAP } \\
\text { Benchmarking } \\
\text { (Processes) }\end{array}$ & $\begin{array}{l}\text { Processes are in place, however there } \\
\text { seems to be some disconnect between } \\
\text { the business and IT }\end{array}$ & $\begin{array}{l}\text { Process- } \\
\text { Based }\end{array}$ & $\begin{array}{l}\text { System Quality and } \\
\text { Organizational Impact }\end{array}$ \\
\hline $\begin{array}{l}\text { SAP } \\
\text { Benchmarking } \\
\text { (Outcomes) }\end{array}$ & $\begin{array}{l}\text { Lack of strategy, governance, } \\
\text { processes, ownership, high utilisation } \\
\text { and underinvestment of SAP }\end{array}$ & $\begin{array}{l}\text { Value- } \\
\text { Based }\end{array}$ & $\begin{array}{l}\text { System Quality and } \\
\text { Organizational Impact }\end{array}$ \\
\hline
\end{tabular}

\subsection{Additional Analysis of Survey Data}

\subsubsection{Data Gathering and Analysis}

The following demographic questions were used against the IS-Impact and ISO 9126 constructs which were taken from a survey of 140 respondents:

1. What SAP module do you use? (1. Finance. 2. HR/Payroll., 3. SRM. 4. Logistics. 5. SAP BW. 6. Portal, MSS or ESS.)

2. What tasks do you use SAP for that are required for your job? (1. Development. 2. Management. 3. Financial/Forecasting. 4. Data entry/processing. 5. Procurement)

3. How many years experience do you have using SAP? (1. 1 to 5 years. 2.5 to 10 years. 3. 10 or $>$ )

4. How many organizational levels are there between you and the CEO? And what is your role in the organization? (1. CEO - 5. Processor/Data Entry)

5. Do you use SAP to enter data or extract reports or other? (1. Entering Data. 2.

Extracting. 3. Other)

In particular, the researcher investigated: 
1. The overall mean scores on a range of dimensions are of interest (as these can be compared where possible with "objectives" metrics from the benchmarking data)

2. The standard deviations (as these might indicate areas where there was a lack of consensus in the organization)

3. And following (2) the researcher conducted further analysis to determine if any explanations could by suggested for metrics with high standard deviations.

\subsubsection{Results}

\subsubsection{Descriptive Statistics}

The researcher conducted descriptive statistics in order observe general trends in user perceptions with regard to the quality of SAP in the organization on a range of dimensions (Field, 2005). The descriptive results are outlined below in table 11.

Table 11: IT Impact Descriptive Statistics

\begin{tabular}{|c|c|c|c|}
\hline & $\mathbf{N}$ & Mean & Std. Deviation \\
\hline Q1.9 & 131 & 1.85 & .669 \\
\hline Q1.10 & 131 & 1.92 & .751 \\
\hline Q1.11 & 131 & 2.11 & .761 \\
\hline Q1.12 & 131 & 2.12 & .804 \\
\hline Q1.13 & 131 & 1.85 & .707 \\
\hline Q1.14 & 131 & 2.35 & .841 \\
\hline Q1.15 & 131 & 2.44 & .861 \\
\hline Q1.16 & 131 & 2.85 & 1.203 \\
\hline Q1.17 & 131 & 2.78 & 1.125 \\
\hline Q1.18 & 131 & 2.90 & 1.066 \\
\hline Q1.19 & 131 & 2.83 & 1.075 \\
\hline Q1.20 & 131 & 2.24 & .824 \\
\hline Q1.21 & 131 & 2.32 & .767 \\
\hline Q1.22 & 131 & 2.88 & .977 \\
\hline Q1.23 & 131 & 2.74 & .873 \\
\hline Q1.24 & 131 & 2.50 & .706 \\
\hline Q1.25 & 131 & 2.65 & .784 \\
\hline Q1.26 & 131 & 2.59 & .812 \\
\hline Q1.27 & 131 & 2.37 & .788 \\
\hline Q1.28 & 131 & 2.37 & .737 \\
\hline Q1.29 & 131 & 2.24 & .910 \\
\hline Q1.30 & 131 & 3.71 & .890 \\
\hline Q1.31 & 131 & 2.08 & .734 \\
\hline Q1.32 & 131 & 3.69 & .885 \\
\hline
\end{tabular}




\begin{tabular}{|l|l|l|l|} 
Q1.33 & 131 & 2.87 & 1.063 \\
Q1.34 & 131 & 2.78 & 1.055 \\
Q1.35 & 131 & 3.12 & 1.074 \\
Q1.36 & 131 & 2.21 & .617 \\
Q1.37 & 131 & 2.22 & .777 \\
Q1.38 & 131 & 2.76 & .951 \\
Q1.39 & 131 & 2.22 & .777 \\
Q1.40 & 131 & 2.16 & .732 \\
Q1.41 & 131 & 2.66 & .967 \\
Q1.42 & 131 & 2.74 & .873 \\
Q1.43 & 131 & 2.50 & .758 \\
Q1.44 & 131 & 2.41 & .700 \\
Q1.45 & 131 & 2.28 & .715 \\
Q1.46 & 131 & 2.31 & .743 \\
Q1.47 & 131 & 2.19 & .692 \\
Q1.48 & 131 & 2.27 & .785 \\
Q1.49 & 131 & 1.56 & .646 \\
Q1.50 & 131 & 1.69 & .755 \\
Q1.51 & 131 & 1.62 & .717 \\
Q1.55 & 131 & 1.92 & .847 \\
Q1.56 & 131 & 2.00 & .894 \\
Q1.57 & 131 & 1.94 & .848 \\
Q1.58 & 131 & 2.08 & .869 \\
Q1.59 & 131 & 2.20 & .836 \\
Q1.60 & 131 & 2.39 & .846 \\
Q1.61 & 131 & 2.03 & .850 \\
Q1.62 & 131 & 2.09 & .845 \\
Valid N & 131 & & \\
(list & & & \\
wise) & & & \\
\hline & & &
\end{tabular}

The descriptive statistics that in general, individual respondents are inclined in a positive way towards SAP (mean scores are mostly above the half-way point of 2.5 ) and there is a general agreement amongst responses (standard deviations are mostly <1). In order to capture the results in detail, the researcher will explain the items that had a low standard deviation then move towards outlining the results of those with a high standard deviation. The items with a low standard deviation are presented in table 12:

Table 12: Items with a low standard deviation

\begin{tabular}{|l|r|r|r|}
\hline & $\mathrm{N}$ & \multicolumn{1}{c|}{ Mean } & $\begin{array}{c}\text { Std. } \\
\text { Deviation }\end{array}$ \\
\hline Q1.49 & 131 & 1.56 & .646 \\
Q1.51 & 131 & 1.62 & .717
\end{tabular}




\begin{tabular}{|l|l|l|l|} 
Q1.50 & 131 & 1.69 & .755 \\
Q1.13 & 131 & 1.85 & .707 \\
Q1.9 & 131 & 1.85 & .669 \\
Q1.10 & 131 & 1.92 & .751 \\
Q1.55 & 131 & 1.92 & .847 \\
Q1.57 & 131 & 1.94 & .848 \\
\hline
\end{tabular}

These are the metrics for which there is the highest degree of agreement. Q1.9 had a mean score of 1.85 that is strongly agreed by participants with a standard deviation of .669, which suggests there is a general agreement that SAP can perform the tasks required. Similarly, Q1.10 had a mean score of 1.92 and standard deviation of .751, suggesting that SAP produces results as expected, with a general agreement between participants. Q1.13 had a mean score of 1.85 which suggested SAP users perceived SAP prevented unauthorized access and a general agreement with a standard deviation of .707 .

Q1.49 had a mean score of 1.56, where participants believed changes about SAP and its processes should be clearly communicated with a standard deviation of .646. Similarly, participants believed ownership of SAP needed to be clearly highlighted, with Q1.50 having a mean score of 1.69 and standard deviation of .755. Q1.51 had a mean score of 1.62 and standard deviation of .717, which suggested participants strongly, agreed that business unit collaboration is important to the success of SAP, which was supported by a low standard deviation score. Interestingly, the benchmarking exercise suggested the organization had a number of deficiencies in these key areas. The survey data suggests that respondents throughout the organization believe these deficiencies should be addressed.

Q1.55 had a mean score of 1.92 and standard deviation, which showed there is a lot of agreement between participants where they strongly agree that SAP has had a positive impact on their work. Similarly, Q1.57 had a similar weighting with a mean score of 1.94 and standard deviation of .848, which outlined that participants seemed to strongly believe SAP has been beneficial for the organization. However this generally positive sentiment from survey respondents was not matched by the objective findings from the benchmarking exercise, which placed the organization below average on many dimensions.

The above results indicate that the participant's view of SAP is widely shared, and there are few differences between responses on many dimensions. Users appear to be satisfied with SAP 
within the organization, and believe collaboration is a critical component to the success and ongoing operation.

Next the study outlines the results of the items from the IS Impact model which had a higher standard deviation as per below in table 13:

Table 13: Items with a high standard deviation

\begin{tabular}{|l|r|r|r|}
\hline & $\mathrm{N}$ & \multicolumn{1}{c|}{ Mean } & $\begin{array}{c}\text { Std. } \\
\text { Deviation }\end{array}$ \\
\hline Q1.34 & 131 & 2.78 & 1.055 \\
Q1.17 & 131 & 2.78 & 1.125 \\
Q1.19 & 131 & 2.83 & 1.075 \\
Q1.16 & 131 & 2.85 & 1.203 \\
Q1.33 & 131 & 2.87 & 1.063 \\
Q1.18 & 131 & 2.90 & 1.066 \\
Q1.35 & 131 & 3.12 & 1.074 \\
\hline
\end{tabular}

Q1.16 had a mean score of 2.85 and a standard deviation of 1.203, which suggested users agree it is easy to comprehend how to use SAP, however there is still some disagreement between users. Q1.17 had a mean score of 2.78 and a standard deviation of 1.125, which implied users still perceived that users could use the SAP system easily, yet with the higher standard deviation it outlined there was some level of disagreement between participants. Q1.19 had a mean score of 2.83 and standard deviation of 1.075, there was some disagreement between responses. Q1.33 had a mean score of 2.87 and standard deviation of 1.063, Q1.34 had a mean of 2.78 and standard deviation of 1.055 and lastly, Q1.35 had a mean score of 3.12 and standard deviation of 1.074. These three metrics show that users agree that the SAP system is easy and use and learn but also disagree that it is often difficult to get access to information that is in SAP. With the items with a higher standard deviation shows how much variation or dispersion exists from the averages, but as some of the questions are negatively worded, they support the findings that there is a general consensus that SAP is generally usable and the participants find the system to be adequate.

Next the research outlines the key remaining items which were calculated.Q1.11 had a mean of 2.11 and standard deviation of .761, Q1.12 had a mean score of 2.12 and standard deviation of .804. These items referred to the functionality of SAP where SAP could interact with other applications and whether SAP was compliant with standards. 
Q1.14 and Q1.15 referred to the reliability of SAP, where SAP was capable of handling errors and SAP could resume working and restore lost data after a failure. These items scored a mean of 2.35 and 2.44 with standard deviations of .841 and .861 .

Q1.20 and Q1.21 referred to the efficiency of SAP, whether SAP responds quickly and utilizes resources efficiently. These items had a mean score of 2.24 and 2.32 with standard deviations of .824 and .767 , indicating little difference between opinions.

Q1.22, Q1.23, Q1.24 and Q1.25 referred to the maintainability of SAP, which determined if faults in SAP could be easily diagnosed, could be easily modified, corrected or improved; could continue functioning if changes were made and if SAP could be tested easily. The mean score of the maintainability items were $2.88,2.74,2.50$ and 2.65 with standard deviations of $.977, .873$, .706 and .784 .

Q1.26 and Q1.27 referred to the portability of SAP, where SAP can be installed easily and also replace other applications within the organization. The mean score were 2.59 and 2.37 , with a standard deviation of .812 and .788. Q1.28 had a mean score of 2.37 and standard deviation of .788 which outlined users perceived SAP to be completely integrated and consistent. Q1.29 had a mean score of 2.24 and standard deviation of .910 which outlined there was agreement that SAP was readily available 100 per cent of the time.

Table 14: Items relating to System Quality

\begin{tabular}{|l|r|r|r|}
\hline & $\mathrm{N}$ & Mean & $\begin{array}{c}\text { Std. } \\
\text { Deviation }\end{array}$ \\
\hline Q1.30 & 131 & 3.71 & .890 \\
Q1.31 & 131 & 2.08 & .734 \\
Q1.32 & 131 & 3.69 & .885 \\
Q1.36 & 131 & 2.21 & .617 \\
Q1.37 & 131 & 2.22 & .777 \\
Q1.38 & 131 & 2.76 & .951 \\
Q1.39 & 131 & 2.22 & .777 \\
Q1.40 & 131 & 2.16 & .732 \\
Q1.41 & 131 & 2.66 & .967 \\
Q1.42 & 131 & 2.74 & .873 \\
Valid N & 131 & & \\
(listwise) & & & \\
\hline
\end{tabular}

Q1.30 to Q1.42 refers to the system quality of SAP as outlined in table 14.

Q1.30 had a mean score of 3.71 and .890 standard deviation; this suggested that users believed data from SAP doesn't often need correction as the metric is negatively worded. Q1.31 had a 
lower mean of 2.08 and standard deviation of .734 that suggests that data from SAP was current enough. Q1.32 had a mean score of 3.69 and standard deviation of .885, which similar to Q1.30 was a negatively worded metric.

Users perceived SAP was not missing key data. Q1.36 referred to SAP meeting user unit requirements, this has a mean score of 2.21 and standard deviation of .617. Q1.37 had a mean score of 2.22 and standard deviation of .777, which confirmed SAP, includes the necessary features and functions for the users to perform their role. Q1.38 had a mean score of 2.76 and a standard deviation of .951, which suggests SAP's user interface, can be easily adapted to one's personal approach. Q1.39 had a mean score of 2.22 and standard deviation of .777 that suggests SAP is always up and running as necessary. Q1.40 had a mean score of 2.16 and standard deviation of .732, which suggest users perceive that SAP responds quickly. Q1.41 had a mean score of 2.66 with a standard deviation of .967 that validates that users perceive that the SAP system responds quickly. Lastly, Q1.42 had a mean score of 2.74 and standard deviation of .873 that referred to SAP being easily modifiable.

Table 15: Items relating to Organizational Impact

\begin{tabular}{|l|r|r|r|}
\hline & $\mathrm{N}$ & \multicolumn{1}{c|}{ Mean } & $\begin{array}{c}\text { Std. } \\
\text { Deviation }\end{array}$ \\
\hline Q1.43 & 131 & 2.50 & .758 \\
Q1.44 & 131 & 2.41 & .700 \\
Q1.45 & 131 & 2.28 & .715 \\
Q1.46 & 131 & 2.31 & .743 \\
Q1.47 & 131 & 2.19 & .692 \\
Q1.48 & 131 & 2.27 & .785 \\
Valid N & 131 & & \\
(listwise) & & & \\
\hline
\end{tabular}

Overall, the descriptive statistics suggest there is little difference in perceptions of organizational impact, which also suggests that the results would not identify many differences in the ANOVA analysis or K-Means cluster analysis.

\subsubsection{K-Means Cluster Analysis}

K-Means cluster analysis is a type of data classification carried out by separating the data collected into groups. The purpose of this analysis was to determine if there were any demographic trends (e.g. years of experience, modules used, or seniority in the organization) that might explain differences in scores on the survey items. The aim of cluster analysis is to 
categorize $n$ objects in $k(k>1)$ groups, called clusters, by using $p(p>0)$ variables. Subsequently, there are two main sub categories of clustering procedures. The procedure to be undertaken with this study is that the numbers of clusters are pre-defined; this is known as the K-Means Clustering method (Field, 2005). The results of the cluster analysis are included in appendix viii.

In order to determine whether there are any demographic or organization factors that have an influence on attitudes towards SAP within the case organization the data demographic data and the cluster memberships were compared. Individuals in cluster 2 generally had higher scores on all attributes than cluster those in 1 or cluster 3 . However, there were no identifiable demographic or organizational factors in common between the cluster members. regardless of demographics such as what module is used, task use, years use of the SAP system or whether they are in an executive or user position, the perceptions of the system are similar, with general agreement.

\subsubsection{ANOVA Analysis}

An ANOVA analysis was undertaken to see if any of the demographic factors collected could explain the high standard deviations on some items, particularly those relating to the usability of the system. For example, it might be possible that less experienced users had lower scores on the usability-related questions than more experienced users, or that some modules were less usable than others. A one-way between groups ANOVA was conducted using a range of demographic factors (e.g. years of experience, purpose for using the system) to see of there were any significant differences between groups with regard to their perceptions of the usability of the system. See appendix xi for results.

Conducting the ANOVA tests on the usability items based on the demographic characteristics found that the differences could not be explained by the demographic factors measured. There were no significant differences based on any of our demographic questions. This means that the research was unable to, based on our study, to offer any empirical explanation for the variability in perceptions of SAP usability. Overall, it appeared to make little difference to what SAP module is used, what daily tasks are done through SAP, how many years' experience respondents had with SAP, how many organizational levels are between the user and the CEO and also whether SAP was used from a reporting or data entry perspective. 


\subsubsection{Discussion}

"User-based" measures in this study include our survey data. While respondents were reporting on their perceptions of (for example) system quality or organization impact, since they are selfreported perceptual measures they cannot be assumed to be accurate or objective. In our previous study the researcher examined the equivalence of two sets of measures of system quality. The researcher returns to the quantitative data in this study to examine whether analysis of the descriptive statistics provides any insights about the quality and value management of SAP in the case organization. The questions are based on ISO 9126 and IS-Impact measures, with some additional measures that were added based on previous qualitative research in the case organization.

The descriptive statistics overall did not provide a great deal of insight. The average scores on most items were neither particularly high nor particularly low, most were a little above the halfway point. The standard deviations likewise were not very large, with the exception of the questions relating to the usability of the system.

This suggests that perceptions of SAP were generally homogeneous within the organization, where participants are generally moderately satisfied with SAP on most dimensions. Also SAP was implemented in 1996 in the case organization, thus is in a very mature state, which indicates the system is stable and well embedded. This could explain the relatively lackluster scores and the high degree of consistency in the responses.

Where differences in opinion did exist between respondents (as evidenced by items with higher standard deviations) these could possibly explained by demographic factors which the researcher did not measure, or by personality differences between respondents, such as their level of optimism. A summary of the additional survey results is provided below in table 16.

Table 16: Summary of Additional Survey Results

\begin{tabular}{|l|l|l|l|}
\hline $\begin{array}{l}\text { Source of } \\
\text { evidence }\end{array}$ & $\begin{array}{l}\text { Quality management } \\
\text { perspective(s) }\end{array}$ & $\begin{array}{l}\text { Quality } \\
\text { "type" }\end{array}$ & Intended outcome \\
\hline $\begin{array}{l}\text { Descriptive } \\
\text { statistics }\end{array}$ & User-perspective & User-based & $\begin{array}{l}\text { System quality and } \\
\text { Organizational impact }\end{array}$ \\
\hline $\begin{array}{l}\text { K-means } \\
\text { Cluster } \\
\text { Analysis }\end{array}$ & User-perspective & User-based & System quality \\
\hline
\end{tabular}




\begin{tabular}{|l|l|l|l|}
\hline ANOVA & User-perspective & User-based & $\begin{array}{l}\text { System quality } \\
\text { (usability) }\end{array}$ \\
\hline
\end{tabular}

\subsection{Card Sorting to Establish Equivalence between Measures 4.5.1 Data Gathering and Analysis}

The comparison between the benchmarking data and IS-Impact card sorting data offers insights of whether the components of the IS Impact model's main constructs, system quality and organizational impact can be associated with SAP management practices. It seems intuitive that a range of quality and value management processes "ought" to be able to be related to a range of quality and impact perceptions about the same focal system. However, as it turned out, this was not particularly easy to do. Initially, despite being associated with the same system, the research felt the measures were incommensurate; it was almost impossible to ascertain which IS-Impact, or ISO 9126 item should be expected to "improve" as a result on improvements in management processes.

The researcher opted to attempt to establish equivalence at a higher level, focussing on the general themes of System Quality and Organizational Impact. Card sorting was used as an established method for knowledge elicitation, and has been widely used in various fields such as Psychology, Knowledge Engineering, Software Engineering and website design (Nurmuliani et al, 2004). This method of data collection was used as firstly, card sorting can be used to investigate respondents recall knowledge of the domain entity. Secondly, card sorting is a useful technique to distinguish between high and low level problems. Thirdly, it offers more insights into the target population's views of the topic. It can also provide an input for another technique and further analysis (Nurmuliani et al, 2004). While in general most researchers have suggested that the card-sorting method is an excellent approach to help develop classifications, it can also be used for existing classifications (Nurmuliani, 2004). The research wanted to understand if the SAP best practice metrics were perceived as being likely to lead to the outcomes measured in the IS-Impact core constructs. The SAP best practice metrics used were solutions/IT portfolio management, strategy and business alignment, value management, business improvement; business continuity and total cost of ownership and lastly, IT governance. The IS-Impact constructs that were to be used for the card sorting were organizational impact and system quality. In order for the results to be consistent and have a high level of validity and rigor, the 
procedure to conduct the card-sorting exercise was executed following steps by Nurmuliani et al (2004).

The researcher coordinated the card sorting activity, which consisted gathering a group of ten SAP experts from the SAP support team. The organization recommended the activity to be conducted by participants who have a vast knowledge of SAP, with the general years of experience of the team exceeding ten years. The participants are listed below:

\author{
11. SAP Functional Consultant - Finance \\ 12. SAP Functional Consultant - HR \\ 13. SAP Functional Consultant - Payroll \\ 14. SAP Functional Consultant - Logistics \\ 15. SAP Functional Consultant - SRM \\ 16. SAP Functional Consultant - Developer/ABAP \\ 17. SAP Functional Consultant - Security \\ 18. SAP Functional Consultant - Basis \\ 19. SAP Functional Consultant - Basis \\ 20. SAP Application Support Manager
}

. The card sorting procedure followed the below five steps:

1. At the start of the exercise, a brief explanation of the sorting exercise and verbal instructions were given to participants. But also the main purpose of the card-sorting activity and how it related to the previous study conducted.

2. The participants were given the cards, which were the best practice items and the “outcomes", system quality and organizational impact. The participants were given time to read through all the cards to familiarise themselves with the content of the cards.

3. The participants were instructed to sort the cards into the two groups, but also a group 'not applicable'. The cards were placed on the table and arranged into groups.

4. After the sorting was completed, the participants chosen criteria and categories were then recorded in a excel spreadsheet.

5. At the end of the sorting exercise, the participants provided feedback and provided further clarification of the classifications chosen which was recorded and then transcribed. 
Once the data had been collected and recorded within an excel spread-sheet, the data from the study was analysed in terms of the number of times a practice was associated with an outcome by the participants. The full results of the card sorting exercise can be viewed under appendix $x$.

\subsubsection{Results}

\subsubsection{Solutions/IT Portfolio Management Processes}

Solutions/IT Portfolio Management refers to the application of systematic management to large classes of items managed by enterprise information technology capabilities (SAP, 2013). The results are as followed, eight out of twelve items from the SAP benchmarking were identified to be linked or have a correlation to system quality from the IS Impact model. The below results in table 17 present what participants in the card sorting related the benchmarking best practices to the IS Impact model.

There were notably four items that were unable to be identified as either system quality or organizational impact through the card sorting exercise. These items had a component of strategy, infrastructure, incentives for adoption and portfolio management. While eight items were clearly distinguished between the two IS Impact construct. The common construct that related best to the Solutions/IT Portfolio Management best practice benchmarking measure was system quality.

Note: The results in the below table indicate the number of respondents selecting this outcome or theme.

\section{Table 17: Solutions/IT Portfolio Management}

$\begin{array}{lll}\text { \# } & \text { Construct } & \text { Result } \\ 1 & \text { The company has a consolidated single solution/ platform landscape } & \text { Unclear } \\ 2 & \begin{array}{l}\text { The company has a strategy in place for a single solution/ platform landscape } \\ \text { consolidation }\end{array} & \text { Unclear } \\ & \begin{array}{l}\text { The company has a strategy for the application of support and enhancement } \\ \text { packs }\end{array} & \text { SQ-9 } \\ 4 & \text { The strategy for the application of support and enhancement packs is enforced } & \text { SQ-8 } \\ 5 & \text { The company has a no - modification strategy } & \text { SQ-8 }\end{array}$


6 The company enforces the no - modification strategy $\quad$ SQ-8

7 The business units have incentives aligned with the adoption of a standard, common solution The company has a master data strategy to drive common definitions and standards Master data strategy is already implemented or is in the process of implementing

The company always evaluates licensed SAP solution for meeting business requirements before looking at niche products The company has a strategy to maximize the value of integration for the SAP solutions The company evaluates vendor viability and business strategy as part of the IT portfolio management

The benchmarking data scaled how the case organization compared to industry peers. The scaling of company coverage is scaled from 1 to 5 , with 1 being no coverage and 5 being full coverage. Company importance is scaled from 1 to 5 , with 1 being not important, and 5 being highly important. The data outlined the case organization presented excessive applications across the IT landscape with a company coverage of 1 and company importance being 2 . There was limited strategy in place for the use of a single solution with company coverage and importance at 2. Vendor applications are heavily customised with limited no-modification strategy; this had a company coverage and importance of 1 . The organization had a limited strategy in place to maximise the value of integration for the vendor or legacy IT solutions, with a company coverage and importance of 1 .

The case organization had a high number of critical interfaces from SAP to other applications to support the above data. The benchmarking data found applications per billion dollars in revenue for the case organization to be 97.6, which was listed as below average. The peer group average was listed at 18.1 and the top $25 \%$ organizations run at a value of 4.6 . There appears to be a presence of duplication of applications within the organization with a limited formulised single solution strategy. 


\subsubsection{Strategy and Business Alignment}

Strategy and Business Alignment refers to the dynamic state in which a business organization is able to use information technology (IT) effectively to achieve business objectives, generally improved financial performance or marketplace competitiveness (SAP, 2013).

Eight of the ten items were identified as being likely to lead to organizational impact. The two items that were unable to be distinguished as leading to either system quality or organizational management were items that related to IT business planning and IT responsibility. Note that this does not mean these practices do not contribute to these outcomes. They may well contribute to varying degrees to both outcomes. It simply means the researcher was unable to establish a basis on which to compare the measures.

\section{Table 18: Strategy and Business Alignment}

\# Construct

Result

1 The company is using IT to enable strategic and competitive advantages

OI-10

The company has established common, simple and streamlined IT and business

2 process standards across the organization

OI-8

The company has defined IT roles and responsibilities which are consistently applied across the organization

OI-9

The company undergoes a formal budgeting and planning process to approve initiatives and drive business value

The company undergoes a formal annual portfolio rationalization process to reduce operating expense

The company has a strategic IT roadmap or rolling 3-5 year plan based on

6 business and IT strategy

Regular IT and business planning meetings are conducted, with a joint planning

7 methodology in place

IT is included in the prioritization process early on so that an appropriate roadmap can be developed

OI-8

OI-7

10

IT facilitates a high degree of integration with the company's ecosystem

Unclear

\subsubsection{Value Management}

Value management refers to the proven approach to deliver value through three stages, which is the discovery phase which encompasses benchmark performance, clarify initiatives with defined 
success metrics communicated through a robust business case and ensure that executives are accountable for outcomes. Secondly, realisation phase which encompasses drive project prioritisation based on value throughout the implementation, design processes for value and build management visibility into the project design. Lastly, the final stage is the optimisation phase which includes institutionalize VM capabilities across the portfolio, foster performance based thinking; making success visible and to enable management visibility and discipline (SAP, 2013). There were six best practice constructs relating to value management, the card sorting exercise showed, unsurprisingly, that five constructs were perceived as leading towards the organizational impact theme from IS Impact, rather than the system quality theme.

Table 19: Value Management

Result

1

IT business case incorporates financial outcomes into the annual operating plan/ budget

OI-10

2

IT operating metrics for initiatives are linked to financial measures, including incentive plans

3

IT implementation program includes regular business case reviews as a part of governance

$4 \quad$ IT tracks value realized from SAP implementations

IT continue to optimize the value from the SAP solutions on a regular basis after being fully operational

The business understands the full lifecycle costs and benefits of our existing and planned SAP solution/s

\subsubsection{Business Improvement}

Business improvement refers to the systematic approach to assist an organization optimise its underlying processes to achieve more efficient results (SAP, 2013).

The Business improvement construct received mixed responses from participants with two out of the three items being related to the system quality construct and the third being aligned more closely to organizational impact.

\section{Table 20: Business Improvement}


A standardized end-to-end test management process exists for both new

1 developments as well as for maintenance of the productive solution, including the SQ-7 corresponding approval procedures

Business critical processes are technically analyse end to end, including

2 interfaces, with focus on performance, technical correctness, transactional correctness, and data consistency Business key performance indicators are defined to measure the success of the business process execution and to detect deviations of the business process flow

OI-9

\subsubsection{Business Continuity and Total Cost of Ownership}

Business continuity firstly refers to the efforts to minimize business downtime of SAP systems. The business will require reliability of the SAP environment and its data. To safeguard the continuation of the organization, even when a single serious unexpected event happens and key processes and resources become inaccessible. The organization needs a visible business continuity plan that extends to all organizational mission critical functions (SAP, 2013). Total cost of ownership refers to the total of direct capital investment in hardware and software including indirect costs of installation, training, repairs, downtime, technical support, upgrades and enhancements (SAP, 2013).

Unsurprisingly, all five processes from the SAP benchmarking best practices, were aligned to the IS Impact theme of system quality.

\section{Table 21: Business Continuity and Total Cost of Ownership}

$\#$

\section{Construct}

There is a defined process to conduct end-to-end root cause analysis across the

1 software components using the "SAP Solution Manager Diagnostics" functionality

Result SQ-10 Automated procedures for monitoring the infrastructure (including, hardware, SQ-10 network, systems, operating system) are in place Automated monitoring and error handling procedures for mission critical SQ-10 business processes and interfaces are in place There are defined procedures to ensure data integrity across SAP and non-SAP SQ-9 components A defined strategy exists to control database growth as well as an archiving SQ-10 concept 


\subsubsection{IT Governance}

IT governance refers to executive management's ability to direct, evaluate and measure the use of an enterprise IT resource in support of the achievement of the organizations strategic ambition. Leadership, organizational structure and processes are used to leverage IT resources to produce the information required and drive the alignment, delivery of value, management of risk optimised use of resources, sustainability and the management of performance (SAP, 2013). From the six main benchmarking best practice processes, IT governance revealed to be difficult to relate clearly too any specific outcome. This may be because governance is aimed at managing the relationship between the technical management of the system and its business outcomes, and therefore governance processes will potentially lead to multiple benefits in more than one area. Only two of the processes could be related to the organizational impact IS Impact construct.

\section{Table 22: IT Governance}

\# Construct

Company's IT decisions are strategically aligned with the business needs

1

2

4

5

Company's 3-5 year future growth trend is kept in mind for deciding investment level and setting priority

The Company's IT performance management is linked with the business outcomes

The Company's IT Architecture is an integral part of top management's business planning

Company has a strategy to upgrade IT Infrastructure in an incremental manner

\author{
Result \\ OI-10 \\ OI-10 \\ Unclear \\ Unclear \\ Unclear
}

\subsubsection{Discussion}

It was relatively difficult to establish equivalence between the various processes included in the SAP benchmarking, and the user perceptions captured in the IS-Impact survey. This proved impossible at a detailed level (comparing specific processes with specific items evaluated in the survey). At a higher level, the majority of processes were seen as contributing clearly towards either system quality or organizational impacts. This supports our research framework that separates technical (system) management processes and business (value) management processes. 
System management may be necessary but not sufficient to create organizational value and impact.

Items that closely linked IT governance and organizational impact were; the company's IT decisions are strategically aligned with the business needs and the company's 3-5 year future growth trend is kept in mind for deciding investment level and setting priority. This relates well with the definition of organization as 'the impacts of the IS at the organizational level; namely improved organizational results and capabilities (Gable et al, 2008).

Value management processes that were perceived as leading to organizational impact were; IT business case incorporates financial outcomes into the annual operating plan. IT operating metrics for initiatives are linked to financial measures, including incentive plans. IT implementation program includes regular business case reviews as a part of governance. IT tracks value realised from SAP implementations. Lastly, the business understands the full lifecycle costs and benefits of our existing and planned SAP solutions. However the metric, IT continue to optimise the value from the SAP solution on a regular basis after being fully operational was undecided between participants during the card sorting exercise.

The SAP benchmark best practice item of business improvement was linked to both organizational impact and system quality. The items which were perceived to be closely related to system quality were; a standardised end to end test management process exists for both new developments as well as for maintenance of the productive solution, including the corresponding approval procedures. And business critical processes are technically analysed end to end, including interfaces, with focus on performance, technical correctness, transactional correctness, and data consistency. The following metric, business key performance indicators are defined to measure the success of the business process execution and to detect deviations of the business process flow, was perceived to be more correlated well to the IS Impact organizational impact construct.

IT strategy and business alignment was perceived as being related to organizational impact. Participants as relating well to the organizational impact construct identified the following metrics. These items were; the company is using IT to enable strategic and competitive advantages, the company has established common, simple and streamlined IT and business process standards across the organization; the company has defined IT roles and responsibilities 
which are consistently applied across the organization; the company undergoes a formal budgeting and planning process to approve initiatives and drive business value; the company undergoes a formal annual portfolio rationalization process to reduce operating expense; the company has a strategic IT roadmap or rolling 3-5 year plan based on business and IT strategy; IT is included in the prioritization process early on so that an appropriate roadmap can be developed; IT facilitates a high degree of integration with the company's ecosystem. However, the following metrics were unclear from the perceptions of the participants. These items were; regular IT and business planning meetings are conducted, with a joint planning methodology in place; business has embraced IT as their responsibility.

However, three SAPS benchmarking best practice metrics were unable to be defined by either organizational impact or system quality. These items were, the company's IT performance management is linked with the business outcomes. The company's IT architecture is an integral part of top managements business planning and lastly, company has a strategy to upgrade IT infrastructure in an incremental manner.

Business continuity following metrics was heavily perceived to be related to system quality. These items were; there is a defined process to conduct end-to-end root cause analysis across the software components using the "SAP Solution Manager Diagnostics" functionality; automated procedures for monitoring the infrastructure (including, hardware, network, systems, operating system) are in place; automated monitoring and error handling procedures for mission critical business processes and interfaces are in place; there are defined procedures to ensure data integrity across SAP and non-SAP components; a defined strategy exists to control database growth as well as an archiving concept.

Lastly, solutions/IT portfolio management was perceived to be related to system quality. These items were; the company has a strategy for the application of support and enhancement packs; the strategy for the application of support and enhancement packs is enforced; The company has a no - modification strategy; the company has a master data strategy to drive common definitions and standards; master data strategy is already implemented or is in the process of implementing; the company always evaluates licensed SAP solution for meeting business requirements before looking at niche products; the company has a strategy to maximize the value of integration for the SAP solutions. 
However, the following items were unclear through the card sorting exercise; the company has a consolidated single solution/ platform landscape, the company has a strategy in place for a single solution/ platform landscape consolidation; the business units have incentives aligned with the adoption of a standard, common solution; the company evaluates vendor viability and business strategy as part of the IT portfolio management.

Comparing results from the benchmarking exercise and the surveys, there are two broad observations that can be made based on the card sorting. First, how relatively difficult it is to establish any basis for comparison between measures that were not designed to complement one another - even when they are for the same system in the same organization. At an item-by-item level the formative items that purported to measure system quality, from the IS-Impact and ISO 9126 models, could not be directly related to any processes for technical system management or value management included in the benchmarking. This affords several explanations - either that the relationships are complicated, and one process may lead to several outcomes, or one outcome may be the result of several processes, or that there are gaps in either or both sets of measures. However, this has a number of important implications: if the IS-Impact or ISO survey identified areas of weakness, it might be difficult to know which processes to use in order to correct the problem.

Second, the organization's performance on a range of system and value management processes appears to be a relatively poor predictor of user perceptions and satisfaction. Very broadly, user perceptions on most system quality, organizational impact, and ISO dimensions, with the exception of those relating to system usability, were average or slightly above average, while the organization's performance on most bench-marked processes was poor. It seems that (relatively) satisfied users are not necessarily a good indicator that the system is being well managed, nor will poor management processes necessarily result in wide-spread dissatisfaction.

\subsection{Actual Outcomes versus Perceived Outcomes}

The results from this section outline the actual outcomes versus perceived outcomes, which is derived from the benchmarking summative measures versus the IS Impact data.

\section{Figure 20: Actual Business Satisfaction}




\section{Business Satisfaction Rating}

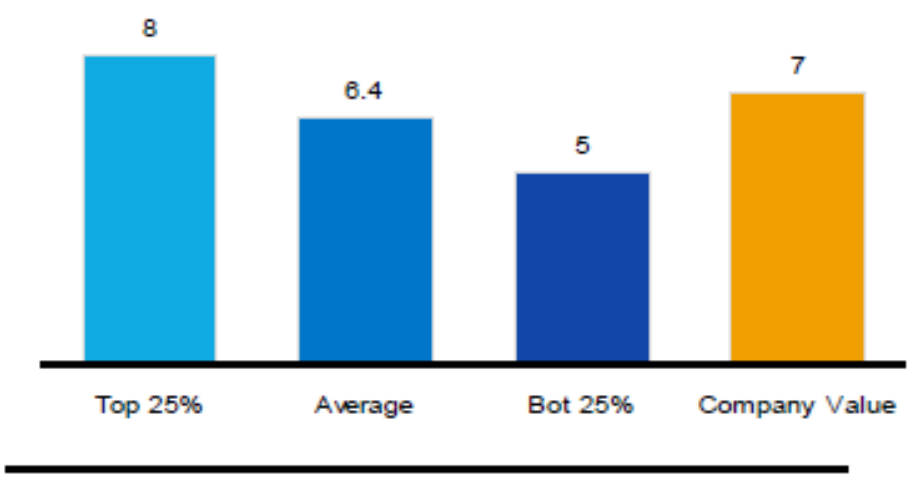

Key observations outlined that business satisfaction (figure 20) within the case organization was listed highly in the SAP benchmarking data. The peer group average for business satisfaction was 6.4; furthermore the top 24 per cent ranked with 8.0, the case organization in this instance was listed at 7.0. The business satisfaction can be highly validated by the responses from the IS Impact data. The system quality metric 'SAP is easy to learn' had a median Likert score of 2.8, where 'SAP is easy to learn' had a score of 2.7 that suggest that participants believe SAP is easy to learn and also to use. Getting information out of information was also agreed with a median score of 3.1 .

The IS Impact qualitative results also validated that business satisfaction of SAP, from multiple participants who have diversified roles within the organization. An HR business advisor stated "I think it is a user friendly system, easy to navigate and delivers results reasonably fast". A Corporate card specialist outlines 'It's a 'beauty with brains' tool. I find it really easy to use and very helpful. It's got everything you need but it's just a bit of a pain when it is down". A senior account manager comments 'Think it is very powerful and intuitive - I like that it actually works!". A graduate account states "It's very useful, quite easy to use and understand".

\section{Figure 21: Unplanned Downtime}




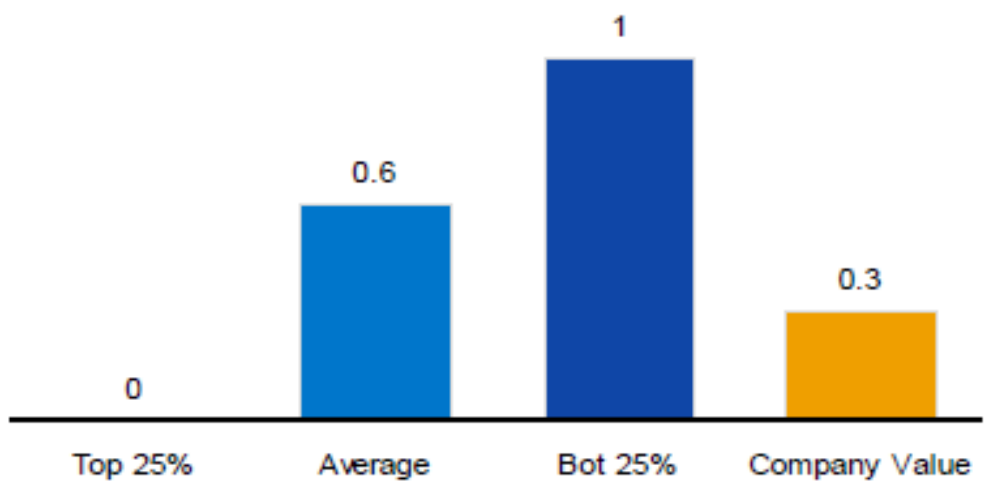

Further key findings relating to actual outcomes versus perceived outcomes demonstrated the stability of SAP within the case organization. Actual unplanned downtime as outlined by figure 21 indicates the peer group average for this summative metric was 0.6 , which accounts for 60 minutes of planned downtime; the top 25 per cent had 0.0 minutes of downtime. The case organization was in-between the peer group average and top 25 per cent group with only 0.3 (30 minutes) of unplanned downtime. This actual outcome of stability can be validated by the perceived outcomes from the IS Impact data. The measurement used for the availability of SAP from the IS Impact model asked the following 'The SAP system is available 100\% of the time'. The perceived median response for the reliability was 2.2 , which outlines users agree that SAP is reliable and available 100 per cent of the time. To further validate the actual outcome of unplanned downtime is the perceived qualitative responses. One senior manager notes, "It's adequate. The look and feel and user experience isn't great. It's not very intuitive compared to some other HR systems. But it's reliable and useable". Another senior manager states "[SAP] Good product and it's always there, I've had not reliability issues when using SAP which is a testament to stability of the product". Following this a senior systems specialists "I love it! I think SAP when used correctly can reduce, and streamline business and ensure an enterprise is fully automated and full connected in all areas of its working data, it's a product that never goes down".

Figure 22: Changes per 100 Active Users 


\section{Changes per 100 Active Users (last quarter)}

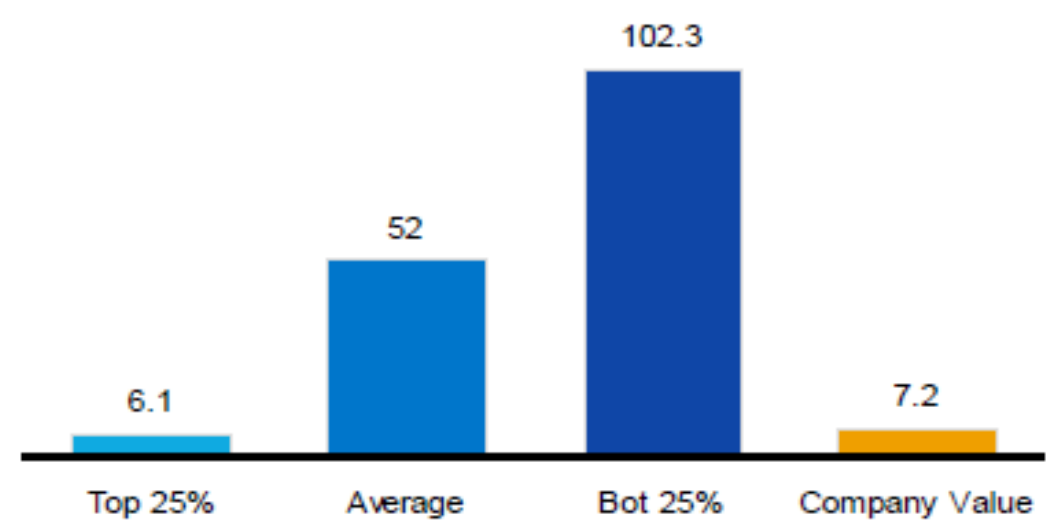

Lastly, changes to the SAP system from development and staging (test) into the production environment is reflected in figure 22. The summative results outline that changes per 100 actives users, the case organization exhibits 7.2, which is well below the average and near the top 25 per cent of the per group. The peer group average is 52 and bottom 25 per cent resulted 102.3 changes per 100 active users. The above result outlines that the SAP system can manage the correct amount of changes to its users. This can be validated by the responses from the IS Impact data. The metric 'SAP can be easily modified, corrected or improved.' Provided a median score of 2.7, suggests that the participants agree that the system can be easily modified by changes into SAP. It also suggests that the system can be easily modified.

\subsection{SAP Benchmarking (2012) and Hackett Benchmarking (2009)}

The Hackett benchmarking was conducted in 2009 that was employed by the case organization to determine how the organization peered against competitors; the Hackett group carried out this benchmarking programme. Although the metrics were not available from the case organizations the results were provided. The results of the Hackett benchmarking provided similarities to assist with explaining the previous results. The high level constructs outlined by Hackett were high cost per end user, high complexity, lack of business alignment and mixed degree of governance. The key findings are outlined below in table 23:

Table 23: Hackett Group Benchmarking Results (2009).

- Overall cost per end user is $77 \%$ to $140 \%$ higher than World-Class

- Very high investment in technology

- High process costs than Peers and World-Class in all process groups except End User Support and 
Enterprise Architecture Planning driven by high outsourcing costs.

- High infrastructure volumes supported

- High number of applications reported

- Application functionality is fragmented and there is a high degree of customization

- Lower levels of transaction automation and self-service capabilities provided

- $9 \%$ of stakeholder respondents view IT as a Valued Business Partner

- Low stakeholder scores on innovation, business communications, partnerships and customer orientation and organizational alignment

- Lower levels of standards definition and adherence for application development

- Low utilization of SLA's for internal clients, but pretty good for vendors and supplies

- Most projects go through a PMO gate process, but the quality of the process is questionable and there are lower levels of project delivery success for application projects

- CTO is not on the executive committee and only controls $60 \%$ of IT spend.

The SAP benchmarking presented similarities with the Hackett survey. The following similarities are outlined as; the organizational also experienced high cost per end user in comparison to other organizations benchmarked. The organization experienced a large IT spend as a percentage of revenue, experienced low revenue per employee; high complexity within their IT landscape with a high percentage of applications per billion in revenue, high infrastructure volumes supported; high number of master data files maintained; high total of interfaces per billion in revenue; large IT infrastructure internal full time equivalent cost; $50 \%$ of IT projects generate positive return on investment; business satisfaction perceived high; low perception of business unit collaboration; no presence of Centre's of Excellence and lastly, lack of alignment between business and IT.

The above results indicate the organization has not provided solutions to rectify the above problems since 2009, with the 2012 SAP benchmarking data providing indicators that the organization has yet to apply a sound strategy. The results also indicate the problems with quality are at an organizational level rather than at an end user level. 


\section{Chapter 5. DISCUSSION}

This chapter will discuss the overview of the findings, incorporating the multiple methods used but also aligning the findings with the Garvin (1984) quality model that was used as a fundamental model for this research. The researcher has also adopted Gable et al.'s (2008) IS Impact model in our study, more specifically the quality constructs, system quality and organizational impact. The model suggests that there are 15 attributes that determine the success of the system quality of SAP and also eight attributes that contribute to the organizational impact of SAP. Adopting several other measurement methods that include the practitioners standard of the ISO9126 interviews, archival analysis and benchmarking, furthers this. Following this research outlines the outcomes from the comparisons between the multiple methods. Lastly, the research will discuss the conceptual model that outlines the key components to measuring the success of SAP through multiple perspectives.

\subsection{Discussion}

An overview of findings via the multiple methods is outlined below in table 24. The IS Impact method demonstrated some key findings towards this research. It was firstly suitable for use when organizations are trying to gather an overall view of the value of the IS and management of the IS and suited for a mature implementation based on the metrics used.

Table 24: Overview of Findings

\begin{tabular}{|l|l|l|l|}
\hline Method & Key Insights & Suitable For & Comments \\
\hline IS-Impact & $\begin{array}{l}\text { End user perspectives } \\
\text { were content that SAP } \\
\text { was reliable, stable, } \\
\text { usable and cost } \\
\text { effective. }\end{array}$ & $\begin{array}{l}\text { Rank and file } \\
\text { respondents don't have } \\
\text { this information }\end{array}$ \\
$\begin{array}{l}\text { Management } \\
\text { The satisfaction levels } \\
\text { from end users may not } \\
\text { necessarily provide a } \\
\text { successful operational } \\
\text { outcome. }\end{array}$ & $\begin{array}{l}\text { Mature } \\
\text { Implementations }\end{array}$ & $\begin{array}{l}\text { Tend to be } \\
\text { homogenized/incorpor } \\
\text { ated into org } \\
\text { processes/no strongly } \\
\text { held positive or } \\
\text { negative views }\end{array}$ \\
\hline
\end{tabular}




\begin{tabular}{|c|c|c|c|}
\hline ISO 9126 & $\begin{array}{l}\text { Users perceived } \\
\text { functionality, } \\
\text { reliability, user ability, } \\
\text { efficiency, } \\
\text { maintainability and } \\
\text { portability constructs } \\
\text { satisfactory. }\end{array}$ & $\begin{array}{l}\text { Measuring system } \\
\text { quality from a end } \\
\text { user perspective. } \\
\text { Mature } \\
\text { implementation }\end{array}$ & $\begin{array}{l}\text { Objective data such as } \\
\text { downtime statistics, } \\
\text { SAP customised } \\
\text { changes were not } \\
\text { available to } \\
\text { respondents. No high } \\
\text { level detail of this. }\end{array}$ \\
\hline Interviews & $\begin{array}{l}\text { Ownership issues, } \\
\text { governance and lack of } \\
\text { communication } \\
\text { between business and } \\
\text { IT goals. }\end{array}$ & $\begin{array}{l}\text { Process, Satisfaction } \\
\text { of the IS, } \\
\text { Governance issues. } \\
\text { Underlying end user } \\
\text { issues }\end{array}$ & $\begin{array}{l}\text { Although users } \\
\text { expressed they were } \\
\text { happy with the current } \\
\text { quality of SAP. There } \\
\text { was a common theme } \\
\text { which resonated } \\
\text { through the interviews. } \\
\text { The issues were } \\
\text { largely associated with } \\
\text { the ownership, } \\
\text { traceability and } \\
\text { strategic direction of } \\
\text { SAP. }\end{array}$ \\
\hline $\begin{array}{l}\text { Archival } \\
\text { Analysis }\end{array}$ & $\begin{array}{l}\text { No identifiable } \\
\text { documents to manage } \\
\text { the TCO of the system } \\
\text { or reduced the cost per } \\
\text { user or any other } \\
\text { overall value } \\
\text { management metric }\end{array}$ & $\begin{array}{l}\text { Current state of IS, } \\
\text { operational metrics, } \\
\text { strategy. }\end{array}$ & $\begin{array}{l}\text { Archival analysis } \\
\text { supported the lack of } \\
\text { management } \\
\text { surrounding SAP. }\end{array}$ \\
\hline Benchmarking & $\begin{array}{l}\text { High cost per end user. } \\
\text { High complexity within } \\
\text { IT landscape. Large IT } \\
\text { infrastructure. High } \\
\text { number of master data } \\
\text { files }\end{array}$ & $\begin{array}{l}\text { Value } \\
\text { Management/TCO } \\
\text { Best run, process } \\
\text { health check }\end{array}$ & $\begin{array}{l}\text { Key insights included } \\
\text { system quality and } \\
\text { organizational impacts }\end{array}$ \\
\hline
\end{tabular}

Findings suggest that the IS-Impact model, in particular the system quality largely measures product quality, or perceptions of by end users. The metrics used from the IS Impact model incorporated system quality and organizational impact constructs.

The overarching themes established from the IS-Impact results outlined end user perspectives relating to system quality, believed SAP was very usable, stable, met user requirements, included the necessary features and functions, user interface could be easily adapted to ones personal approach, responded quickly, required only a minimum number of fields and screens to achieve a task, fully integrated and consistent and easily modifiable or improved. 
From an organizational impact construct perspective users were generally in support that SAP was cost effective, reduced staff costs, reduction in operational costs, leading to overall productivity improvements, improved outcomes or outputs, increased capacity to manage a growing volume of activity and lastly resulted in business processes.

While these perspectives were satisfactory, it still struggles to capture the reality of how SAP is performing within the organization as most participants were end users of the system and did not have a substantial weighting on the higher level information of the performance of SAP from an operational level, which was more available through the SAP benchmarking.

The ISO 9126 model informed what the current state of SAP was from a system quality perspective. This method measured the system quality of the IS, however is a practitioners standard. As with the IS-Impact model, the system quality construct was generally positively received by participants. Users were satisfied with the functionality. This is where the application was suitable, accurate, complied and had security provisioning in place. The reliability of SAP was highly agreed by participants, this was a result of the maturity, fault tolerance and SAP's ability to recover from any unplanned downtime.

User ability scored highly, with the characteristics of understandability, learnability, operability all being highly ranked items.

Efficiency such as resource utilization and system response time were satisfactory. Maintainability and the portability also were satisfactory by the end users, with users perceiving that the application was changeable yet could adapt to their business processes.

The Interview method conducted outline the current state of the IS within the organization. This method was highly informative when it comes to understanding processes, satisfaction levels, governance issues or underlying end user issues, but also gaining further insights at a executive or managerial level. The key findings found that the organization had several issues pertaining to ownership, governance and partnership between the IT division and business.

The Head of Finance further outlines the issues surrounding business ownership of SAP, "So I think the General Manager is or was officially, I'm not sure it might pass to the Group Controller, the business ownership has been a little bit ad hoc over the last couple of years because we aren't making any changes to it. There isn't a clear direction around it because we've been focused on the upgrade." This outlines the inconsistency with the communication and ownership surrounding SAP. 
The interview determined key themes in which ownership, process governance and the direction of SAP was misaligned. This was largely due to the lack of communication between IT goals and business goals as illustrated by the Head of Human Resources explains issues surrounding communication when driving initiatives, “Everyone's striving for different goals, so it's very hard to get that balance, it's just because the business is so fragmented. It also largely due to the miscommunication between the business goals from our level and the higher IT goals set out by the executive board".

Figure 23: Interview Key Findings

\section{Ownership}

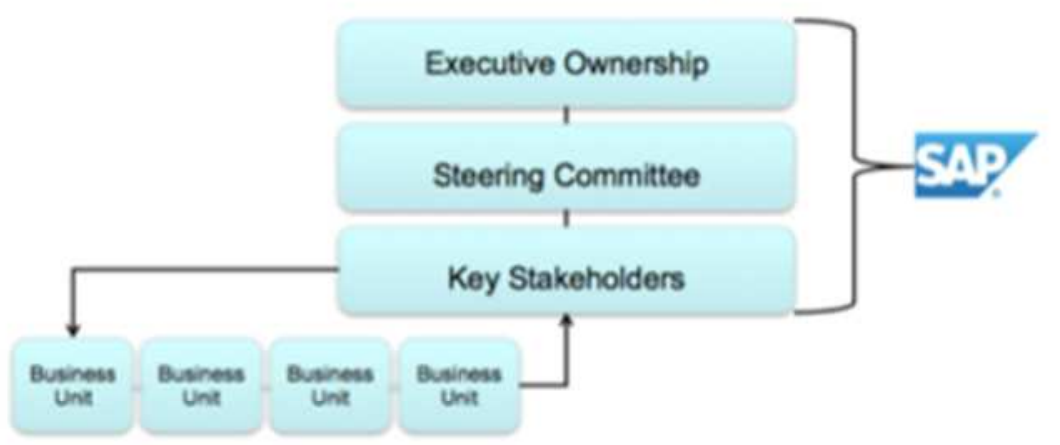

- Gather and Facilitate Key Business Leaders

- Conduct Monthly Steering Committee

- Strategic Enterprise Architecture

\section{Partnership}

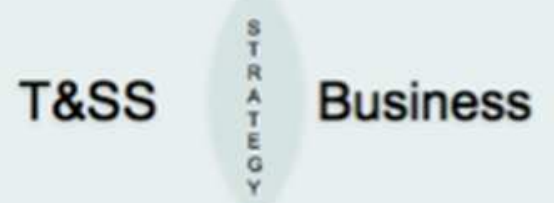

- Align business needs with T\&SS ability - Synergy

- Business Leaders working with Enterprise Architect

- Overall vision of 'where' and 'what' SAP can deliver 
Figure 23 outlines the importance of having key ownership and partnership models in place. It is critical for the organization to ensure key stakeholders are involved through the decision process, which will solidify the ownership model. The fundamental steps are to ensure the organization gathers and facilitates key business leaders; this includes each core module owner. Conduct monthly steering committee's and lastly, have a strategic enterprise architecture surrounding SAP.

The archival analysis outlined that there were no identifiable documents to manage the total cost of ownership of SAP or reduce the cost per user or any other overall value management metric. This is supported by the SAP value management best practice metric results also. This isn't overly surprising, based on the other objective measures deployed, they are consistent and demonstrate results that the organization had poor TCO and also less than satisfactory portfolio management of SAP, which has seen a lack of investment since their SAP package upgrade in 2010, which was forced purely by the vendor not being able to support an older version. Furthermore, this demonstrates that the organization seeks to take a rather reactive approach rather than having a sound SAP strategic roadmap in place with a proactive mind-set. Luftman \& McLean (2010) outline key enablers and inhibitors of IT. The inhibitors exhibit the conditions revealed through the results of the surveys and archival analysis.

The benchmarking method was used for measuring total cost of ownership and best-run processes. Both benchmarks demonstrate considerable findings relating to the current state of SAP within the case organization. In comparison to the IS-Impact and ISO 9126 surveys conducted, the SAP benchmarking provided more substantial and objective findings of the current state of SAP. It outlined key process-based findings, such as the management and service quality of SAP.

From a system quality perspective, the benchmarking outlined the case organization exhibited high complexity within their IT landscape with a high percentage of applications per billion in revenue. Secondly, there is a high number of master data files maintained. There are high infrastructure volumes supported, and also a high total of interfaces per billion in revenue from SAP to other legacy systems. There is also overall a high level of applications presently employed within the organization, which leads to a high cost per end user in comparison to other organizations. 
However in light of this, downtime of SAP was in-between the peer group average and top 25 per cent group with only 0.3 (30 minutes) of unplanned downtime. This actual outcome of stability can be validated by the perceived outcomes from the IS Impact and ISO 9126 data.

The results presented from the SAP best practices were sub metrics; solution/IT portfolio management; strategy and business alignment; value management; business improvement; business continuity and TCO and IT governance. These metrics all displayed a consistent message in their measurement power. The common theme from these best practice metrics outlined that the case organization had many deficiencies, despite the users being satisfied by the use and stability of the system. Several sources of data within the SAP best practice metrics illustrated the organization had excessive applications across the IT landscape, there appeared to be limited strategy in place to maximise the value of integration for SAP or legacy IT solutions, this can be further validated by the high number of critical interfaces from SAP to other IT applications, these exhibiting organizational impacts from the use of SAP.

Figure 24 displays the overview of the SAP benchmarking findings, and how it relates to the core organizational impact issues that were established in figure 23.

Figure 24: Overview of SAP Benchmarking 


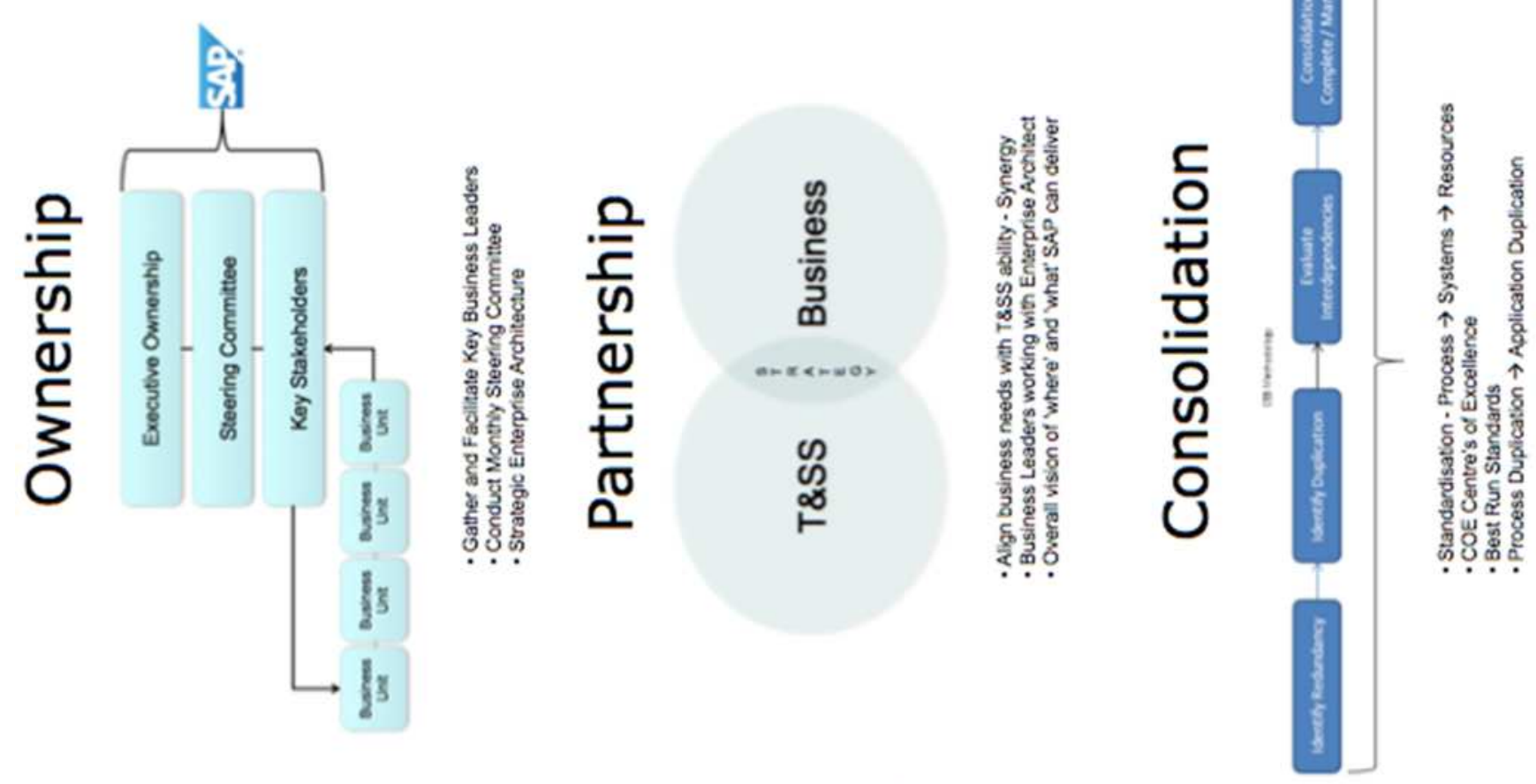

REALISATION

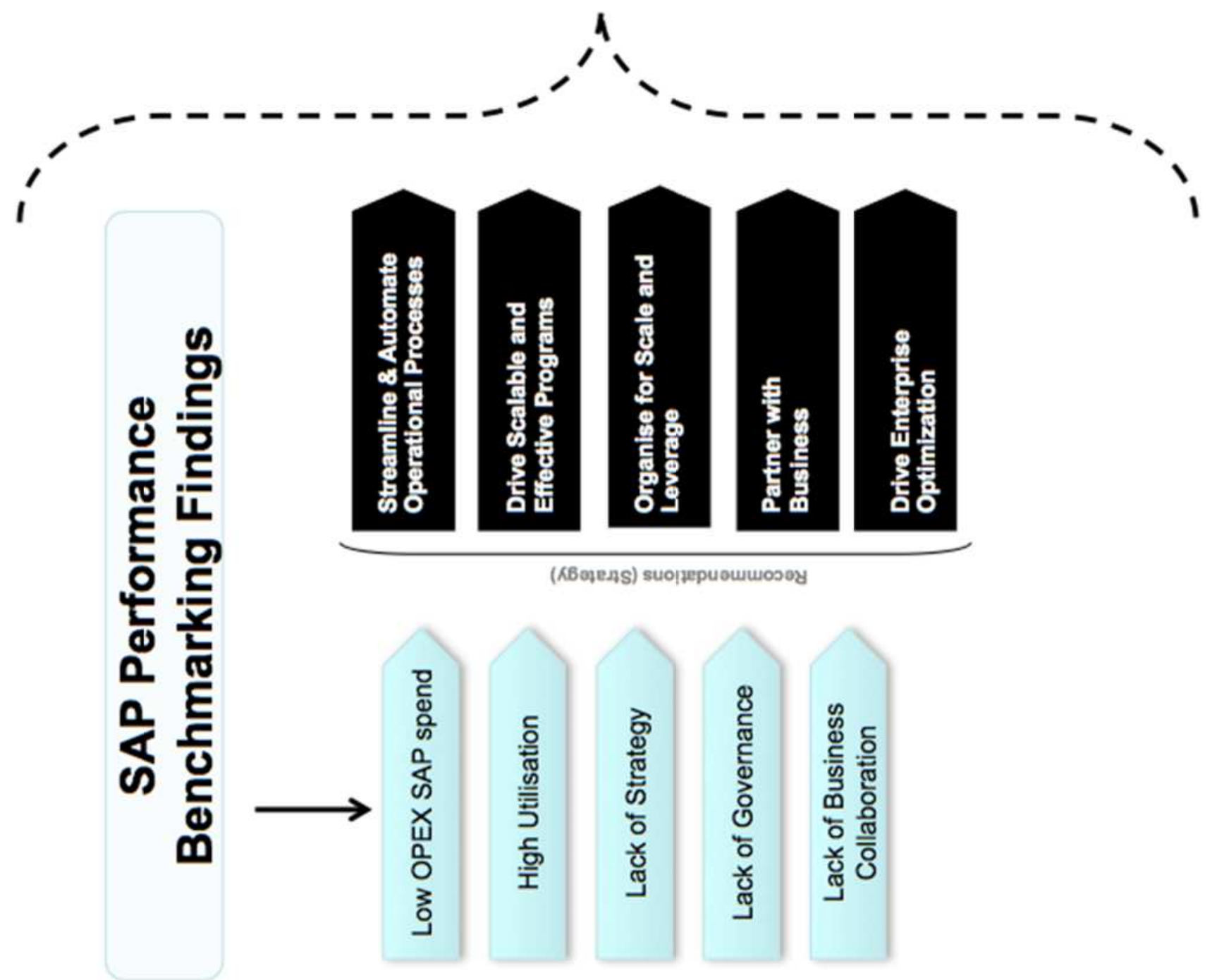


The most influential findings from the SAP benchmarking highlight the follow areas:

- Low operational expenditure spend on SAP, this is highlighted below in figure 25. The below figure outlines that in comparison to total IT spend across all applications, SAP's investment is considerably low.

Figure 25: SAP Spend vs. IT Spend

\section{IT Spend (\% of Revenue) vs. SAP Spend ( $\%$ of IT Spend)}

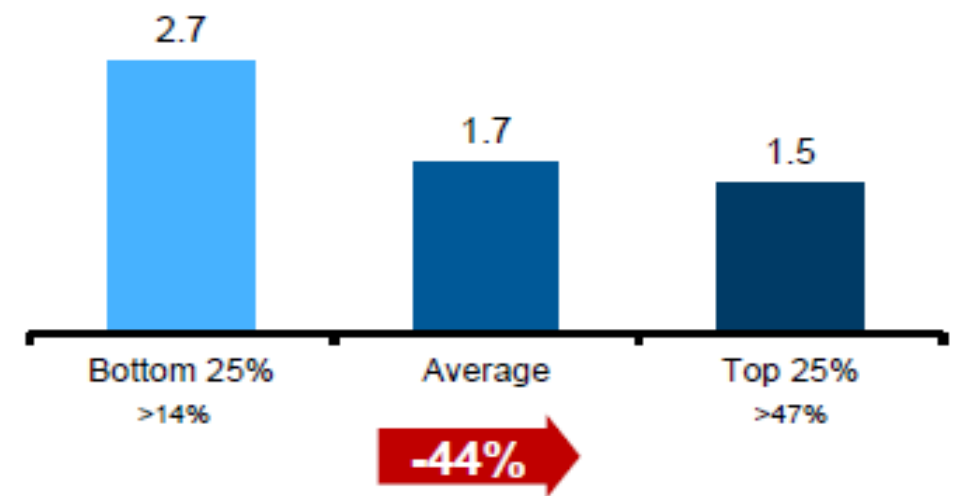

- High utilisation, heavy usage by the business

- Lack of IT strategy and more importantly lack of alignment between business strategy and IT strategy

- Lack of governance around SAP

- Lack of business collaboration for what is an enterprise wide system.

Overall the benchmarking acknowledges several recommendations to resolve the deficiencies through the use of SAP. The first recommendation is to streamline and automate operational processes. In order to achieve this, the organization needs to standardize IT technical operations and invest in automated change and release management programmes.

Secondly, the organization needs to drive scalable and effective programs. To achieve this, the organization must drive joint leadership between IT and business. They must measure solution re-use and standardization and lastly, formalise project portfolio management processes.

Thirdly, the organization must organise for scale and leverage. The organization must consolidate IT services and sourcing using centre of excellence. Rationalize and integrate IT 
suppliers to support future strategy. Deploy technologies for asset leverage and establish an integrated operational platform. Lastly, the organization must adopt a unified (development and application) platform. Following on from organising for scale and leverage, the organization must partner with the business. This includes aligning IT performance metrics to business impact metrics. Adopt value management disciplines and capabilities; and drive joint multi-year planning and prioritisation.

Lastly, the final recommendation is to drive enterprise optimisation. This will include standardising data at an enterprise level, standardising processes and applications. Lastly, drive IT investments to support enterprise scale. The realisation for these recommendations will ensure there is a rigorous governance and ownership model in place, alignment between business and IT and lastly, allow for IT consolidation with SAP being one of the core applications for growth.

The overarching issue of the quality and efficacy of measures used in IS research was the motivating factor for this research. The key Garvin (1984) dimensions of quality were influential and employed for this research. The user-based approach defines quality in terms of the subjective perceptions of individual users. The difficulty of this approach is that each individual may value particular quality characteristics differently. This approach relies on the ability to obtain and aggregate a wide spectrum of individual preferences into a meaningful overall definition of quality at a market level. This makes survey-style research particularly useful for this approach.

With the use of multiple methods for this research, the research was able to apply several survey methods. The methods deployed here for the user-based qualities included the ISImpact and ISO 9126 survey data. In order to have substantial results, descriptive statistics between the IS Impact/ISO 9126 survey results and benchmarking. Following this, an ANOVA analysis via one-way between groups was conducted, finalised by the use of the KMeans cluster analysis to determine if there were two or more distinctive groups amongst the user-based results. Table 25 provides a brief overview of the comparative findings. The comparison method was used to determine whether there was any equivalence in results between two methods.

Table 25: Comparative Findings 


\begin{tabular}{|c|c|c|c|}
\hline \multicolumn{2}{|c|}{ Comparison } & Result & Reasoning \\
\hline $\begin{array}{l}\text { User-Based } \\
\text { (Surveys) }\end{array}$ & $\begin{array}{l}\text { Value-Based } \\
\text { (Summative } \\
\text { measures from } \\
\text { survey and } \\
\text { bench- } \\
\text { marking) }\end{array}$ & $\begin{array}{l}\text { Little } \\
\text { Equivalence }\end{array}$ & $\begin{array}{l}\text { End users may not be a very good } \\
\text { measurement. Satisfaction of the IS } \\
\text { does not necessarily equate to value. } \\
\text { In fact, maximum value may require } \\
\text { some sacrifices in user satisfaction. } \\
\text { Also different stakeholders have } \\
\text { different perspectives. }\end{array}$ \\
\hline $\begin{array}{l}\text { System } \\
\text { Management - } \\
\text { Process Based } \\
\text { (Benchmarking, } \\
\text { interviews) }\end{array}$ & $\begin{array}{l}\text { (ISO } \\
\text { standards) }\end{array}$ & $\begin{array}{l}\text { Largely } \\
\text { Equivalent }\end{array}$ & $\begin{array}{l}\text { The organization appears to carry out } \\
\text { technical system management using } \\
\text { mature and rigorous processes. As a } \\
\text { result, the technical characteristics of } \\
\text { the system, as measured by the survey } \\
\text { based on ISO standards, were perceived } \\
\text { as being average or above average }\end{array}$ \\
\hline $\begin{array}{l}\text { Value } \\
\text { Management - } \\
\text { Process Based }\end{array}$ & $\begin{array}{l}\text { Value-Based } \\
\text { Summative } \\
\text { measures } \\
\text { bench-marking } \\
\text { Summative } \\
\text { measures from } \\
\text { the survey }\end{array}$ & Equivalent & $\begin{array}{l}\text { Lack of attention to value management } \\
\text { processes appears to have resulted in } \\
\text { relatively poor performance in } \\
\text { managing the overall value of the } \\
\text { system. } \\
\text { This was NOT diagnosed effectively by } \\
\text { the survey, which showed respondents } \\
\text { as being mostly happy with the impact } \\
\text { of the system. This could be a result of } \\
\text { the different organizational levels } \\
\text { involved in the benchmarking (mostly } \\
\text { more senior staff) and the survey (a } \\
\text { mixture of levels). }\end{array}$ \\
\hline Process & Outcome & Equivalent & $\begin{array}{l}\text { Process that the organization gave a lot } \\
\text { of attention to which resulted in good } \\
\text { outcomes. }\end{array}$ \\
\hline
\end{tabular}

Findings suggest that the IS-Impact model, in particular the "system quality" construct largely measures perceptions of "product quality" that is, the degree to which the system contains of exhibits various properties of characteristics. The research found both models to be equivalent in focus and explanatory power. A paper based on this previous study found the "system quality" construct in both models to be similar in its explanatory power for the organization (Ali et al., 2012). This suggests that users perceived SAP to be easy to use, learn and was easily accessible within the organization and whether only the IS-Impact was used or just the ISO 9126 metrics, the results would be similar. .

This was consistent throughout the descriptive statistics. There were limited differences between the measurement methods, with no significant differences. If there were to be any 
difference in perceptions of the system quality, both the IS Impact and ISO 9126 models did not capture this. The research found that there did not seem to be any significant differences in user perceptions of the quality of the SAP system based on any of the demographics captured. This result suggested that it made little difference to what SAP module is used, what daily tasks are done through SAP, how many years experience with SAP, how many organizational levels are between the user and the CEO and also whether SAP is used from a reporting or data entry perspective. It suggests perceptions of SAP were consistent and homogeneous throughout the organization, where participants are generally satisfied with SAP. .

This is further validated by the ANOVA and K-Means results, where no further significant differences were presented from both measurement models. The reasoning for the consistency could be explained by the current state of SAP within the case organization. SAP was implemented in 1996, almost 20 years, thus SAP is in a very mature state that indicates the system is stable as opposed to an organization that has had an implementation of only three years with some instability.

Another interesting finding is that users of the system are generally moderately satisfied with SAP despite the fact that the benchmarking exercise suggests that organizational management of SAP falls short of best practice in many areas. This could be explained by the fact that the benefits from "best practice" SAP management occur largely at an organizational or management level and may not benefit "rank and file" users. These users are therefore fairly satisfied despite (for example) high numbers of interfaces, high cost of ownership, and so on. It could also be explained by the fact that users may have limited experience in "best practice" organizations and therefore may not have a solid basis for comparison when evaluating the system.

The process-based or manufacturing approach can be summarised as "conformance to specifications" (Garvin, 1984). This is a 'supply-side' definition that does not concern itself with defining what desirable quality features are, but with ensuring that once defined the products or services that are produced reliably demonstrate those characteristics.

The methods employed here to gather sufficient validated data was the SAP benchmarking, archival analysis and card sorting between the IS-Impact constructs, system quality and organizational impact with the SAP best practices. 
The high number of applications could be a result of the organizations lack of defined business processes, such as the lack of having a SAP 'Centres of Excellence', which isn't surprising that this consistency of undefined processes also leads to poor end-to-end root cause analysis across applications.

The overarching issues identified from the multiple sources of data related to the SAP strategy and business alignment being unsatisfactory. This includes the organization having limited goals in place for portfolio rationalisation, alignment between IT performance management and IT architecture. This undocumented strategy has resulted in the organization only generating 50 per cent return on investment on IT projects or the lack of detailed business cases and financial ROI analysis are not completed for all major implementations

\subsection{Conceptual Model}

This final section will discuss the conceptual model outlined in figure 26; the model was presented earlier in the literature review (figure 11). However, the model has been extended to incorporate the 'IS Business Management Perspective' construct. Firstly the research will outline what each construct is measuring, and then following this the research will discuss the relationships between the constructs.

\section{Figure 26: Conceptual Model}




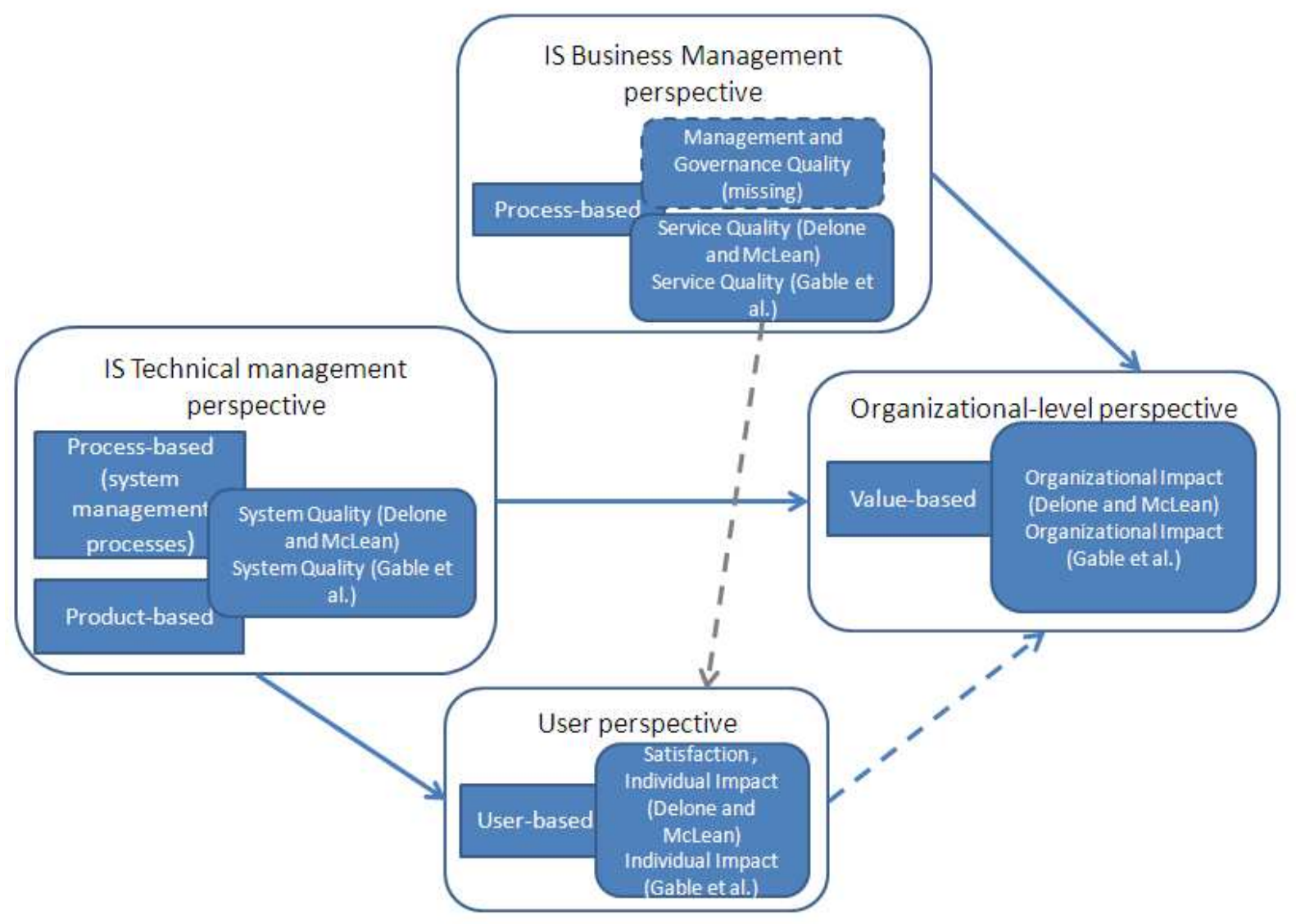

The model suggests the first construct as the 'IS Technical Management Perspective'. This construct measures both process and product-based perspectives on system management. This construct focuses on system qualities such as performance, features and durability, along with the process-based qualities that focus on achieving conformance and reliability. The key items being measured are system management and system quality. This construct is primarily concerned with the operation of the system and management processes related to the on-going stability.

The second construct is the 'User Perspective' construct. This construct is user-based, which focuses on aesthetics and perceived quality (Garvin, 1984). The measurement here is the individual impact from using SAP. The third construct is the 'IT Business Management Perspective' which is process based. This measures the management and governance qualities of SAP. The final construct is the 'Organizational-Level Perspective'. This construct is value-based, and is primarily only concerned with the organizational impact of SAP.

Based on our research, the suggestion that the first construct 'IS Technical Management Perspective' has a direct relationship with both the user perspective and organizational level 
perspective. As this construct is process-based and product-based it will have an impact on the user perspective, if the system is unstable and experiences substantial unplanned downtime, this would have a negative effect towards the user's satisfaction of the SAP system. The research found the system to be stable and well managed at a technical level, based on the archival analysis, and the user community's "above average" perceptions on most system quality indicators in the survey supports this.

Also, if the SAP system experiences technical issues, this will also have a negative effect at the organization-level, being value-based. By having on-going technical issues through unplanned downtime or continued customisation, this will result in more cost for the organization long term. Although the research did find evidence that SAP costs could be managed more effectively, there did not seem to be any evidence of cost issues arising from poor technical system management.

One of our most interesting findings is that 'User Perspective' has only a weak and an indirect relationship to the organizational level perspective. In particular, the research found that users were relatively happy with the system, despite below average performance in many benchmarked processes and outcomes. In fact, the reverse could be the case, if the organization was to deploy a new application for users to use to minimise TCO of it's IT landscape, the affect could be a decrease in operational costs, yet user satisfaction could be low, with users being less than satisfied with the new system, however the application produces the correct processes and output for the users to carry out their daily tasks (DeLone $\&$ McLean, 1992; Gable et al. 2002). The research suggests that organization-level "valuebased" quality does not arise automatically from satisfied users, and in fact, the two types of quality may sometimes be in conflict with one another.

The 'IS Business Management Perspective' has a direct relationship with the organizationallevel perspective and also an indirect relationship with the user perspective construct. As this construct is process based, service quality could have an affect on the end user, if the system is not performing to a level that is satisfactory the users will experience dissatisfaction. However as mentioned above, while users could be dissatisfied with the system, if it produces the correct outputs for their daily tasks then there may not be an affect at the organization level. The direct relationship demonstrates that both the management and governance quality and also service quality will have an impact on the organization-level. As 
exhibited through the results, if the organization experiences managerial and governance issues, this can result in a less than satisfactory total cost of ownership, which will ultimately prove costly for the organization.

This dimension seemed to be the "missing link" between the various quality management approaches in our case organization. The archival analysis showed plenty of evidence of attention to technical system management, but little attention to business value management. This was supported by the interview data in the previous study, which identified gaps in governance and strategy. SAP benchmarking findings also suggested a vacuum in this area. A lack of attention to business value management explains the poor performance on "value" metrics such as total cost of ownership. Overall, the system appeared to be stable and well managed at a technical level, which satisfied rank-and-file users, but lacking any commitment to value management at an upper organizational level. 


\section{Chapter 6. CONCLUSION}

This final chapter will conclude the research, outlining the overall motivation for this research with some of the most key findings. This will be followed by the research limitations and finalised by key recommendations and future research.

The method of using multiple data collection methods allowed for a rigorous view of how SAP operated from a quality perspective. The qualitative methods used such as the interviews and card sorting provided insights into how users perceived the system within the case organization. The generalisation is that SAP is a very robust and easily accessible application for users, but more importantly it completes the tasks as required and is not overly difficult to use or learn.

Comparatively the quantitative methods such as the SAP benchmarking, IS-Impact/ISO surveys demonstrated a less subjective view, in that SAP is lacking a rigorous strategy. The use of these multiple methods allowed the research to identify what quality metrics based on the various perspectives of Garvin's (1984) interpretation of quality is best used. The use of the SAP benchmarking and IS-Impact/ISO allowed demonstrating a slight degree of separation from the qualitative methods. These methods showed great consistency together, with similarities in measurement power, the benchmarking and IS-Impact/ISO data was heavily analysed with no large differences. This suggests the consistency and the quality metrics, but also establishes the core issues relating to the case organization.

Petter et al (2007) has encouraged further research to be continued based on the IS-Impact model of IS success. However, there is vast literature on IS success at both individual and organization levels, with empirical studies demonstrating minimal improvement over the past two decades. It's important to also consider the use of practitioner based metrics, such as SAP benchmarking. Although DeLone and McLean (2003) suggest an attempt should be made to reduce the number of different measures significantly in order for research results to be compared and findings to be validated (DeLone and McLean, 2003). It could be possible to find equilibrium of using both methods without reinventing the wheel. It also allows for practitioners to easily absorb these measures, where historically, measuring IS quality or system quality has predominantly used academic based models and literature. However, the 
benchmarking and ISO 9126 model demonstrates the measurement power shows limited difference from the IS-Impact.

Empirical evidence suggests that valid and reliable measures have yet to be developed and consistently applied for system quality (Petter et al, 2007). Rigorous success measurements are required, although the development of models such as the D\&M model and IS-Impact have been vast in literature, it is important to validate each construct in greater detail (Petter et al, 2007; Gable et al 2003; Ifinedo, 2006, Seddon et al, 2002; Rivard et al, 1984; Rivard et al, 1997). Thus embarking to further improve system quality constructs the use of qualitative and quantitative methods further validates the appropriate measures to use, but it also exhibits measures that are not relevant when measuring system quality.

Our study has a number of implications for reseachers engaged in measuring the quality and impact of ERP systems:

1. Surveys of end-user perceptions are not necessarily a good way to capture organization-level impacts. A small number of expert informants may provide a better representation.

2. User satisfaction "at the coal-face" is not necessarily a good predictor of organizational-level value and impact, in some cases; strategies that may improve the value to the organization (such as reducing the number of third-party, "best of breed" applications) may reduce user satisfaction.

3. Organizational performance is inherently comparative, and may be hard to capture in isolation in a single organizational study. A benchmarking approach may be preferred.

4. Establishing direct 1:1 equivalence between IS management processes (both at a technical system level and a business level) and the system and organizational outcomes arising from those processes is difficult. It may therefore be difficult to understand what processes to change if the outcomes are not as good as the organization expects. 


\subsection{Research Limitations}

While there are significant contributions from this research, there are also a number of limitations, as with any research. This section discusses the limitation of this study and explains how these limitations have been addressed.

Firstly, the data collection (IS-Impact, ISO and Benchmarking surveys, interviews, card sorting and archival analysis) in this study were constrained to one organization and one application. SAP and one of the largest telecommunication organizations in New Zealand. Evidently, the main limitation with this is that it imposes a limitation on the generalisability of the findings. However, due to the size of data collection and the small market in New Zealand of large organizations using a full suite of SAP, the case organization was seen as the best fit, but also allowed the researcher to collect large amounts of data from the site without compromising strict timelines for submission of this thesis.

With this limitation, generalisations are based on the New Zealand macro environment and telecommunications industry. The use of multiple organizations of similar size and diverse industries could allow for more generalisations.

Qualitative research is often criticised for its lack of objectiveness. Findings may rely on an unsystematic process to interpret the data that is categorised as significant and relevant. Although the interview data in a qualitative approach assisted with the purpose of this study, it has certain limitations. The data gathered could be rendered less than perfect by respondents as they provide answers that are socially acceptable. However, the researcher carried out appropriate validity checks to ensure credibility of responses to remove bias.

The interviews presented a limitation, where only one member from the executive space of the organization was conducted. This limits the number of perceptions and biases the importance of these perceptions that represent the company. Due to time and access constraints, this study would be unable to capture all of the perceptions of all the people associated with SAP in the company. The findings on this research are limited to the influential stakeholders within the organization. An extension to the study would seek an inclusion of the perceptions of those that have some influence on the business's strategic direction, such as the Chief Information Officer. Increasing the sample to a broader range of 
firms would aid the ability of these perceptions to be generalised further. However, the executive who was interviewed was the business owner of SAP, and made the holistic decisions of the operational side of the application.

The IS-Impact/ISO 9126 data was only analysed through 136 responses, if these responses were spread across other organizations that had SAP implemented, this would further validate generalisations. It is important to also note another limitation is that quantitative research, by virtue of its rigid structure, is not the most flexible method and, when handled improperly, is especially vulnerable to statistical error. There is also a risk of unintentional misuse of sampling and weighting that can completely undermine the accuracy, validity, and projectability of a quantitative research study.

The SAP benchmarking data was only peered against organizations within the telecommunications, banking and utilities industries. The inclusion of banking and the utilities sector was mandatory, as SAP New Zealand did not have enough data to make a rigorous comparison. Along with this, the researcher was limited with the peer grouping demographic information, as SAP New Zealand was unable to provide this data. Future research could look to include more countries but using the same industry to give a more detailed comparison when being peer grouped.

While our literature review was extensive related to this study, it is important to outline that it is possible that other potentially viable journals were overlooked. However, the researched does believe the leading papers relating to IS success and system quality has been captured. Also though a rigorous process of model development, data collection and validation was followed, there could be possible measurement errors that cannot be ruled out. Further research should validate the above model to determine a model of completeness at least for the system quality, but also organizational impact and organizational complexities and how these measures influence SAP success.

\subsection{Recommendations for Further Research}

Although some suggestions for further research have been discussed above along with the limitations, this section further outlines the number of recommendations for future work. 
1. Employ multiple method approach to multiple organizations; this would eliminate the limitation of generalizability.

2. Conduct a benchmarking programme and ensure the peer group across the industry is available.

3. Simplify metrics used; find equilibrium to combine academic quality metrics and also practitioner based. Although the IS Impact model measure very similar system quality metrics as the practitioner based model of the ISO 9126, the benchmarking provides more ability to provide a holistic model.

4. Include various ERP's such as SAP, Oracle and Microsoft; this would determine whether the models and metrics used in this research could be applied to alternative ERP's and not just SAP.

5. Carry out qualitative interviews with the executive board to get a more rigorous view of the strategic decisions surround the organization.

\subsection{Concluding Comments}

Research academics have created various models, such as the prominent models for success (DeLone \& McLean, 1992; Ballentine et al, 1996; Gable et al, 2008; Ifinedo, 2006), stressing the importance to solidify an appropriate model with consistent success metrics to better understand intangible and tangible benefits. The research questions proposed were:

What are quality measures based on the various perspectives of quality (Garvin, 1984) consistent and commensurate? How do the different approaches to quality measure complement each other? Are they consistent? What insights triangulating different quality measures can derive?

The overall goal of this exploratory study was to investigate measures used to determine if the various perspectives of quality are consistent and if the diverse approaches to quality measurement complement each other. By focusing on Garvin's (1984) quality dimensions, the research was able to also measure IS success by adopting a case organization using SAP a form of an Enterprise System and information system. This was conducted by using on of the largest telecommunication organizations in New Zealand. The research also found relationships between literature and stakeholders perceptions of the constructs derived from the IS-Impact model and how to measure the success of SAP. The objectives for this research 
was to further validate system quality measures used for ERP system success using the IS impact model also as the foundation and empirically investigating the measures of system quality and organizational impact. Another objective was to determine what stakeholders believed were the organizational impacts of ERP systems within their organization. The last object through the quantitative analysis was to compare which model offered completeness to measuring the system quality of SAP.

Further analysis of results provided that Luftman \& McLean's (2010) enablers and inhibitors of IT and business alignment still is relevant, as exhibited by this research.

Through extensive analysis the research identified additional measures that were respectively as important determining the success of SAP. This study not only revealed additional measures, this study responded to Barki’s (2008) 'Thar's Gold in Them Thar constructs' constructs reconceptualization. Establishing a clear and explicit definition was an important step for further validating constructs. In order for the IS discipline to move forward, it is important for IS researchers to further validate measures to identify the success of SAP. This research has assisted by ensuring the system quality has been rigorously tested, and if multiple methods show similarities through measurement power. This is a continued effort in order to provide benefit to the IS discipline but also to practitioners, closing the gap between rigor and relevance.

Garvin (1984) suggested the quality constructs are more than just theoretical niceties; they are the key to using quality as a competitive weapon. Organizations must learn to think critically about how their approach to quality changes as a product such as SAP, moves from design to market, and must devise ways to cultivate these multiple perspectives. Once these approaches have been adopted, cost savings, market share gains and profitability improvements can be expected, as such if quality is left stagnant the organization will be fighting for market position. 


\section{Chapter 7. REFERENCES}

- Ali, A., Tate, M., Rabaa'i, A., Zhang, M. (2012) A critical evaluation and comparison of two formative measures of system quality using criterion variables. In Australasian Conference on Information Systems (ACIS), 3 - 5 December 2012, Geelong, NSW.

- Au, N., Ngai, E. W. T., Cheng, T. C. E. (2008). Extending the understanding of end user information systems satisfaction formation: An equitable needs fulfilment model approach. MIS Quarterly. 32(1). 43-66.

- Babbie, E. (1997). The practice of Social Research, Eleventh Edition. Wadsworth Cengage Learning. Belmont, CA. USA.

- Ballantine, J., Bonner, M., Levy, M., Martin, A., Munro, I., \& Powell, L.P. (1996). The 3D model of information systems success: the search for the dependent variable continues. Information Resources Management Journal - Special issue: information systems success measurement. (9)(4). 5-14.

- Barki, H. (2008). Thar's Gold in Them Thar Constructs. MIS Quarterly. (39). 2. 9-20.

- Behkamal, B., Kahani, M., \& Akbari, M. K. (2009). Customizing ISO 9126 quality model for evaluation of B2B applications. Information and software technology, 51(3), 599-609.

- Benbasat, I., \& Barki, H. (2007). Quo vadis, TAM? Journal of the association for Information Systems. 8(4). 211-218.

- Benbasat, I., D. K. Goldstein, et al. (1987). "The case Research Strategy in Studies of Information Systems." MIS Quarterly. 11(3): 369 - 386.

- Chan, E. Y. (2000). IT value: The great divide between qualitative and quantitative and individual and organizational measures. Journal of Management Information Systems. 16(4). 225-261.

- Chang, J., \& King, R. W. (2000). The development of measures to assess the performance of the information systems function: a multiple-constituency approach. Proceeding ICIS 'OO Proceedings of the twenty first international conference on information Systems. 640646

- Chang, I. S., Gable, G., Smythe, E., Timbrell, G. (2000). A Delphi examination of public sector ERP implementation issues. Association for Information Systems. 494-500.

- Chua, W.F. (1986). Radical Developments in Accounting Thought. The Accounting Review. 61. 601-632. 
- Chua, B. B., \& Dyson, L. E. (2004). Applying the ISO 9126 model to the evaluation of an elearning system. In Proc. of ASCILITE (pp. 5-8).

- Cox, A. and Thompson, I. (1998). On the appropriateness of benchmarking. Journal of General Management, 23, 1-20.

- Creswell, J. W. (2003). Research Design: Qualitative, Quantitative, and Mixed Methods approaches. (2nd Ed.). Thousand Oaks, CA: Sage Publications.

- Curd, M., and Cover, J. A. (1998). Philosophy Of Science: The Central Issues. W.W. Norton \& Company, New York, New York.

- Daneva, M. (2001). Evaluating the Value-added Benefits of Using Requirements Reuse Metrics in ERP Projects. ACM SIGSOFT Software Engineering Notes. 26(3). 155-163.

- Dattakumar, R., \& Jagadeesh, R. (2003). A review of literature on benchmarking. Benchmarking: An International Journal. (10). 3.

- DeLone, W.H., \& McLean, E.R. (1992). Information systems success: The quest for the dependent variable. Information Systems Research. 3(1), 60-95.

- DeLone, W.H., McLean, E.R. (2003). The DeLone and McLean model of Information Systems success: A ten-year update. Journal of Management Information Systems. 19(4). 9-30.

- Edwards, J. R. (2010). The Fallacy of Formative Measurement. Organizational Research Methods. 14(2). 370-388

- Elisa, F. N., \& Lan, C. (2009). Validating the IS-Impact Model: Two Exploratory Case Studies in China and Malaysia. Pacific Asia Conference on Information Systems (PACIS). 1-12.

- Falconer, D. J., \& Mackay, D. R. (1999). The key to the mixed method dilemma. In Proceedings of the 10th Australasian Conference on Information Systems (pp. 1-3).

- Farbey, B., Land, F., \& Targett, D. (1999). Moving IS Evaluation Forward: Learning Themes and Research Issues. Journal of Strategic Information Systems. 8(2). 189-207.

- Field, A. (2005). Discovering Statistics Using SPSS. London, Sage.

- Frisk, E. (2008). Interpretative IT Evaluation in the Public Sector: Two Steps Forward and one Backwards. Proceedings of the $2^{\text {nd }}$ European Conference on Information Management and evaluation.

- Gable, G. G., Sedera, D., \& Chan, T. (2008). Re-conceptualising Information System success: The IS-Impact Measurement Model. Journal of the Association for Information Systems. 9(7). 377-408. 
- Gable, G., D. Sedera, and T. Chan. (2003) "Enterprise Systems Success: A Measurement Model." Proceedings of the 24th, International Conference on Information Systems. Seattle. Washington. 576-591.

- Gartner. (2010). Vendor Focus for SAP: SAP Value Management Services. Retrieved from http://global.sap.com/latinamerica/files/Gartner_Vendor_Focus_for_SAP_VM.pdf

- Gartner. (2012). IT Trends. Retrieved from http://www.gartner.com/technology/research/top-10-technology-trends/

- Garvin, D. A. (1984). What does product quality really mean? Sloan management review, 26(1).

- Gefen, D., D. Straub, et al. (2000). "Structural equation Modelling and Regression." Communications of the Association for Information of Information Systems. 4(7): 1-70.

- Gorla, N., Somers, M. T., \& Wong, B. (2010). Organizational Impact of System Quality, Information Quality, and Service Quality. Journal of Strategic Information Systems. 19. 207-228.

- Golafshani, N. (2003). Understanding Reliability and Validity in Qualitative Research. The Qualitative Report. (8) 4. 597-607.

- Hawking, P., \& Stein, A. (2004). Revisiting ERP Systems: Benefit Realisation. Proceedings of the 37th Hawaii International Conference on System Sciences.

- Heo, J., \& Han, I. (2001). Performance measure of information systems in evolving computing environments: an empirical investigation. Information \& Management. 4(40). 243-256.

- Guba, E. G., \& Lincoln, Y. S. (1989). Fourth generation evaluation. Newbury Park: Sage.

- Hitt, L. M., \& Brynjolfsson, E. (1996). Productivity, Business Profitability and Consumer Surplus: Three Different Measures of Information Technology Value. MIS Quarterly. $121-142$

- Hitt, L. M., Wu, D. J., \& Zhou, X. (2002). Investment in enterprise resource planning: Business impact and productivity measures. J. of Management Information Systems, 19(1), 71-98.

- Holm, A., \& Mattsson, S. (2008). A benchmarking model for maintenance and support assignments in an ERP environment. IT University of Goteborg. REPORT NO. 2008:080 ISSN: 1651-4769.

- Hong, K. H., \& Kim, Y.G. (2002). The critical success factors for ERP implementation: an organizational fit perspective. Information and Management. 25-40. 
- Huang, R., Zmud, R. W., \& Price, R. L. (2010). Influencing the effectiveness of IT governance practices through steering committees and communication policies. European Journal of Information Systems, 19(3), 288-302.

- Ifinedo, P. (2007). Interactions between organizational size, culture and structure and some IT factors in the context of ERP success assessment: An exploratory investigation. The Journal of Computer Information Systems. 47(4). 28-44.

- Ifinedo, P., Nazmun, N. (2009). Prioritization of enterprise resource planning (ERP) systems success measures: viewpoints of two organizational stakeholder groups. Proceedings of the 2006 ACM symposium on applied computing. 1554-1560.

- Ifinedo, P., Nazmun, N. (2006). Quality, Impact and Success of ERP Systems: A study involving some firms in the Nordic-Baltic Region. Journal of Information Technology Impact. 6(1). 19-46.

- Kaplan, R. S., \& Norton, D. P. (1992). The Balanced Scorecard - Measures That Drive Performance. Harvard Business Review. 70(1), 71-79

- Kitchenham, B., \& Pfleeger, L. S. (1996). Software Quality: The Elusive Target. Guest Editors Introduction: National Computing Centre. 12-21

- Kronbichler, A. S., Ostermann, H., \& Staudinger, R. (2010). A Comparison of ERPSuccess Measurement Approaches. Journal of Information Systems and Technology Management. 7(2). 281-310.

- Livari, J. (2002). An Empirical Test of the DeLone-McLean Model of Information System Success. ACM New York. 2(36). 8-27.

- Luftman, J., \& Ben-Zvi, T. (2010). Key issues for IT Executives 2010. MIS Quarterly. 9(1). 49-59.

- Markus, L. M., Axline, S., Petrie, D., \& Tanis, C. (2003). Learning from adopters' experiences with ERP: problems encountered and success achieved. Journal of Information Technology. 15. 245-265.

- Meliville, N., Kraemer, K., Gurbaxani, V. (2004). Review: information technology and organizational performance: An integrative model of IT business value. MIS Quarterly. 28(2). 283-322.

- Mishra, A. K., \& Mishra, K. E. (2012). 34 Positive Organizational Scholarship and Trust in Leaders. 
- Myers, B. L., Kappelman, L.A., \& Prybutok, V. R. (1997). A comprehensive model for assessing the quality and productivity of the information systems function: toward a theory for information systems assessment. IRM Journal. 10(1). 6-25

- Myers, M. D. and Newman, M. 2007. 'The Qualitative Interview in IS research: Examining the craft'. Information and Organization. 17(1). 2-26.

- Myers, B. L., Kappelman, L. A., \& Prybutok, V. R. (1997). A comprehensive model for assessing the quality and productivity of the information systems function: toward a theory for information systems assessment. Information Resources Management Journal (IRMJ), 10(1), 6-26.

- Myers, M. D. 2006. “Qualitative Research in Information Systems”. Retrieved April, 23, 2011 from http://www.qual.auckland.ac.nz/

- Myers, M. D. (1997). "Qualitative Research in Information Systems." MIS Quarterly 21(2): 241-242.

- Nurmuliani, D, Z., \& Williams, S. P. (2014). Using card sorting techniques to classify requirements change. Proceedings of the $12^{\text {th }}$ IEEE international requirements engineering conference.

- Robey, D., \& Newman, M. (1996). Sequential patterns in information systems development: an application of a social process model. ACM Transactions on Information Systems (TOIS), 14(1), 30-63.

- Orlikowski, W. J., \& Baroudi, J. J. (1991). Studying Information Technology in Organizations: Research Approaches and Assumptions. Information Systems Research. 2(1), 1-28.

- Padayachee, I., Kotze, P., \& Van Der Merwe, A. (2010). ISO9126 external systems quality characteristics, sub characteristics and domain specific criteria for evaluating eLearning systems. South African Institute for Computer Scientists and Information Technologists.

- Petter, D., Straub, D., \& Rai, A. (2007). Specifying formative constructs in Information Systems research. MIS Quarterly. (31)4. 623-656.

- Pinsonneault, A., \& Rivard, S. (1998). Information Technology and the Nature of Managerial Work: From the Productivity Paradox to the Icarus Paradox? MIS Quarterly. 22(3). 287-311.

- Punch, K. F. 2005. Introduction to Social Research Quantitative and Qualitative Approaches (2nd ed.). London: Sage. 
- Rao, M. (2005). Measuring the Success of Information Systems: Case Study of a University Student Services System. University of Texas. 408-418.

- Rabaai, A. A. (2009). Assessing Information Systems Success Models: Empirical Comparison (Research in Progress). Australian Conference on Information Systems. 447455.

- Rabaai, A. A., \& Gable, G. (2009). Extending the IS-Impact Model into the Higher Education Sector. Australian Conference on Information Systems. 1-13.

- Ravichandran, T., \& Rai, A. (1999). Total quality management in information systems development: key constructs and relationships. Journal of Management Information Systems, 16(3), 119-155.

- Rivard, S., Poirier, G., Raymond, L., and Bergeron, F. (1997). Development of a measure to assess the quality of user-developed applications. The DATA BASE for Advances in Information Systems. 28(3). 44-58.

- Rivard, S. and Huff, S.L. (1984). User Developed Applications: Evaluation of Success from the DP Department Perspective. MIS Quarterly. 8(1). 39-50.

- SAP. (2013). Value Management. Retrieved from https://valuemanagement.sap.com/

- Seddon, B. P., Graeser, V., \& Willcocks, P. L. (2002). Measuring Organizational IS Effectiveness: An Overview and Update of Senior Management Perspectives. The database for advances in information systems. 33(2).

- Seddon, B. P. (1997). A Respecification and Extension of the DeLone and McLean Model of IS Success. Institutes for operations research. 8(3).

- Sia, S. K., Soh, C., \& Weill, P. (2010). Global IT management: structuring for scale, responsiveness, and innovation. Communications of the ACM, 53(3), 59-64.

- Shannon, C., \& Weaver, W. (1949). The mathematical theory of communication. Univ. IIIinois Press, London.

- Shang, S., \& Seddon, P. B. (2002). Assessing and managing the benefits of enterprise systems: the business manager's perspective. Information Systems Journal. 12. 271-299.

- Sousa, R., \& Voss. C. A. (2001). Quality management revisited: a reflective review and agenda for future research. Journal of Operations Management. 91-109

- Strauss, A. \& Corbin, J. (1998). Basics of Qualitative Research Techniques and Procedures for Developing Grounded Theory (2nd Edition). London: Sage.

- Telecom New Zealand (2011, 2012 and 2013). Annual Report. Retrieved from http://investor.telecom.co.nz/phoenix.zhtml?c=91956\&p=irol-reportsAnnual 
- Tallon, P. P., Kraemer, K., \& Gurbaxani, V. (2000). Executives' perceptions of the business value of information technology: A process-orientated approach. Journal of Management Information Systems. 16(40. 145-173.

- Trochim, W. (2006). Research Methods, Knowledge Base. Retrieved April, 23, 2011 via http://www.socialresearchmethods.net/kb/intres.php

- Wang, T. G. E., \& Chen, H. F. J. (2005). Effects of Internal Support and Consultant quality on the consulting process and ERP system quality. Science Direct: Decision Support Systems. 42. 1029-1041.

- Weber, R. (2004). Editor's Comments: The Rhetoric of Positivism Versus Interpretivism: A Personal View. MIS Quarterly. (28) 1. 3-7.

- Yin, R. K. (1994). Case study research: Design and methods (2 ed.) Vol. 5. Thousand Oaks, CA: Sage Publications

- Zeiss, B., Vega, D., Schieferdecker, I., Neukirchen, H., \& Grabowski, J. (2007). Applying the ISO 9126 quality model to test specifications. Software Engineering, 231-242.

- Zhang, L., Lee, M.K.O., Zhang, Z., \& Chan, J. 2002. A framework for Enterprise Resource Planning Systems Implementation Success in China. In: Proceedings of Pacific-Asia Conference on Information Systems. 
$\underline{\text { Appendix }}$ 


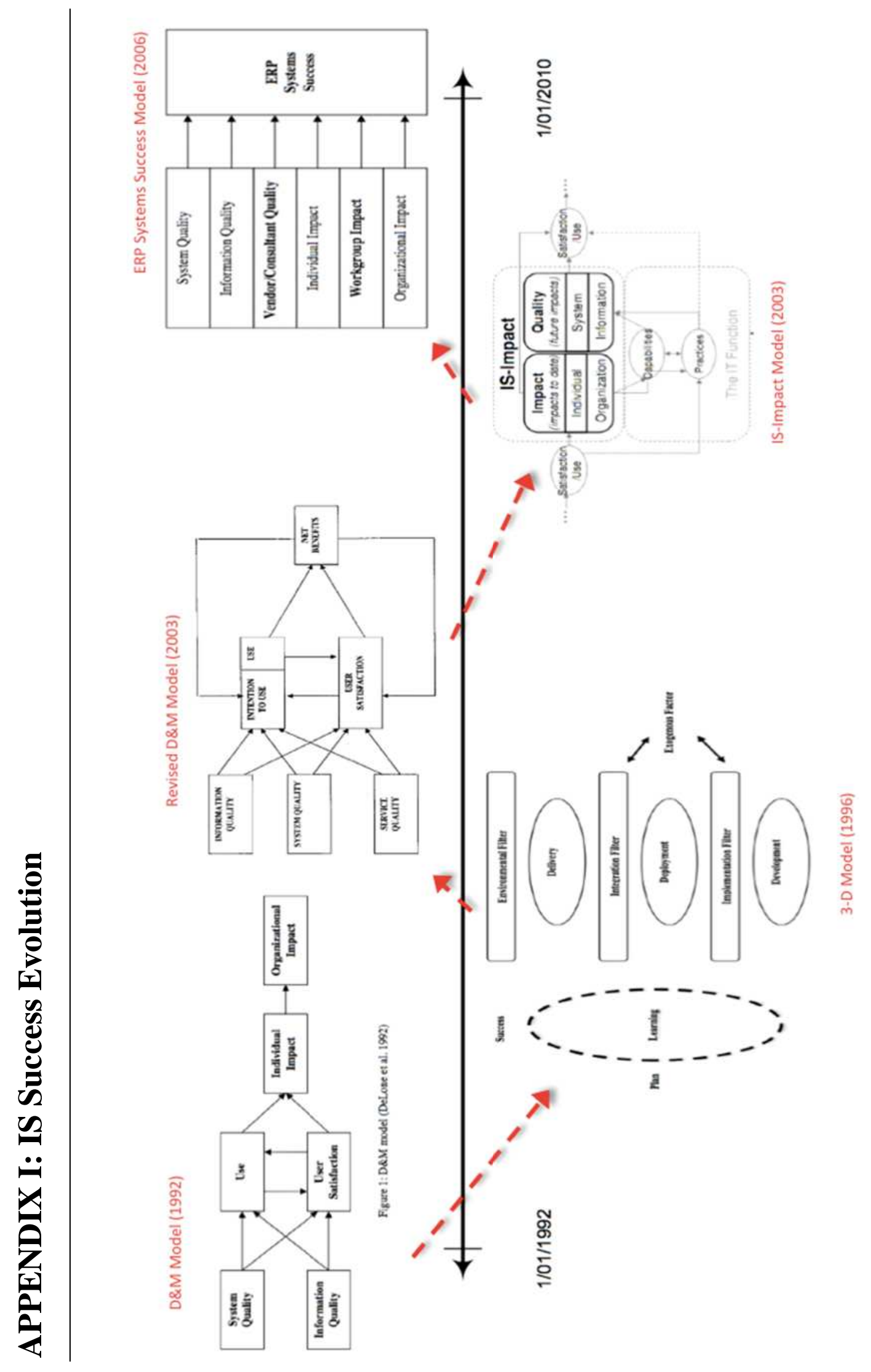




\section{APPENDIX II: IS-Impact Characteristics}

System Quality and Organizational Impact constructs operationalized as outlined by Gable et al (2003)

\section{System Quality}

1. Data from the IS often needs correction

2. Data from the IS is current enough

3. The IS is missing key data

4. The IS is easy to use

5. The IS is easy to learn

6. It is often difficult to get access to information that is in the IS

7. The IS meets the units requirements

8. The IS includes necessary features and functions

9. The IS always does what it should

10. The IS user interface can be easily adapted to ones personal approach

11. The IS system is always up and running as necessary

12. The IS system responds quickly enough

13. The IS requires only the minimum number of fields and screens to achieve a task

14. All data within the IS is fully integrated and consistent

15. The IS can be easily modified, corrected or improved.

\section{Organizational Impact}

1. The IS is cost effective

2. The IS has resulted in reduced staff costs

3. The IS has resulted in cost reductions (e.g. inventory holding costs, administration expenses)

4. The IS has resulted in overall productivity improvement

5. The IS has resulted in improved outcomes or outputs

6. The IS has resulted in an increased capacity to manage a growing volume of activity

7. The IS has resulted in improved business processes. 


\section{APPENDIX III: ISO 9126 Characteristics}

Explanations of the characteristics and sub characteristics that can be related to system quality

ISO $9126 \mathrm{Characteristic} \mathrm{and} \mathrm{sub-characteristics} \mathrm{[7]}$

\begin{tabular}{|c|c|c|}
\hline Characteristic & Sub Characteristics & Explanation \\
\hline Functionality & $\begin{array}{l}\text { Suitability } \\
\text { Accurateness } \\
\text { Interoperability } \\
\text { Compliance } \\
\text { Security }\end{array}$ & $\begin{array}{l}\text { 'Can software perform the tasks required?' } \\
\text { 'Is the result as expected?' } \\
\text { 'Can the system interact with another system?' } \\
\text { 'Is the system compliant with standards?' } \\
\text { 'Does the system prevent unauthorized access?' }\end{array}$ \\
\hline Reliability & $\begin{array}{l}\text { Maturity } \\
\text { Fault tolerance } \\
\text { Recoverability }\end{array}$ & $\begin{array}{l}\text { 'Have most of the faults in the software been eliminated over } \\
\text { time?' } \\
\text { 'Is the software capable of handling errors?' } \\
\text { 'Can the software resume working \& restore lost data after } \\
\text { failure?' }\end{array}$ \\
\hline Usability & $\begin{array}{l}\text { Understandability } \\
\text { Learnability } \\
\text { Operability } \\
\text { Attractiveness }\end{array}$ & $\begin{array}{l}\text { 'Does the user comprehend how to use the system easily?' } \\
\text { 'Can the user learn to use the system easily?' } \\
\text { 'Can the user use the system without much effort?' } \\
\text { 'Does the interface look good?' }\end{array}$ \\
\hline Efficiency & $\begin{array}{l}\text { Time Behaviour } \\
\text { Resource utilization }\end{array}$ & $\begin{array}{l}\text { 'How quickly does the system respond?' } \\
\text { 'Does the system utilize resources efficiently?' }\end{array}$ \\
\hline Maintainability & $\begin{array}{l}\text { Analyzability } \\
\text { Changeability } \\
\text { Stability } \\
\text { Testability }\end{array}$ & $\begin{array}{l}\text { 'Can faults be easily diagnosed?' } \\
\text { 'Can the software be easily modified?' } \\
\text { 'Can the software continue functioning if changes are made?' } \\
\text { 'Can the software be tested easily?' }\end{array}$ \\
\hline Portability & $\begin{array}{l}\text { Adaptability } \\
\text { Installability } \\
\text { Conformance } \\
\text { Replaceability }\end{array}$ & $\begin{array}{l}\text { 'Can the software be moved to other environments?' } \\
\text { 'Can the software be installed easily?' } \\
\text { 'Does the software comply with portability standards?' } \\
\text { 'Can the software easily replace other software?' }\end{array}$ \\
\hline
\end{tabular}

Source: Padayachee et al (2010) 


\section{APPENDIX IV: IS-Impact \& ISO 9126 Survey}

What SAP module do you use?

$\square$ Finance $\square$ Human Resources/Payroll $\square$ SRM $\square$ Logistics $\square$ SAP BW $\square$ Portal (MSS/ESS)

What tasks do you use SAP for that are required for your job?

How many years experience do you have using SAP?

$1-5$

6-10

11>

How many orgenizational levels are there between you and the CEO? and what is your role in the organisation?

What do you think of SAP?

Do you use SAP to enter data or extract reports?

Entering Data

Extracting Reports

Other

$0 \%$

Sunvey Completion $100 \%$ 
Data from SAP often needs correction

$\bigcirc$ Strongly Agree $\bigcirc$ Agree $\bigcirc$ Neither Agree nor Disagree $\bigcirc$ Disagree $\bigcirc$ Strongly Disagree

Data from the SAP is current enough

$\bigcirc$ Strongly Agree $\bigcirc$ Agree $\bigcirc$ Neither Agree nor Disagree $\bigcirc$ Disagree $\bigcirc$ Strongly Disagree

SAP is missing key data

$\bigcirc$ Strongly Agree $\bigcirc$ Agree $\bigcirc$ Neither Agree nor Disagree $\bigcirc$ Disagree $\bigcirc$ Strongly Disagree

SAP is easy to use

$\bigcirc$ Strongly Agree $\bigcirc$ Agree $\bigcirc$ Neither Agree nor Disagree $\bigcirc$ Disagree $\bigcirc$ Strongly Disagree

SAP is easy to learn

$\bigcirc$ Strongly Agree $\bigcirc$ Agree $\bigcirc$ Neither Agree nor Disagree $\bigcirc$ Disagree $\bigcirc$ Strongly Disagree

It is often difficult to get access to information that is in SAP

O Stronalv Aaree $\bigcirc$ Aqree $\bigcirc$ Neither Aqree nor Disaqree $\bigcirc$ Disaqree $\bigcirc$ Stronqly Disaqree

SAP is capable of handling errors

$\bigcirc$ Strongly Agree $\bigcirc$ Agree $\bigcirc$ Neither Agree nor Disagree $\bigcirc$ Disagree $\bigcirc$ Strongly Disagree

SAP can resume working and restore lost data after failure

Strongly Agree $\bigcirc$ Agree $\bigcirc$ Neither Agree nor Disagree $\bigcirc$ Disagree $\bigcirc$ Strongly Disagree

It is easy to comprehend how to use SAP

Strongly Agree $\bigcirc$ Agree $\bigcirc$ Neither Agree nor Disagree $\bigcirc$ Disagree $\bigcirc$ Strongly Disagree

The user can use the system easily

$\bigcirc$ Strongly Agree $\bigcirc$ Agree $\bigcirc$ Neither Agree nor Disagree $\bigcirc$ Disagree $\bigcirc$ Strongly Disagree

Using SAP requires little effort

$\bigcirc$ Strongly Agree $\bigcirc$ Agree $\bigcirc$ Neither Agree nor Disagree $\bigcirc$ Disagree $\bigcirc$ Strongly Disagree

The interface looks good

$\bigcirc$ Strongly Agree $\bigcirc$ Agree $\bigcirc$ Neither Agree nor Disagree $\bigcirc$ Disagree $\bigcirc$ Strongly Disagree

The SAP system responds quickly

$\bigcirc$ Strongly Agree $\bigcirc$ Agree $\bigcirc$ Neither Agree nor Disagree $\bigcirc$ Disagree $\bigcirc$ Strongly Disagree 
SAP utilizes resources efficiently

$\bigcirc$ Strongly Agree $\bigcirc$ Agree $\bigcirc$ Neither Agree nor Disagree $\bigcirc$ Disagree $\bigcirc$ strongly Disagree

Faults in SAP can be easily diagnosed

$\bigcirc$ Strongly Agree $\bigcirc$ Agree $\bigcirc$ Neither Agree nor Disagree $\bigcirc$ Disagree $\bigcirc$ Strongly Disagree

SAP can be easily modified, corrected or improved

$\bigcirc$ Strongly Agree $\bigcirc$ Agree $\bigcirc$ Neither Agree nor Disagree $\bigcirc$ Disagree $\bigcirc$ Strongly Disagree

SAP can continue functioning if changes are made

$\bigcirc$ Strongly Agree $\bigcirc$ Agree $\bigcirc$ Neither Agree nor Disagree $\bigcirc$ Disagree $\bigcirc$ Strongly Disagree

SAP can be tested easily

$\bigcirc$ Strongly Agree $\bigcirc$ Agree $\bigcirc$ Neither Agree nor Disagree $\bigcirc$ Disagree $\bigcirc$ Strongly Disagree

SAP can be installed easily

$\bigcirc$ Strongly Agree $\bigcirc$ Agree $\bigcirc$ Neither Agree nor Disagree $\bigcirc$ Disagree $\bigcirc$ Strongly Disagree

SAP can replace other applications within the organisation

$\bigcirc$ Strongly Agree $\bigcirc$ Agree $\bigcirc$ Neither Agree nor Disagree $\bigcirc$ Disagree $\bigcirc$ Strongly Disagree

SAP can perform the tasks required

Strongly Agree $\bigcirc$ Agree $\bigcirc$ Neither Agree nor Disagree $\bigcirc$ Disagree $\bigcirc$ Strongly Disagree

SAP produces results as expected

Strongly Agree $O$ Agree $O$ Neither Agree nor Disagree $O$ Disagree $\bigcirc$ Strongly Disagree

SAP can interact with other applications

$\bigcirc$ Strongly Agree $\bigcirc$ Agree $\bigcirc$ Neither Agree nor Disagree $\bigcirc$ Disagree $\bigcirc$ Strongly Disagree

SAP is compliant with standards

$O$ Strongly Agree $O$ Agree $O$ Neither Agree nor Disagree $\bigcirc$ Disagree $\bigcirc$ Strongly Disagree

\section{SAP prevents unauthorised access}

$O$ Strongly Agree $\bigcirc$ Agree $O$ Neither Agree nor Disagree $O$ Disagree $O$ Strongly Disagree 
$\bigcirc$ Strongly Agree $\bigcirc$ Agree $\bigcirc$ Neither Agree nor Disagree $\bigcirc$ Disagree $\bigcirc$ Strongly Disagree

SAP has resulted in cost reductions (e.g. inventory holding costs, administration expenses)

$\bigcirc$ Strongly Agree $\bigcirc$ Agree $\bigcirc$ Neither Agree nor Disagree $\bigcirc$ Disagree $\bigcirc$ Strongly Disagree

SAP has resulted in overall productivity improvement

$\bigcirc$ Strongly Agree $\bigcirc$ Agree $\bigcirc$ Neither Agree nor Disagree $\bigcirc$ Disagree $\bigcirc$ Strongly Disagree

SAP has resulted in improved outcomes or outputs

$\bigcirc$ Strongly Agree $\bigcirc$ Agree $\bigcirc$ Neither Agree nor Disagree $\bigcirc$ Disagree $\bigcirc$ Strongly Disagree

SAP has resulted in an increased capacity to manage a growing volume of activity

$\bigcirc$ Strongly Agree $\bigcirc$ Agree $\bigcirc$ Neither Agree nor Disagree $\bigcirc$ Disagree $\bigcirc$ Strongly Disagree

SAP has resulted in improved business processes.

$\bigcirc$ Strongly Agree $\bigcirc$ Agree $\bigcirc$ Neither Agree nor Disagree $\bigcirc$ Disagree $\bigcirc$ Strongly Disagree

SAF can be tested easıy

Changes about SAP and its processes needs to be clearly communicated

$\bigcirc$ Strongly Agree $\bigcirc$ Agree $\bigcirc$ Neither Agree nor Disagree $\bigcirc$ Disagree $\bigcirc$ Strongly Disagree

Ownership of SAP needs to be clearly highlighted

$\bigcirc$ Strongly Agree $\bigcirc$ Agree $\bigcirc$ Neither Agree nor Disagree $\bigcirc$ Disagree $\bigcirc$ Strongly Disagree

Business Unit Collaboration Is important to the success of SAP

$\bigcirc$ Strongly Agree $\bigcirc$ Agree $\bigcirc$ Neither Agree nor Disagree $\bigcirc$ Disagree $\bigcirc$ Strongly Disagree

Do you consider SAP to be a success in your organisation?

Is there anything else you would like to say about SAP in your organisation? 
Overall, I believe SAP has excellent technical system quality

$\bigcirc$ Strongly Agree $\bigcirc$ Agree $\bigcirc$ Neither Agree nor Disagree $\bigcirc$ Disagree $\bigcirc$ Strongly Disagree

Overall, I believe the information produced by SAP will continue to support the organization in the future

$\bigcirc$ Strongly Agree $\bigcirc$ Agree $\bigcirc$ Neither Agree nor Disagree $\bigcirc$ Disagree $\bigcirc$ Strongly Disagree

Overall, I believe SAP has excellent information quality

$\bigcirc$ Strongly Agree $\bigcirc$ Agree $\bigcirc$ Neither Agree nor Disagree $\bigcirc$ Disagree $\bigcirc$ Strongly Disagree

Lastly, for these questions, please consider your overall experience and impressions of SAP and how you believe it will support the organization in the future

Overall, I believe SAP has had a positive impact on my work

$\bigcirc$ Strongly Agree $\bigcirc$ Agree $\bigcirc$ Neither Agree nor Disagree $\bigcirc$ Disagree $\bigcirc$ Strongly Disagree

Overall, I believe SAP has been good for my job performance

$\bigcirc$ strongly Agree $\bigcirc$ Agree $\bigcirc$ Neither Agree nor Disagree $\bigcirc$ Disagree $\bigcirc$ Strongly Disagree

Overall, I believe SAP has been beneficial for the organisation

$\bigcirc$ strongly Agree $\bigcirc$ Agree $\bigcirc$ Neither Agree nor Disagree $\bigcirc$ Disagree $\bigcirc$ Strongly Disagree

Overall I believe SAP has made the organization for effective

$\bigcirc$ strongly Agree $\bigcirc$ Agree $\bigcirc$ Neither Agree nor Disagree $\bigcirc$ Disagree $\bigcirc$ Strongly Disagree

Overall, I believe the technical system qualities of SAP will continue to support the organization in the future

$\bigcirc$ Strongly Agree $\bigcirc$ Agree $\bigcirc$ Neither Agree nor Disagree $\bigcirc$ Disagree $\bigcirc$ Strongly Disagree 


\title{
APPENDIX V: SAP Benchmarking Template, Best Run \& TCO
}

\author{
Best Run Template
}

\section{Page 1}

\section{Q.1.}

\section{Best Run IT: Survey Instructions}

Welcome to the SAP Best Run $\pi$ Benchmarking survey. The survey will help you assess your $\pi$ organization's current process and technology performance, based on key performance indicators and best practices vis-a-vis your peers. The assessment covers certain core processes including $\pi$ Strategy and Business Alignment, $\pi /$ Solutions Portfolio Management, $\Pi$ Governance, Value Management, $\Pi$ Architecture and Center of Excellence. Knowing your strengths vis-a-vis peers, and identifying potential improvement opportunities will help you position your organization for growth and profitability. Upon submission of this survey, you will receive a confidential and comprehensive analysis report, comparing your organization's performance against your peers, and recommending high-impact strategies for improvement.

Here are a few tips before you get started:

\section{Survey Structure}

The survey has five pages:

- Project Info includes participant profile information to be gathered.

- Page 1 includes general instructions.

- Page 2 includes participant profile, key performance indicators and information technology deployed.

- Page 3 includes a series of best practices which will help you to assess their importance and adoption/coverage for your organization.

- Maturity Model includes descriptions of maturity stages for each best practice listed on Page 3. They should be used as a gage for best practices

Coverage $(1-5)$

\section{Navigation}

- Click on the "Page" tab to navigate between pages.

- Click on the "Save" button to save the data you have filled in the answer fields

- Click on the "Cancel" button to exit the survey. Kindly note that any changes you made to the survey will not be saved if you cancel,

- Click on the "Request Help" button in case you need any help on completing the survey. A benchmarking team member will get in touch with you.

- Click on the "Request Validation" button to review/ validate the data you have provided. Validation of the data is required so that we can provide you

with a meaningful and valid analysis. Kindly note, in case there are any validation issues, a benchmarking team member will get back to you.

- Click on the "Show Results" button to view your benchmarking results online or to download your benchmarking analysis report

\section{Survey Completion Instructions}

- An online glossary is in place to address the most common questions. The glossary can be accessed by clicking on the "Help button placed at the bottom of the question.

- Please provide all data for the timeframe you indicated in the project set up which should be preferably rolling 12 months and based on most recent annual figures. ONLY for the divisions/geographies in scope.

- In case a question with a numeric answer is not applicable for your organization or in case you cannot answer a question, please leave the answer field blank and do not enter ZERO $\left({ }^{\prime \prime} \mathrm{O}^{\mathrm{T}}\right)$

- For $\%$ responses, please indicate numbers only without the $\%{ }^{*}$ sign (e.g., 20 , NOT 0.2 or $20 \%$ )

\section{Terms and Conditions}

By your entering of data into this survey, you are indicating your agreement with and acceptance of the terms and conditions associated with SAP's Benchmarking Program

Click here to review the Terms and Conditions

\section{Page 2}


Please provide the following basic information (based on most recent annual figures - preferably rolling 12 months. ONLY for the 1 divisions/geographies in scope):

\begin{tabular}{|l|l|}
\hline Metric & Answer \\
\hline Annual Revenue Growth (in \%) & \\
\hline Operating Income (in selected currency) & \\
\hline Cost of Goods Sold (in selected currency) & \\
\hline Sales, General And Administrative Expense (in selected currency) & \\
\hline Number Of Employees & \\
\hline
\end{tabular}

2 Please choose the statement that best describes your company's organization: (Help)

Please indicate what best describes the ultimate goal of your company's ERP 3 strategy:

Other ERP Strategy, please specify:

(Help)

4 Who is your dominant ERP applications vendor?

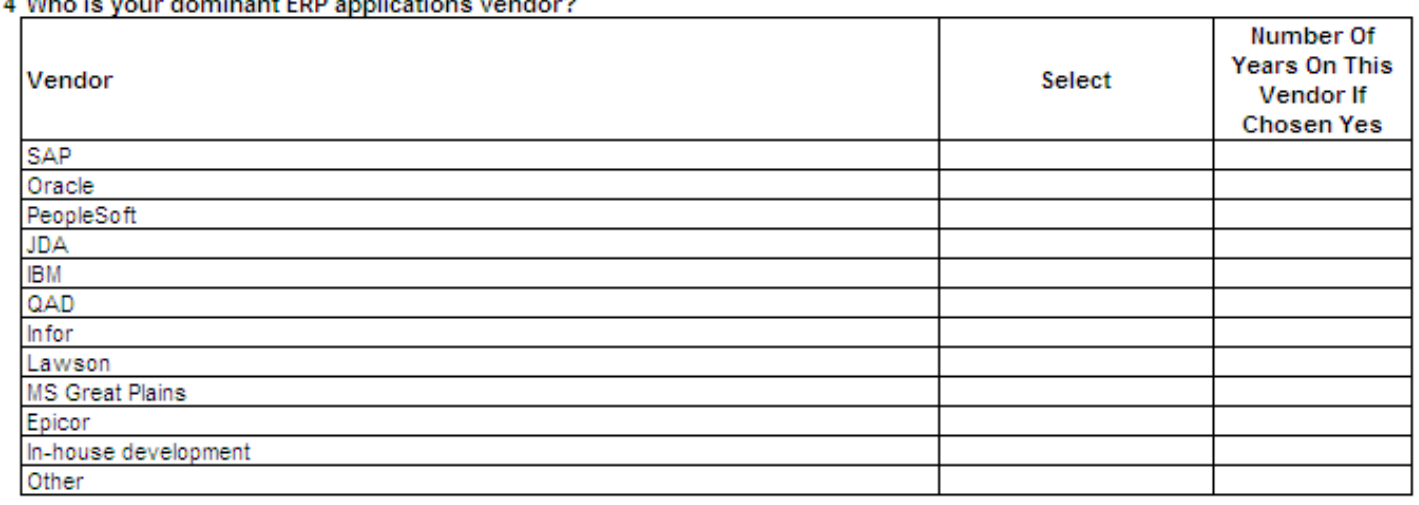

Others, please specify:

(Help) 
Please provide total number of country versions you have deployed for the 5 dominant ERP applications vendor(s): (Help)

Please provide total number of language versions you have deployed for the 6 dominant ERP applications vendor(s):

(Help)

7 What is the total number of applications are there in your solutions portfolio? (Help)

Please indicate out of your top 5 ERP applications (measured by number of 8 users), how many versions are you behind on an average: (Help)

Please provide the total number of releases rolled out or updates made to 9 the system in last year for the top 5 vendors? (Help)

Please provide the total production instances of top 5 ERP applications are you 10 running:

Please provide on average, how many systems do you have per production landscape for top 5 ERP applications (e.g. develop, test, training, production, etc):

(Help)

11 Please provide the total number of interfaces in your IT landscape:

Please provide the total number of critical interfaces: (Help)

12 Please provide user breakdown details:

\begin{tabular}{|l|l|}
\hline User Type & User Number \\
\hline Total Licensed Users & \\
\hline Active Users & \\
\hline Number Of Users On Non-licensed/ In-house Developed Solutions & \\
\hline
\end{tabular}
(Help) 


\section{Best Run IT: IT Effectiveness}

Please indicate your business satisfaction rating on a scale of 1-10? $(1=$ Very 13 dissatisfied, $10=$ Very satisfied) (Help)

Please indicate the importance of technology enablement for these business processes: (Importance : $1=$ Not important; $5=$ 14 Extremely important)

Please indicate how effectively these business processes are automated: (Effectiveness: $1=$ Not enabled; $5=$ Completely enabled)

Please indicate how effectively technology provides full visibility and timely data across these business processes: (Effectiveness: 1 $=$ No visibility and data seldom on time; 5 = Full visibility and data always on time

Please indicate NA for both importance and effectiveness if the business process is not applicable to your organization:

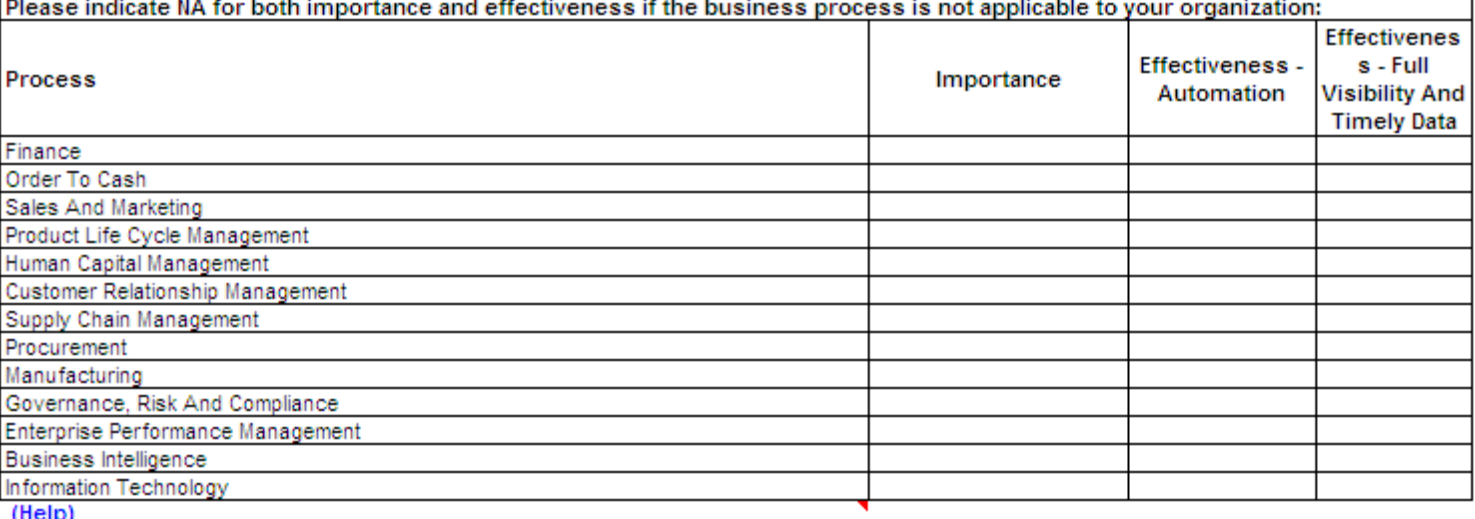

(Help)

15 Technology Impacts Business Performance. Please provide the following KPIs:

\begin{tabular}{|l|c|}
\hline Business Process & KPI Value \\
\hline Time To Close Annual Books (in days) & \\
\hline New Products Or Services As \% Of Revenue (in \%) & \\
\hline Order/ Service Fill Rate (in \%) & \\
\hline
\end{tabular}

(Help)

How many master data files do you maintain? (please note that this is the number of files and not the number of 16 records)

\begin{tabular}{|l|l|}
\hline Data Type & Number Of Master Files \\
\hline Product & \\
\hline Customer & \\
\hline Supplier & \\
\hline Employee & \\
\hline
\end{tabular}

(Help)

17 Please provide the total number of change requests (transports) released to production excluding planned cutover release over the past 3 months:

\begin{tabular}{|l|l|}
\hline Please provide the size of current change request backlog: & \\
\hline
\end{tabular} (Help)

18 Please provide the following Information Technology metrics: \% Unplanned Downtime - IT: (Help) 
Best Run IT: IT Efficiency

19 Please provide the total number of IT projects that were completed over the last 12 months:

Please provide the number of IT Projects (that were completed over last 12 months) had a positive ROI (return on investment): (Help)

20 What was your total IT Spend for the last financial year by the categories specified below? (in selected currency)

\begin{tabular}{|l|c|}
\hline Budget & Answer \\
\hline Total M Budget (in selected currency) & \\
\hline Total M Internal FTEs & \\
\hline Average Loaded Cost Per Internal FTE & \\
\hline Bl-related Spend (in selected currency) & \\
\hline
\end{tabular}

Please provide the IT Training and Development as \% of Total IT Spend for the past 12 months:

(Help)

21 Please provide a breakup of your total IT budget in Q20 above into the "Strategic Spend" and

\begin{tabular}{|l|c|}
\hline Spend Category & $\%$ Of Total IT Spend \\
\hline Strategic Investments & \\
\hline Operational Investments & \\
\hline
\end{tabular}

(Help)

22 Please provide a breakup of total IT internal FTEs and total IT budget in Q20 above in following categories (please note that these categories are independent from the breakup provided above):

\begin{tabular}{|l|c|}
\hline Category & $\begin{array}{c}\text { Number Of Internal } \\
\text { FTEs }\end{array}$ \\
\hline$\Pi$ Development & \\
\hline$\Pi$ Testing & \\
\hline$\Pi$ Infrastructure And Maintenance & \\
\hline$\Pi$ Legacy System Maintenance And Enhancement (both hardware and software) & \\
\hline
\end{tabular}

\begin{tabular}{|l|c|c|}
\hline Category & $\begin{array}{c}\text { Internal Headcount } \\
\text { Costs }\end{array}$ & $\begin{array}{c}\text { Contracting/ } \\
\text { Consulting } \\
\text { Costs }\end{array}$ \\
\hline$\Pi$ Development & & \\
\hline$\Pi$ Testing & & \\
\hline$\Pi$ Infrastructure And Maintenance & & \\
\hline$\Pi$ Legacy System Maintenance And Enhancement (both hardware and software) & & \\
\hline
\end{tabular}

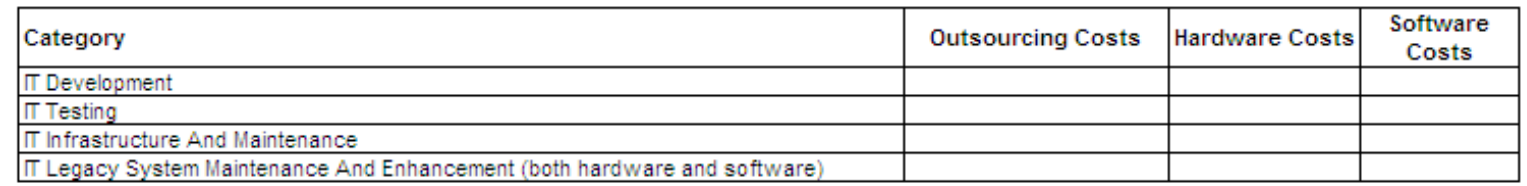

Other IT Spend

(Help) 


\section{Best Run IT: Organization}

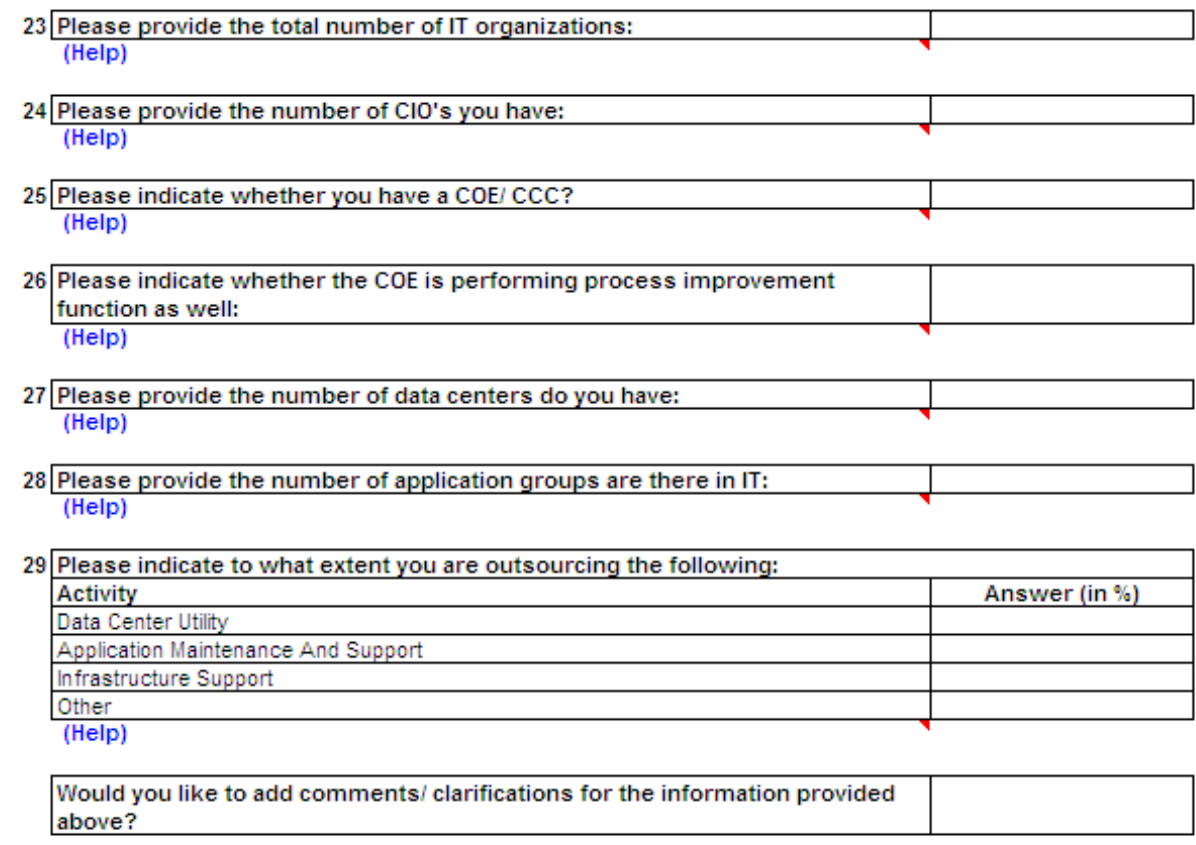

\section{Page 3}

\section{$\operatorname{SAP}$}

\section{Best Run IT: Best Practices}

On a scale of 1-5, please rank each best practice in terms of importance and degree of coverage: Importance: 1 = Not important; 5 = Extremely important

Coverage: 1 = No coverage today - Organization does not employ this best practice; $5=$ Best practice is fully adopted Please indicate NA for both importance and coverage if best practice is not applicable to your organization

\begin{tabular}{|c|c|c|}
\hline \multirow{2}{*}{$\begin{array}{l}30 \text { Best Practices - IT Strategy And Business Alignment } \\
\text { The company is using } \pi \text { to enable strategic and competitive advantages }\end{array}$} & Importance & Coverage \\
\hline & & \\
\hline $\begin{array}{l}\text { The company has established common, simple and streamlined } \Pi \text { and business process } \\
\text { standards across the organization }\end{array}$ & & \\
\hline $\begin{array}{l}\text { The company has defined } \pi \text { roles and responsibilities which are consistently applied across } \\
\text { the organization }\end{array}$ & & \\
\hline $\begin{array}{l}\text { The company undergoes a formal budgeting and planning process to approve initiatives and } \\
\text { drive business value }\end{array}$ & & \\
\hline $\begin{array}{l}\text { The company undergoes a formal annual portfolio rationalization process to reduce operating } \\
\text { expense }\end{array}$ & & \\
\hline $\begin{array}{l}\text { The company has a strategic } \pi \text { roadmap or rolling } 3-5 \text { year plan based on business and } \pi \\
\text { strategy }\end{array}$ & & \\
\hline $\begin{array}{l}\text { Regular } \Pi \text { and business planning meetings are conducted, with a joint planning methodology } \\
\text { in place }\end{array}$ & & \\
\hline $\begin{array}{l}\Pi \text { is included in the prioritization process early on so that an appropriate roadmap can be } \\
\text { developed }\end{array}$ & & \\
\hline II facilitates a high degree of integration with the company's ecosystem & & \\
\hline Business has embraced $\pi$ as their responsibility & & \\
\hline
\end{tabular}




\begin{tabular}{|c|c|c|}
\hline Best Practice - Solutions/ IT Portfolio Management & Importance & Coverage \\
\hline The company has a consolidated single solution/ platform landscape & & \\
\hline The company has a strategy in place for a single solution/ platform landscape consolidation & & \\
\hline $\begin{array}{l}\text { The company has a strategy and enforce the application of support or enhancement packs } \\
\text { from vendors }\end{array}$ & & \\
\hline The company has and enforce a no-modification strategy for vendor applications & & \\
\hline $\begin{array}{l}\text { The business units have incentives aligned with the adoption of standards and common } \\
\text { solutions }\end{array}$ & & \\
\hline The company has a master data strategy to drive common definitions and standards & & \\
\hline $\begin{array}{l}\text { The company always evaluates licensed vendor(s) or legacy } \Pi \text { solution for meeting business } \\
\text { requirements before looking at niche products }\end{array}$ & & \\
\hline $\begin{array}{l}\text { The company has a strategy to maximize the value of integration for the vendor(s) or legacy } \\
\Pi \text { solutions }\end{array}$ & & \\
\hline $\begin{array}{l}\text { The company evaluates vendor viability and business strategy as part of the } \Pi \text { portfolio } \\
\text { management }\end{array}$ & & \\
\hline
\end{tabular}

\begin{tabular}{|c|c|c|}
\hline 2 Best Practice - IT Governance & Importance & Coverage \\
\hline $\begin{array}{l}\text { The company has a set of } \Pi \text { principles that help to make decisions on } \Pi \text { architecture, } \\
\text { infrastructure, business applications and prioritization. For example, standardize technology } \\
\text { and process wherever possible }\end{array}$ & & \\
\hline The Company's $\Pi$ performance management is linked with the business outcomes & & \\
\hline The Company's $\pi$ Architecture is an integral part of top management's business planning & & \\
\hline Company has a strategy to upgrade $\pi$ Infrastructure in an incremental manner & & \\
\hline $\begin{array}{l}\text { The company has defined a set of policies (e.g. data standards like UN/CEFACT CCTS) and } \\
\text { choices (e.g. SSO must be used in web interfaces) to ensure a consistent } \Pi \text { architecture }\end{array}$ & & \\
\hline The company has adopted a risk-analysis template for making $\Pi$ investments & & \\
\hline $\begin{array}{l}\text { The company reconciles the } \Pi \text { investment portfolio against enterprise wide strategic } \\
\text { initiatives and individual business units }\end{array}$ & & \\
\hline
\end{tabular}

\begin{tabular}{|c|c|c|}
\hline Best Practice - Value Management & Importance & Coverage \\
\hline $\begin{array}{l}\text { Industry best practices supporting technology and process excellence are available and } \\
\text { reviewed during strategy reviews }\end{array}$ & & \\
\hline IT Plans are developed over a multi year horizon & & \\
\hline $\begin{array}{l}\text { Initiatives are prioritized based on a defined set of criteria, taking into account business value, } \\
\text { organizational readiness, potential risks and technology impact }\end{array}$ & & \\
\hline Benchmarking is used to drive ongoing process improvement & & \\
\hline $\begin{array}{l}\text { Benchmarking includes comparisons with external peers as well as internal benchmarking } \\
\text { between divisions and/ or regions }\end{array}$ & & \\
\hline $\begin{array}{l}\text { A detailed quantitative business case and financial ROI analysis is completed for all major } \\
\text { implementations, outlining benefit areas, specific sources of benefit for each area, and } \\
\text { proposed operational impacts or changes }\end{array}$ & & \\
\hline Business cases follow a clear and consistent standard format & & \\
\hline $\begin{array}{l}\text { There is a clear and documented linkage between the organization's strategic objectives and } \\
\text { each business case objective }\end{array}$ & & \\
\hline
\end{tabular}

\begin{tabular}{|c|c|c|}
\hline Best Practice - IT Architecture & Importance & Coverage \\
\hline $\begin{array}{l}\text { The company deploys } \Pi \text { landscape modeling, inventory documentation and utilization to } \\
\text { manage the business of } \Pi\end{array}$ & & \\
\hline \multicolumn{3}{|l|}{$\begin{array}{l}\text { The company has reference architecture model which is the foundation for all applications, } \\
\text { systems in the landscape }\end{array}$} \\
\hline \multicolumn{3}{|l|}{$\begin{array}{l}\text { The company enforces a policy across all relevant business units to capture the information } \\
\text { on business processes, information entities and systems in the landscape }\end{array}$} \\
\hline The company's plans to use service oriented architecture (SOA) & & \\
\hline \multicolumn{3}{|l|}{ The company has SOA in its $3-5$ years $\Pi$ roadmap } \\
\hline \multicolumn{3}{|l|}{ The company is deriving significant benefits from SOA } \\
\hline The company has clearly defined security policy that governs intra-company communication & & \\
\hline The company has clearly defined security policy that governs external communication & & \\
\hline
\end{tabular}




\begin{tabular}{|l|l|l|}
\hline 35 & Importance & Coverage \\
\hline A formal COE exists that is either physically or virtually centralized across the organization & & \\
\hline The COE is perceived as a key enabler of business strategy by company leadership & & \\
\hline $\begin{array}{l}\text { The COE is aligned with the business processes, rather than with functional areas or } T \text { sub- } \\
\text { portfolios }\end{array}$ & & \\
\hline Business input into the functioning and organization of COE is high & & \\
\hline & & \\
\hline There are regular and formal reviews of the COE/ Support Organization design and services & & \\
\hline Sareer planning and talent retention is an active component of the COE & & \\
\hline
\end{tabular}

Please describe other best practices your company has adopted to drive leading 36 performance:

Optional 3rd Party Involvement:

37 Please provide the name, email address, phone number and organization name of any person(s) other than yourself you wish to give permission to actively participate in the benchmarking process. This person(s) will be included in any and all interactions between you and the SAP team related to the validation and comparative results of this survey. By entering this persons contact information, you indicate that you are giving permission for this person(s) to view your organization's survey data, benchmark results, and related communications; to participate in meetings; and to submit/correct benchmark related data to SAP on your behalf. You also agree that, regarding all aspects of the SAP Benchmarking program, this person(s) is subject to the same level of confidentiality to you as you are to SAP.

Copyright SAP. All Rights Reserved 


\section{Total Cost of Ownership Template}

\section{Page 1}

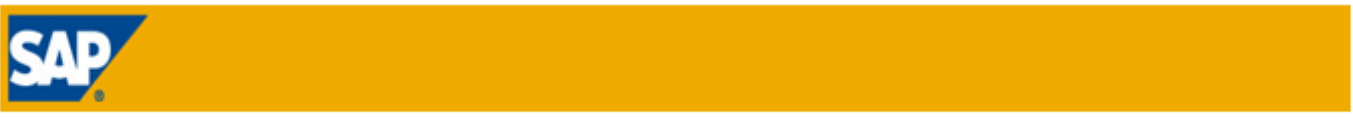

\section{Total Cost Of Ownership: Survey Instructions}

Welcome to the SAP Total Cost of Ownership Benchmarking survey. The survey will help you assess your our company's ongoing SAP operations performance, based on key performance indicators and best practices vis-a-vis your peers. The assessment covers core processes including $\Pi$ Governance, Value Management, Solution Portfolio Management, I Service Organization and Delivery, Business Process Improvement and Test Management and Business Continuity and TCO.

Knowing your strengths vis-a-vis peers, and identifying potential improvement opportunities will help you position your organization for growth and profitability. Upon submission of this survey, you will receive a confidential and comprehensive analysis report, comparing your company's performance against your peers, and recommending high-impact strategies for improvement.

Here are a few tips before you get started:

\section{Survey Structure}

The survey has five pages:

- Project Info includes participant profile information to be gathered.

- Page 1 includes general instructions.

- Page 2 includes participant profile, key performance indicators and information technology deployed.

- Page 3 includes a series of best practices which will help you to assess their importance and adoption/coverage for your organization.

- Maturity Model includes descriptions of maturity stages for each best practice listed on Page 3 . They should be used as a gage for best practices

Coverage $(1-5)$

\section{Navigation}

- Click on the "Page" tab to navigate between pages.

- Click on the "Save" button to save the data you have filled in the answer fields.

- Click on the "Cancel" button to exit the survey. Kindly note that any changes you made to the survey will not be saved if you cancel.

- Click on the "Request Help" button in case you need any help on completing the survey. A benchmarking team member will get in touch with you.

- Click on the "Request Validation" button to review/ validate the data you have provided. Validation of the data is required so that we can provide you

with a meaningful and valid analysis. Kindly note, in case there are any validation issues, a benchmarking team member will get back to you.

- Click on the "Show Results" button to view your benchmarking results online or to download your benchmarking analysis report.

\section{Survey Completion Instructions:}

- An online glossary is in place to address the most common questions. The glossary can be accessed by clicking on the "Help" button placed at the bottom of the question.

- Please provide all data for the timeframe you indicated in the project set up which should be preferably rolling 12 months and based on most recent annual figures. ONLY for the divisions/ geographies in scope.

- In case a question with a numeric answer is not applicable for your organization or in case you cannot answer a question, please leave the answer field blank and do not enter ZERO $\left({ }^{\circ} 0^{\circ}\right)$

- For $\%$ responses, please indicate numbers only without the $\%^{x}$ sign (e.g., 20 , NOT 0.2 or $20 \%$ )

\section{Terms and Conditions}

By your entering of data into this survey, you are indicating your agreement with and acceptance of the terms and conditions associated with SAP's Benchmarking Program

Click here to review the Terms and Conditions

Copyright SAP. All Rights Reserved

Page 2 


\section{TCO: Participant Profile}

\begin{tabular}{|l|l|l|}
\hline Please indicate the regions and number of countries in the scope of the survey: & \multicolumn{1}{|c|}{ Select Yes/ No } & Number Of Countries \\
\hline Regions & & \\
\hline North America & & \\
\hline Latin America & & \\
\hline Europe & & \\
\hline Middle East And Africa & & \\
\hline Asia Pacific & & \\
\hline
\end{tabular}

\begin{tabular}{|l|l|}
\hline $\begin{array}{l}\text { Please provide the following basic information (based on most recent annual figures - } \\
\text { preferably rolling } 12 \text { months. ONLY for the divisions/geographies in scope): }\end{array}$ \\
\hline Metric & Answers \\
\hline Number Of Employees & \\
\hline Number Of Locations & \\
\hline
\end{tabular}

\section{TCO: SAP Solution Details}

3 Please indicate the SAP solution scope in the questions below:

\begin{tabular}{|l|l|l|}
\hline SAP ERP (or R/3) & $\begin{array}{c}\text { Number Of Instances In } \\
\text { Production }\end{array}$ & $\begin{array}{c}\text { Are You Running Multiple, } \\
\text { Different Releases? }\end{array}$ \\
\hline FI - Finance & & \\
\hline CO - Controlling & & \\
\hline MMA - Materials Management & & \\
\hline PP - Production Planning & & \\
\hline PS - Project Systems & & \\
\hline LE - Logistics Execution & & \\
\hline PM - Plant Maintenance & & \\
\hline QM - Quality Management & & \\
\hline SD - Sales And Distribution & & \\
\hline
\end{tabular}

\begin{tabular}{|l|l|l|}
\hline SAP Technology Platform Solutions & $\begin{array}{c}\text { Number Of Instances In } \\
\text { Production }\end{array}$ & $\begin{array}{c}\text { Are You Running Multiple, } \\
\text { Different Releases? }\end{array}$ \\
\hline SAP Business Intelligence (BW) & & \\
\hline SAP Master Data Management (MDM) & & \\
\hline SAP Enterprise Portal & & \\
\hline SAP Exchange Infrastructure (XI) & & \\
\hline SAP Mobile Solutions & & \\
\hline SAP xApplications (e.g. XRPM, etc.) & & \\
\hline
\end{tabular}

\begin{tabular}{|l|c|c|}
\hline SAP Solution Scenarios & $\begin{array}{c}\text { Number Of Instances In } \\
\text { Production }\end{array}$ & $\begin{array}{c}\text { Are You Running Multiple, } \\
\text { Different Releases? }\end{array}$ \\
\hline SAP Supply Chain Management (SCM, APO) & & \\
\hline SAP Supplier Relationship Management (SRM, EBP) & & \\
\hline SAP Customer Relationship Management (CRM) & & \\
\hline SAP Product Lifecycle Management (PLM) & & \\
\hline SAP Human Capital Management (HCM, HR) & & \\
\hline
\end{tabular}

\begin{tabular}{|l|l|l|}
\hline SAP Industry Specific Solutions & $\begin{array}{c}\text { Number Of Instances In } \\
\text { Production }\end{array}$ & $\begin{array}{c}\text { Are You Running Multiple, } \\
\text { Different Releases? }\end{array}$ \\
\hline Aerospace And Defense/ Defense And Security & & \\
\hline Automotive & & \\
\hline Banking Or Insurance & & \\
\hline Chemicals/ Pharmaceuticals & & \\
\hline Consumer Products & & \\
\hline Public Sector & & \\
\hline Oil And Gas & & \\
\hline Retail Apparel And Footwear Solution & & \\
\hline Telecommunications & & \\
\hline Utilities & & \\
\hline Other & & \\
\hline
\end{tabular}




\begin{tabular}{|l|c|c|}
\hline SME Solutions & $\begin{array}{c}\text { Number Of Instances In } \\
\text { Production }\end{array}$ & $\begin{array}{c}\text { Are You Running Multiple, } \\
\text { Different Releases? }\end{array}$ \\
\hline SAP Business One & & \\
\hline SAP All-In-One & & \\
\hline SAP Business ByDesign & & \\
\hline
\end{tabular}

4 Please provide the user breakdown details for survey scope:

\begin{tabular}{|l|l|l|}
\hline Licensing & User Number & Comments \\
\hline Named Professional Users & & \\
\hline Named Limited Professional Users & & \\
\hline (Help) & & \\
\hline
\end{tabular}
(Help)

\begin{tabular}{|l|l|l|}
\hline System Usage & User Number & Comments \\
\hline Active Users (excluding MSS and ESS users) & & \\
\hline Concurrent Users & & \\
\hline MSS/ ESS Users & & \\
\hline
\end{tabular}

(Help)

Please provide the average DAILY number of SAP Steps for a reasonable period $>7$ days

5 (update, update to, RFC, batch \& spool) based on standard SAP reports as per the glossary:

(Help)

6 Please provide the number of years you have been live on SAP:

(Help)

Please provide the total number of SAP production instances

7 that you are running:

(Help)

Please provide the average number of systems per production landscape (e.g. develop,

8 test, training, production, etc):

(Help)

\begin{tabular}{l|l|}
\cline { 2 - 2 } & Please indicate your dominant solution landscape strategy: \\
\hline Solution Landscape Strategy & \multicolumn{1}{|c|}{ Yes/ No } \\
\hline GlobaV Centralized System & \\
\hline Regional Systems & \\
\hline Systems By Country & \\
\hline Systems By Function/ Business Unit & \\
\hline Other, please specify: & \\
\hline (Help)
\end{tabular}

Please provide the total number of interfaces from non - SAP

10 solutions to the SAP solution:

(Help)

Please provide the estimated total number of critical interfaces

11 from non - SAP solutions to the SAP solution:

(Help)

12 Please specify the following based on the reporting from SAP solutions:

\begin{tabular}{|l|l}
\hline Customization Parameter & Number \\
\hline
\end{tabular}

User Exits

$Y / Z$ Programs

(Help)

13 Please indicate whether you have Solution Manager implemented:

14 If yes, do you use Solution Manager for:

\begin{tabular}{|l|l|}
\hline Solution Manager Usage & Yes/ No \\
\hline Implementation Projects & \\
\hline System Operations/ Monitoring & \\
\hline Incident Management & \\
\hline Help Desk & \\
\hline
\end{tabular}

(Help) 
15 Please provide the total number of Language Versions: (Help)

Please provide the total number of Country Versions (only

include special country version not covered by standard SAP

16 solution; for example, Greece, Romania, Russia, etc.):

(Help)

Please rate the importance of the following performance criteria on how your IT

17 performance is measured/ rated: ( 1 = Not Important, 5 = Extremely Important)

\begin{tabular}{|l|l|}
\hline Performance Criteria & Importance \\
\hline Overall Costs of $\Pi$ & \\
\hline Response to Requests for Service & \\
\hline System Response Times & \\
\hline Downtime & \\
\hline Level of Enhancement/ New Functionality Funded in Base Service Level & \\
\hline Account Management Coverage & \\
\hline Stability of System & \\
\hline Process Capability Delivered & \\
\hline Other, please specify: & \\
\hline
\end{tabular}

18 Please indicate the number of Database and Operating Systems:

\begin{tabular}{|l|l|}
\hline System & Number \\
\hline Database Systems & \\
\hline Operating Systems & \\
\hline
\end{tabular}

(Heln)

TCO: SAP Solution Availability (for core systems e.g. ERP, CRM, SRM, BW)

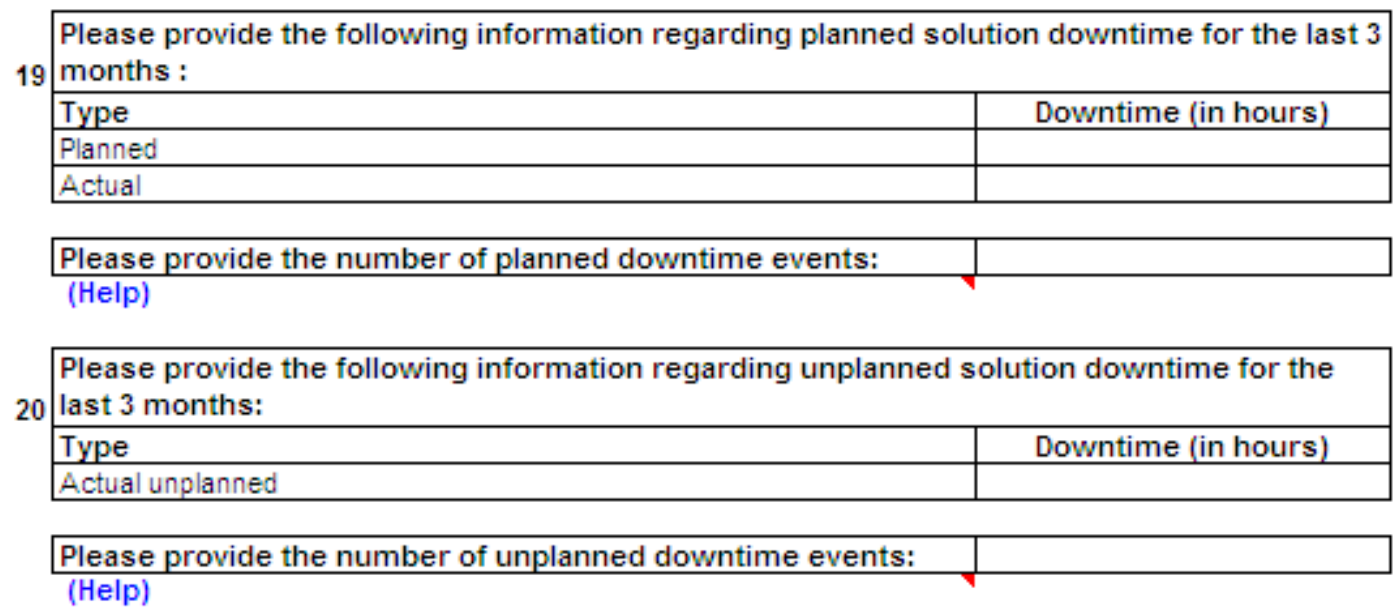


TCO: SAP Infrastructure/ Systems Availability (for core systems e.g. ERP, CRM, SRM, BW)

Please provide the following information regarding planned SAP infrastructure/ systems 21 downtime for the last 3 months:

\begin{tabular}{|l|c|}
\hline Type & Downtime (in hours) \\
\hline Planned & \\
\hline Actual & \\
\hline
\end{tabular}

Please provide the number of SAP infrastructure/ systems planned downtime events:

(Help)

Please provide the following information regarding unplanned SAP infrastructure/ systems 22 downtime for the last 3 months:

\begin{tabular}{|l|l|}
\hline Type & Downtime (in hours) \\
\hline Actual Unplanned &
\end{tabular}

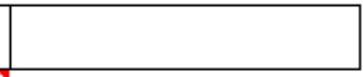

unplanned downtime events:

(Help)

\section{TCO: Incidents And Change Management}

23 Please provide the following information regarding incidents (including service requests and auto gen tickets):

\begin{tabular}{|l|c|c|}
\hline Please provide the number of incidents/ tickets and time spent on resolving them for the following time periods: \\
\hline Time Period & $\begin{array}{c}\text { Total SAP Incidents Or } \\
\text { Tickets Opened }\end{array}$ & $\begin{array}{c}\text { Total Labor Hours Spent } \\
\text { Resolving Incidents Or } \\
\text { Tickets }\end{array}$ \\
\hline Last month & & \\
\hline Last quarter & & \\
\hline Last year & & \\
\hline
\end{tabular}

Please provide a breakdown of the total incidents for last 3 months:

\begin{tabular}{|l|l|}
\hline Category & Number Of Incidents \\
\hline Break-Fix & \\
\hline Enhancement & \\
\hline End User & \\
\hline Other & \\
\hline
\end{tabular}

Other

(Help)

\begin{tabular}{|c|c|}
\hline $\begin{array}{l}\text { Please provide the percentag } \\
\text { for last } 3 \text { months: }\end{array}$ & se headcount categori \\
\hline Headcount Category & Number Of Incidents \\
\hline Application Support & \\
\hline Programmers/ Developers & \\
\hline Data Center/ System Management & \\
\hline Data Management & \\
\hline Help Desk & \\
\hline End User Training (if appropriate) & \\
\hline Resolved By SAP & \\
\hline
\end{tabular}

(Help)

24 Please indicate how the incidents percentages by resolution cal $\quad$ Estimated

25 Please indicate whether you have a super/ key user program:

If you are having super/ key user program, please indicate the

percentage of end-user incidents they resolve: 
Please provide the following information regarding the changes associated with all of your 26 solutions (e.g., ERP, SCM, SRM etc.):

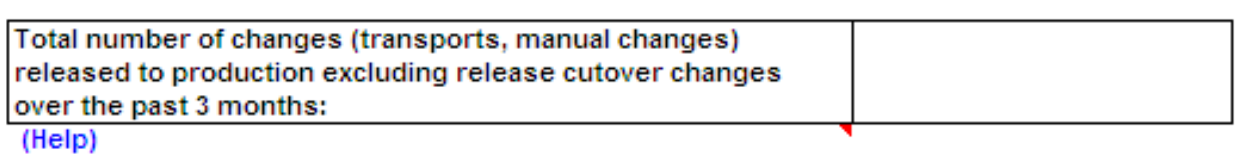

\begin{tabular}{|l|l|}
\hline Please provide a breakdown of transports for the last 3 months: \\
\hline Category & Number Of Transports \\
\hline Break-Fix & \\
\hline Enhancement & \\
\hline Other & \\
\hline
\end{tabular}

(Help)

Please indicate what best characterizes your change management strategy:

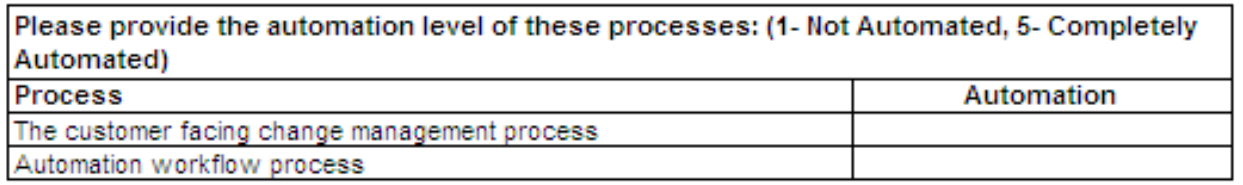

Please indicate whether you have automation of the 1-

transport process (ABAP or Java Stack):

Page 3

SAP.

TCO: SAP Related IT Ongoing Operations Metrics

Please provide your total IT Spend for the last financial year by the categories specified below 27 (in selected currency):

\begin{tabular}{|l|l|}
\hline People/ Services Related Costs & \multicolumn{1}{|c|}{ Answer } \\
\hline Internal Headcount Costs (excluding capitalization/ depreciation) & \\
\hline External Spend (excluding capitalization/ depreciation) & \\
\hline Contracting/ Consulting & \\
\hline Outsourcing & \\
\hline Depreciation/ Amortization (capitalized services) & \\
\hline
\end{tabular}

Depreciation/ Amortization (capitalized services)

\begin{tabular}{|l|c|}
\hline Technology/ Infrastructure Costs & Answer \\
\hline Technology Costs (software, hardware, networking. PC's etc.) & \\
\hline Depreciation/ Amortization & \\
\hline
\end{tabular}

\begin{tabular}{|l|c|}
\hline Annual Overall IT Budget & Answer \\
\hline T Operating Budget Total (excluding depreciation/ amortization) & \\
\hline Depreciation/ Amortization Total & \\
\hline
\end{tabular}

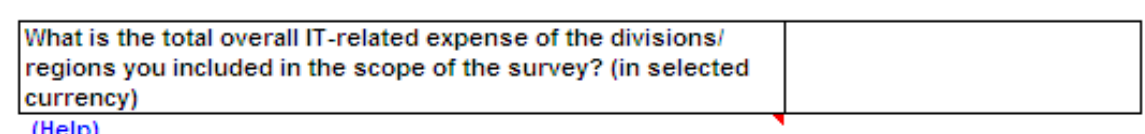
(Help)

Please provide your total SAP Budget for the last financial year by the categories specified 28 below (in selected currency):

\begin{tabular}{|l|l|}
\hline SAP People/ Services Related Costs & \multicolumn{1}{|c|}{ Answer } \\
\hline Internal Headcount Costs (excluding capitalization/ depreciation) & \\
\hline External Spend (excluding capitalization/ depreciation) & \\
\hline Contracting/ Consulting & \\
\hline Outsourcing & \\
\hline Depreciation/ Amortization (capitalized services) & \\
\hline
\end{tabular}


SAP Technology/ Infrastructure Costs

Technology Costs (e.g. software/ hardware maintenance, non-people

related costs) excluding depreciation/ amortization

Depreciation/ Amortization

\begin{tabular}{|l|c|}
\hline Annual Overall SAP Budget & Answer \\
\hline SAP Budget Total (excluding depreciation/ amortization) & \\
\hline Depreciation/ Amortization Total & \\
\hline
\end{tabular}

\begin{tabular}{|l|l|}
\hline $\begin{array}{l}\text { Please provide your Total Annual SAP Budget for last financial } \\
\text { year (in selected currency): }\end{array}$ & \\
\hline
\end{tabular}

\begin{tabular}{|l|c|}
\hline Total SAP Related FTEs (internal only) & Answer \\
\hline Number Of Internal SAP FTEs & \\
\hline Average Loaded Cost Per Internal SAP FTE & \\
\hline
\end{tabular}
(Help) $29 \begin{aligned} & \text { Please provide the SAP budget for ongoing operations and support ONLY (no } \\ & \text { implementation/ upgrade project costs and no depreciation/ amortization) for the last financial } \\ & \text { year by the categories specified below (in selected currency): }\end{aligned}$

\begin{tabular}{|l|l|}
\hline SAP People/ Services Related Costs & Answer \\
\hline Internal Headcount Costs (excluding capitalization/ depreciation) & \\
\hline External Spend (excluding capitalization/ depreciation) & \\
\hline Contracting/ Consulting & \\
\hline Outsourcing & \\
\hline
\end{tabular}

\begin{tabular}{|l|c|}
\hline SAP Technology/ Infrastructure Costs & Answer \\
\hline $\begin{array}{l}\text { Technology Costs (e.g. software/ hardware maintenance, non - people } \\
\text { related costs) excluding depreciation/ amortization }\end{array}$ & \\
\hline
\end{tabular}

\begin{tabular}{|l|l|}
\hline $\begin{array}{l}\text { Please provide your Annual Overall SAP Operating Budget for } \\
\text { ongoing operations and support ONLY (in selected currency): }\end{array}$ & \\
\hline
\end{tabular}

\begin{tabular}{|l|l|}
\hline Total SAP Support FTEs (internal only) & \multicolumn{1}{|c|}{ Answer } \\
\hline $\begin{array}{l}\text { Number Of Internal SAP Support FTEs (should match the total provide in } \\
\text { Q33) }\end{array}$ & \\
\hline Average Loaded Cost Per Internal SAP Support FTE & \\
\hline IHoln) & \\
\hline
\end{tabular}

Please break down your SAP related IT operations costs by function as defined below:

IMPORTANT: Only allocate the net FTE portion that is applicable to support operations (not implementation/ upgrade projects).

30 Please enter monetary values in thousands in the currency you selected before. Please provide based on most recent annual figures -

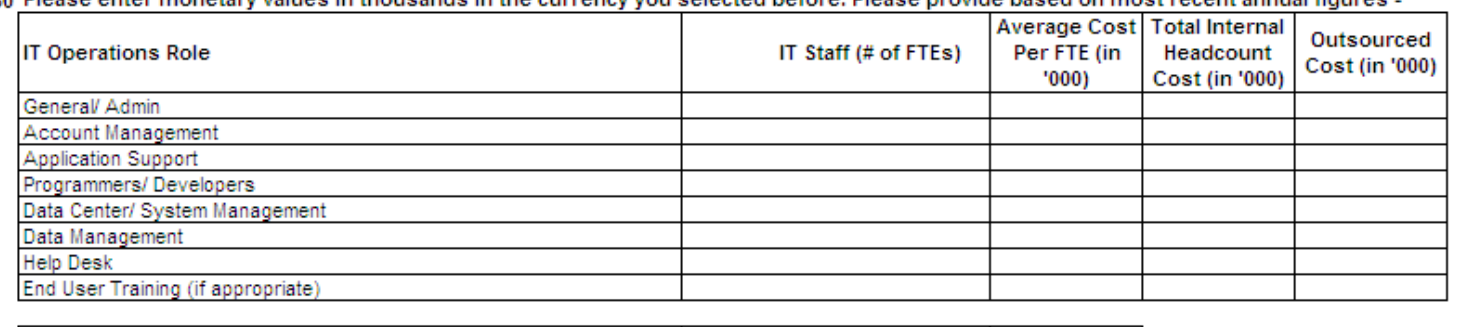

\begin{tabular}{|l|l|l|}
\hline IT Operations Role & External Spend (in '000) & $\begin{array}{c}\text { Total Cost By } \\
\text { Function (in } \\
\text { '000) }\end{array}$ \\
\hline General Admin & & \\
\hline Account Management & & \\
\hline Application Support & & \\
\hline Programmers/ Developers & & \\
\hline Data Center/ System Management & & \\
\hline Data Management & & \\
\hline Help Desk & & \\
\hline End User Training (if appropriate) & & \\
\hline
\end{tabular}


Please specify the percentage allocation by role to pure support, "keeping the lights on" activities such as issue resolution, problem fixes, etc. vs. continuous improvement tasks such as solution enhancements outside implementation projects/major functionality releases e.g. adding/ changing screen fields, adding/ enhancing reports, etc: (Please note: this will not affect your previous answers and will provide an

31 additional analysis)
\begin{tabular}{|l|c|c|c|}
\hline IT Operations Role & $\begin{array}{c}\text { IT Staff Percentage' } \\
\text { Allocation To Pure Support } \\
\text { (vs. cont. improvements/ } \\
\text { enhancements) }\end{array}$ & $\begin{array}{c}\text { 'Outsourcing' } \\
\text { Spend } \\
\text { Percentage } \\
\text { Allocation To } \\
\text { Pure Support }\end{array}$ & $\begin{array}{c}\text { 'Contracting/ } \\
\text { consulting' } \\
\text { spend } \\
\text { Percentage } \\
\text { Allocation To }\end{array}$ \\
\hline GeneraV Admin & & & \\
\hline Account Management & & & \\
\hline Application Support & & & \\
\hline Programmers / Developers & & & \\
\hline Data Center/ System Management & & & \\
\hline Data Management & & & \\
\hline Help Desk & & & \\
\hline End User Training (if appropriate) & & & \\
\hline
\end{tabular}

(Help)

TCO: Support Organization

\begin{tabular}{|c|c|c|}
\hline \multicolumn{3}{|c|}{$\begin{array}{l}32 \text { Please indicate whether have a COE/ CCC: } \\
\text { (Help) }\end{array}$} \\
\hline & $\begin{array}{l}\text { Please indicate whether your COE/ CCC certified (select "No" if } \\
\text { you do not have a } \operatorname{COE} / \mathrm{CCC} \text { ): }\end{array}$ & \\
\hline \multicolumn{3}{|c|}{ 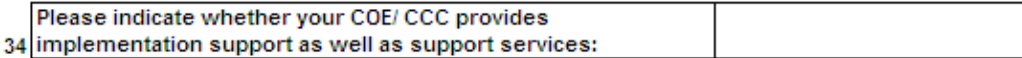 } \\
\hline \multicolumn{3}{|c|}{35 Please indicate your funding model for the $\mathrm{COE} / \mathrm{CCC}$ : } \\
\hline 36 & $\begin{array}{l}\text { Please indicate the degree of centralization of your support } \\
\text { organization: }\end{array}$ & \\
\hline & $\begin{array}{l}\text { Please specify, if "Others" has been chosen as the degree of } \\
\text { centralization: }\end{array}$ & \\
\hline
\end{tabular}

Please indicate which regions does the support organization

37 service:

Would you like to add comments/clarifications for the Total

38 Cost of Ownership KPI information provided above?

Page 4 


\section{TCO: Best Practices}

On a scale of 1-5, please rank each best practice in terms of importance and degree of coverage: Importance: $\mathbf{1}$ = Not important; 5 = Extremely important

Coverage: 1 = No coverage today - Organization does not employ this best practice; $5=$ Best practice is fully adopted Please indicate IA for both importance and coverage if best practice is not applicable to your organization

39 Best Practices - IT Governance
\begin{tabular}{|l|l|l|}
\hline \multicolumn{1}{|c|}{ Best Practice } & Importance & Coverage \\
\hline Company's I decisions are strategically aligned with the business needs & & \\
\hline $\begin{array}{l}\text { Company's } 3-5 \text { year future growth trend is kept in mind for deciding investment level and } \\
\text { setting priority }\end{array}$ & & \\
\hline The Company's ח performance management is linked with the business outcomes & & \\
\hline The Company's I Architecture is an integral part of top management's business planning & & \\
\hline Company has a strategy to upgrade T Infrastructure in an incremental manner & & \\
\hline
\end{tabular}

40 Best Practices - Value Management

Best Practices - Value Management
\begin{tabular}{|l|l|l|}
\hline \multicolumn{1}{|c|}{ Best Practice } & Importance & Coverage \\
\hline$\pi$ business case incorporates financial outcomes into the annual operating plan/ budget & & \\
\hline$\Pi$ operating metrics for initiatives are linked to financial measures, including incentive plans & & \\
\hline$\Pi$ implementation program includes regular business case reviews as a part of governance & & \\
\hline$\Pi$ tracks value realized from SAP implementations & & \\
\hline $\begin{array}{l}\text { T continue to optimize the value from the SAP solutions on a regular basis after being fully } \\
\text { operational }\end{array}$ & & \\
\hline $\begin{array}{l}\text { The business understands the full lifecycle costs and benefits of our existing and planned } \\
\text { SAP solution/s }\end{array}$ & & \\
\hline
\end{tabular}

41 Best Practices - Solution Portfolio Management

\begin{tabular}{|c|c|c|}
\hline Best Practice & Importance & Coverage \\
\hline \multicolumn{3}{|l|}{ The company has a consolidated single solution/ platform landscape } \\
\hline \multicolumn{3}{|l|}{ The company has a strategy in place for a single solution/ platform landscape consolidation } \\
\hline \multicolumn{3}{|l|}{ The company has a strategy for the application of support and enhancement packs } \\
\hline \multicolumn{3}{|l|}{ The strategy for the application of support and enhancement packs is enforced } \\
\hline \multicolumn{3}{|l|}{ The company has a no-modification strategy } \\
\hline \multicolumn{3}{|l|}{ The business units have incentives aligned with the adoption of a standard, common solution } \\
\hline \multicolumn{3}{|l|}{ The company has a master data strategy to drive common definitions and standards } \\
\hline \multicolumn{3}{|l|}{ Master data strategy is already implemented or is in the process of implementing } \\
\hline \multicolumn{3}{|l|}{$\begin{array}{l}\text { The company always evaluates licensed SAP solution for meeting business requirements } \\
\text { before looking at niche products }\end{array}$} \\
\hline \multicolumn{3}{|l|}{ The company has a strategy to maximize the value of integration for the SAP solutions } \\
\hline
\end{tabular}

42 Best Practices - IT Service Organization And Delivery

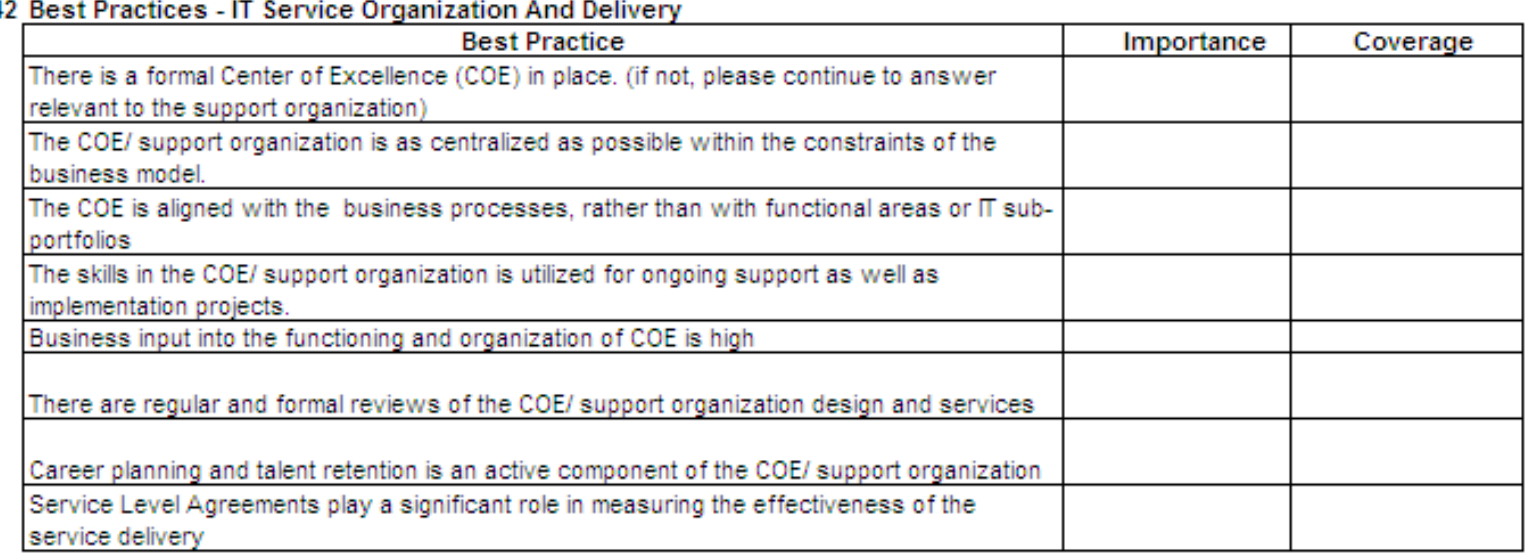




43 Best Practices - Business Process Improvement And Test Management
\begin{tabular}{|l|l|l|}
\hline \multicolumn{1}{|c|}{ Best Practice } & Importance & Coverage \\
\hline $\begin{array}{l}\text { A standardized end-to-end test management process exists for both new developments as } \\
\text { well as for maintenance of the productive solution, including the corresponding approval } \\
\text { procedures }\end{array}$ & & \\
\hline $\begin{array}{l}\text { Business critical processes are technically analyzed end to end, including interfaces, with } \\
\text { focus on performance, technical correctness, transactional correctness, and data } \\
\text { consistency }\end{array}$ & & \\
\hline $\begin{array}{l}\text { Business key performance indicators are defined to measure the success of the business } \\
\text { process execution and to detect deviations of the business process flow }\end{array}$ & \\
\hline
\end{tabular}

44 Best Practices - Business Continuity And TCO
\begin{tabular}{|l|l|l|}
\hline \multicolumn{1}{|c|}{ Best Practice } & Importance & Coverage \\
\hline $\begin{array}{l}\text { There is a defined process to conduct end-to-end root cause analysis across the software } \\
\text { components using the "SAP Solution Manager Diagnostics" functionality }\end{array}$ & \\
\hline $\begin{array}{l}\text { Automated procedures for monitoring the infrastructure (including, hardware, network, } \\
\text { systems, operating system) are in place }\end{array}$ & & \\
\hline $\begin{array}{l}\text { Automated monitoring and error handling procedures for mission critical business processes } \\
\text { and interfaces are in place }\end{array}$ & & \\
\hline There are defined procedures to ensure data integrity across SAP and non-SAP components & & \\
\hline A defined strategy exists to control database growth as well as an archiving concept & & \\
\hline
\end{tabular}

Please describe other best practices your company has adopted to drive Total 45 Cost of Ownership performance:

Optional 3rd Party Involvement:

46 Please provide the name, email address, phone number and organization name of any person(s) other than yourself you wish to give permission to actively participate in the benchmarking process. This person(s) will be included in any and all interactions between you and the SAP team related to the validation and comparative results of this survey. By entering this persons contact information, you indicate that you are giving permission for this person(s) to view your organization's survey data, benchmark results, and related communications; to participate in meetings; and to submit/correct benchmark related data to SAP on your behalf. You also agree that, regarding all aspects of the SAP Benchmarking program, this person(s) is subject to the same level of confidentiality to you as you are to SAP. 


\section{APPENDIX VI: Card Sorting}

\section{Card Sorting Attributes}

\begin{tabular}{|c|c|}
\hline \multirow[t]{5}{*}{ IT Governance } & Company's IT decisions are strategically aligned with the business needs \\
\hline & Company's 3-5 year future growth trend is kept in mind for deciding investment level and setting priority \\
\hline & The Company's IT performance management is linked with the business outcomes \\
\hline & The Company's IT Architecture is an integral part of top management's business planning \\
\hline & Company has a strategy to upgrade IT Infrastructure in an incremental manner \\
\hline \multirow[t]{6}{*}{$\begin{array}{l}\text { Value } \\
\text { Management }\end{array}$} & IT business case incorporates financial outcomes into the annual operating plan/ budget \\
\hline & IT operating metrics for initiatives are linked to financial measures, including incentive plans \\
\hline & IT implementation program includes regular business case reviews as a part of governance \\
\hline & IT tracks value realized from SAP implementations \\
\hline & IT continue to optimize the value from the SAP solutions on a regular basis after being fully operational \\
\hline & The business understands the full lifecycle costs and benefits of our existing and planned SAP solution/s \\
\hline \multirow[t]{3}{*}{$\begin{array}{l}\text { Business } \\
\text { Improvement }\end{array}$} & $\begin{array}{l}\text { A standardized end-to-end test management process exists for both new developments as well as for } \\
\text { maintenance of the productive solution, including the corresponding approval procedures }\end{array}$ \\
\hline & $\begin{array}{l}\text { Business critical processes are technically analysed end to end, including interfaces, with focus on } \\
\text { performance, technical correctness, transactional correctness, and data consistency }\end{array}$ \\
\hline & $\begin{array}{l}\text { Business key performance indicators are defined to measure the success of the business process } \\
\text { execution and to detect deviations of the business process flow }\end{array}$ \\
\hline \multirow[t]{3}{*}{$\begin{array}{l}\text { IT Strategy and } \\
\text { Business } \\
\text { Alignment }\end{array}$} & The company is using IT to enable strategic and competitive advantages \\
\hline & $\begin{array}{l}\text { The company has established common, simple and streamlined IT and business process standards across } \\
\text { the organization }\end{array}$ \\
\hline & $\begin{array}{l}\text { The company has defined IT roles and responsibilities which are consistently applied across the } \\
\text { organization }\end{array}$ \\
\hline
\end{tabular}




\begin{tabular}{|c|c|}
\hline & $\begin{array}{l}\text { The company undergoes a formal budgeting and planning process to approve initiatives and drive } \\
\text { business value }\end{array}$ \\
\hline & The company undergoes a formal annual portfolio rationalization process to reduce operating expense \\
\hline & The company has a strategic IT roadmap or rolling 3-5 year plan based on business and IT strategy \\
\hline & Regular IT and business planning meetings are conducted, with a joint planning methodology in place \\
\hline & IT is included in the prioritization process early on so that an appropriate roadmap can be developed \\
\hline & IT facilitates a high degree of integration with the company's ecosystem \\
\hline & Business has embraced IT as their responsibility \\
\hline \multirow[t]{5}{*}{$\begin{array}{l}\text { Business } \\
\text { Continuity and } \\
\text { TCO }\end{array}$} & $\begin{array}{l}\text { There is a defined process to conduct end-to-end root cause analysis across the software components } \\
\text { using the "SAP Solution Manager Diagnostics" functionality }\end{array}$ \\
\hline & $\begin{array}{l}\text { Automated procedures for monitoring the infrastructure (including, hardware, network, systems, operating } \\
\text { system) are in place }\end{array}$ \\
\hline & $\begin{array}{l}\text { Automated monitoring and error handling procedures for mission critical business processes and interfaces } \\
\text { are in place }\end{array}$ \\
\hline & There are defined procedures to ensure data integrity across SAP and non-SAP components \\
\hline & A defined strategy exists to control database growth as well as an archiving concept \\
\hline \multirow[t]{11}{*}{$\begin{array}{l}\text { Solutions/IT } \\
\text { Portfolio } \\
\text { Management }\end{array}$} & The company has a consolidated single solution/ platform landscape \\
\hline & The company has a strategy in place for a single solution/ platform landscape consolidation \\
\hline & The company has a strategy for the application of support and enhancement packs \\
\hline & The strategy for the application of support and enhancement packs is enforced \\
\hline & The company has a no - modification strategy \\
\hline & The company enforces the no - modification strategy \\
\hline & The business units have incentives aligned with the adoption of a standard, common solution \\
\hline & The company has a master data strategy to drive common definitions and standards \\
\hline & Master data strategy is already implemented or is in the process of implementing \\
\hline & $\begin{array}{l}\text { The company always evaluates licensed SAP solution for meeting business requirements before looking at } \\
\text { niche products }\end{array}$ \\
\hline & The company has a strategy to maximize the value of integration for the SAP solutions \\
\hline
\end{tabular}




\section{System Quality}

16. Data from the IS often needs correction

17. Data from the IS is current enough

18. The IS is missing key data

19. The IS is easy to use

20. The IS is easy to learn

21. It is often difficult to get access to information that is in the IS

22. The IS meets the units requirements

23. The IS includes necessary features and functions

24. The IS always does what it should

25. The IS user interface can be easily adapted to ones personal approach

26. The IS system is always up and running as necessary

27. The IS system responds quickly enough

28. The IS requires only the minimum number of fields and screens to achieve a task

29. All data within the IS is fully integrated and consistent

30. The IS can be easily modified, corrected or improved.

\section{Organizational Impact}

8. The IS is cost effective

9. The IS has resulted in reduced staff costs

10. The IS has resulted in cost reductions (e.g. inventory holding costs, administration expenses)

11. The IS has resulted in overall productivity improvement

12. The IS has resulted in improved outcomes or outputs

13. The IS has resulted in an increased capacity to manage a growing volume of activity

14. The IS has resulted in improved business processes. 


\section{APPENDIX VII: Archival Analysis}

\section{Overview of SAP Application}

Introduction

The German company SAP is the eighth largest software company in the world. Its products are integrated on-line real-time business applications.

For many years the flagship product has been the real-time system $\mathrm{R} / 2$, which is an IBM mainframe based product. The $R / 3$ product is a client server based version of the product - using Unix as a technology platform.

$\mathrm{R} / 3$ is a highly integrated open systems environment. The applications embodied within it are designed to automate almost all areas of medium to large sized businesses. Emphasis is placed on business areas such as accounting and finance, manufacturing, production planning, human resources, plant maintenance, project maintenance and quality assurance.

In January 2004, a project commenced to build a new Production server (PortalPrd) for users to login to the SAP HR Portal via URL

portalprd.telecom.co.nz). This new Portal will deliver full ESS (Employee Self Service) and MSS (Manager Self Service) functions. It includes tasks such as timesheeting, leave applications and approvals, career management and reporting. The data for all these functions comes from the backend systems (SE241, SE242, SE243 and SF916). The portal is just a way of gaining access to it. Currently the Internet Transaction Server (ITS) called CP839 provides the front-end for users to log into. Once this new HR SAP portal goes into production, it will take the front-end role of the HR SAP system from CP730.

The idea behind SAPs client server philosophy is to exploit the distribution of parts of the system across several computers and to fully utilise the power of the desktop PC. The client server concept provides a high degree of flexibility with regards to configuration options.

The core of the system is the database server, which carries out all database changes and batch processes.

The application programs reside on application servers, which surround the database server. Each of these systems contains a complete copy of the $\mathrm{R} / 3$ kernel system. The technical core of the SAP system is referred to as the Basis System and is written in ANSI-C. All of the SAP applications are written in SAP's own 4GL, called ABAP/4. A number of PCs are attached to each application server and act as presentation servers. All of the presentation processing is carried out on the desktop. 


\section{Overview of SAP Application, Continued}

History In the middle of 1993, the PACE group was commissioned to rationalize and prioritise the 52 (then) BIS projects that existed at the time.

Following the rationalisation, individual projects were divided into two groups to form two sub-projects (one which was Profile - PRO for projects, FI for finance and LE for logistics) and placed in the Super Project "Resource Management and Analysis" (RMA).

In the middle of 1994, the Project Management project was added to the Profile sub-project.

In March 1998 a new project, named Antelope, was formed to review the processes performed in SAP. This project re-engineered many of the processes, upgraded SAP to version 3.1a and then to version 4.0b (in February 1999) and replatformed it to a Sun Enterprise System 10000.

In March 2001 the SAP R/3 system was upgraded from 4.0B to 4.6C. The project was a technical upgrade only and there was no process improvement.

In July 2001 SAP R/3 was rolled out to the AAPT group of companies.

In February 2002 SAP Playpen was shunted from SE237 to SE244.

In March 2004, EDS and Intelligroup joined to deliver a fully operational SAP HR solution (a component of SAP) across to the Telecom Group. Access to the solution is via a SAP supported browser version supplied by Telecom NZ. EDS and Intelligroup delivered SAP HR to support the following business functions:

- Organizational Management

- Personnel Administration

- Performance and Compensation Management including Appraisals

- Recruitment (interface to RecruitSoft)

- Personnel Development

- Training and Event Management

- Employee Self Service

- Manager Self Service

- Portals/Security

- Interfaces

- Data Conversions

- Reporting

- Retain SPOT Telephone Directory.

In October 2004, the SAP HR Portal project (access via URL

portalprd.telecom.co.nz) went live. This new Portal delivers full ESS (Employee Self Service) and MSS (Manager Self Service) functions.

Continued on next page 


\section{Overview of SAP Application, Continued}

History, continued
The pre-production server SE244 was refreshed by server SF2184 in March 2007.

In June 2008 the HP1161 (AKMDRFS001) server was decommissioned.

In December 2008 the development environment was migrated from SE245 to SF2184.

In 1Q2009 the staging environment was migrated from SE245 to ST2777 (application) and ST2779 (database).

The production environment was migrated from SE241, SE242 and SE243 to ST2774, ST2775, ST2776, ST2778 and a new production router (HP2780) was introduced.

In October 2009 six new SAP HR portal servers were introduced under WR 144572. The servers were SF1853, ST2769, ST2770, ST2771, ST2772 and ST2773.

In the first half of 2010 the following activities took place:

- CP1188 was decommissioned (WR235667). The development portal (PID) was relocated to SF1853 (app and DB) and the Acc Portal (PIA) was relocated to ST2769 (app) and ST2773 (DB).

- The production portal (PIP) was relocated from HP1198 to ST2770/ST2771 (app) and ST2772 (DB). 


\section{Overview of SAP Application, Continued}

Business benefit The following business benefits are expected as a result of the implementation of SAP R/3 4.6c Human Resources with Enterprise Portal 6.0 and BW 3.0b:

- Increased productivity by connecting people, processes, and information so employees conduct business efficiently, effectively, and in line with business goals and strategies

- Improved change processes and increased market positioning by integrating corporate vision with individual tasks

- Reduced administrative costs through streamlined HR processes

- Enhanced globalisation, with regulatory support for Telecom's global organization

- Improved relationships through networking, communication, and data sharing among employees, managers, and business units

- Increased employee retention rates through greater empowerment and job satisfaction

- Expanded access to standardised reports and legal reporting capabilities

- Alignment of business to best practices

- Cost reduction through the decommissioning or integration of disparate HR systems

- Increased profitability through the alignment of talent and experience with key corporate initiatives.

Telecom

Portfolio

Manager

Users

Expected life
Yam Shung Wong

Primary Portfolio Manager

Email: yamshung.wong@telecom.co.nz

Most employees within the Telecom and AAPT use the SAP HR tools. Approximately 5,500 users in New Zealand and approximately 1,800 in Australia.

SAP is a core system that follows a supplier upgrade path, with a release upgrade anticipated every 2 years. Replacement of SAP in the foreseeable future is unlikely. 


\section{Overview of SAP Application, Continued}

SAP R/3 modules

Systems replaced by SAP

Availability
The SAP modules purchased for the Telecom system are:

- Projects System

- Controlling

- Assets Management

- General Ledger

- Accounts Payable

- Accounts Receivable

- Materials Management

- Warehouse Management

- Sales and Distribution

- Basis Component

- Common Applications

- Payroll

- ECCS

- Human Resources.

The following is a list of the applications that have been replaced by SAP and the existing data was not kept:

- Account Rep Reporting

- Reflex Contract Management

- Inventory Analysis

- Inventory Forecasting

- Overseas Purchasing

- Vendor Search

- Vendor Reporting

- Logistics Supply Contracts Management

- SRS

- Disbursement Register

- Job Tracking System

- Contract Management System

- Bar-coding.

- ESSBASE

- PMP.

The application is available 24 hours per day, seven days a week. All backups are online. There will also be planned outages during month-end processing and on scheduled occasion for maintenance. 


\section{Overview of SAP Application, Continued}

Future As released by SAP.

amendments

HP support teams

Service

Delivery

Manager

(SDM)

Application portfolio and platforms:
The following HP teams are involved in the support of the SAP application

- ITO Unix Engineering

- Workplace Services (WPS)

- Application Services Australia and New Zealand

- Oracle Database Administration

- NZ Contact Centre (NZCC).

For further information on HP support teams refer to Chapter 4 - Support Requirements in this manual.

The Service Delivery Managers provide an escalation point for the customer within HP Operations. They will assist in getting the correct focus on any issue impacting the customer.

The Service Delivery Manager for SAP is Jo Renner - 0272313415.

The application portfolio indicates the hours of online availability required of the application.

The following table details the application portfolio for SAP.

\begin{tabular}{|c|c|l|}
\hline & A & Online availability is required 24 hours x 7 days \\
\hline $\mathbf{X}$ & B & Online availability is required 7:00am - 11:00pm x 7 days \\
\hline & C & $\begin{array}{l}\text { Online availability is required 7:00am - 7:00pm x 6 days } \\
\text { (Mon - Sat) }\end{array}$ \\
\hline & D & $\begin{array}{l}\text { Online availability is required 8:00am - 5:00pm x 5 days } \\
\text { (Mon - Fri) }\end{array}$ \\
\hline
\end{tabular}




\section{Overview of SAP Application, Continued}

Application tier The application tier indicates which services are likely to be covered by the Application Maintenance Packet budget.

The following table details the application tier for SAP.

\begin{tabular}{|c|c|l|}
\hline & 1 & $\begin{array}{l}\text { Applications that are integral to Telecom's core day-to-day } \\
\text { business activities, which have immediate high customer } \\
\text { visibility }\end{array}$ \\
\hline $\mathbf{X}$ & 2 & $\begin{array}{l}\text { Applications that support Telecom's core day-to-day business } \\
\text { activities that have little or no immediate customer visibility }\end{array}$ \\
\hline & 3 & $\begin{array}{l}\text { In-house or back-office applications that do not affect } \\
\text { Telecom's core day-to-day business activities and have no } \\
\text { customer visibility }\end{array}$ \\
\hline & 4 & Applications that are inactive or are pending decommissioning \\
\hline & 5 & $\begin{array}{l}\text { Applications which Telecom has provided no budget for at all, } \\
\text { and are therefore not supported at all by SDG }\end{array}$ \\
\hline
\end{tabular}

Application Services A\&NZ coverage
The AS A\&NZ coverage indicates the hours that HP will have resources available to resolve faults.

The following table details the ADM (Application Delivery Maintenance) coverage for SAP.

\begin{tabular}{|c|c|l|}
\hline & A & Online availability is required 24 hours x 7 days \\
\hline & B & Online availability is required 7:00am - 11:00pm x 7 days \\
\hline & C & $\begin{array}{l}\text { Online availability is required 7:00am - 7:00pm x 6 days } \\
\text { (Mon - Sat) }\end{array}$ \\
\hline X & D & $\begin{array}{l}\text { Online availability is required 8:00am - 5:00pm x 5 days } \\
\text { (Mon - Fri) }\end{array}$ \\
\hline & Z & $\begin{array}{l}\text { All ADM services provided by a named third party supplier. } \\
\text { A work request is required for any maintenance or support work }\end{array}$ \\
\hline
\end{tabular}

Funding is provided within work packet WP804 for HP support of some SAP components (Basis support). 
Contact the HP work packet owner for further information:

- Heather McLean (heather.mclean@hp.com)

Overview of SAP Application, Continued

Key Production Key Production Environments are used by Service Delivery Managers and Environment service restoration teams in managing Severity 1 or 2 problems, to ensure restoration of the service to the Telecom client.

The SAP application and platforms are classified in the following Key Production Environment (KPE):

- Telecom Internal

Application specific software
The following table details the SAP application specific software installed on the SAP platforms.

\begin{tabular}{|l|l|l|}
\hline \multicolumn{1}{|c|}{ Platform } & \multicolumn{1}{|c|}{ Software } & Description \\
\hline ST2774 & SAP R/3 & SAP software \\
ST2775 & & \\
ST2776 & & \\
ST2777 & & \\
ST2778 & & \\
ST2779 & & \\
SF2184 & & \\
CP1042 & & \\
HP1162 & & \\
HP1274 & & \\
\hline
\end{tabular}




\begin{tabular}{|l|l|l|}
\hline SF1853 & NetWeaver v7.0 & SAP Portal \\
ST2769 & & \\
ST2770 & & \\
ST2771 & & \\
ST2773 & & \\
\hline
\end{tabular}

Application SAP supplied scripts are used to start/stop the SAP application. start/stop/restart

Application Log The system log is located in /var/adm/messages.

file locations 


\section{Chapter 2 \\ Technical Overview}

\section{Overview}

Introduction This chapter provides technical details of the hardware and software used within the SAP environment.

In this chapter This chapter covers the following topics.

\begin{tabular}{|l|c|}
\hline \multicolumn{1}{|c|}{ Topic } & See Page \\
\hline Hardware Configuration & $2-2$ \\
\hline Management Software & $2-7$ \\
\hline Databases & $2-8$ \\
\hline User Information & $2-10$ \\
\hline Network & $2-11$ \\
\hline
\end{tabular}




\section{Hardware Configuration}

\begin{tabular}{|c|c|c|c|c|}
\hline Environment & $\begin{array}{c}\text { Platform } \\
\text { Name }\end{array}$ & Platform Usage & Product Name & $\begin{array}{l}\text { Operating } \\
\text { System }\end{array}$ \\
\hline \multirow[t]{9}{*}{ Production } & ST2774 & Application server & Sun Sunfire T5120 & Solaris 2.10 \\
\hline & ST2775 & Application server & $\begin{array}{l}\text { Sun Enterprise } \\
\text { T5120 }\end{array}$ & Solaris 2.10 \\
\hline & ST2776 & Application server & $\begin{array}{l}\text { Sun Enterprise } \\
\text { T5120 }\end{array}$ & Solaris 2.10 \\
\hline & ST2778 & Database server & Sun Sunfire T5220 & Solaris 2.10 \\
\hline & HP2780 & SAP Router & HP Proliant BL460C & $\begin{array}{l}\text { MS Windows } \\
2003\end{array}$ \\
\hline & HP1162 & SAP Imaging server & HP Proliant DL360 & $\begin{array}{l}\text { MS Windows } \\
2000\end{array}$ \\
\hline & ST2770 & Application server (HR Portal) & Sun Sunfire T2000 & Solaris 2.10 \\
\hline & ST2771 & Application server (HR Portal) & Sun Sunfire T2000 & Solaris 2.10 \\
\hline & ST2772 & Database server (HR Portal) & Sun Sunfire T2000 & \begin{tabular}{|l|} 
Solaris 2.10 \\
\end{tabular} \\
\hline \multirow{4}{*}{$\begin{array}{l}\text { Development / } \\
\text { Training }\end{array}$} & SF2184 & $\begin{array}{l}\text { R/3 Training, Playpen and } \\
\text { Development SRM server }\end{array}$ & Sun Sunfire V490 & Solaris 2.9 \\
\hline & CP1042 & $\begin{array}{l}\text { Development and Acceptance } \\
\text { ITS server }\end{array}$ & $\begin{array}{l}\text { Compaq Proliant } \\
\text { DL380 }\end{array}$ & $\begin{array}{l}\text { MS Windows } \\
2000\end{array}$ \\
\hline & HP1274 & Development ITS server & $\begin{array}{l}\text { Compaq Proliant } \\
\text { DL380 }\end{array}$ & $\begin{array}{l}\text { MS Windows } \\
2003\end{array}$ \\
\hline & SF1853 & $\begin{array}{l}\text { Development Application and } \\
\text { Database server (HR Portal) }\end{array}$ & Sun Sunfire V440 & Solaris 2.10 \\
\hline \multirow[t]{4}{*}{ Staging } & ST2777 & R/3 Application server & Sun Sunfire T5120 & Solaris 2.10 \\
\hline & ST2779 & $\mathrm{R} / 3$ Database server & Sun Netra T5220 & Solaris 2.10 \\
\hline & ST2769 & Application Server (HR Portal) & Sun Sunfire T2000 & \begin{tabular}{|l|} 
Solaris 2.10 \\
\end{tabular} \\
\hline & ST2773 & Database Server (HR Portal) & Sun Sunfire T2000 & Solaris 2.10 \\
\hline
\end{tabular}


Hardware Configuration, Continued

Hardware locations
The SAP platforms are located as follows:

\begin{tabular}{|c|c|c|}
\hline $\begin{array}{c}\text { Platform } \\
\text { Name }\end{array}$ & Rack Name & Location \\
\hline HP1162 & MDR-A01-003 & \multirow{7}{*}{$\begin{array}{l}\text { Level } 5 \\
\text { Mayoral Drive Building } \\
31 \text { Airedale St } \\
\text { Auckland }\end{array}$} \\
\hline SF2184 & MDR-E04-007 & \\
\hline HP1274 & MDR-A03-003 & \\
\hline $\begin{array}{l}\text { ST2769 } \\
\text { ST2770 } \\
\text { ST2771 } \\
\text { ST2772 } \\
\text { ST2773 } \\
\text { ST2777 } \\
\text { ST2779 }\end{array}$ & MDR-C07-011 & \\
\hline $\begin{array}{l}\text { ST2774 } \\
\text { ST2775 } \\
\text { ST2776 } \\
\text { ST2778 }\end{array}$ & MDR-A08-002 & \\
\hline HP2780 & MDR-A03-001 & \\
\hline SF1853 & MDR-A08-003 & \\
\hline CP1042 & N/A & $\begin{array}{l}\text { Level } 4 \\
\text { CPC Exchange } \\
\text { 25-27 Cambridge St } \\
\text { Wellington }\end{array}$ \\
\hline
\end{tabular}


Hardware Configuration, Continued

Hardware asset The following table lists the asset tag and support coverage for the SAP tag and support hardware.

coverage

\begin{tabular}{|c|c|c|c|c|c|}
\hline Environment & $\begin{array}{c}\text { Platform } \\
\text { Name }\end{array}$ & Asset Tag & $\begin{array}{c}\text { Service } \\
\text { Type }\end{array}$ & $\begin{array}{c}\text { Hours of } \\
\text { Cover }\end{array}$ & $\begin{array}{c}\text { Service } \\
\text { Category }\end{array}$ \\
\hline \multirow[t]{9}{*}{ Production } & ST2774 & 30584165 & Full & $24 \times 7$ & $\mathrm{C}$ \\
\hline & ST2775 & 30584166 & Full & $24 \times 7$ & $\mathrm{C}$ \\
\hline & ST2776 & 30584167 & Full & $24 \times 7$ & $\mathrm{C}$ \\
\hline & ST2778 & 30584169 & Full & $24 \times 7$ & $\mathrm{C}$ \\
\hline & HP2780 & 30584171 & Full & $24 \times 7$ & $\mathrm{C}$ \\
\hline & HP1162 & EDS834119 & Full & $24 \times 7$ & $\mathrm{C}$ \\
\hline & ST2770 & 30584161 & Full & $24 \times 7$ & $\mathrm{C}$ \\
\hline & ST2771 & 30584162 & Full & $24 \times 7$ & $\mathrm{C}$ \\
\hline & ST2772 & 30584163 & Full & $24 \times 7$ & $\mathrm{C}$ \\
\hline \multirow{4}{*}{$\begin{array}{l}\text { Development / } \\
\text { Training }\end{array}$} & SF2184 & 30098295 & Full & $12 \times 5$ & B \\
\hline & CP1042 & EDS834019 & Full & $12 \times 5$ & B \\
\hline & HP1274 & 30066195 & Full & $12 \times 5$ & B \\
\hline & SF1853 & 30098154 & Full & $24 \times 7$ & $\mathrm{C}$ \\
\hline \multirow[t]{4}{*}{ Staging } & ST2769 & 30584160 & Full & $24 \times 7$ & $\mathrm{C}$ \\
\hline & ST2773 & 30584164 & Full & $24 \times 7$ & $\mathrm{C}$ \\
\hline & ST2777 & 30584168 & Full & $24 \times 7$ & $\mathrm{C}$ \\
\hline & ST2779 & 30584170 & Full & $24 \times 7$ & $\mathrm{C}$ \\
\hline
\end{tabular}

Data Centre The hardware service category definitions are:

hardware

service category

definitions

- A Base Service, $24 \times 7$ cover, no DRP

- B Full Service, $12 \times 5$ cover, no DRP

- C Full Service, $24 \times 7$ cover, no DRP 


\section{Hardware Configuration, Continued}

Hardware configuration
The following table lists the hardware configuration for the SAP platforms.

\begin{tabular}{|c|c|c|}
\hline Environment & $\begin{array}{c}\text { Platform } \\
\text { Name }\end{array}$ & Configuration \\
\hline \multirow[t]{8}{*}{ Production } & ST2774 & $\begin{array}{l}64 \times \text { CPUs } \\
65408 \mathrm{Mb} \text { RAM } \\
612 \mathrm{~Gb} \text { total disk installed }\end{array}$ \\
\hline & $\begin{array}{l}\text { ST2775 } \\
\text { ST2776 }\end{array}$ & $\begin{array}{l}64 \times \text { CPUs } \\
65408 \mathrm{Mb} \text { RAM } \\
\text { 340Gb total disk installed }\end{array}$ \\
\hline & ST2778 & $\begin{array}{l}64 \times \text { CPUs } \\
65408 \mathrm{Mb} \text { RAM } \\
2138 \mathrm{~Gb} \text { total disk installed }\end{array}$ \\
\hline & HP2780 & $\begin{array}{l}4 \times \text { CPUs } \\
144 \mathrm{~Gb} \text { total disk installed }\end{array}$ \\
\hline & HP1162 & $1 \times \mathrm{CPU}$ \\
\hline & ST2770 & $\begin{array}{l}32 \times \text { CPUs } \\
32760 \mathrm{Mb} \text { RAM }\end{array}$ \\
\hline & ST2771 & $\begin{array}{l}32 \times \text { CPUs } \\
32640 \mathrm{Mb} \text { RAM }\end{array}$ \\
\hline & ST2772 & $\begin{array}{l}16 \times \text { CPUs } \\
16256 \mathrm{Mb} \text { RAM } \\
\text { 57Gb total disk installed }\end{array}$ \\
\hline
\end{tabular}




\begin{tabular}{|l|l|l|}
\hline Development / & SF2184 & $4 \times$ CPUs \\
& & $32768 \mathrm{Mb}$ RAM \\
& & $3133 \mathrm{~Gb}$ total disk installed \\
\cline { 2 - 3 } & CP1042 & $2 \times$ CPUs \\
Development / & HP1274 & $73 \mathrm{~Gb}$ total disk installed \\
\hline \multirow{2}{*}{ Training } & & $2 \times$ CPUs \\
\cline { 2 - 3 } & SF1853 & $72 \mathrm{~Gb}$ total disk installed \\
& & $32768 \mathrm{CPU}$ ( RAM \\
& & $506 \mathrm{~Gb}$ total disk installed \\
\hline
\end{tabular}

Continued on next page 
Hardware Configuration, Continued

Hardware configuration (continued)

\begin{tabular}{|l|l|l|}
\hline \multicolumn{1}{|c|}{ Environment } & \multicolumn{1}{|c|}{ Platform } & \multicolumn{1}{c|}{ Configuration } \\
\hline Staging & ST2779 & $64 \times$ CPUs \\
$65408 \mathrm{Mb}$ RAM \\
\end{tabular}

HP technical support

The ITO Unix Engineering team is responsible for the technical support of the Sun servers.

The Workplace Services (WPS) team is responsible for the technical support of the HP and Compaq servers

Shared host Only SAP applications are co-hosted on the SAP servers. 


\section{Management Software}

Hardware Information Technology Outsourcing (ITO) installs various software tools specific software and scripts to assist with the management, scheduling and reporting on platforms monitored in the ITO environment. The following table details the software installed on the SAP platforms.

\begin{tabular}{|c|c|c|}
\hline $\begin{array}{c}\text { Platform } \\
\text { Name }\end{array}$ & Software & Description \\
\hline \multirow{7}{*}{$\begin{array}{l}\text { SF1853 } \\
\text { SF2184 } \\
\text { ST2769 } \\
\text { ST2770 } \\
\text { ST2771 } \\
\text { ST2772 } \\
\text { ST2773 } \\
\text { ST2774 } \\
\text { ST2775 } \\
\text { ST2776 } \\
\text { ST2777 } \\
\text { ST2778 } \\
\text { ST2779 }\end{array}$} & TSM Client & $\begin{array}{l}\text { Automated backup and tape management } \\
\text { software }\end{array}$ \\
\hline & Opsware & System patching software \\
\hline & CA Unicentre Agent & System monitoring and reporting tool \\
\hline & $\begin{array}{l}\text { Unix management and } \\
\text { monitoring scripts }\end{array}$ & Contact ITO Unix Engineering for details \\
\hline & $\begin{array}{l}\text { CA eTrust Policy } \\
\text { Compliance }\end{array}$ & OSAC audit compliance scanning \\
\hline & Control-SA & Security software \\
\hline & SMCsudo & Storage management software \\
\hline \multirow{5}{*}{$\begin{array}{l}\text { HP2780 } \\
\text { HP1162 } \\
\text { CP1042 } \\
\text { HP1274 }\end{array}$} & SCOM & System monitoring and reporting tool \\
\hline & TSM Client & $\begin{array}{l}\text { Automated backup and tape management } \\
\text { software }\end{array}$ \\
\hline & McAfee Virus Scan & Antivirus software \\
\hline & SMS & System patching software \\
\hline & ePCM & OSAC audit compliance scanning \\
\hline
\end{tabular}




\section{Databases}

Databases

The table below provides details on the SAP databases.

\begin{tabular}{|l|l|l|l|}
\hline \multicolumn{1}{|c|}{ Environment } & Platform Name & \multicolumn{1}{|c|}{ Database Name } & \multicolumn{1}{c|}{ Software } \\
\hline Production & ST2778 & PRD & Oracle 10.2.0.4.0 \\
\cline { 2 - 4 } & ST2772 & PIP & Oracle 10.2.0.4.0 \\
\hline Development / Test & SF2184 & D46 & Oracle 10.2.0.4.0 \\
\cline { 2 - 4 } & SF1853 & PID & Oracle 10.2.0.4.0 \\
\cline { 2 - 4 } Staging & ST2779 & A46 & Oracle 10.2.0.4.0 \\
\hline \multirow{2}{*}{$\begin{array}{l}\text { SF2184 } \\
\text { Sreduction / }\end{array}$} & D46 & Oracle 10.2.0.4.0 \\
\cline { 3 - 4 } & & Y40 & Oracle 10.2.0.4.0 \\
\cline { 3 - 4 } & & SMD & Oracle 10.2.0.4.0 \\
\cline { 2 - 4 } & ST2773 & PIA & Oracle 10.0.4.0 \\
\hline
\end{tabular}

House-keeping requirements
- Weekly full backup and Daily incremental backup. This is performed using the SAP BRBACKUP utility and TSM.

- Daily SAP checks. This provides information for tablespace monitoring, alert file checks and other database related monitoring.

Distribution of The disk layout for the PRD database follows a SAP standard layout. The data relevant files systems are:

Redo logs and their mirror copies

/oracle/PRD/mirrlog A

/oracle/PRD/mirrlogB

/oracle/PRD/origlog $\mathrm{A}$

/oracle/PRD/origlogB

Archived redo log files

/oracle/PRD/saparch

Data and index datafiles

/oracle/PRD/sapdata1 - /oracle/PRD/sapdata7

Temporary space for database reorganization work /oracle/PRD/sapreorg 
Databases, Continued

Database Scripts are installed on the SAP platforms to automatically stop/start the start/stop/restart SAP databases.

This can also be done manually by the SAP team.

Current sizing The following table details the size of the SAP production databases at the time of writing.

For up to date information contact the SAP support team (see Chapter 4 Support for contact details).

\begin{tabular}{|l|l|l|}
\hline \multicolumn{1}{|c|}{ Platform } & \multicolumn{1}{|c|}{ Database } & \multicolumn{1}{c|}{ Size } \\
Name & \multicolumn{1}{|c|}{ Name } & \\
\hline ST2778 & PRD & $1161 \mathrm{~Gb}$ \\
\hline ST2772 & PIP & $9 \mathrm{~Gb}$ \\
\hline
\end{tabular}

Nature of data The system holds all Telecom's financial data including accounts payable, general ledger, inventory, sales $\&$ distribution and logistics.

Importance of This data is critical to the operation of all areas of Telecom's business.

data

Archive Every full backup includes a double archive of the database redo logs.

requirements

Purging requirements

Data will be purged in conjunction with purging strategy. 


\section{User Information}

Location of SAP users are located in all Telecom sites across NZ, Australia, UK, USA users and Samoa.

Number of users

\begin{tabular}{|c|c|c|}
\hline $\begin{array}{l}\text { Go-Live or } \\
\text { Current Number }\end{array}$ & $\begin{array}{c}\text { Maximum } \\
\text { Concurrent Users }\end{array}$ & $\begin{array}{c}\text { Maximum Active User } \\
\text { Accounts }\end{array}$ \\
\hline 11,500 & $\begin{array}{l}\text { Average of } 600 \\
\text { (since Portal Go Live) }\end{array}$ & $\begin{array}{l}1600 \text { full users and } \\
11,500 \text { via the HR Portal }\end{array}$ \\
\hline
\end{tabular}

UNIX level security

Only HP application administration personnel and hardware support teams requirements will have access to the servers.

Application level security requirements

User software Internet Browser and SAP GUI application. interface

User hardware Standard Telecom desktop. 


\section{Network}

LAN/WAN Users connect to the SAP servers via the Telecom Internal Data Network (IDN).

Hardware dependencies

The main effect of failure will be to delay the data interfaces described in Chapter 3 - Interfaces.

\section{Chapter 3 \\ Interfaces}

\section{Overview}

Introduction This chapter provides details on the systems that interface with SAP, the methods of interface and impacts of failure.

In this chapter This chapter covers the following topics.

\begin{tabular}{|l|c|}
\hline \multicolumn{1}{|c|}{ Topic } & See Page \\
\hline Interfaces & $3-2$ \\
\hline
\end{tabular}




\section{Interfaces}

Interface

summary
For further information on the SAP application interfaces contact Telecom Finance Systems (Refer Chapter 4 - Support for contact details)

\section{Chapter 4 Support Requirements}

\section{Overview}

Introduction

This chapter details the support requirements and supporting teams for the SAP application.

In this chapter This chapter covers the following topics.

\begin{tabular}{|l|c|}
\hline \multicolumn{1}{|c|}{ Topic } & See Page \\
\hline Support Model Overview & $4-2$ \\
\hline Support Details & $4-3$ \\
\hline Additional Support Details & $4-11$ \\
\hline
\end{tabular}

Support numbers
The following numbers are available for support within the Telecom environment.

You will be presented with IVR options for the various menus available.

\begin{tabular}{|l|l|}
\hline \multicolumn{1}{|c|}{ Group } & \multicolumn{1}{|c|}{ Number } \\
\hline Telecom staff & Phone: 0800 805300 \\
\hline HP staff supporting Telecom & Phone: 0800 429 439 \\
\hline
\end{tabular}




\section{Support Model Overview}

Support overview diagram
The following diagram is taken from the Technology Operations' Support Model - SAP Hardware Replacement and Portal Rollout document.

SAP Hardware Replacement and Portal Support Overview

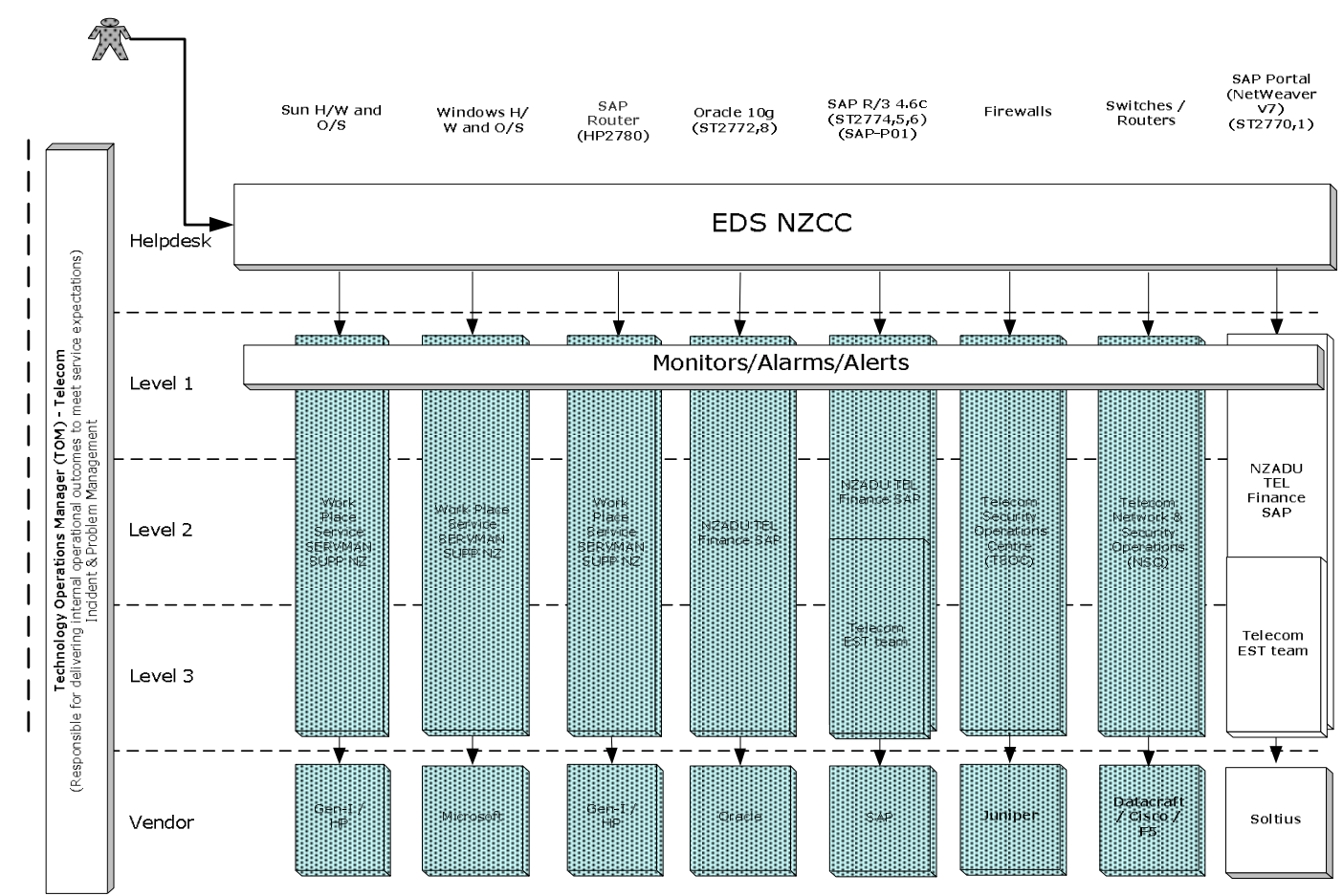




\section{Support Details}

Support The following table details each group's responsibilities for support, and contacts matrix provides contact information for each group.

DW team names are shown in brackets.

\section{ITO Unix Engineering (TCNW_SFW_UNIX_MPHASIS_IN or Z_SFW_UNIX_NZ)}

\begin{tabular}{|c|c|}
\hline Area of Support & Support Details \\
\hline $\begin{array}{l}\text { Responsible for the day to day } \\
\text { running of the UNIX platforms. } \\
\text { - } \text { Operation of system } \\
\text { hardware (IPL/reboot, } \\
\text { power-up, power-down } \\
\text { and restarts) } \\
\text { - System-level security } \\
\text { - Setup and maintenance of } \\
\text { non-application user ID } \\
\text { access } \\
\text { - Operating system installs } \\
\text { - Host communications } \\
\text { management } \\
\text { - Vendor management } \\
\text { Maintenance of PTF/Patch } \\
\text { register } \\
\text { Maintenance of tools, } \\
\text { utilities and system } \\
\text { management products } \\
\text { Escalation of severity } 1 \\
\text { issues. }\end{array}$ & $\begin{array}{l}\text { Business Hours } \\
\text { Rob Gouldstone } \\
\text { Unix Team Leader } \\
\text { L3, } 55 \text { - } 59 \text { Nelson Street } \\
\text { Auckland } \\
\text { Phone: } 093578676 \\
\text { Ext: } 4676\end{array}$ \\
\hline
\end{tabular}

Continued on next page 


\section{Support Details, Continued}

\section{ITO Workplace Services (WPS)}

Responsible for the day to day running of the Intel platforms.

\begin{tabular}{|c|c|}
\hline Area of Support & Contact Details \\
\hline $\begin{array}{l}\text { Server Management } \\
\text { - Wintel Server - hardware and } \\
\text { - } \text { operating systems } \\
\text { - } \text { Distributed backups } \\
\text { - Citrix } \\
\text { - VmWare } \\
\text { - Data Centre/Mid range services. }\end{array}$ & $\begin{array}{l}\text { Z_WPS_SERVMAN_SUPP_NZ } \\
\text { Team Leader: Simon Yates } \\
\text { Phone: } 094872215 \\
\text { TCNW_WPS_SUPPORT_MY } \\
(24 x 7)\end{array}$ \\
\hline $\begin{array}{l}\text { Directory Operations } \\
\text { - Active Directory services } \\
\text { - DNS/DHCP } \\
\text { - Replication and monitoring } \\
\text { - Group policy } \\
\text { - Security access standards } \\
\text { - Distributed server services } \\
\text { - Activate. }\end{array}$ & $\begin{array}{l}\text { Z_WPS_DIROPS_SUPP_NZ } \\
\text { Team Leader: Brett Duncan } \\
\text { Phone: } 094876389\end{array}$ \\
\hline $\begin{array}{l}\text { Software Distribution } \\
\text { - OS and security patch management } \\
\text { - Software distribution. }\end{array}$ & $\begin{array}{l}\text { Z_WPS_SOFTDIST_SUPP_NZ } \\
\text { Team Leader: Caroline Sealy } \\
\text { Phone: } 094872994\end{array}$ \\
\hline $\begin{array}{l}\text { End Point Security (EPS) } \\
\text { - Anti Virus. }\end{array}$ & $\begin{array}{l}\text { Z_SEC_ENDPOINT_AP } \\
\text { Team Leader: Deborah Hawkins } \\
\text { Email: EndpointSecurity@hp.com } \\
\qquad \text { (include Telecom NZ in subject line) }\end{array}$ \\
\hline
\end{tabular}




\begin{tabular}{|l|l|}
\hline End User Support & Z_WPS_ENDUSER_SUPP_NZ \\
- $\begin{array}{l}\text { Level } 2 \text { (Lan Admin) support } \\
\text { across capabilities and accounts }\end{array}$ & \\
- Desktop refresh & Team Leader: Peter Gaze \\
- CCC (Certification). & Phone: 094872351 \\
\hline
\end{tabular}

Continued on next page 


\section{Support Details, Continued}

\section{ITO SD Operations (Z_OPS_TNZ_DATACENTRES_NZ)}

\begin{tabular}{|l|lc|}
\hline \multicolumn{1}{|c|}{ Area of Support } & \multicolumn{1}{|c|}{ Support Details } \\
\hline $\begin{array}{l}\text { Responsible for the day to day } \\
\text { running of the following: }\end{array}$ & $\begin{array}{l}\text { ITO Operations (Auckland) } \\
\text { L5, 31 Airedale St, Auckland. } \\
\text { Phone: } 093577124\end{array}$ \\
$\begin{array}{l}\text { - } \begin{array}{l}\text { Batch processing } \\
\text { Rooms } \\
\text { Media management and }\end{array} \\
\begin{array}{l}\text { adherence to data retention plans } \\
\text { Extn: }\end{array}\end{array}$ & $\begin{array}{l}\text { Fax: } \\
\text { ITO Operations (Hamilton) }\end{array}$ \\
& L6, HTC Building, Hamilton \\
& Phone: 07 834 5141 \\
& Extn: & 75141 \\
& Fax: & 078383308 \\
\hline
\end{tabular}

\section{Change Management Telecom (TCNW_SMT_CM_NZ)}

\begin{tabular}{|c|c|}
\hline Area of Support & Support Details \\
\hline $\begin{array}{l}\text { Responsible for the Change } \\
\text { Management process to ensure that } \\
\text { any modifications into the Service } \\
\text { Delivery Environment are } \\
\text { performed in a controlled and } \\
\text { approved manner. }\end{array}$ & $\begin{array}{l}\text { Email: Telchangemgmt@eds.com } \\
\text { Escalation: } \\
\text { Sharon Lintott } \\
\text { Phone: 04-528-1790 } \\
\text { Cell: 0210-472-255 } \\
\text { Email: sharon.lintott@hp.com }\end{array}$ \\
\hline
\end{tabular}




\section{Support Details, Continued}

\section{New Zealand Contact Centre (TCNW_CCO_SUPPORT_PH)}

\begin{tabular}{|c|c|}
\hline Area of Support & Contact Details \\
\hline $1^{\text {st }}$ Level Support & $\begin{array}{l}\text { Phone: } 0800805300 \text { (Telecom staff) } \\
\text { Phone: } 0800429439 \text { Option 1(HP } \\
\text { staff) } \\
\text { The NZCC will create a DW incident } \\
\text { and assign it to the appropriate second } \\
\text { level support group if it cannot be } \\
\text { resolved live. } \\
\text { Hours: 24x7 } \\
\text { Name: Timothy Ricamonte } \\
\text { Email: tjricamonte@ hp.com }\end{array}$ \\
\hline $\begin{array}{l}\text { User Access Provisioning (UAP) } \\
\text { - Provision of user access forms } \\
\text { for SAP }\end{array}$ & $\begin{array}{l}\text { Use the Telecom forms site on the } \\
\text { intranet to obtain access forms. If } \\
\text { application has an online form. } \\
\text { http://intranet.telecom.co.nz/intranet/cda/to } \\
\text { p/contentPage/0,2964,1508,00.html } \\
\text { or } \\
\text { If there is a paper form with the users } \\
\text { specific requirement of a specific } \\
\text { application (that there is no current On } \\
\text { Line Template for this app) then they } \\
\text { would go to a linked page off Service } \\
\text { Requests page and go to UAP (User } \\
\text { Access Provisioning) Page } \\
\text { http://intranet.telecom.co.nz/intranet/cda/to } \\
\text { p/contentPage/0,2964,1509,00.html }\end{array}$ \\
\hline
\end{tabular}




\section{Support Details, Continued}

\section{Desktop Support (Field Support)}

\begin{tabular}{|l|l|}
\hline \multicolumn{1}{|c|}{ Area of Support } & \multicolumn{1}{|c|}{ Support Details } \\
\hline Provide desktop support for: & $\begin{array}{l}\text { Phone: 0800 805 300 (Telecom staff) } \\
\text { Phone: 0800 429 439 (HP staff) }\end{array}$ \\
Peripherals. & $\begin{array}{l}\text { The NZCC will create a DW request } \\
\text { and assign it to the appropriate regional } \\
\text { field support team for the area } \\
\text { concerned. }\end{array}$ \\
& Hours: $8 \mathrm{am}-5 \mathrm{pm}$ \\
\hline
\end{tabular}

7. Database Administration Group (TCNW_ASFO_DBA_ORA_OPS_NZ or TCNW_ASFO_DBA_SQL_SYB_NZ)

\begin{tabular}{|l|l|}
\hline \multicolumn{1}{|c|}{ Area of Support } & \multicolumn{1}{|c|}{ Contact Details } \\
\hline $\begin{array}{l}\text { Second level support for Oracle } \\
\text { and SQL databases and } \\
\text { interfaces. }\end{array}$ & $\begin{array}{l}\text { Phone: 0800 805 300 (Telecom staff) } \\
\text { Phone: 0800 429 439 (HP staff) }\end{array}$ \\
& $\begin{array}{l}\text { The NZCC will create a DW request } \\
\text { and assign it to the appropriate DBA } \\
\text { support team. }\end{array}$ \\
\hline
\end{tabular}

8. Telecom Network \& Security Operations (TCNW_CLI_NSO_NZ)

\begin{tabular}{|l|l|}
\hline \multicolumn{1}{|c|}{ Area of Support } & \multicolumn{1}{c|}{ Contact Details } \\
\hline $\begin{array}{l}\text { Second level support for firewall } \\
\text { and network security issues }\end{array}$ & $\begin{array}{l}\text { Phone: 0800 805 300 (Telecom staff) } \\
\text { Phone: 0800 429 439 (HP staff) }\end{array}$ \\
& $\begin{array}{l}\text { Hours of support: } \\
\text { http://ekmscontent.apac.eds.com/lnfo /APAC T } \\
\text { elecom New Zealand/supprocedures/SPG/Tel } \\
\text { ecom Network Security Operations.html }\end{array}$ \\
\hline
\end{tabular}




\section{Support Details, Continued}

9. Application Services A\&NZ (TCNW_ASFO_FINANCE_SAP_NZ

TCNW_ASFO_PC_APPS_NZ

TCNW_ASFO_HR_APPS_NZ)

\begin{tabular}{|l|l|}
\hline \multicolumn{1}{|c|}{ Area of Support } & \multicolumn{1}{c|}{ Contact Details } \\
\hline $\begin{array}{l}\text { Second level HP support for SAP } \\
\text { (Basis support only) }\end{array}$ & $\begin{array}{l}\text { Phone: 0800 805 300 (Telecom staff) } \\
\text { Phone: 0800 429 439 (HP staff) }\end{array}$ \\
& $\begin{array}{l}\text { The NZCC will create a DW request } \\
\text { and assign it to } \\
\text { TCNW_ASFO_FINANCE_SAP_NZ if } \\
\text { it cannot be resolved live. }\end{array}$ \\
\hline
\end{tabular}

10. Telecom Finance Systems (TCNW_CLI_ADMS_ES_NZ)

\begin{tabular}{|l|l|}
\hline \multicolumn{1}{|c|}{ Area of Support } & \multicolumn{1}{c|}{ Contact Details } \\
\hline $\begin{array}{l}\text { Telecom application } \\
\text { development, support and } \\
\text { maintenance for SAP. }\end{array}$ & Contact: Martin Rigby or Gayle Stokes \\
& Email: FIS_SYSOPS@telecom.co.nz \\
\hline
\end{tabular}

11. Oracle NZ LTD

\begin{tabular}{|l|l|}
\hline \multicolumn{1}{|c|}{ Area of Support } & \multicolumn{1}{|c|}{ Contact Details } \\
\hline $\begin{array}{l}\text { Vendor support of Oracle } \\
\text { upgrades, fixes and patches }\end{array}$ & $\begin{array}{l}\text { Coordinated by } \\
\text { TCNW_ASFO_DBA_ORA_OPS_NZ }\end{array}$ \\
& Phone: 0800 NZ ORACLE \\
08006967622 \\
\hline
\end{tabular}


12. Sequel NZ LTD

\begin{tabular}{|l|l|}
\hline \multicolumn{1}{|c|}{ Area of Support } & \multicolumn{1}{|c|}{ Contact Details } \\
\hline $\begin{array}{l}\text { Vendor support of SQL } \\
\text { upgrades, fixes and patches }\end{array}$ & $\begin{array}{l}\text { Coordinated by } \\
\text { TCNW_ASFO_DBA_SQL_SYB_NZ }\end{array}$ \\
& Phone: 044953350 \\
\hline
\end{tabular}

Continued on next page 


\section{Support Details, Continued}

13. Gen-i

\begin{tabular}{|l|l|}
\hline \multicolumn{1}{|c|}{ Area of Support } & \multicolumn{1}{c|}{ Contact Details } \\
\hline $\begin{array}{l}\text { Vendor support of HP hardware } \\
\text { and operating system. }\end{array}$ & $\begin{array}{l}\text { Coordinated by the Workplace Services } \\
\text { team }\end{array}$ \\
& $\begin{array}{l}1^{\text {st }} \text { Contact Help Desk: } \\
\text { Jackie Adamson } 9218006\end{array}$ \\
& Alternative Contact: \\
Rochelle Wright \\
09 921 8042
\end{tabular}

14. Sun Microsystems NZ LTD

\begin{tabular}{|l|l|}
\hline \multicolumn{1}{|c|}{ Area of Support } & \multicolumn{1}{c|}{ Contact Details } \\
\hline $\begin{array}{l}\text { Vendor support of Sun hardware } \\
\text { and operating system. }\end{array}$ & Coordinated by ITO Unix Engineering \\
& $\begin{array}{l}\text { Phone: 0800 SUNPLA (0800 786752) } \\
\text { for Platinum contracts (Category A) } \\
\text { Phone: 0800 ASKSUN (0800 275786) } \\
\text { for all other SUN contracts (Category B) }\end{array}$ \\
\hline
\end{tabular}

15. Storage Management (Z_MFR_ESS_NZ and Z_OPS_ENTSTOR_NZ)

\begin{tabular}{|l|l|}
\hline \multicolumn{1}{|c|}{ Area of Support } & \multicolumn{1}{|c|}{ Contact Details } \\
\hline $\begin{array}{l}\text { Support of the following storage } \\
\text { resources: }\end{array}$ & TSM and Tape Silos \\
& Contact: tsmadmin \\
\hline
\end{tabular}




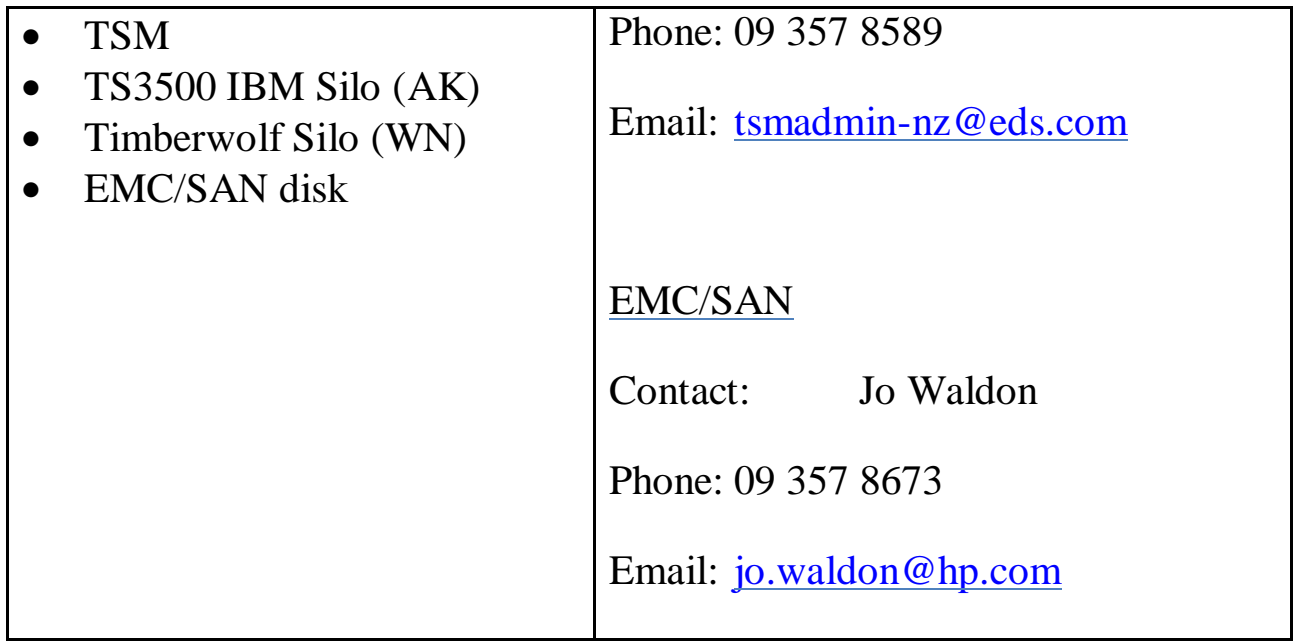

Continued on next page 


\section{Support Details, Continued}

16. Virtual Control Centre (VCC)

\begin{tabular}{|l|l|}
\hline \multicolumn{1}{|c|}{ Area of Support } & \multicolumn{1}{c|}{ Contact Details } \\
$\begin{array}{l}\text { Monitoring Server Alerts } \\
\text { CA-Unicenter }\end{array}$ & $\begin{array}{l}\text { The VCC will create a DW case and } \\
\text { assign it to the appropriate hardware } \\
\text { support team. }\end{array}$ \\
& $\begin{array}{l}\text { Contacts: } \\
\text { AP VCC SUPPORT Team: } \\
\text { VCC Support AP@eds.com }\end{array}$ \\
& Thu Dinh - 61 29012-5182 \\
& Dang Dinh - 6129012-5172 \\
\hline
\end{tabular}




\section{Additional Support Details}

Parameter \& TCNW_ASFO_FINANCE_SAP_NZ support parameters for the SAP

Table

Maintenance

support

Menu application.

Maintenance

TCNW_ASFO_FINANCE_SAP_NZ support specific Menu Options for support the SAP application.

Business release TCNW_ASFO_FINANCE_SAP_NZ supports business releases for the support SAP application. 


\section{Chapter 5 \\ Procedures}

\section{Overview}

Introduction This chapter details the operational and technical procedures for the SAP platforms and application.

In this chapter This chapter covers the following topics.

\begin{tabular}{|l|c|}
\hline \multicolumn{1}{|c|}{ Topic } & See Page \\
\hline Procedure Table for the SAP Platform & $5-2$ \\
\hline Procedure Table for the SAP Application & $5-3$ \\
\hline
\end{tabular}




\section{Procedure Table for the SAP Platform}

Introduction

This table shows the operational and technical procedures for HP to action for the SAP platforms.

\begin{tabular}{|c|c|c|}
\hline Procedure & Description & Contact or Document \\
\hline Backups & $\begin{array}{l}\text { File system and database } \\
\text { backups. }\end{array}$ & $\begin{array}{l}\text { Refer to Chapter } 6 \text { - Data Management } \\
\text { or contact Enterprise Storage BUR. }\end{array}$ \\
\hline File Transfers & $\begin{array}{l}\text { System interfacing - file } \\
\text { transfer }\end{array}$ & Contact the application support team \\
\hline Archiving & & $\begin{array}{l}\text { Refer to Chapter } 2 \text { - Databases or contact } \\
\text { the Database Administration team }\end{array}$ \\
\hline IPL/Reboots & $\begin{array}{l}\text { Restart system from boot } \\
\text { disk }\end{array}$ & $\begin{array}{l}\text { Contact ITO Unix Engineering or } \\
\text { Workplace Services }\end{array}$ \\
\hline $\begin{array}{l}\text { Platform Power } \\
\text { Up/Down }\end{array}$ & $\begin{array}{l}\text { Planned outage power } \\
\text { downs/ups }\end{array}$ & $\begin{array}{l}\text { Refer to the associated Change Request } \\
\text { or contact ITO Unix Engineering or } \\
\text { Workplace Services }\end{array}$ \\
\hline $\begin{array}{l}\text { Application Shutdown } \\
\text { and Restart }\end{array}$ & $\begin{array}{l}\text { Controlled shutdown and } \\
\text { restart }\end{array}$ & $\begin{array}{l}\text { Refer to the associated Change Request } \\
\text { or contact the application support team }\end{array}$ \\
\hline $\begin{array}{l}\text { Application Recovery } \\
\text { and Restart }\end{array}$ & $\begin{array}{l}\text { Recovery after an } \\
\text { unplanned downtime }\end{array}$ & Contact the application support team \\
\hline Application Installs & $\begin{array}{l}\text { Install of new/revised } \\
\text { versions of application } \\
\text { software }\end{array}$ & $\begin{array}{l}\text { Refer to the associated Change Request } \\
\text { or contact ITO Unix Engineering or } \\
\text { Workplace Services }\end{array}$ \\
\hline $\begin{array}{l}\text { Operating System } \\
\text { Installs }\end{array}$ & $\begin{array}{l}\text { Install of new/revised } \\
\text { version of operating system } \\
\text { software }\end{array}$ & $\begin{array}{l}\text { Refer to the associated Change Request } \\
\text { or contact ITO Unix Engineering or } \\
\text { Workplace Services }\end{array}$ \\
\hline Disk Management & $\begin{array}{l}\text { Disk space monitoring and } \\
\text { maintenance }\end{array}$ & $\begin{array}{l}\text { Contact the ITO Unix Engineering or } \\
\text { Workplace Services }\end{array}$ \\
\hline $\begin{array}{l}\text { Dynamic Monitoring } \\
\text { and Alerting }\end{array}$ & $\begin{array}{l}\text { System Dynamically } \\
\text { signals a predefined alert }\end{array}$ & $\begin{array}{l}\text { Contact ITO Unix Engineering, } \\
\text { Workplace Services or the Database } \\
\text { Administration team }\end{array}$ \\
\hline
\end{tabular}




\begin{tabular}{|l|l|l|}
\hline $\begin{array}{l}\text { Security - User Id's } \\
\text { and Passwords }\end{array}$ & $\begin{array}{l}\text { Maintenance of non- } \\
\text { application users on the } \\
\text { system }\end{array}$ & $\begin{array}{l}\text { Contact ITO Unix Engineering or } \\
\text { Workplace Services }\end{array}$ \\
\hline $\begin{array}{l}\text { Performance } \\
\text { Monitoring and } \\
\text { Reporting }\end{array}$ & $\begin{array}{l}\text { System monitoring against } \\
\text { pre-defined levels (daily } \\
\text { reporting) }\end{array}$ & $\begin{array}{l}\text { Contact Peter Poortman or refer to the } \\
\text { EDS BAU Process Document (40985) }\end{array}$ \\
\hline $\begin{array}{l}\text { Comms administration } \\
\text { and monitoring }\end{array}$ & $\begin{array}{l}\text { Management of user access } \\
\text { network }\end{array}$ & $\begin{array}{l}\text { Refer to Telecom Network Security } \\
\text { Operations (NSO) }\end{array}$ \\
\hline
\end{tabular}




\section{Procedure Table for the SAP Application}

Introduction This table shows the operational procedures for HP to action for the SAP application support.

NOTE: Only Basis support is provided by HP. All other SAP application support is provided directly by Telecom.

\begin{tabular}{|c|c|c|}
\hline Procedure & Description & Contact or Document \\
\hline $\begin{array}{l}\text { Operational } \\
\text { Support }\end{array}$ & $\begin{array}{l}\text { - Investigating and answering customer queries } \\
\text { - Monthly faults analysis and review } \\
\text { - Regular progress reporting of all changes i.e. } \\
\text { faults, proposals, etc } \\
\text { - Interaction with operations teams i.e. Unix, } \\
\text { DBA, Data Centre, etc } \\
\text { - Proactive monitoring and impact assessments } \\
\text { for changes to upstream/downstream systems }\end{array}$ & Workpacket \# WP804 \\
\hline $\begin{array}{l}\text { Corrective } \\
\text { Maintenance }\end{array}$ & $\begin{array}{l}\text { Pre-approved and Subject to Budget faults } \\
\text { management. Investigate and correct defects that } \\
\text { have resulted from errors in the system's } \\
\text { development or operation }\end{array}$ & $\begin{array}{l}\text { Workpacket \# WP804 } \\
\text { and DW Incident } \\
\text { Management Process }\end{array}$ \\
\hline $\begin{array}{l}\text { Perfective and } \\
\text { Adaptive } \\
\text { Maintenance }\end{array}$ & $\begin{array}{l}\text { System improvement proposals and support to } \\
\text { Operations due to operating system upgrades. }\end{array}$ & Workpacket WP804 \\
\hline $\begin{array}{l}\text { Supplier } \\
\text { Management }\end{array}$ & License purchasing and management etc & Workpacket \# WP804 \\
\hline $\begin{array}{l}\text { Release } \\
\text { Management }\end{array}$ & $\begin{array}{l}\text { Management and planning of all software } \\
\text { changes into releases as a result of system } \\
\text { faults or enhancements (work requests) } \\
\text { - Change Control Management. }\end{array}$ & $\begin{array}{l}\text { Workpacket \# WP804 } \\
\text { and DW Change } \\
\text { Management Process }\end{array}$ \\
\hline $\begin{array}{l}\text { Project } \\
\text { Management }\end{array}$ & $\begin{array}{l}\text { Management of all software changes (activities } \\
\text { relating to maintenance and support undertaken } \\
\text { within the Work Packet). }\end{array}$ & Workpacket \# WP804 \\
\hline Documentation & $\begin{array}{l}\text { - Maintain high level system requirements } \\
\text { documentation } \\
\text { - } \\
\text { Maintain coding standards and user guides. }\end{array}$ & Workpacket \# WP804 \\
\hline Consultancy & $\begin{array}{l}\text { Client meetings to answer queries with regards to } \\
\text { system performance to identify potential areas for } \\
\text { improvement and advise possible developments }\end{array}$ & Workpacket \# WP804 \\
\hline
\end{tabular}




\section{Chapter 6 \\ Data Management}

\section{Overview}

Introduction This chapter discusses the Data Retention Policy and related media management requirements for SAP.

In this chapter This chapter covers the following topics.

\begin{tabular}{|c|c|}
\hline \multicolumn{1}{|c|}{ Topic } & See Page \\
\hline Data Retention Plan for SAP & $6-2$ \\
\hline
\end{tabular}




\section{Data Retention Plan for SAP}

Introduction The Data Retention Plan for this application is either detailed in this PARM on page 6-4 or if there is no specific plan, complies with the Generic Data Retention Plan of the National Media Management Policy manual (document number 4997, page 3-4.)

\section{Backups} defined

Backup frequencies
The SAP backup strategy employs two types of backup, on-line and offline. A backup will be run each day using one of these methods.

The on-line backup for the database runs at the same time as the database is available for processing. This may mean that the backup takes longer, as it has to compete for system resources with other processes that may be running. On-line backups are incremental - meaning that only those files that have been modified since the last backup are backed up.

Off-line backups are full backups of all database files. For off-line backups, the system must be shut down. The rest of the Unix file system is also backed up at this time.

Every backup includes a double archive of the database redo logs.

The various reports etc., written in $\mathrm{ABP} / 4$ code, are contained within the database. The code is backed up with the rest of the database.

The operating system along with SAP executable's and parameter files are backed up every night to the Silo (this is a separate backup to the daily on line backups).

- An on-line backup is run on every working day

- If requested an additional Full System backup is taken. 
Data Retention Plan for SAP, Continued

Backup media SAP employs the following media type(s) to perform backups.

\begin{tabular}{|l|l|}
\hline \multicolumn{1}{|c|}{ Platform Name } & Equipment Type \\
\hline SF1853 & Tape Library LT03/LT04 cartridges \\
ST2769 & \\
ST2771 & \\
ST2772 & \\
ST2773 & \\
ST2774 & \\
ST2775 & \\
ST2776 & \\
ST2777 & \\
ST2778 & \\
ST2779 & \\
HP2780 & \\
HP1162 & \\
SF2184 & \\
\hline CP1042 & \\
\hline
\end{tabular}

Continued on next page 
Data Retention Plan for SAP, Continued

Backup matrix The table below shows the backup model for the SAP servers.

\begin{tabular}{|c|c|c|c|c|}
\hline Platform & $\begin{array}{c}\text { Information } \\
\text { Saved }\end{array}$ & Type & Frequency & $\begin{array}{c}\text { Retention } \\
\text { Period }\end{array}$ \\
\hline $\begin{array}{l}\text { SF1853 } \\
\text { ST2769 } \\
\text { ST2770 } \\
\text { ST2771 } \\
\text { ST2772 } \\
\text { ST2773 } \\
\text { ST2774 } \\
\text { ST2775 } \\
\text { ST2776 } \\
\text { ST2777 }\end{array}$ & File system & TSM & Daily & 40 days \\
\hline $\begin{array}{l}\text { ST2778 } \\
\text { ST2779 } \\
\text { HP2780 } \\
\text { HP1162 } \\
\text { SF2184 } \\
\text { HP1274 } \\
\text { CP1042 }\end{array}$ & & & Monthly & 400 days \\
\hline
\end{tabular}




\begin{tabular}{|l|l|l|l|l|} 
SF1853 & $\begin{array}{l}\text { Oracle and SQL } \\
\text { databases }\end{array}$ & TSM & Daily & \\
ST2772 & & & & \\
ST2773 & & & & \\
SF2184 & & & & \\
ST2779 & & & & \\
SF2184 & & & & \\
\hline
\end{tabular}

Continued on next page 


\section{Data Retention Plan for SAP, Continued}

\section{Media \\ Management}

\section{Tape Libraries:}

The IBM Tape Libraries (TS3584-AKL Silo \& TS3584-HLZ Silo) remove the need for automated jobs, tape ejects, physical tape off-siting or tape scanning via CA-ASM. The Tape Libraries have the functionality to offsite backups of production data and replicate data between MDR5 and HTC6 using FC IP Links

Both of the new units provide capacity for approximately 5000 LT03/LT04 cartridges and address the capacity constraints of the aging backup units and provide capacity for future backup growth.

\section{Silo:}

Each morning an automated job runs on the Timbwolfe Silo. Backups from the previous day are ejected from the Silo, the identification barcodes on each tape are scanned and the location entered into the CA-ASM system. Tapes are then taken off site by courier.

For further details on:

- the CA-ASM system, see document National Media Management Procedures Manual (10743)

\section{Tape Libraries:}

The Tape Libraries do not require physical tape off-siting. Electronic data from the MDR Tape Library is off-sited to the HTC Tape Library and vice versa via FC IP Links.

\section{Silo:}

For on-site and off-site storage of media, see document National Media Management Policy Manual (4997).

Note: Offsite storage is managed by Online Security Services. Contact the Tape Librarian for contact details. 


\section{Data Retention Plan for SAP, Continued}

Restores

Tape Libraries:

Production data is replicated between the MDR5 and HTC6 Tape Libraries hence restores are straightforward and carried out by Technical Support (either the DBA, Server support technician or Storage team).

Silo:

The table below describes the stages and participants involved to restore data from tapes stored offsite.

Note: A Change Request (if changes to the system structure will result, e.g. new libraries or file systems) or Service Request is required to restore data to a production system.

\begin{tabular}{|c|l|l|}
\hline Stage & \multicolumn{1}{|c|}{ Who } & \multicolumn{1}{c|}{ Description } \\
\hline 1 & Technical Support & Identify the tape required. \\
\hline 2 & Tape Librarian & Obtains the required tape from offsite. \\
\hline 3 & Technical Support & Restores the data required. \\
\hline
\end{tabular}




\section{Chapter 7 \\ HP Process Compliance}

\section{Overview}

Introduction This chapter details SAP's compliance to the generic processes as documented in the EDS BAU Processes manual (40985). Where SAP does not comply, details on specific processes are included in this chapter.

This chapter also details additional process-related information, if applicable such as second level access, change approvers, customer request process etc.

In this chapter This chapter covers the following topics.

\begin{tabular}{|l|c|}
\hline \multicolumn{1}{|c|}{ Topic } & See Page \\
\hline SAP Specific User Access Process & $7-2$ \\
\hline SAP Specific Change Management Process & $7-3$ \\
\hline SAP Specific Problem Management Process & $7-9$ \\
\hline SAP Specific Security Process & $7-12$ \\
\hline SAP Contingency Plan & $7-13$ \\
\hline
\end{tabular}

Compliance $\quad$ SAP complies with the following HP BAU processes:

\begin{tabular}{|l|c|}
\hline \multicolumn{1}{|c|}{ Process } & Compliance Y/N \\
\hline UAP & Y \\
\hline Change Management & Y \\
\hline Problem Management (DW) & Y \\
\hline Escalation & Y \\
\hline Security & Y \\
\hline Contingency Plan & $\mathbf{Y}$ \\
\hline Performance Monitoring & $\mathbf{Y}$ \\
\hline
\end{tabular}




\section{SAP Specific User Access Process}

User access provisioning
Requests for basic ESS access to SAP Portal for all employees except Contractors are made via a batch job run daily using program ZHRU0020P and dependant on the appropriate HR screens being completed at the time of its execution.

Additional access to the SAP Portal or R/3 frontend is then requested via the applicable form available on the Telecom Exchange Forms site, (Alphabetical list of forms $>\mathrm{S}>\mathrm{SAP}$ Access) or the URL link http://intranet.telecom.co.nz/intranet/cda/top/contentPage/0,1533,32502,00 .html\#S. This is to be completed by the applicant and forwarded to their cost centre manager (or authorised delegate) by email. The cost centre manager forwards the form to email fis_sysops@telecom.co.nz or fax 04474-5414, and the Telecom Finance Systems Security Administrator will set up or change the users access. Applications that do not go via the cost centre manager will be rejected.

Access to the SAP portal for Telecom users is via a URL. Authentication to the portal will be via Meta Directory so when accessing any SAP HR functions via the portal, no password will be required after the user has logged onto the portal. For existing non-HR functions in SAP, they will still be done via the GUI.

Password resets Password Resets for all NZ users are carried out by the HP NZ Contact Centre (NZCC) on 0800805300.

Password Resets for all Australian users are carried out by the HP Australia helpdesk on 1800150600 . Call centre staff also have the option to contact Andrea Duble (0061 35445 4112) or Dianne Peck (0061 35445 4111).

Hung SAP sessions are cleared by the TCNW_ASFO_FINANCE_SAP_NZ team.

Users may require additional access to the role in which they have been assigned in the SAP Portal, or they may require sufficient rights to a transaction due to the role they have been assigned for their job.

Users must complete SAP Logon Request Form (available on the Telecom Exchange Forms site).

For access to additional SAP transactions authorisation is required by the appropriate Telecom Manager. 


\section{SAP Specific Change Management Process}

Introduction SAP uses Change Management as follows:

1. Changes to the production environment are logged via a DW Release Instance (RI)

2. The DW process is followed for the transportation of application changes into Production.

3. Change Control is obtained for any procedure that requires a system outage that would impact user access to the SAP Production systems.

The following pages detail the Change Management process for SAP production where changes are scheduled via a DW Release Instance (RI). It outlines the purpose for Change Management, the area responsible for managing changes and the process for implementing changes.

Change

Management standards

Controlling changes to the SAP environment is vital in ensuring integrity of the system. Without this it would not be possible to place reliance on the configuration or application software to perform as required.

From a system integrity perspective, changes to the SAP environment need to be considered at both the configuration level and the ABAP software level.

This standard will deal with both situations.

Co-ordination Change management for SAP is coordinated by

TCNW_CLI_ADMS_ES_NZ or TCNW_ASFO_FINANCE_SAP_NZ and includes the following areas of responsibility:

- Application changes

- Hardware changes

- Software changes

- Database changes.

Change Management process

The SAP application complies with the HP BAU Change Management Process.

Continued on next page 


\section{SAP Specific Change Management Process, Continued}

ITO responsibilities

The procedure
ITO (in particular Unix and WPS) will be responsible for the migration of all changes to the SAP R/3 system.

The following table shows the process for a standard change request.

\begin{tabular}{|c|l|}
\hline Stage & \multicolumn{1}{|c|}{ Description } \\
\hline 1 & $\begin{array}{l}\text { The person requesting the change, completes the SAP Change } \\
\text { Request Form (also called the Transport form), and obtains the } \\
\text { required signoff(s) (unless it is the manager of the area making } \\
\text { the request). }\end{array}$ \\
\hline 2 & $\begin{array}{l}\text { For authorisation, co-ordination, scheduling and business } \\
\text { notification, the SAP Change Request form is forwarded to the } \\
\text { Systems Administrators of the } \\
\text { TCNW_ASFO_FINANCE_SAP_NZ group. }\end{array}$ \\
\hline $\begin{array}{l}\text { Requirements: } \\
\text { All Change Request forms must be authorised by the Telecom } \\
\text { Representative requesting the change, approved member(s) of } \\
\text { TCNW_ASFO_FINANCE_SAP_NZ and where applicable a } \\
\text { Project Manager(s). }\end{array}$ \\
\hline
\end{tabular}

Requirements Version installation requests will follow the software installation procedures (refer document Methods and Procedures - 6099) and SAP install request Transport procedures and naming conventions.

Software migration process

All changes will follow a similar path from development, to acceptance, to both training and production platforms.

Four systems will be used for changing the Configuration, Master Data and Transactions necessary to support Telecom. 


\section{SAP Specific Change Management Process, Continued}

\author{
Change \\ Management \\ procedures
}

The SAP R/3 specific change processes are:

- Configuration changes

- Manual configuration changes

- ABAP changes

- Priority 1 fault changes

- Other fault changes

- Report changes

- Authorisation changes.

The person making the change (usually the Functional Consultant or the like) will identify the need for a configuration change.

This change will have a SAP Change Request number (known as a Transport number in SAP), and description.

- Configuration: Any changes to the system are made through Tools $>$ AcceleratedSAP $>$ Customizing $>$ SPRO or for Security changes through Tools $>$ Administration $>$ User Administration $>$ Role Administration

- Master Data: Organization / Structure data, RC code, GL account numbers.

- Application Data: Variable transaction data e.g. Purchase order, Journal entry. 


\section{SAP Specific Change Management Process, Continued}

Configuration The following steps outline the configuration change process.

changes

\begin{tabular}{|c|c|}
\hline Step & Action \\
\hline 1 & $\begin{array}{l}\text { TCNW_ASFO_FINANCE_SAP_NZ is authorised to give access to D46 (client } \\
080 \text { ) for the changes to be made. }\end{array}$ \\
\hline 2 & $\begin{array}{l}\text { The person making the change (usually the Functional Consultant, Abapper, } \\
\text { Security Analyst or Basis Consultant) creates the SAP Change Request number(s) } \\
\text { for the required change(s). }\end{array}$ \\
\hline 3 & $\begin{array}{l}\text { Unit testing is completed by the person making the change (usually the Functional } \\
\text { Consultant, Abapper, Security Analyst or Basis Consultant) and is signed off. The } \\
\text { Basis Team of the TCNW_ASFO_FINANCE_SAP_NZ group are requested by the } \\
\text { Telecom Finance Systems group to import the changes from D46 (client 070) to } \\
\text { A46. }\end{array}$ \\
\hline 4 & $\begin{array}{l}\text { The Functional Consultant, Security Analyst or Basis Consultant co-ordinates the } \\
\text { appropriate Acceptance testing. The appropriate CMM documentation is checked } \\
\text { against the change to ensure it has been updated. }\end{array}$ \\
\hline 5 & $\begin{array}{l}\text { Once the business signs off the Acceptance test, the appropriately authorised SAP } \\
\text { Change Request form is sent to the Systems Administrators of the } \\
\text { TCNW_ASFO_FINANCE_SAP_NZ group for collating into a scheduled release. } \\
\text { The Basis Consultants of the TCNW_ASFO_FINANCE_SAP_NZ group schedule } \\
\text { the SAP Change Request numbers containing the changes and corrections to the } \\
\text { PRD client. }\end{array}$ \\
\hline 6 & $\begin{array}{l}\text { The Basis Consultants of the TCNW_ASFO_FINANCE_SAP_NZ group checks } \\
\text { the changes transported successfully to PRD. } \\
\text { The transport status of the changes are relayed to the Telecom Finance Systems } \\
\text { group. }\end{array}$ \\
\hline
\end{tabular}

Continued on next page 
SAP Specific Change Management Process, Continued

\author{
Change \\ Management \\ lead time
}

Change
Approvers list

Agreed planned outage window
The notification lead times are as per the Change Management Process:

- Category 1 (Severity 1): 8 Calendar Days

- Category 2 (Severity 2): 3 Calendar Days

- Category 3 (Severity 3): 4 Business hours - changes raised before 12:00 midday for action on the same night

- Category E (Emergency): No Lead Time

Note: All category 1 and $\mathrm{E}$ changes must be represented at the next available TAM in a waiting for approval state.

For more information and definitions of each category contact the Change Management Telecom team (refer to Chapter 4 - Support for contact details)

\section{Mandatory approvers:}

- TCNW_SMT_CM_NZ

- Z_SFW_UNIXTECH_AP (Unix servers only)

- Z_SFW_UNIX_NZ (Unix servers only)

- Z_WPS_SERVMAN_SUPP_NZ (Intel servers only)

- Z_WPS_SERVMAN_SHIFT_NZ (Intel servers only)

- TCNW_CLI_ADMS_ES_NZ

- TCNW_ASFO_FINANCE_SAP_NZ

- TCNW_SMT_SDM_NZ.

Additional approvers (where applicable):

- Z_OPS_ENTSTOR_NZ

- Z_MFR_ESS_NZ

- Z_WPS_DIROPS_SUPP_NZ (Intel servers only)

- Z_WPS_SOFTDIST_SUPP_NZ (Intel servers only)

- Z_WPS_ENDUSER_SUPP_NZ (Intel servers only)

- TCNW_ASFO_DBA_ORA_OPS_NZ

- TCNW_ASFO_DBA_SQL_SYB_NZ

- TCNW_ASFO_PC_APPS_NZ

- TCNW_ASFO_HR_APPS_NZ.

All outages must be negotiated with the client on a case by case basis.

Continued on next page 


\section{SAP Specific Change Management Process, Continued}

Planned outage All outages must be approved by the mandatory approvers shown on the approvers list previous page.

Notification A one week lead time for planned outages would be appropriate.

lead time

Notification If a News Flash Group needs to be notified for a planned outage, a system

Method message is to be posted in SAP and an email is sent to Telecom key module users so they can advise their staff and impacted third parties.

Definition of The definition of Categories and Lead Times can be found in the EDS

Categories and BAU Process Document (40985). This will assist in identifying Categories Lead Times and Impacts for planned changes. 


\section{SAP Specific Problem Management Process}

\author{
Problem \\ Management \\ process
}

The following table represents the support process for the SAP Portal by the Helpdesk and HR staff. The following diagram is a high level representation of the support process, which needs to be followed by all support staff.

The process adheres to support principles, which ensure that:

- The user has a single point of contact for problem resolution

- The process is cyclical and the user is always provided with updates and a problem resolution

- Helpdesks and HR Consultants understand the resolution to every problem they register

- We keep track of solutions and problems in the one location with one owner

- A problems and resolutions report is distributed to all support staff on a regular basis

In the event that a HR Consultant receives a call from their business group managers, the managers can e-mail the HR Consultant with the problem if the issue cannot be resolved over the phone.

Support roles The following table details the roles and responsibilities of support staff. and responsibilities

\begin{tabular}{|l|l|l|}
\hline \multicolumn{1}{|c|}{ Role } & \multicolumn{1}{|c|}{ Responsibility } & \multicolumn{1}{c|}{ Resource } \\
\hline User & $\begin{array}{l}\text { Contact either their helpdesk or HR consultant for } \\
\text { assistance in using The Portal or to report any } \\
\text { problems. } \\
\text { Implement solutions to problems in a timely } \\
\text { manner so the issue can be closed. }\end{array}$ & $\begin{array}{l}\text { Employees, managers, } \\
\text { co-ordinators and } \\
\text { contractors }\end{array}$ \\
\hline
\end{tabular}




\begin{tabular}{|c|c|c|}
\hline $\begin{array}{l}\text { Helpdesk / HR } \\
\text { Consultant }\end{array}$ & $\begin{array}{l}\text { - Helpdesk staff and, possibly HR Consultants will } \\
\text { be the first level support for users. } \\
\text { - Communicate status, progress and resolution of } \\
\text { problems to users. } \\
\text { In the first instance, attempt to resolve the problem } \\
\text { based on current knowledge of systems, The Portal } \\
\text { training documentation, FAQs and } \\
\text { problem/resolution report supplied by The Portal } \\
\text { project team. } \\
\text { Register any problems that cannot be resolved via } \\
\text { e-mail to ThePortalSupport@ telecom.co.nz } \\
\text { providing as much information in the e-mail as is } \\
\text { possible }\end{array}$ & $\begin{array}{l}\text { Payroll helpdesks in } \\
\text { Australia and New } \\
\text { Zealand } \\
\text { HR Client Services } \\
\text { Contractor } \\
\text { Administrator } \\
\text { Call centre support } \\
\text { staff (Andrea/Dianne) }\end{array}$ \\
\hline
\end{tabular}

Continued on next page 
SAP Specific Problem Management Process, Continued

Support roles and responsibilities (continued)

\begin{tabular}{|c|ll|l|}
\hline \multicolumn{1}{|c|}{ Role } & \multicolumn{1}{|c|}{ Responsibility } & \multicolumn{1}{c|}{ Resource } \\
\hline $\begin{array}{l}\text { The Portal } \\
\text { Support Manager }\end{array}$ & $\begin{array}{l}\text { Owner of ThePortalSupport@ @elecom.co.nz } \\
\text { mailbox } \\
\text { Prioritisation and allocation of problems } \\
\text { - } \begin{array}{l}\text { Update enhancement register when required } \\
\text { Delivery of weekly problems and resolutions report }\end{array}\end{array}$ & Rayleen Tuffery \\
\hline $\begin{array}{c}\text { The Portal } \\
\text { Support Team }\end{array}$ & $\begin{array}{l}\text { Resolve assigned problems according to their } \\
\text { priority } \\
\text { Liaise with Helpdesk staff or HR Consultant who } \\
\text { registered the problem }\end{array}$ & $\begin{array}{l}\text { The Portal project team } \\
\text { including HP and } \\
\text { Intelligroup resources } \\
\text { Also includes The } \\
\text { Portal Support } \\
\text { Manager }\end{array}$ \\
\hline
\end{tabular}

Escalation The OSS system is accessed by a direct link from the SAP cluster and can process be used to search for known resolutions to problems, request advice or assistance and log faults. This system is used in tandem with the standard $\mathrm{HP} / \mathrm{Telecom}$ escalation procedures.

Continued on next page 
SAP Specific Problem Management Process, Continued

Support

Process steps

The following diagram details the support process steps.

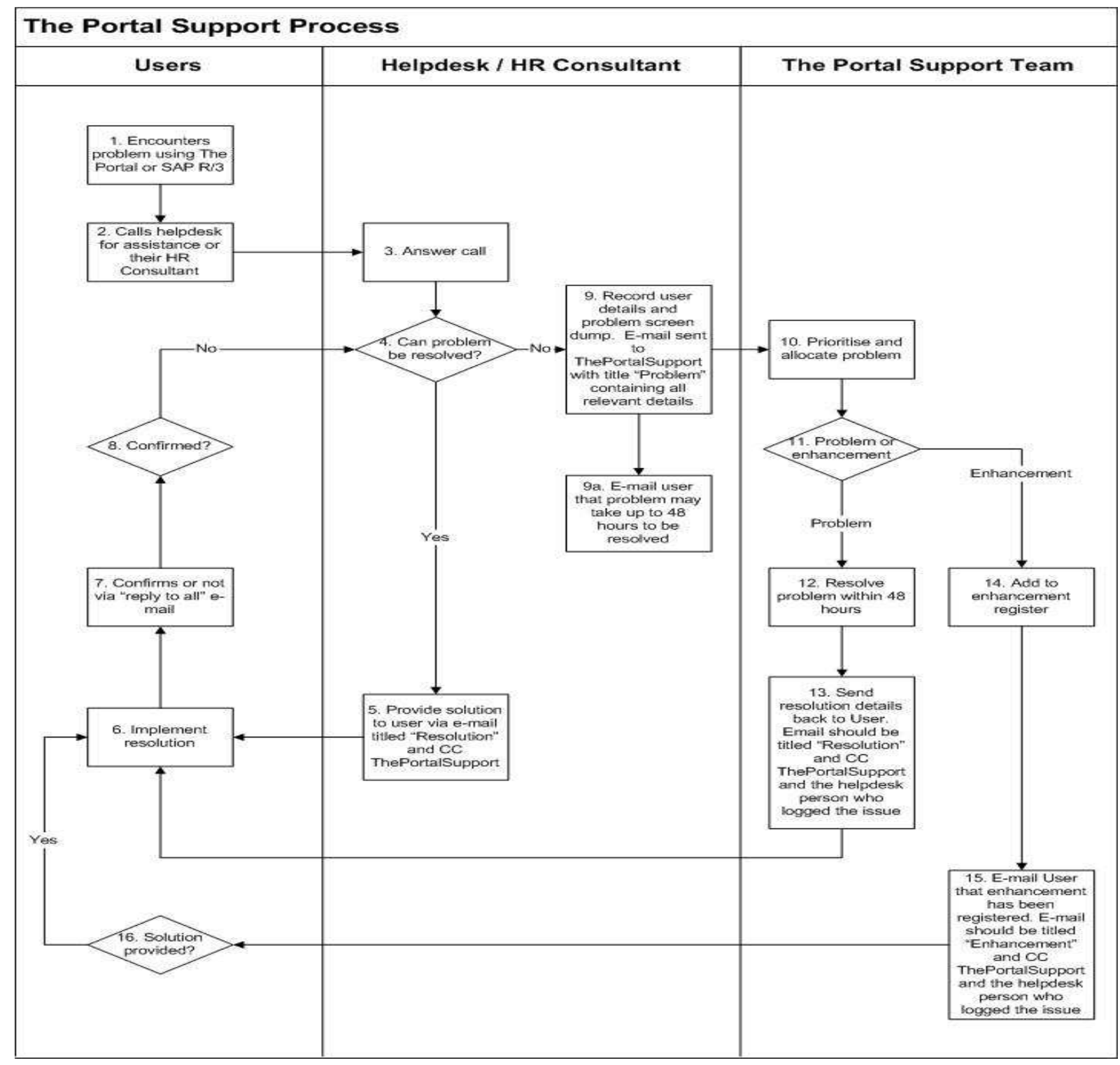




\section{SAP Specific Security Process}

Password controls

Physical security
The following controls are applied to SAP as variations to the standard logical security process:

- The system automatically prompts for a change of password every 47 days unless the user changes their LAN password via the APR system which synchronises all Production systems passwords using the Control-SA tool.

- The six previously used passwords are disallowed.

SAP complies with the standard physical security guidelines. 


\section{SAP Contingency Plan}

Possible failure Network failure on a database machine.

points

Recovery

priorities

The priority for recovery of the application is production boxes first boxes first, then development, then pre-production / staging. Once the SAP application is available, all activities are available.

Initiating

As previously mentioned, failover is an automated process for both HA

contingency cluster and other machines. Notification that a failure has occurred should be in accordance with standard escalation processes.

HP

responsibilities

- Ensuring that the failover completes and that SAP is running on two machines instead of three machines

- Failing back to normal operation following resolution of the fault.

Disaster

There is no Disaster recovery Plan in place for SAP. Telecom Finance

recovery

Information Systems have accepted this risk. 


\section{APPENDIX VIII: K-Means Results}

\section{K MEANS RESULTS}

Cluster Membership

\begin{tabular}{|c|c|c|}
\hline Case Number & Cluster & Distance \\
\hline 1 & 2 & 6.302 \\
\hline 2 & 3 & 5.729 \\
\hline 3 & 3 & 5.729 \\
\hline 4 & 3 & 6.955 \\
\hline 5 & 3 & 7.508 \\
\hline 6 & 2 & 5.139 \\
\hline 7 & 1 & 4.285 \\
\hline 8 & 1 & 2.316 \\
\hline 9 & 3 & 5.655 \\
\hline 10 & 3 & 5.021 \\
\hline 11 & 1 & 3.645 \\
\hline 12 & 1 & 4.928 \\
\hline 13 & 1 & 3.211 \\
\hline 14 & 2 & 4.416 \\
\hline 15 & 2 & 4.433 \\
\hline 16 & 3 & 6.024 \\
\hline 17 & 2 & 6.270 \\
\hline 18 & 2 & 6.180 \\
\hline 19 & 2 & 4.469 \\
\hline 20 & 2 & 5.093 \\
\hline 21 & 1 & 1.956 \\
\hline 22 & 1 & 2.041 \\
\hline 23 & 1 & 2.871 \\
\hline 24 & 1 & 2.235 \\
\hline 25 & 2 & 5.129 \\
\hline 26 & 1 & 5.563 \\
\hline 27 & 1 & 3.969 \\
\hline 28 & 2 & 4.198 \\
\hline 29 & 2 & 4.202 \\
\hline 30 & 1 & 2.745 \\
\hline 31 & 2 & 4.650 \\
\hline 32 & 1 & 2.284 \\
\hline 33 & 1 & 2.191 \\
\hline 34 & 2 & 4.753 \\
\hline 35 & 2 & 4.740 \\
\hline
\end{tabular}




\begin{tabular}{|c|c|c|}
\hline 36 & 1 & 5.120 \\
\hline 37 & 2 & 3.579 \\
\hline 38 & 2 & 4.004 \\
\hline 39 & 2 & 3.500 \\
\hline 40 & 2 & 5.982 \\
\hline 41 & 3 & 5.614 \\
\hline 42 & 2 & 4.877 \\
\hline 43 & 2 & 6.631 \\
\hline 44 & 2 & 4.359 \\
\hline 45 & 3 & 5.461 \\
\hline 46 & 1 & 4.790 \\
\hline 47 & 2 & 5.491 \\
\hline 48 & 2 & 4.394 \\
\hline 49 & 1 & 2.963 \\
\hline 50 & 2 & 4.419 \\
\hline 51 & 3 & 4.374 \\
\hline 52 & 2 & 5.003 \\
\hline 53 & 3 & 3.841 \\
\hline 54 & 3 & 5.362 \\
\hline 55 & 2 & 5.607 \\
\hline 56 & 2 & 4.531 \\
\hline 57 & 3 & 4.401 \\
\hline 58 & 2 & 5.525 \\
\hline 59 & 2 & 3.152 \\
\hline 60 & 2 & 6.210 \\
\hline 61 & 2 & 4.261 \\
\hline 62 & 3 & 5.097 \\
\hline 63 & 3 & 4.564 \\
\hline 64 & 2 & 5.408 \\
\hline 65 & 2 & 6.177 \\
\hline 66 & 1 & 3.012 \\
\hline 67 & 1 & 4.841 \\
\hline 68 & 3 & 6.274 \\
\hline 69 & 2 & 5.117 \\
\hline 70 & 3 & 3.495 \\
\hline 71 & 3 & 3.516 \\
\hline 72 & 2 & 6.826 \\
\hline 73 & 3 & 5.355 \\
\hline 74 & 3 & 6.157 \\
\hline 75 & 1 & 5.864 \\
\hline 76 & 1 & 5.615 \\
\hline 77 & 2 & 6.116 \\
\hline 78 & 1 & 4.690 \\
\hline
\end{tabular}




\begin{tabular}{|c|c|c|}
\hline 79 & 1 & 3.790 \\
\hline 80 & 1 & 3.158 \\
\hline 81 & 1 & 4.550 \\
\hline 82 & 2 & 6.327 \\
\hline 83 & 2 & 5.514 \\
\hline 84 & 2 & 7.271 \\
\hline 85 & 2 & 5.235 \\
\hline 86 & 2 & 6.946 \\
\hline 87 & 2 & 8.355 \\
\hline 88 & 2 & 5.120 \\
\hline 89 & 1 & 3.757 \\
\hline 90 & 2 & 5.714 \\
\hline 91 & 2 & 5.268 \\
\hline 92 & 1 & 3.708 \\
\hline 93 & 2 & 7.267 \\
\hline 94 & 1 & 4.545 \\
\hline 95 & 1 & 2.522 \\
\hline 96 & 1 & 6.076 \\
\hline 97 & 2 & 4.391 \\
\hline 98 & 1 & 3.327 \\
\hline 99 & 2 & 6.612 \\
\hline 100 & 2 & 5.451 \\
\hline 101 & 1 & 5.903 \\
\hline 102 & 1 & 6.841 \\
\hline 103 & 2 & 4.915 \\
\hline 104 & 3 & 5.179 \\
\hline 105 & 2 & 5.268 \\
\hline 106 & 1 & 3.708 \\
\hline 107 & 2 & 7.267 \\
\hline 108 & 3 & 4.374 \\
\hline 109 & 2 & 5.003 \\
\hline 110 & 3 & 3.841 \\
\hline 111 & 3 & 5.362 \\
\hline 112 & 2 & 5.607 \\
\hline 113 & 2 & 4.531 \\
\hline 114 & 2 & 6.270 \\
\hline 115 & 2 & 6.180 \\
\hline 116 & 2 & 4.469 \\
\hline 117 & 2 & 5.093 \\
\hline 118 & 1 & 1.956 \\
\hline 119 & 1 & 2.041 \\
\hline 120 & 1 & 3.757 \\
\hline 121 & 2 & 5.714 \\
\hline
\end{tabular}




\begin{tabular}{|l|l|l|}
122 & 3 \\
123 & 1 \\
124 & 1 \\
125 & 1 \\
126 & 2 \\
127 & 2 \\
128 & 3 \\
129 & 2 \\
130 & 2 \\
131 & 2 & 5.021 \\
& & 3.645 \\
& & 4.928 \\
\end{tabular}

Distances between Final Cluster Centers

\begin{tabular}{|l|r|r|r|}
\hline Cluster & 1 & 2 & \multicolumn{1}{|c|}{3} \\
\hline 1 & & 5.131 & 9.079 \\
2 & 5.131 & & 4.823 \\
3 & 9.079 & 4.823 & \\
\hline
\end{tabular}

Number of Cases in each Cluster

\begin{tabular}{|ll|r|}
\hline & 1 & 40.000 \\
Cluster & 2 & 65.000 \\
& 3 & 26.000 \\
Valid & & 131.000 \\
Missing & & .000 \\
\hline
\end{tabular}




\section{APPENDIX XI: ANOVA Results}

Descriptive

\begin{tabular}{|c|c|c|c|c|c|c|c|c|c|}
\hline & & \multirow[t]{2}{*}{$\mathbf{N}$} & \multirow[t]{2}{*}{ Mean } & \multirow[t]{2}{*}{$\begin{array}{c}\text { Std. } \\
\text { Deviation }\end{array}$} & \multirow[t]{2}{*}{$\begin{array}{l}\text { Std. } \\
\text { Error }\end{array}$} & \multicolumn{2}{|c|}{$\begin{array}{c}\text { 95\% Confidence Interval for } \\
\text { Mean }\end{array}$} & \multirow[t]{2}{*}{ Minimum } & \multirow[t]{2}{*}{ Maximum } \\
\hline & & & & & & Lower Bound & Upper Bound & & \\
\hline & 1 & 61 & 2.82 & 1.204 & .154 & 2.51 & 3.13 & 1 & 5 \\
\hline & 2 & 49 & 2.88 & 1.130 & .161 & 2.55 & 3.20 & 1 & 5 \\
\hline \multirow[t]{4}{*}{ USA1 } & 3 & 21 & 2.90 & 1.411 & .308 & 2.26 & 3.55 & 1 & 5 \\
\hline & Total & $\begin{array}{r}13 \\
1\end{array}$ & 2.85 & 1.203 & .105 & 2.65 & 3.06 & 1 & 5 \\
\hline & 1 & 61 & 2.82 & 1.073 & .137 & 2.54 & 3.09 & 1 & 5 \\
\hline & 2 & 49 & 2.73 & 1.114 & .159 & 2.41 & 3.05 & 1 & 5 \\
\hline \multirow[t]{4}{*}{ USA2 } & 3 & 21 & 2.76 & 1.338 & .292 & 2.15 & 3.37 & 1 & 5 \\
\hline & Total & $\begin{array}{r}13 \\
1\end{array}$ & 2.78 & 1.125 & .098 & 2.58 & 2.97 & 1 & 5 \\
\hline & 1 & 61 & 3.05 & 1.023 & .131 & 2.79 & 3.31 & 1 & 5 \\
\hline & 2 & 49 & 2.88 & 1.073 & .153 & 2.57 & 3.19 & 1 & 5 \\
\hline \multirow[t]{4}{*}{ USA3 } & 3 & 21 & 2.52 & 1.123 & .245 & 2.01 & 3.04 & 1 & 5 \\
\hline & Total & $\begin{array}{r}13 \\
1\end{array}$ & 2.90 & 1.066 & .093 & 2.72 & 3.09 & 1 & 5 \\
\hline & 1 & 61 & 2.84 & 1.052 & .135 & 2.57 & 3.11 & 1 & 5 \\
\hline & 2 & 49 & 2.88 & 1.092 & .156 & 2.56 & 3.19 & 1 & 5 \\
\hline \multirow[t]{4}{*}{ USA4 } & 3 & 21 & 2.71 & 1.146 & .250 & 2.19 & 3.24 & 1 & 5 \\
\hline & Total & $\begin{array}{r}13 \\
1\end{array}$ & 2.83 & 1.075 & .094 & 2.65 & 3.02 & 1 & 5 \\
\hline & 1 & 61 & 2.64 & .876 & .112 & 2.41 & 2.86 & 1 & 4 \\
\hline & 2 & 49 & 2.69 & .940 & .134 & 2.42 & 2.96 & 1 & 5 \\
\hline \multirow[t]{4}{*}{ USA4 } & 3 & 21 & 2.62 & 1.284 & .280 & 2.03 & 3.20 & 1 & 5 \\
\hline & Total & $\begin{array}{r}13 \\
1\end{array}$ & 2.66 & .967 & .084 & 2.49 & 2.82 & 1 & 5 \\
\hline & 1 & 61 & 2.75 & .943 & .121 & 2.51 & 3.00 & 1 & 5 \\
\hline & 2 & 49 & 2.88 & .927 & .132 & 2.61 & 3.14 & 2 & 5 \\
\hline \multirow[t]{4}{*}{ USA3 } & 3 & 21 & 2.52 & 1.030 & .225 & 2.05 & 2.99 & 1 & 5 \\
\hline & Total & $\begin{array}{r}13 \\
1\end{array}$ & 2.76 & .951 & .083 & 2.60 & 2.93 & 1 & 5 \\
\hline & 1 & 61 & 2.93 & 1.078 & .138 & 2.66 & 3.21 & 1 & 5 \\
\hline & 2 & 49 & 2.86 & 1.021 & .146 & 2.56 & 3.15 & 1 & 5 \\
\hline \multirow[t]{2}{*}{ USA } & 3 & 21 & 2.71 & 1.146 & .250 & 2.19 & 3.24 & 1 & 5 \\
\hline & Total & $\begin{array}{r}13 \\
1\end{array}$ & 2.87 & 1.063 & .093 & 2.69 & 3.05 & 1 & 5 \\
\hline
\end{tabular}




\begin{tabular}{|c|c|c|c|c|c|c|c|c|c|}
\hline & 1 & 61 & 2.89 & 1.050 & .134. & 2.62 & 3.15 & 1 & 5 \\
\hline & 2 & 49 & 2.67 & 1.029 & .147 & 2.38 & 2.97 & 1 & 5 \\
\hline \multirow[t]{4}{*}{ USA2 } & 3 & 21 & 2.71 & 1.146 & 250 & 2.19 & 3.24 & 1 & 4 \\
\hline & Total & 13 & 2.78 & 1.055 & .092 & 2.60 & 2.96 & 1 & 5 \\
\hline & 1 & 61 & 3.10 & 1.106 & .142 & 2.82 & 3.38 & 2 & 5 \\
\hline & 2 & 49 & 3.16 & .943 & .135 & 2.89 & 3.43 & 2 & 5 \\
\hline \multirow[t]{2}{*}{ USA3 } & 3 & 21 & 3.10 & 1.300 & .284 & 2.50 & 3.69 & 1 & 5 \\
\hline & Total & 13 & 3.12 & 1.074 & .094 & 2.94 & 3.31 & 1 & 5 \\
\hline
\end{tabular}

\section{ANOVA}

\begin{tabular}{|c|c|c|c|c|c|c|}
\hline & & Sum of Squares & df & Mean Square & $\mathrm{F}$ & Sig. \\
\hline & Between Groups & .153 & 2 & .077 & .052 & .949 \\
\hline \multirow[t]{3}{*}{ USA1 } & Within Groups & 188.091 & 128 & 1.469 & & \\
\hline & Total & 188.244 & 130 & & & \\
\hline & Between Groups & .203 & 2 & .102 & .079 & .924 \\
\hline \multirow[t]{3}{*}{ USA2 } & Within Groups & 164.377 & 128 & 1.284 & & \\
\hline & Total & 164.580 & 130 & & & \\
\hline & Between Groups & 4.354 & 2 & 2.177 & 1.944 & .147 \\
\hline \multirow[t]{3}{*}{ USA3 } & Within Groups & 143.356 & 128 & 1.120 & & \\
\hline & Total & 147.710 & 130 & & & \\
\hline & Between Groups & .394 & 2 & .197 & .168 & .845 \\
\hline \multirow[t]{3}{*}{ USA4 } & Within Groups & 149.912 & 128 & 1.171 & & \\
\hline & Total & 150.305 & 130 & & & \\
\hline & Between Groups & .116 & 2 & .058 & .061 & .941 \\
\hline \multirow[t]{3}{*}{ USA4 } & Within Groups & 121.426 & 128 & .949 & & \\
\hline & Total & 121.542 & 130 & & & \\
\hline & Between Groups & 1.849 & 2 & .925 & 1.022 & .363 \\
\hline \multirow[t]{3}{*}{ USA3 } & Within Groups & 115.815 & 128 & .905 & & \\
\hline & Total & 117.664 & 130 & & & \\
\hline & Between Groups & .770 & 2 & .385 & .338 & .714 \\
\hline \multirow[t]{3}{*}{ USA } & Within Groups & 146.023 & 128 & 1.141 & & \\
\hline & Total & 146.794 & 130 & & & \\
\hline & Between Groups & 1.322 & 2 & .661 & .591 & .555 \\
\hline \multirow[t]{3}{*}{ USA2 } & Within Groups & 143.258 & 128 & 1.119 & & \\
\hline & Total & 144.580 & 130 & & & \\
\hline & Between Groups & .133 & 2 & .066 & .057 & .945 \\
\hline \multirow[t]{2}{*}{ USA3 } & Within Groups & 149.913 & 128 & 1.171 & & \\
\hline & Total & 150.046 & 130 & & & \\
\hline
\end{tabular}


Post Hoc Tests

Homogeneous Subsets

USA1

Tukey B

\begin{tabular}{|l|r|r|}
\hline Q1.4 & N & \multicolumn{1}{|c|}{$\begin{array}{c}\text { Subset for } \\
\text { algha }=0.05\end{array}$} \\
\cline { 3 - 3 } & & \multicolumn{2}{|c|}{1} \\
\hline 1 & 61 & 2.82 \\
2 & 49 & 2.86 \\
3 & 21 & 2.90 \\
\hline
\end{tabular}

Means for groups in homogeneous subsets are displayed.

a. Uses Harmonic Mean Sample

Size $=35.536$

b. The group sizes are unequal. The harmonic mean of the group sizes is used. Typel error levels are not guaranteed.

\section{USA2}

Tukey B
\begin{tabular}{|l|r|r|}
\hline Q1.4 & N & $\begin{array}{c}\text { Subset for } \\
\text { alpha }=0.05\end{array}$ \\
\cline { 3 - 3 } & & \multicolumn{1}{|c|}{1} \\
\hline 2 & 49 & 2.73 \\
3 & 21 & 2.78 \\
1 & 61 & 2.82 \\
\hline
\end{tabular}

Means for groups in homogeneous subsets are displayed.

a. Uses Harmonic Mean Sample

Size $=35.636$

b. The group sizes are unequal. The harmonic mean of the group sizes is used. Typel etrorlevels are not guaranteed.

USA3

Tukey B

\begin{tabular}{|l|r|r|}
\hline Q1.4 & \multirow{2}{*}{ N } & \multicolumn{1}{c|}{$\begin{array}{c}\text { Subset for } \\
\text { alpha }=0.05\end{array}$} \\
\cline { 3 - 3 } & & \multicolumn{1}{|c|}{1} \\
\hline 3 & 21 & 2.52 \\
2 & 49 & 2.88 \\
1 & 61 & 3.05 \\
\hline
\end{tabular}

Means for groups in homogeneous subsets are displayed.

a. Uses Harmonic Mean Sample Size $=35.536$.

b. The group sizes are unequal. The harmonic mean of the group sizes is used. Typel error levels are not guaranteed.

\section{USA4}

Tukey B
\begin{tabular}{|l|r|r|}
\hline Q1.4 & N & $\begin{array}{c}\text { Subset for } \\
\text { alpha }=0.05\end{array}$ \\
\cline { 3 - 3 } & & 1 \\
\hline 3 & 21 & 2.71 \\
1 & 61 & 2.84 \\
2 & 49 & 2.88 \\
\hline
\end{tabular}

Means for groups in homogeneous subsets are displayed.

a. Uses Harmonic Mean Sample

Size $=35.536$.

b. The group sizes are unequal. The harmonic mean of the group sizes is used. Type l error levels are not guaranteed.

\section{USA4}

Tukey B
\begin{tabular}{|l|r|r|}
\hline Q1.4 & N & $\begin{array}{c}\text { Subset for } \\
\text { alpha }=0.05\end{array}$ \\
\cline { 3 - 4 } & & \multicolumn{2}{|c|}{1} \\
\hline 3 & 21 & 2.62 \\
1 & 61 & 2.64 \\
2 & 49 & 2.69 \\
\hline
\end{tabular}

Means for groups in homogeneous subsets are displayed.

a. Uses Harmonic Mean Sample Size $=35.536$.

b. The group sizes are unequal. The harmonic mean of the group sizes is used. Type lerror levels are not guaranteed.

USA3

Tukey B

\begin{tabular}{|c|c|c|}
\hline \multirow[t]{2}{*}{ Q1.4 } & \multirow[t]{2}{*}{$N$} & $\begin{array}{l}\text { Subset for } \\
\text { alpha }=0.05\end{array}$ \\
\hline & & 1 \\
\hline 3 & 21 & 2.52 \\
\hline 1 & 61 & 2.75 \\
\hline 2 & 49 & 2.88 \\
\hline
\end{tabular}

Means for groups in homogeneous subsets are displayed.

a. Uses Harmonic Mean Sample Size $=35.536$

b. The group sizes are unequal. The harmonic mean of the group sizes is used. Type lerror levels are not guaranteed.

USA

Tukey B

\begin{tabular}{|l|r|r|}
\hline Q1.4 & N & \multicolumn{1}{|c|}{$\begin{array}{c}\text { Subset for } \\
\text { alpha }=0.05\end{array}$} \\
\cline { 3 - 3 } & & \multicolumn{1}{|c|}{1} \\
\hline 3 & 21 & 2.71 \\
2 & 49 & 2.86 \\
1 & 61 & 2.93 \\
\hline
\end{tabular}

Means for groups in homogeneous subsets are displayed.

a. Uses Harmonic Mean Sample Size $=35.536$. 


\section{APPENDIX X: Card Sorting Results}

\begin{tabular}{|c|c|c|}
\hline Construct & Definition & \\
\hline $\begin{array}{l}\text { Organizational } \\
\text { Impact }\end{array}$ & $\begin{array}{l}\text { Refers to impacts of the IS at the } \\
\text { organizational level; namely improved } \\
\text { organizational results and capabilities }\end{array}$ & \\
\hline System Quality & $\begin{array}{l}\text { The System Quality of the (IS) is a } \\
\text { multifaceted construct designed to capture } \\
\text { how the system performs from a technical } \\
\text { and design perspective }\end{array}$ & \\
\hline \multirow[t]{5}{*}{ IT Governance } & $\begin{array}{l}\text { Company's IT decisions are strategically aligned } \\
\text { with the business needs }\end{array}$ & Ol-10 \\
\hline & $\begin{array}{l}\text { Company's 3-5 year future growth trend is kept in } \\
\text { mind for deciding investment level and setting } \\
\text { priority }\end{array}$ & Ol-10 \\
\hline & $\begin{array}{l}\text { The Company's IT performance management is } \\
\text { linked with the business outcomes }\end{array}$ & Unclear \\
\hline & $\begin{array}{l}\text { The Company's IT Architecture is an integral part } \\
\text { of top management's business planning }\end{array}$ & Unclear \\
\hline & $\begin{array}{l}\text { Company has a strategy to upgrade IT } \\
\text { Infrastructure in an incremental manner }\end{array}$ & Unclear \\
\hline \multirow[t]{6}{*}{$\begin{array}{l}\text { Value } \\
\text { Management }\end{array}$} & $\begin{array}{l}\text { IT business case incorporates financial outcomes } \\
\text { into the annual operating plan/ budget }\end{array}$ & Ol-10 \\
\hline & $\begin{array}{l}\text { IT operating metrics for initiatives are linked to } \\
\text { financial measures, including incentive plans }\end{array}$ & Ol-10 \\
\hline & $\begin{array}{l}\text { IT implementation program includes regular } \\
\text { business case reviews as a part of governance }\end{array}$ & Ol-10 \\
\hline & $\begin{array}{l}\text { IT tracks value realized from SAP } \\
\text { implementations }\end{array}$ & $\mathrm{Ol}-8$ \\
\hline & $\begin{array}{l}\text { IT continue to optimize the value from the SAP } \\
\text { solutions on a regular basis after being fully } \\
\text { operational }\end{array}$ & Unclear \\
\hline & $\begin{array}{l}\text { The business understands the full lifecycle costs } \\
\text { and benefits of our existing and planned SAP } \\
\text { solution/s }\end{array}$ & Ol-9 \\
\hline \multirow[t]{2}{*}{$\begin{array}{l}\text { Business } \\
\text { Improvement }\end{array}$} & $\begin{array}{l}\text { A standardized end-to-end test management } \\
\text { process exists for both new developments as well } \\
\text { as for maintenance of the productive solution, } \\
\text { including the corresponding approval procedures }\end{array}$ & SQ-7 \\
\hline & $\begin{array}{l}\text { Business critical processes are technically } \\
\text { analyzed end to end, including interfaces, with } \\
\text { focus on performance, technical correctness, } \\
\text { transactional correctness, and data consistency }\end{array}$ & $S Q$ \\
\hline
\end{tabular}




\begin{tabular}{|c|c|c|}
\hline & $\begin{array}{l}\text { Business key performance indicators are defined } \\
\text { to measure the success of the business process } \\
\text { execution and to detect deviations of the business } \\
\text { process flow }\end{array}$ & Ol-9 \\
\hline \multirow[t]{10}{*}{$\begin{array}{l}\text { IT Strategy and } \\
\text { Business } \\
\text { Alignment }\end{array}$} & $\begin{array}{l}\text { The company is using IT to enable strategic and } \\
\text { competitive advantages }\end{array}$ & Ol-10 \\
\hline & $\begin{array}{l}\text { The company has established common, simple } \\
\text { and streamlined IT and business process } \\
\text { standards across the organization }\end{array}$ & Ol-8 \\
\hline & $\begin{array}{l}\text { The company has defined IT roles and } \\
\text { responsibilities which are consistently applied } \\
\text { across the organization }\end{array}$ & Ol-9 \\
\hline & $\begin{array}{l}\text { The company undergoes a formal budgeting and } \\
\text { planning process to approve initiatives and drive } \\
\text { business value }\end{array}$ & Ol-10 \\
\hline & $\begin{array}{l}\text { The company undergoes a formal annual portfolio } \\
\text { rationalization process to reduce operating } \\
\text { expense }\end{array}$ & Ol-9 \\
\hline & $\begin{array}{l}\text { The company has a strategic IT roadmap or } \\
\text { rolling 3-5 year plan based on business and IT } \\
\text { strategy }\end{array}$ & Ol-9 \\
\hline & $\begin{array}{l}\text { Regular IT and business planning meetings are } \\
\text { conducted, with a joint planning methodology in } \\
\text { place }\end{array}$ & Unclear \\
\hline & $\begin{array}{l}\text { IT is included in the prioritization process early on } \\
\text { so that an appropriate roadmap can be developed }\end{array}$ & Ol-8 \\
\hline & $\begin{array}{l}\text { IT facilitates a high degree of integration with the } \\
\text { company's ecosystem }\end{array}$ & Ol-7 \\
\hline & Business has embraced IT as their responsibility & Unclear \\
\hline \multirow[t]{5}{*}{$\begin{array}{l}\text { Business } \\
\text { Continuity and } \\
\text { TCO }\end{array}$} & $\begin{array}{l}\text { There is a defined process to conduct end-to-end } \\
\text { root cause analysis across the software } \\
\text { components using the "SAP Solution Manager } \\
\text { Diagnostics" functionality }\end{array}$ & SQ-10 \\
\hline & $\begin{array}{l}\text { Automated procedures for monitoring the } \\
\text { infrastructure (including, hardware, network, } \\
\text { systems, operating system) are in place }\end{array}$ & SQ-10 \\
\hline & $\begin{array}{l}\text { Automated monitoring and error handling } \\
\text { procedures for mission critical business processes } \\
\text { and interfaces are in place }\end{array}$ & SQ-10 \\
\hline & $\begin{array}{l}\text { There are defined procedures to ensure data } \\
\text { integrity across SAP and non-SAP components }\end{array}$ & SQ-9 \\
\hline & $\begin{array}{l}\text { A defined strategy exists to control database } \\
\text { growth as well as an archiving concept }\end{array}$ & SQ-10 \\
\hline \multirow[t]{4}{*}{$\begin{array}{l}\text { Solutions/IT } \\
\text { Portfolio } \\
\text { Management }\end{array}$} & $\begin{array}{l}\text { The company has a consolidated single solution/ } \\
\text { platform landscape }\end{array}$ & unclear \\
\hline & $\begin{array}{l}\text { The company has a strategy in place for a single } \\
\text { solution/ platform landscape consolidation }\end{array}$ & unclear \\
\hline & $\begin{array}{l}\text { The company has a strategy for the application of } \\
\text { support and enhancement packs }\end{array}$ & SQ-9 \\
\hline & $\begin{array}{l}\text { The strategy for the application of support and } \\
\text { enhancement packs is enforced }\end{array}$ & SQ-8 \\
\hline
\end{tabular}




\begin{tabular}{|l|l|l|}
\hline & The company has a no - modification strategy & SQ-8 \\
\hline & $\begin{array}{l}\text { The company enforces the no - modification } \\
\text { strategy }\end{array}$ & SQ-8 \\
\hline & $\begin{array}{l}\text { The business units have incentives aligned with } \\
\text { the adoption of a standard, common solution }\end{array}$ & unclear \\
\hline & $\begin{array}{l}\text { The company has a master data strategy to drive } \\
\text { common definitions and standards }\end{array}$ & SQ-8 \\
\hline $\begin{array}{l}\text { Master data strategy is already implemented or is } \\
\text { in the process of implementing }\end{array}$ & SQ-8 \\
\hline & $\begin{array}{l}\text { The company always evaluates licensed SAP } \\
\text { solution for meeting business requirements before } \\
\text { looking at niche products }\end{array}$ & SQ-7 \\
\hline & $\begin{array}{l}\text { The company has a strategy to maximize the } \\
\text { value of integration for the SAP solutions }\end{array}$ & SQ-7 \\
\hline $\begin{array}{l}\text { The company evaluates vendor viability and } \\
\text { business strategy as part of the IT portfolio } \\
\text { management }\end{array}$ & unclear \\
\hline
\end{tabular}




\section{APPENDIX XI: HEC Form}

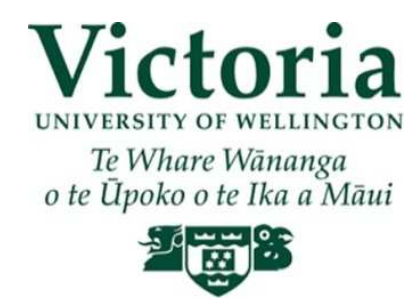

SIM HUMAN ETHICS COMMITTEE

Application for Approval of Research Projects

Please email applications to your supervisor, who will then email it to a SIM HEC member for a preliminary review.

Note: The Human Ethics Committee attempts to have all applications approved within 6 working days, but a longer period may be necessary if applications require substantial revision.

\section{NATURE OF PROPOSED RESEARCH:}

(a) Student Research

(b) If Student Research

Degree MCom ... Course Code ... INFO 591

(c) Project Title: A Multi-Method study of the quality and impact of SAP implementation in a large organization

\section{INVESTIGATORS:}

(a) Principal Investigator

Name Azim Ali

e-mail address azim.ali@vuw.ac.nz.

School/Dept/Group School of Information Management 
(b) Other Researchers Name Position

(c) Supervisor (in the case of student research projects)

\section{Professor: Dr Mary Tate}

\section{DURATION OF RESEARCH}

(a) Proposed starting date for data collection - After HEC approval has been granted.

(Note: that NO part of the research requiring ethical approval may commence prior to approval being given)

(b) Proposed date of completion of project as a whole November 2013

\section{PROPOSED SOURCE/S OF FUNDING AND OTHER ETHICAL CONSIDERATIONS}

\footnotetext{
(a) Sources of funding for the project

Please indicate any ethical issues or conflicts of interest that may arise because of sources of funding

e.g. restrictions on publication of results
}

None

(b) Is any professional code of ethics to be followed

If yes, name 
If yes, name and indicate when/if approval will be given

Briefly Outline:

(a) The objectives of the project

This project is part of Masters of Commerce INFO 591 research dissertation requirements, which assesses the metrics to measure IS success. The purpose of this study adopts a single case study investigating the stakeholder views from the largest telecommunications organization in New Zealand, using SAP R/3 a dominant enterprise resource planning system

The research questions proposed are:

1. What metrics can be used to measure the success of SAP post implementation?

Objectives are to further validate measures used for SAP system success using the IS impact model as the foundation and empirically investigating the measures of system quality and organizational impact as more objective measures. Another objective is to determine what stakeholders believe are the organizational impacts of ERP systems within their organization.

\section{(b) Method of data collection}

Data will be collected through a card sorting exercise. We will be following Zimmerman \& Akerlerea (2002) guidelines on Card Sorting. The following steps will be taken; (1) we will provide a brief explanation of the overall project in general terms; (2) Provide an example to illustrate how card sorting works, using a deck of cards to illustrate various groupings i.e. colour, suits, aces, jacks to illustrate group labels; (3) give participants a stack of cards; (4) give participants blank cards and explain that they can add cards by writing their ideas on a card, and that they can make duplicate idea cards, if they would like to place the ideas in two or more stakes; (4) ask participants to lay the cards out in front of them on the table, arrange the cards into groups or piles that make sense to them. Stress that there are no correct or incorrect answers, number of piles or number of cards required. Emphasizing that we are seeking only to understand how they think about the topic; (6) give participants a pad of blank colored post-its, instructing participants to write a label on a post-it for each group, and then clip all cards in the group together. The label might be a single word or a phrase; (7) 
meet individually with each participant as they finish sorting and labelling their cards. Then review the labels with each participant.

(c) The benefits and scientific value of the project

Although there is much literature available on IS success as well as on ERP success, little is known about the objective measures used to measure SAP which is an Enterprise Resource System, a very popular IS system. Therefore, this study will develop a better understanding of what measures an organization adopts if any, to determine the success of SAP. Having a better understanding of the IS Impact model and how it relates to SAP specific benchmarking will be beneficial for theory, as we are looking at the IS Impact model from a academic perspective but also utilising the SAP benchmarking programme from a practitioners perspective to determine the relevance between the two methods.

(d) Characteristics of the participants

This phase of the research project aims to assemble 10 participants for the card sorting activity. The participants will include industry experts (e.g. SAP functional specialists responsible for the success of SAP and Managers of SAP).

(e) Method of recruitment

A convenience sampling strategy will be used to identify research participants for card sorting exercise. The participants will consist of industry experts. The researcher has personal contacts to staff working for Telecom in New Zealand (Wellington); the researcher is also in an employee at Telecom. These functional specialists and managers develop and maintain SAP as part of their jobs. Due to their knowledge about SAP, these functional specialists and managers will be approached for participation in this project.

All initial contacts will be made via email, telephone or face-to-face conversations.

(f) Payments that are to be made/expenses to be reimbursed to participants

None 
(g) Other assistance (e.g. meals, transport) that is to be given to participants

Refreshments (e.g. coffee, mineral water, and biscuits) will be offered to the participants during the card sorting exercise.

(h) Any special hazards and/or inconvenience (including deception) that participants will encounter

None

(i) State whether consent is for: (Please indicate as many as it applies)
(i) the collection of data
$\mathbf{Y}$
(ii) attribution of opinions or information
$\mathbf{N}$
(iii) release of data to others
$\mathbf{N}$
(iv) use for a conference report or a publication $\mathbf{Y}$
(v) use for some particular purpose (specify) $\mathbf{N}$

Attach a copy of any questionnaire or interview schedule to the application

I have attached a copy of the set of questions that will be used in the card sorting exercise.

(j) How is informed consent to be obtained (see paragraphs 4.31(g), 5.2, 5.5 and 5.61 of the Guidelines)

(i) the research is strictly anonymous, an information sheet is supplied and informed consent is implied by voluntary participation in filling out a questionnaire for example (include a copy of the information sheet)

(ii) the research is not anonymous but is confidential and informed consent will be obtained through a signed consent form (include a copy of the consent form and information sheet)

\section{$\mathbf{Y}$}


(iii) the research is neither anonymous nor confidential and informed consent will be obtained through a signed consent form (include a copy of the consent form and information sheet)

$\mathbf{N}$

(iv) informed consent will be obtained by some other method (please specify and provide details)

With the exception of anonymous research as in (i), if it is proposed that written consent will not be obtained, please explain why

(k)If the research will not be conducted on a strictly anonymous basis state how issues of confidentiality of participants are to be ensured if this is intended. (See paragraph 4.3.1(e) of the Guidelines). (e.g. who will listen to tapes, see questionnaires or have access to data). Please ensure that you distinguish clearly between anonymity and confidentiality. Indicate which of these are applicable.

(i) access to the research data will be restricted to the investigator

\section{$\mathbf{N}$}

(ii) access to the research data will be restricted to the investigator and their supervisor (student research)

(iii) all opinions and data will be reported in aggregated form in such a way that individual persons or organizations are not identifiable

Y

(iv) Other (please specify)

N/A

(1) Procedure for the storage of, access to and disposal of data, both during and at the conclusion of the research. (see section 7 of the guidelines). Indicate which are applicable: 
(i) all written material (questionnaires, interview notes, etc) will be kept in a locked file and access is restricted to the investigator

(ii) all electronic information will be kept in a password-protected file and access will be restricted to the investigator

$\mathbf{Y}$

(iii) all questionnaires, interview notes and similar materials will be destroyed:

(a) at the conclusion of the research

$\mathbf{N}$

or (b) _ $2 \_$years after the conclusion of the research

(iv) any audio or video recordings will be returned to participants and/or electronically wiped

(v) other procedures (please specify):

N/A

If data and material are not to be destroyed please indicate why and the procedures envisaged for ongoing storage and security

N/A

(m)Feedback procedures (See section 8 of the Guidelines). You should indicate whether feedback will be provided to participants and in what form. If feedback will not be given, indicate the reasons why.

A presentation will be provided summarising the results obtained from the card sorting exercise to the SAP manager and also functional specialists. Also a summarised report of the results from the card sorting exercise.

(n)Reporting and publication of results. Please indicate which of the following are appropriate. The proposed form of publications should be indicated on the information sheet and/or consent form. 
(i) publication in academic or professional journals

(ii) dissemination at academic or professional conferences

(iii) deposit of the research paper or thesis in the University Library (student research)

(iv) a case study used for teaching purposes

$\mathbf{N}$

(v) other (please specify) 


\section{APPLICATIONS FOR HUMAN ETHICS APPROVAL}

\section{CHECKLIST}

Have you read the Human Ethics Committee Policy?

Have you read the Faculty of Commerce and Administration's HEC Guide?

Is ethical approval required for your project?

Have you established whether informed consent needs to be obtained for your project?

In the case of student projects, have you consulted your supervisor about any human ethics implications of your research?

Have you included an information sheet for participants which explains the nature and purpose of your research, the proposed use of the material collected, who will have access to it, whether the data will be kept confidential to you, how anonymity or confidentiality is to be guaranteed?

Have you included a written consent form?

If not, have you explained on the application form why you do not need to get written consent?

Are you asking participants to give consent to:

$\square$ collect data from them

$\square$ attribute information to them

$\square$ release that information to others

$\square$ use the data for particular purposes

Have you indicated clearly to participants on the information sheet and/or consent form how they will be able to get feedback on the research from you (e.g. they may tick a box on the consent form indicating that they would like to be sent a summary), and how the data will be stored or disposed of at the conclusion of the research?

Have you included a copy of any questionnaire or interview checklist you propose using?

\section{POINTERS TO AVOID HAVING APPLICATIONS RETURNED BEFORE HEC REVIEW}

- The approval process is speeded up by not requiring the hard copy of your application form with the signatures on it at the initial review process. The complete application (HEC application form, info sheet, consent form, covering letter, questionnaire etc.) is to be emailed as an attachment in one file to your supervisor who will email it to an SIM HEC member for a preliminary review.

- Do not insert a date into item 3 a.

- Delete the "Y" or "N" option that is not required. DO NOT remove any other text from the application form.

- BOLD your answers if you wish but do not alter the font anywhere else in the form. 


\title{
APPENDIX XII: Participants Information Sheet
}

\author{
VICTORIA UNIVERSITY OF WELLINGTON \\ Te Whare Wānanga o te $\bar{U}$ poko o te Ika a Mäui

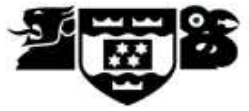 \\ SCHOOL OF INFORMATION MANAGEMENT
}

\section{Participant Information Sheet}

Project title: A multi-method study of the quality and impact of SAP in a large organization

Researcher: Azim Ali, School of Information Management (SIM), Victoria University of

Wellington

Dear Participant,

Thank you for your interest in participating in this research study exploring multi-method study of quality and IS Impact of SAP. I am currently studying towards a MCom degree at Victoria University of Wellington, New Zealand. This project forms a part of my INFO 591 research dissertations.

\section{Research Goal}

This research project aims to understand the metrics used to measure SAP.

Your participation in this research will involve a card sorting exercise anticipated to last approximately 40-60 minutes. Since 10 research participants is required, each participant will be asked to indicate time-slots for which he/she is available for the card sorting exercise session. Based on this, I will organize a time that accommodates every research participant's availability. You will be invited with an email including the exact date and location closer to the date of the group session. 


\section{Confidentiality}

Confidentiality of information shared within each card sorting session is of fundamental importance. It is essential that any information discussed within the card sorting exercise will be treated as confidential by all research participants. Throughout the project, electronic raw data will be stored password protected whereas any written material will be kept in a locked file. All data will be destroyed 2 years after the conclusion of the study. All raw data will be kept confidential, and only accessible to the researcher and his supervisor. Only data in aggregated form will be used in the thesis and in any articles published in academic journals or presentations at conferences. Any information that participants provide will not be attributed to individuals or organizations in which they work. None of the participants will be identifiable in any way.

You have the right to withdraw at any point up to the start of the focus group session or during the focus group session, but any data collected up to that point of withdrawal cannot be removed.

This research study has been reviewed by the SIM Human Ethics Committee and approval has been granted.

If you wish to receive an electronic copy of an interim research report summarizing my analysis of the card sorting exercise, please indicate this on the attached 'consent to participation' form.

If you have any further questions regarding this project please contact me via email: aliazim@myvuw.ac.nz or on my cell phone 0212309476. Alternatively you can contact my supervisor Dr Mary Tate via email Mary.tate@vuw.ac.nz or on landline 044635265.

Regards,

\section{Azim Ali}

Email: aliazim@myvuw.ac.nz 


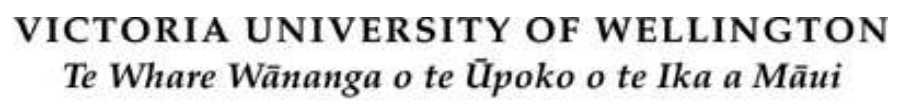

SCHOOL OF INFORMATION MANAGEMENT

\section{Consent to Participation in Research}

Employee (Telecom):

[Please mark each box with a tick to indicate agreement, then sign and date this form]

1. I have been given and have understood an explanation of this research and the confidentiality conditions.

2. I have had an opportunity to ask questions and have them answered to my satisfaction.

3. I agree to be interviewed by Azim Ali for the purposes of this research and I consent to the use of my perceptions, experiences, opinions and information in this research providing they are not attributed to me or my employer.

4. I understand that I have the right to withdraw from this study at any point up to the start of the card sorting session or during the card sorting sessipn. 
5. I understand that any information I provide through the card sorting activity will be kept confidential to the researcher and the supervisor

6. I agree that the information discussed within the card sorting session may be used for this INFO 591 research dissertation and may be presented at academic conferences or published in journal articles.

7. I would like to receive an electonic copy of an interim research report summarising the findings of the card sorting session. Please send it to the below mentioned email.

Email:

8. I understand that all the data collected by the research Azim Ali will be destroyed 2 years after the conclusion of the study.

Name (Participant) :

Signed:

Date:

Name (Researcher) : Azim Ali

Signed:

Date: 


\section{APPENDIX XII: SAP Benchmarking Results}

2011/2012 Annual Report used for financial data, can be found via

http://investor.telecom.co.nz/phoenix.zhtml?c=91956\&p=irol-reportsannualhist 